\title{
Die Rolle von
}

\section{Wnt5a bei der Regression des}

\section{Basalzellkarzinoms}

\author{
Dissertation \\ zur Erlangung des mathematisch-naturwissenschaftlichen Doktorgrades \\ „Doctor rerum naturalium" \\ der Georg-August-Universität Göttingen
}

GEORG-AUGUST-UNIVERSITÄT

GÖTTINGEN

vorgelegt von

Simone König

aus Stade

Göttingen 2012 


\section{Mitglieder des Thesis Commitees}

Prof. Dr. Heidi Hahn (Referentin)

Abteilung Molekulare Entwicklungsgenetik

Georg-August-Universität Göttingen

Prof. Dr. Matthias Dobbelstein (Korreferent)

Abteilung Molekulare Onkologie

Georg-August-Universität Göttingen

Prof. Dr. Felix Brembeck

Abteilung Hämatologie und Onkologie

Universitätsmedizin Göttingen

Tag der Disputation: 
Hiermit erkläre ich, dass die Dissertation mit dem Titel "Die Rolle von Wnt5a bei der Regression des Basalzellkarzinoms" von mir selbständig angefertigt wurde und keine anderen als die angegebenen Hilfsmittel und Hilfen benutzt wurden.

Göttingen, den 31. Januar 2012

Wenn man studiert ... ist Wissenschaft neu und wunderbar, und alles, was bekannt ist, wird so aufgenommen, als habe man es schon immer gewußt.

Erst viel später, nach jahrelanger Forschung mit fehlgeschlagenen und gelungenen Experimenten, mit falschen Spuren, überraschenden Ergebnissen und Augenblicken echter Erkenntnis wird einem klar, wie hart man sich jedes Körnchen Wissen erarbeiten muß, wie jeder Fortschritt sich auf die gesammelten Fortschritte der Vergangenheit gründet, wie jedes Experiment ein Teil des fortlaufenden Stromes der Wissenschaft ist, ein Teil des wachsenden Schatzes menschlichen Wissens, das uns aus der Dunkelheit geführt hat. -Robert L. Sinsheimer- 

1.1 Das Basalzellkarzinom (BCC) _

1.2 Der Hedgehog/Patched (Hh/Ptch) Signalweg __ 2

1.2.1 Der Hh/Ptch Signalweg in Tumoren

1.2.2 Die Rolle von Ptch Mutationen beim BCC

1.2.3 Mausmodell für BCC __ 5

1.3 Wnt Signalwege __ 7

1.3.1 Der kanonische Wnt/B-Catenin Signalweg _ 8

1.3.2 Die nicht-kanonischen Wnt Signalwege _ 9

1.3.2.1 Der Wnt/JNK Signalweg__ 9

1.3.2.2 Der Wnt $/ \mathrm{Ca}^{2+}$ abhängige Signalweg __ 10

1.4 Aktivierung der Wnt Signalwege durch Wnt5a

1.5 Die Rolle von Wnt5a bei Tumoren _ 11

1.5.1 Bedeutung des Wnt5a Signalwegs beim BCC_ 12

1.6 Zielsetzung der Arbeit

2 MATERIAL 17

2.1 Laborgeräte _ 17

2.2 Gebrauchswaren 18

2.3 Chemikalien und Reagenzien

2.4 Gebrauchsfertige Reaktionssysteme 20

2.5 Stammlösungen __ 20

$\mathbf{2 . 6}$ Medien

2.6.1 Medien für die Bakterienkultur 22

2.6.2 Agarplatten _ 23

2.6.3 Medien für die Kultur eukaryotischer Zelllinien ___ 23

2.7 Bakterienstämme, eukaryotische Zelllinien und Primärzellen __ 23

$\begin{array}{llr}2.8 & \text { Plasmide } & 24\end{array}$

$\mathbf{2 . 9}$ Synthetische DNA-Oligonukleotide___ $\mathbf{2 5}$

2.9.1 DNA-Oligonukleotide zur Genotypisierung von Mäusen ___ 25

2.9.2 DNA-Oligonukleotide für Sequenzanalyse __ 25

2.9.3 DNA-Oligonukleotide für RT-PCR __ 26

2.9.4 DNA-Oligonukleotide für quantitative real time PCR (qRT-PCR) __ 26

2.9.5 Sonden für in situ-Hybridisierung ___ 27

\begin{tabular}{ll}
2.10 & Enzyme___ \\
\hline
\end{tabular}

2.11 Antikörper

$\begin{array}{lll}2.11 .1 & \text { Primäre Antikörper___ } 27\end{array}$

2.11.2 Sekundäre Antikörper _ـ 28 
3.1 Molekularbiologische Methoden 30

3.1.1 Isolierung und Aufreinigung von Nukleinsäuren ___ 30

3.1.1.1 Plasmid DNA _ 30

3.1.1.2 Genomische DNA aus Gewebe und Blut___ 30

3.1.1.2.1 Isolierung genomischer DNA aus Schwanzbiopsien__ 30

3.1.1.2.2 Isolierung genomischer DNA aus murinen Föten 30

3.1.1.2.3 Isolierung genomischer DNA aus Blut ___ 31

3.1.1.3 Gesamt-RNA aus eukaryotischer Zellkultur oder Gewebe ___ 31

3.1.1.3.1 Isolierung von Gesamt-RNA aus Hautproben ___ 32

3.1.2 Konzentrationsbestimmung von Nukleinsäuren __ 32

3.1.3 Reverse Transkription ___ 32

3.1.4 Polymerase-Kettenreaktion (PCR) _ 33

3.1.4.1 Semiquantitative RT-PCR 33

3.1.4.2 Quantitative real time PCR (qRT-PCR)___ 33

3.1.4.3 RT Profiler PCR Array__ 34

3.1.5 DNA-Sequenzanalyse _ـ 35

3.1.6 Gezielte Mutagenese 35

3.1.7 Agarosegelelektrophorese _ـ 36

3.1.8 Klonierungen _ـ 36

3.2 Zellbiologische Methoden __ 36

3.2.1 Kultivierung eukaryotischer Zellen _ 36

3.2.1.1 Kokultivierung eukaryotischer Zellen __ 37

3.2.1.2 Transfektion eukaryotischer Zellen___ 38

3.2.2 Isolierung und Kultivierung von peritonealen Makrophagen und BMDM 38

3.2.3 Herstellung konditionierter Medien (CM, engl: conditioned medium) _ 39

3.2.4 Stimulation von ASZO01 mit Wnt5a-CM und rWnt5a

3.2.5 Bestimmung der Zellviabilität___ 40

3.2.6 Untersuchung des Migrationsverhaltens von Zellen ___ 41

3.2.7 5-Bromo-2-Deoxyuridin Assay ___ 41

3.2.8 Isolierung und Kultivierung von Hautstanzen___ 42

3.3 Immunhistochemie und Immunzytochemie___ 43

3.3.1 Dualer Luciferase Assay __ 43

3.3.2 ELISA _ 43

3.3.3 Immunhistologische Antikörperfärbungen___ 44

3.3.3.1 Gewebeentnahme und /-fixierung ___ 44

3.3.3.2 Herstellung von Paraffinschnitten von Geweben ___ 44

3.3.3.3 Hämatoxylin/Eosin (HE)-Färbung, Vermessung des Tumorareals und Antikörperfärbungen_44

3.3.4 In situ-Hybridisierung __ 45

3.3.4.1 Herstellung Digoxigenin-markierter Sonden___ 46

3.3.4.2 Durchführung der in situ-Hybridisierung _ـ 47

3.3.5 Durchflusszytometrische Analysen (FACS) ___ 48

3.3.6 Western Blot___ 50

3.3.7 X-Gal-Färbung von Hautbiopsien _ 51

3.4 Tierexperimentelle Methoden $\quad \mathbf{5 1}$

3.4.1 Mauslinien__

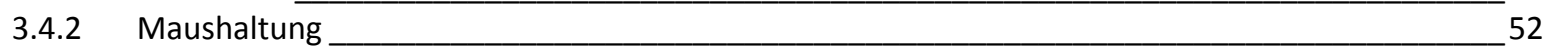

3.4.3 Genotypisierung von Mäusen___ 52

3.4.4 Bestimmung des Kopulationszeitpunktes und der Trächtigkeit___ 52 
3.4.5 Applikation von Medikamenten und Blutabnahme __ 53

3.4.5.1 Intramuskuläre Injektion von Tamoxifen _ 53

3.4.5.2 Topische Applikation von lonomycin __ 53

3.4.5.3 Subkutane Injektion eines Expressionsplasmids__ 53

3.4.5.4 Intraperitoneale Injektion von Clodrolip, Leerliposomen und BLP _ 54

3.4.5.5 Blutabnahme aus dem retroorbitalen Venenplexus__ 54

3.4.5.6 Narkotisierung von Mäusen _ـ 54

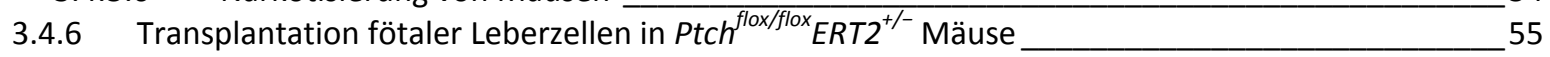

3.4.7 Präparation von Tumoren und Geweben __ 55

3.4.8 Statistische Auswertungsverfahren _ـ

\section{ERGEBNISSE}

4.1 Expression und Funktion von Wnt5a in der BCC-Zelllinie ASZ001 und BCC-tragenden Hautstanzen _ 57

4.1.1 ASZ001 induzieren die Expression von Wnt5a in kokultivierten Makrophagen __ 57

4.1.2 Wnt5a hat keinen Einfluss auf den kanonischen Wnt Signalweg in ASZ001__ 58

4.1.3 Wnt5a induziert die K10 Expression in ASZ001 __ 59

4.1.4 Wnt5a und Aktivierung des Wnt/ $\mathrm{Ca}^{2+}$ Signalwegs induziert die $K 10$ Expression in BCC in Zellkultur 60

4.1.4.1 Einfluss der CaMKII auf die K10 Expression in ASZO01 61

4.1.4.2 Einfluss von Wnt5a und dem CaMKII Inhibitor KN-93 auf die K10 Expression in BCC-tragenden

Hautstanzen

61

4.1.5 Wnt5a oder CaMKII Inhibitor KN-93 haben keinen Einfluss auf die BCC Proliferation in BCCtragenden Hautstanzen

4.1.6 Bedeutung anderer Komponenten des Wnt Signalwegs im BCC __ 64

4.2 Untersuchung der Effekte von $\mathrm{Ca}^{2+}$ und Wnt5a Überexpression auf BCC im Mausmodell ___ 66

4.2.1 Das Calcium-Ionophor lonomycin induziert die BCC-Differenzierung im Mausmodell __ 66

4.2.1.1 Ionomycin hat keinen Einfluss auf die Tumorgröße __ 66

4.2.1.2 Keine eindeutige Verringerung proliferierender BCC-Zellen durch Ionomycin __ 67

4.2.1.3 Ionomycin induziert die Expression von Differenzierungsmarkern in BCC __ 68

4.2.2 Einfluss einer Wnt5a Überexpression auf BCC: Vorarbeiten __ 69

4.3 Untersuchung der Effekte einer verminderten Wnt5a Expression auf BCC im Mausmodell___ $\mathbf{7 1}$

4.3.1 Genetischer Ansatz zur Reduzierung der Wnt5a Expression im BCC-Mausmodell ___ 71

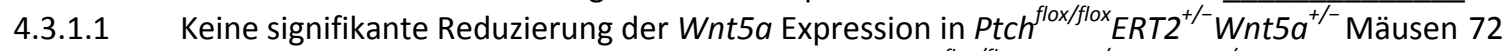

4.3.1.2 Keine signifikante Veränderung der BCC-Größe in Ptch flox/flox $E R T 2^{+/-}$Wnt5a ${ }^{+/-}$Mäusen $\quad 72$

4.3.1.3 Epidermale Hyperplasien in Ptch ${ }^{\text {flox } / f l o x} E R T 2^{+/-}$Wnt5a ${ }^{+/-}$Mäusen __ 73

4.3.2 Rekonstitution des Knochenmarks von Ptch ${ }^{\text {flox/flox }} E R T 2^{+/-}$Mäusen mit Wnt5a-defizienten Zellen_ 74

4.3.3 Applikation von Clodrolip zur Depletion von Wnt5a-exprimierenden Makrophagen__ 76

4.3.3.1 Effiziente Depletion von Makrophagen in Milz und Haut durch Clodrolip _ 77

4.3.3.2 Signifikante Abnahme der Wnt5a Expression in der Haut nach Clodrolipbehandlung __ 79

4.3.3.3 Zunahme der Größe und des proliferativen Verhaltens von BCC nach Clodrolipapplikation _ 80

4.4 Einfluss von Liposomen auf das Wachstum von BCC

4.4.1 Wirkung von Liposomen und BLP auf das BCC-Wachstum im Mausmodell ___ 82

4.4.1.1 Liposomen und BLP hemmen das Tumorwachstum___ 82

4.4.1.2 Liposomen und BLP induzieren K10 Expression in der BCC-tragenden Haut___ 83

4.4.1.3 Liposomen verringern die Makrophagenzahl in der Peritonealhöhle, der Milz und der Haut 84

4.4.2 Wirkung von Liposomen und BLP auf BMDM und ASZOO1 _ 85

4.4.2.1 Wirkung von Liposomen und BLP auf BMDM _ 85

4.4.2.1.1 Liposomen und BLP ändern die Morphologie von BMDM 85

4.4.2.1.2 Keine toxische Wirkung von Liposomen und BLP auf BMDM 86

4.4.2.1.3 BLP, nicht aber Liposomen, führen zur Cytokinfreisetzung aus BMDM

4.4.2.1.4 Liposomen und BLP führen zu vermehrter Migration von BMDM __ 87

4.4.2.1.5 Liposomen und BLP vermindern die Proliferation von BMDM __ 88

4.4.2.1.6 Liposomen führen in BMDM zum Zellzyklusarrest in der G0/G1-Phase __ 89

4.4.2.1.7 Liposomen und BLP induzieren Apoptose in BMDM _ 91 
4.4.2.2 Wirkung von Liposomen oder BLP auf ASZ001___ 92

4.4.2.2.1 Keine Proliferationshemmung von ASZ001 durch Liposomen oder BLP 92

4.4.2.2.2 Keine Stimulation der Apoptose von ASZ001 durch Liposomen oder BLP __ 93

5 DISKUSSION

5.1 Expression und Funktion von Wnt5a in der BCC-Zelllinie ASZ001 und BCC-tragenden Hautstanzen _ 94

5.1.1 Wnt5a wird von BCC-assoziierten Makrophagen exprimiert

5.1.2 Wnt5a induziert die BCC Differenzierung über den Wnt/Ca ${ }^{2+}$ Signalweg in Abhängigkeit der CaMKII_

Modell fur dieFunktion von Wnt5a in BCC-Entwicklung und/-Regression_ 95

5.1.3 Modell für die Funktion von Wnt5a in BCC-Entwicklung und /-Regression___ 98

5.2 Effekt von $\mathrm{Ca}^{2+}$ auf BCC im Mausmodell 99

5.3 Einfluss der Wnt5a Überexpression und der verminderten Wnt5a Expression auf BCC im Mausmodell 101

5.3.1 Einfluss der Wnt5a Überexpression im BCC in vivo

5.3.2 Untersuchung der Effekte einer verminderten Wnt5a Expression auf BCC im Mausmodell ___ 103

5.3.2.1 Einfluss der Deletion eines Wnt5a Allels auf das BCC-Wachstum ___ 103

5.3.2.2 Rekonstitution des Knochenmarks von Ptch flox/flox $E R T 2^{+/-}$Mäusen mit Wnt5a-defizienten

Zellen $\quad 104$

5.3.3 Effektive Depletion Wnt5a-exprimierender Makrophagen durch Clodrolip ___ 106

5.3.4 Effekt der Makrophagendepletion auf das BCC-Wachstum___ 107

5.4 Zusammenfassung der Effekte von $\mathrm{Ca}^{2+}$ sowie einer Wnt5a-Manipulation auf BCC im Mausmodell _ 109

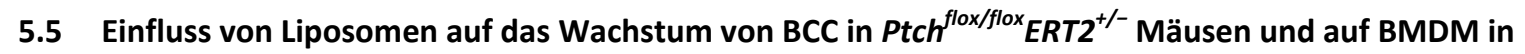
Zellkultur

6 ZUSAMMENFASSUNG

7 ABKÜRZUNGSVERZEICHNIS

8 LITERATURVERZEICHNIS

9 DANKSAGUNG 


\section{Einleitung}

\subsection{Das Basalzellkarzinom (BCC)}

Das Basalzellkarzinom (BCC) ist der häufigste Tumor des Menschen (Rubin, Al et al. 2005). Die Wahrscheinlichkeit in seinem Leben an einem BCC zu erkranken liegt bei Kaukasiern bei etwa 30\% (Abdulla, FR et al. 2005). Basalzellkarzinome wachsen langsam und sind semimaligne Tumoren (Robinson, JK und Dahiya, M 2003). Dies bedeutet, dass sie nur sehr selten metastasieren (Rubin, Al et al. 2005). Selbst nach zweijährigem Wachstum liegt die Metastasierungsrate des BCC bei nur 0,55\% (Walling, HW et al. 2004). Dennoch können BCC in seltenen Fällen auch einen destruktiven Verlauf im Wachstum zeigen und sogar Knochen penetrieren (Gailani, MR et al. 1992; Holmberg, E et al. 1996).

Es gibt verschiedene Subtypen von BCC und generell werden sie in differenzierte und undifferenzierte bzw. solide Tumoren unterteilt (Crowson, AN 2006). Zu den differenzierten BCC gehören der infundibulozystische, keratotische, follikuläre und pleomorphe Typ. Bei den undifferenzierten BCC unterscheidet man zwischen indolenten und aggressiven Tumoren. Zum indolenten Typ zählt man superfizielle und noduläre BCC, zum aggressiven Typ gehören hingegen infiltrative und metatypische BCC (Crowson, AN 2006).

Die Behandlung der BCC ist sowohl Tumor-/ als auch Patientenabhängig und das Spektrum umfasst derzeit diverse chirurgische Eingriffe wie z.B. klassische Exzision, Kürettage oder Kryochirurgie (Goppner, D und Leverkus, M 2011). Außerdem erfolgt die Behandlung der Tumoren mit photodynamischer Therapie sowie Imiquimod, einem topisch applizierten Immunmodulator (Lacarrubba, F et al. 2011; Lien, MH und Sondak, VK 2011).

Retrospektive Studien haben gezeigt, dass die Häufigkeit von BCC in den letzten Jahren stark zugenommen hat und auch in den nächsten Jahren wird die Inzidenz weiter zunehmen. So wird angenommen, dass 25\% aller nach 1994 geborenen Kaukasier ein BCC entwickeln werden (Athar, M et al. 2006).

Die Kosten, die das Gesundheitssystem zur Diagnose und Therapie dieser Hauttumoren aufbringen muss, sind bereits heute enorm. Aufgrund der Inzidenzsteigerung entwickelt sich das BCC immer mehr zu einem Problem für das Gesundheitswesen (Roewert-Huber, $\mathrm{J}$ et al. 2007).

Interessanterweise zeigen etwa 20\% der BCC eine Spontanregression (Curson, C und Weedon, D 1979). Der zugrundeliegende Mechanismus ist nicht bekannt, jedoch scheint die spontane Regression mit Zellen des Immunsystems sowie Cytokinen assoziiert zu sein (Hunt, MJ et al. 1994; Wong, DA et al. 2000). Die Aufklärung des Mechanismus der Spontanregression birgt großes Potential. So könnte ein besseres Verständnis der 
molekularen Grundlagen dieses Vorgangs zu kostengünstigeren und effizienteren Therapien des BCC führen.

Im Gegensatz zu den molekularen Vorgängen bei der Spontanregression von BCC kennt man heute jedoch die Ursache des BCC. So weiß man, dass dieser Tumor durch eine Fehlregulation des Hedgehog/Patched Signalwegs ausgelöst wird (Epstein, EH 2008). Daher soll dieser Signalweg hier etwas ausführlicher beschrieben werden.

\subsection{Der Hedgehog/Patched (Hh/Ptch) Signalweg}

Bei der genetischen Analyse von Drosophila melanogaster Larven identifizierten NüssleinVolhard und Wieschaus die Gene Hedgehog (Hh) und Patched (Ptch) (Nusslein-Volhard, C und Wieschaus, E 1980). Ptch ist der Rezeptor für den Liganden Hh und vermittelt durch einen komplexen Mechanismus das Signal unter anderem über Smoothened (Smo), ein weiteres transmembranes Protein, und über den Transkriptionsfaktor Cubitus interruptus (Ci) ins Zellinnere.

Der Signalweg ist zwischen den Spezies hochkonserviert. In Vertebraten wurden drei $\mathrm{Hh}$ homologe Gene gefunden, Desert hedgehog (Dhh), Indian hedgehog (Ihh) und Sonic hedgehog (Shh). In Wirbeltieren sind weiterhin zwei homologe Ptch Rezeptoren bekannt. Hierbei handelt es sich um Ptch1 und Ptch2, wobei Ptch1 (das im Folgenden als Ptch bezeichnet wird) besser untersucht ist. Auch bei den Gli-Proteinen (ortholog zu Ci aus $D$. melanogaster) liegen in Vertebraten drei Homologe vor, Gli1, Gli2 und Gli3.

Ptch ist ein Protein mit 12 transmembranen Domänen und fungiert als Rezeptor für $\mathrm{Hh}$ Proteine. In Abwesenheit des Hh-Liganden inhibiert Patched katalytisch den 7Transmembranrezeptor Smo, der eine den G-Protein-gekoppelten Rezeptoren ähnliche Struktur besitzt. Hierdurch wird die Signaltransduktion unterbunden. Aufgrund seiner inhibitorischen Aktivität gegenüber Smo ist Ptch ein negativer Regulator der Signalkaskade. Der Prozess der Inhibierung von Smo durch Ptch ist noch nicht vollständig verstanden, erfolgt aber vermutlich nicht durch direkte Interaktion der beiden Proteine sondern über ein durch Ptch sezerniertes Smo-inhibitorisches Molekül. Durch Bindung des Liganden Hh an die extrazellulären Schleifen von Ptch wird die Repression von Smo aufgehoben und resultiert in der physiologischen Aktivierung des $\mathrm{Hh} / \mathrm{Ptch}$ Signalwegs. Der Transduktionsmechanismus, mit dem das Hh-Signal vom Rezeptorkomplex zur Aktivierung seiner Zielgene führt, ist noch unklar. Man weiß jedoch, dass die Familie der Gli ZinkfingerTranskriptionsfaktoren involviert ist. Im inaktiven Zustand des Signalwegs werden die GliTranskriptionsfaktoren von einem Proteinkomplex, an dem Sufu („Suppressor of Fused“) und Kif7 beteiligt sind, im Cytoplasma gehalten. Im aktiven Zustand werden die Gli-Proteine aus 
dem cytoplasmatischen Proteinkomplex entlassen werden und gelangen in den Nukleus. Im Nukleus bewirken die Gli-Proteine dann die Transkription ihrer Zielgene. Gli1 und Gli2 sind die hauptsächlichen Aktivatoren der Hh/Ptch Signalkaskade, dagegen übt Gli3 eine repressorische Aktivität auf die Kaskade aus, welche jedoch durch das Hh-Signal aufgehoben wird. Es ist bekannt, dass durch das Hh-Signal die Transkription von Gli1 aktiviert wird, wobei die transkriptionelle Aktivierung von Gli1 von dem Vorhandensein funktioneller Gli2 und Gli3 Proteine abhängt. Die Expression von Gli1 mRNA ist daher ein zuverlässiger Marker für die Aktivität der Hh/Ptch Signalkaskade. Da Gli-Proteine wiederum die Ptch-Transkription durch autoregulatorisches „Feedback“ stimulieren, gehört auch Ptch zu den heute anerkannten Zielgenen einer aktivierten Hh/Ptch Signalkaskade (Reviews von (Hooper, JE und Scott, MP 2005; Scales, SJ und de Sauvage, FJ 2009; Cohen, MM, Jr. 2010)).

Nach neuesten Erkenntnissen wird primären Zilien eine entscheidende Rolle bei der Hh/Ptch Signaltransduktion in Säugetieren zugeschrieben. Primäre Zilien sind sensorische Organellen auf der Zelloberfläche, die wie Antennen Signale aus der Umgebung der Zelle in das Zellinnere weiterleiten. An ihrer Basis werden sie durch einen als Basalkörper bezeichneten Proteinkomplex vom Zytoplasma der Zelle abgegrenzt und deshalb auch als eigenständige Kompartimente betrachtet. Die Verbindung zwischen primärem Zilium und Hh/Ptch Signalkaskade kann durch invers miteinander korrelierende Level von Ptch und Smo gezeigt werden. So verlässt Ptch nach Bindung von $\mathrm{Hh}$ das Zilium, wobei Smo hineintransloziert, und der Signalweg aktiviert wird (siehe Review (Cohen, MM, Jr. 2010). Zwei aktuelle Studien zeigen, dass die Entstehung von BCC als auch von Medulloblastomen tatsächlich durch Zilien reguliert werden (Han, YG et al. 2009; Wong, SY et al. 2009).

Der Ablauf der Hh-Signaltransduktion bei Säugetieren ist in stark vereinfachter Form in Abbildung 1 dargestellt. 


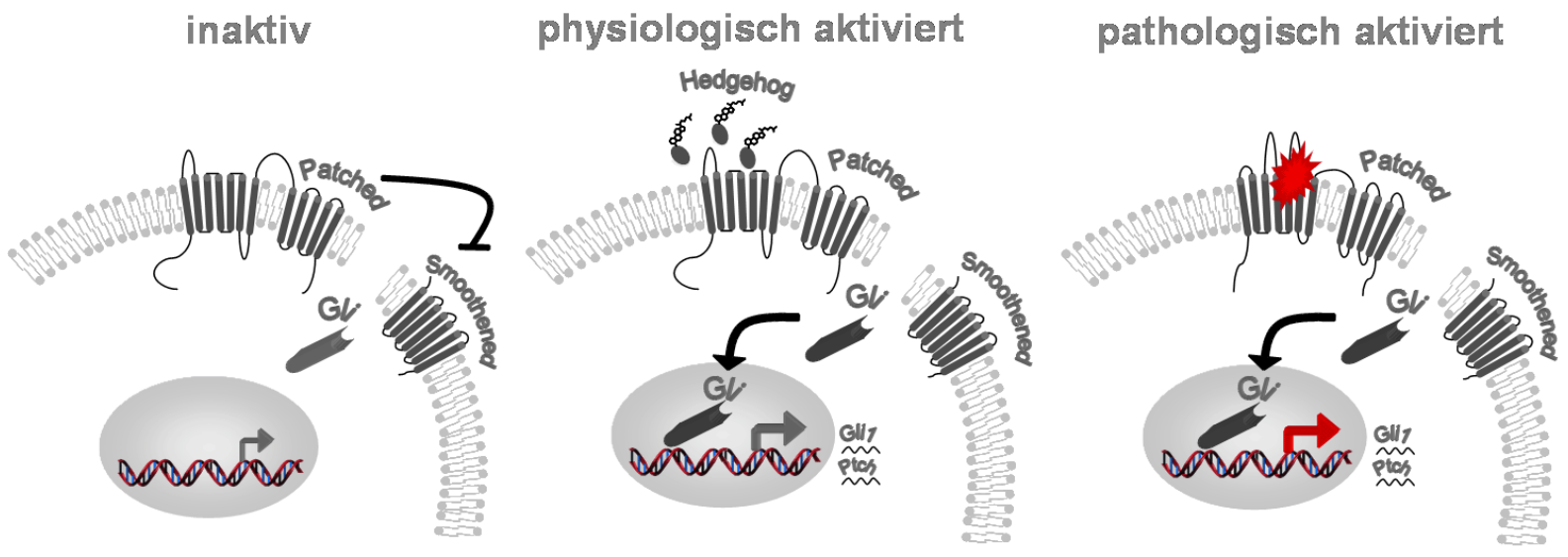

Abbildung 1: Schematische Darstellung des inaktiven, physiologisch und pathologisch aktivierten Hh/Ptch Signalwegs. Gezeigt ist der inaktive (links) und durch die Bindung des Liganden Hedgehog physiologisch aktivierte $\mathrm{Hh} / \mathrm{Ptch}$ Signalweg (Mitte). Eine pathologische Aktivierung (rechts) kann durch eine inaktivierende Patched-Mutation (roter Stern) oder Überexpression von Hedgehog verursacht werden. Der inaktive Zustand der Signalkaskade beruht auf der Inhibition der Aktivität von Smoothened durch Patched. Ausgelöst durch die Bindung des Liganden Hedgehog an Patched oder durch eine inaktivierende PatchedMutation vermittelt Smoothened die Translokation von Gli1 und weiteren Gli-Transkriptionsfaktoren in den Nukleus. Dort wird die Transkription von Zielgenen, darunter Patched (Ptch) und Gli1, ausgelöst.

Diese Abbildung wurde aus der Dissertation von F. Nitzki (2008) übernommen.

Physiologischerweise spielt der Hh/Ptch Signalweg in Vertebraten eine essentielle Rolle bei der embryonalen Musterbildung, Regulation der Zellproliferation, /-differenzierung sowie Apoptose, bei der Entwicklung der Extremitäten, des Skelettsystems und des zentralen Nervensystems (Hammerschmidt, M et al. 1996; Hooper, JE und Scott, MP 2005).

Der physiologischen Aktivierung der Signalkaskade steht die pathologische Aktivierung gegenüber (Abbildung 1). Hierbei kommt es zu einer konstitutiven Aktivierung der Signalkaskade, was zur Deregulation der zellulären Proliferation, Differenzierung und Apoptose führt und schließlich in Entwicklungsstörungen sowie Tumorwachstum resultiert (Wetmore, C 2003; Scales, SJ und de Sauvage, FJ 2009). Deshalb hat die Hh/Ptch Signalkaskade eine bedeutende Funktion in der Regulation des Zellzyklus und eine Deregulation kann daher gravierende Folgen auf die Proliferation von Zellen haben.

\subsubsection{Der Hh/Ptch Signalweg in Tumoren}

Der Zusammenhang zwischen der pathologischen Reaktivierung des Hh/Ptch Signalwegs und der daraus resultierenden Tumorentstehung wurde zum ersten Mal beim Gorlin-GoltzSyndrom (Basalzellnaevus-Syndrom) erkannt (Hahn, H et al. 1996; Johnson, RL et al. 1996). Diese autosomal-dominant vererbte Krankheit ist durch eine Kombination aus Entwicklungsdefekten und einer Prädisposition zu BCC charakterisiert (Gorlin, RJ 1987; Hahn, $\mathrm{H}$ et al. 1996; Johnson, RL et al. 1996) und wird durch Keimbahnmutationen in Ptch hervorgerufen.

Heute weiß man, dass der Hh/Ptch Signalweg bei einer Vielzahl verschiedener Tumorentitäten eine wichtige Rolle spielt. Eine pathologische Aktivierung kann hierbei nicht 
nur durch mutationsbedingte Inaktivierung von Ptch, sondern auch durch aktivierende Mutationen in Hh oder Smo, oder aber durch Überexpression von $\mathrm{Hh}$ oder Gli hervorgerufen werden. So konnte beispielsweise bei Tumoren des Verdauungstraktes, des Pankreas, der Lunge, des Skelettmuskels, der Harnblase und des Ovars die pathologische Aktivierung des Signalwegs festgestellt werden (Berman, DM et al. 2003; Thayer, SP et al. 2003; Watkins, DN et al. 2003; Hamed, S et al. 2004; Chen, X et al. 2007; Zibat, A et al. 2010). Hierbei scheint die Überexpression von Shh eine wichtige Rolle zu spielen. Darüber hinaus konnten aktivierende Smo-Mutationen in Haut- und neuroektodermalen Tumoren detektiert werden (Vorechovsky, I et al. 1997; Reifenberger, J et al. 1998; Xie, J et al. 1998; Lam, CW et al. 1999). Somatische Mutationen von Ptch führen vor allem zu Basalzellkarzinomen. Aber auch andere Tumoren, wie bspw. Medulloblastome oder seltener Rhabdomyosarkome können durch Ptch Mutation entstehen (Raffel, C et al. 1997; Bridge, JA et al. 2000; Reifenberger, J et al. 2005; Tostar, U et al. 2006). Die für die Entstehung von Tumoren verantwortlichen Ptch Mutationen sind dabei häufig in den beiden extrazellulären Schleifen des Proteins lokalisiert (Lindstrom, E et al. 2006).

Die Fehlregulation der $\mathrm{Hh} / \mathrm{Ptch}$ Signalkaskade wird in allen der oben genannten Tumoren durch Überexpression von Gli1 oder Ptch deutlich.

\subsubsection{Die Rolle von Ptch Mutationen beim BCC}

Als molekulare Ursache konnten 1996 sowohl für das hereditäre als auch sporadische Basalzellkarzinom Mutationen in Ptch identifiziert werden (Gailani, MR et al. 1996; Hahn, H et al. 1996). Die weitaus am häufigsten detektierten Veränderungen (70\%) sind loss of function-Mutationen des Ptch-Gens (Reifenberger, J et al. 2005). Aufgrund der Ptch Mutation ist die Hh/Ptch Signalkaskade dereguliert. Tatsächlich zeigen alle untersuchten BCC eine erhöhte Expression der Zielgene des Hh/Ptch Signalwegs, Gli1 und Ptch (Evangelista, M et al. 2006). Neben Ptch Mutationen sind, wenn auch sehr selten, Smo Mutationen für die Entstehung des BCC verantwortlich (Xie, J et al. 1998). All diese Daten zeigen, dass der $\mathrm{Hh} /$ Ptch Signalweg bei der Entstehung von BCC von essentieller Bedeutung ist.

BCC entwickeln sich auch in verschiedenen Tiermodellen, in denen der Hh/Ptch Signalweg dereguliert ist. Exzellente Modelle zur Untersuchung der Pathogenese von BCC sind dabei Mäuse, bei denen sich BCC durch Ptch Mutationen entwickeln.

\subsubsection{Mausmodell für BCC}

BCC konnten in der Maus zum ersten Mal in heterozygoten $\mathrm{Ptch}^{+/-}$Mäusen nach Bestrahlung hervorgerufen werden (Aszterbaum, M et al. 1999; Mancuso, M et al. 2004; Pazzaglia, S et al. 2004). Heute existieren jedoch sehr viel bessere konditionelle BCC-Mausmodelle, in denen sich die Tumoren zu einem bestimmten Zeitpunkt induzieren lassen. Unsere 
Arbeitsgruppe hat ein solches Modell entwickelt. Hierzu wurden zunächst konditionelle Ptch $^{\text {floxflox }}$ Mäuse generiert (Uhmann, A et al. 2007), bei denen die Exone 8 und 9 des PtchGens von loxP-Sequenzen in den Intronen 7 und 9 flankiert sind. Diese Mäuse wurden mit Rosa26ERT2 ${ }^{+-}$Mäusen verpaart (Hameyer, D et al. 2007), die im Folgenden als ERT2 ${ }^{+/-}$ Mäuse bezeichnet werden. Die daraus resultierenden $\mathrm{Ptch}^{\mathrm{flox} /+} E R T 2^{+/-}$Nachkommen wurden wiederum mit $P t c h^{\text {floxfllox }}$ Mäusen gekreuzt, um $P t c h^{f l o x f l o x} E R T 2^{+/-}$Mäuse zu generieren. Da $E R T 2^{+/}$Mäuse eine Tamoxifen-induzierbare Cre-Rekombinase exprimieren, kann die ERT2

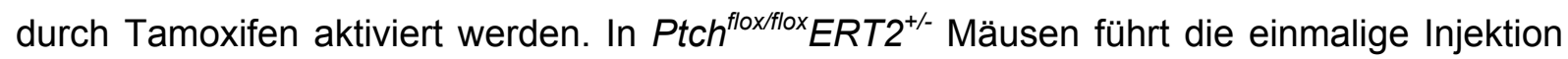

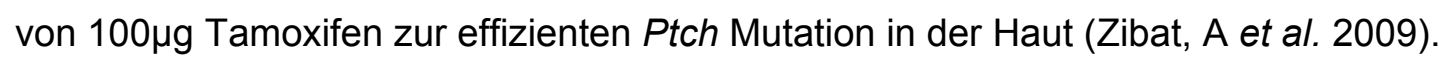

Schon 45 Tage nach Tumorinduktion zeigen alle Mäuse an den Ohren und am Schwanz BCC Vorläuferläsionen (Abbildung 2, oben). Wie Antikörperfärbungen mit K17 oder p63 gezeigt haben, entwickeln sich die Tumoren aus Zellen der äußeren Wurzelscheide des Haarfollikels und auch aus Basalzellen der interfollikulären Epidermis (Daten nicht gezeigt). Aus diesen Vorläuferläsionen entwickeln sich bis zum Tag 90 nach Tumorinduktion vollentwickelte Tumoren. Diese Tumoren wachsen tiefer in die Dermis und ähneln histologisch dem humanen nodulären BCC, welches ein häufiger BCC-Subtyp des Menschen ist. Interessanterweise werden die Tumoren in diesem konditionellen Mausmodell im Laufe der Zeit nicht aggressiver, sondern bilden sich in 100\% der Tiere etwa 250 Tage nach Induktion spontan zurück (regrediente BCC).

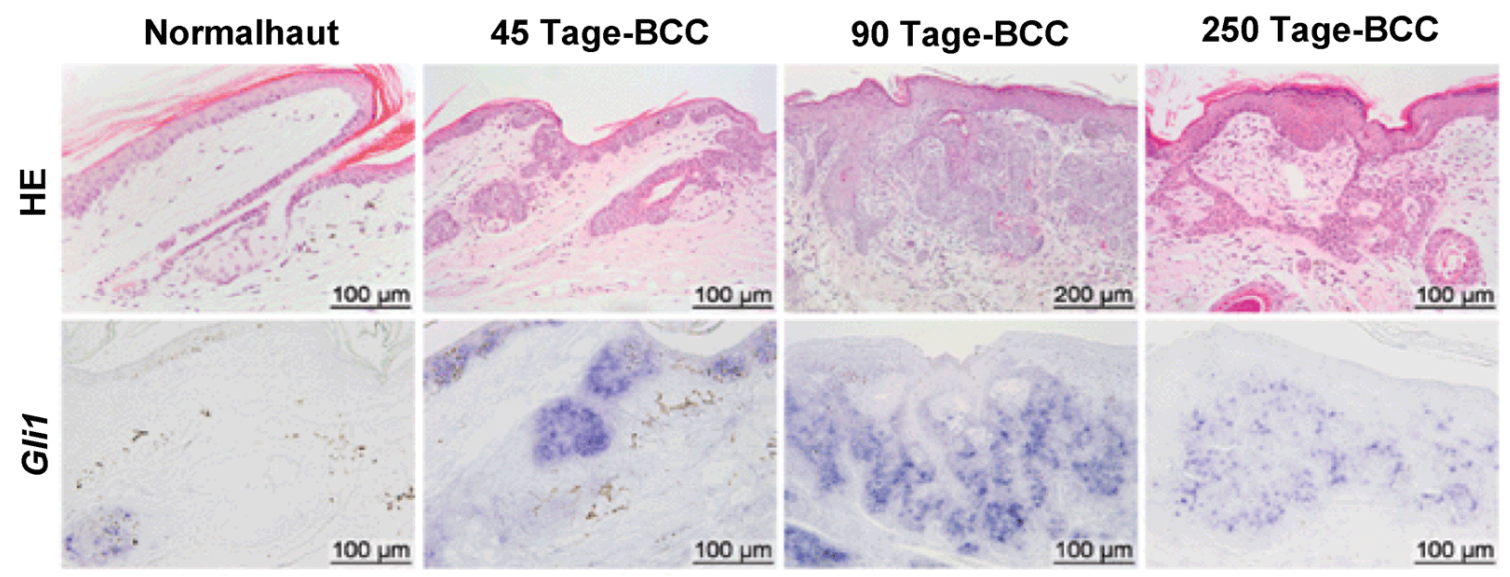

Abbildung 2: Darstellung von Normalhaut im Vergleich zu tumortragender Haut. Dargestellt sind HEgefärbte Paraffinschnitte (oben) und Gli1 in situ-Hybridisierungen (unten) von Tamoxifen-behandelten Ptch flox/flox Mäusen (Normalhaut) im Vergleich zu BCC von Ptch flox/flox $E R T 2^{+/-}$Mäusen. Die Schnitte zeigen Tumoren zu unterschiedlichen Zeitpunkten nach Tumorinduktion. Die Abbildung wurde aus Nitzki et al. (2010) übernommen.

Wie man der Abbildung 2 (unten) außerdem entnehmen kann, wird Gli1 in allen BCCStadien exprimiert. Das bedeutet, dass die Hh/Ptch Signalkaskade auch in den regredienten Stadien weiterhin aktiv ist und die spontane Regression der BCC somit nicht durch eine Inaktivierung des Signalwegs bedingt sein kann. 
Außerdem weisen die vollentwickelten und regredienten BCC im Vergleich zu den Vorläuferläsionen eine 2-/ bzw. 10-fache Reduzierung der Ki67 positiven Zellen auf (Abbildung 3a). Im Gegensatz dazu bleibt die Anzahl Caspase-3 positiver Zellen in allen BCC-Stadien durchgängig niedrig (Abbildung $3 b$ ). Somit ist die Regression der BCC eindeutig mit einer Verminderung der Proliferation und eher weniger mit zunehmender Apoptose assoziiert.
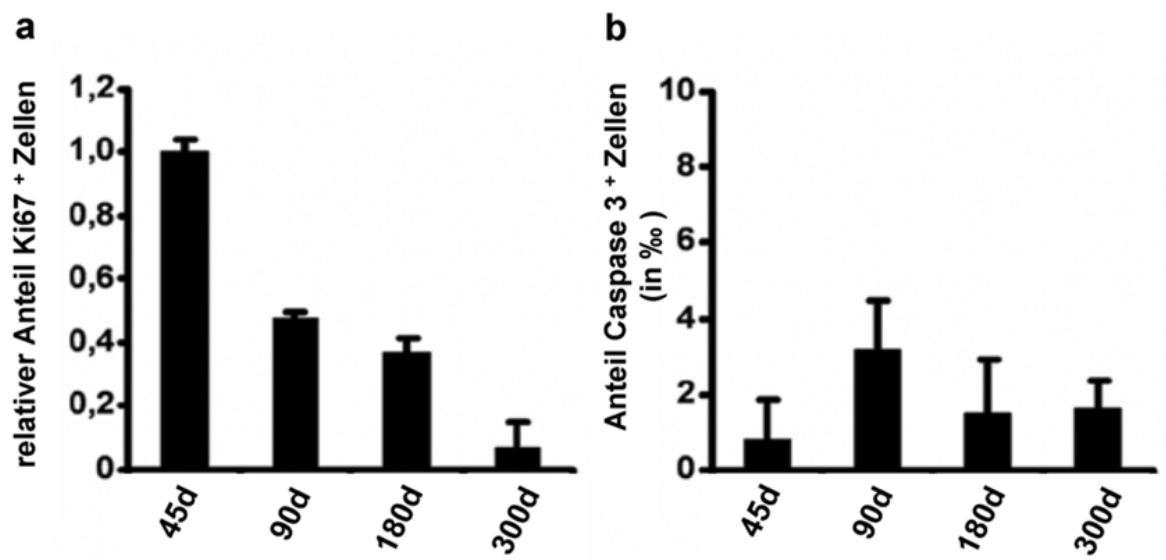

\begin{abstract}
Abbildung 3: Darstellung des Proliferationsindex und der Caspase-Aktivität in BCC von Ptch $^{\text {floxfllox}}$ ERT2 ${ }^{+/-}$Mäusen. Dargestellt sind der relative Anteil Ki67 positiver Zellen (a) sowie der Anteil Caspase-3 positiver Zellen (b) in verschiedenen BCC-Stadien nach Tumorinduktion. Der Anteil Ki67 positiver Zellen wurde in Relation zu den Vorläuferläsionen (45d) dargestellt, deren Anteil auf 1 gesetzt wurde. Die Abbildung wurde aus Nitzki et al. (2010) übernommen.
\end{abstract}

Die $P t c h^{f l o x / f l o x} E R T 2^{+/-}$Maus ist somit ein hervorragendes Modell um molekulare Vorgänge bei sowohl BCC-Pathogenese und /-Progression als auch bei der BCC-Regression zu untersuchen.

\title{
1.3 Wnt Signalwege
}

Der Wnt Signalweg spielt in der frühen Embryonalentwicklung von Vertebraten eine wichtige Rolle und reguliert dabei verschiedene Prozesse wie z. B. die Ausbildung von Körperachsen, Segmentpolarität oder Organanlagen. Auch sind die Wnt Proteine während der Embryonalentwicklung für den Erhalt adulter Gewebestrukturen notwendig (Logan, CY und Nusse, R 2004). Der Name Wnt setzt sich aus den Bezeichnungen für die homologen Gene Wingless (Drosophila) und Int1 (Maus) zusammen (Cabrera, CV et al. 1987; Rijsewijk, F et al. 1987). Bei der Fruchtfliege Drosophila melangonaster führen Mutationen im WinglessGen zu flügellosen Organismen (Sharma, RP und Chopra, VL 1976). Bei Mäusen wird die Entwicklung von Brustkrebs gefördert, wenn durch die Integration des Mouse Mammary Tumorvirus (MMTV) in der Nähe des Int1-Gens (heute Wnt1) seine Expression aktiviert wird (Nusse, R und Varmus, HE 1992). Bislang sind bereits 19 murine sowie humane Wnt-Gene 
bekannt (vgl. Wnt-Homepage: www.stanford.edu/ rnusse/wntwindow.html). Sie sind beispielsweise in die Kardiogenese (Pandur, $\mathrm{P}$ et al. 2002), Nephrogenese (Stark, K et al. 1994) oder die Extremitätenentwicklung (Church, VL und Francis-West, P 2002) involviert. Häufig sind die Wnt Gene jedoch mit malignen und metastasierenden Tumoren assoziiert (siehe Review (Giles, RH et al. 2003)).

Die Wnt Proteine sind eine Gruppe sezernierter Glykoproteine (Zhai, L et al. 2004), die an transmembrane Rezeptoren der Frizzled (Fzd)-Familie binden. Sie wirken auf ihre Zielzellen, indem sie drei verschiedene Signalkaskaden aktivieren können. So stehen dem kanonischen Wnt/ß-Catenin Signalweg die beiden nicht-kanonischen Signalwege, zu denen der Wnt/Ca ${ }^{2+}$ Signalweg sowie der Wnt/JNK Signalweg gehören, gegenüber. Die drei alternativen Signalkaskaden werden in den folgenden Abschnitten genauer beschrieben und sind in Abbildung 4 und 5 dargestellt.

\subsubsection{Der kanonische Wnt/ß-Catenin Signalweg}

Der von den drei alternativen Wnt Signalwegen am besten untersuchte ist der kanonische Wnt/ß-Catenin Signalweg (Abbildung 4). Ist der Wnt Signalweg inaktiv, wird cytoplasmatisches ß-Catenin vom sogenannten „Destruktions-Komplex“ gebunden ( $\mathrm{He}, \mathrm{X}$ et al. 2004; Gordon, MD und Nusse, R 2006). Der Komplex bewirkt eine Phosphorylierung aller 4 Phoshorylierungsstellen von ß-Catenin. Dies ermöglicht es der E3-Ubiquitin-Ligase zu binden und ß-Catenin zu ubiquitinieren. Dadurch kann ß-Catenin im Proteasom abgebaut werden (He, X et al. 2004) (siehe Abbildung 4a). Bei der Aktivierung des Signalwegs werden die Wnt Faktoren an Fzd und seine Co-Rezeptoren wie LRP5/6 gebunden ( $\mathrm{He}, \mathrm{X}$ et al. 2004). Durch Bindung von Wnt an den Fzd/LRP5/6-Rezeptorkomplex wird Axin1 an die Zellmembran transloziert und an den cytoplasmatischen Teil von LRP5/6 gebunden (Zeng, $X$ et al. 2008). Dies führt zur Aktivierung des Proteins Dishevelled (Dvl) und zum Zerfall des „Destruktions-Komplexes“ (Gordon, MD und Nusse, R 2006). ß-Catenin wird somit nicht mehr phosphoryliert oder ubiquitiniert. Es wird daher auch nicht mehr abgebaut und akkumuliert im Cytoplasma (Hatsell, $S$ et al. 2003). Stabilisiertes ß-Catenin wird anschließend in den Nukleus transloziert. Dort fungiert ß-Catenin als transkriptioneller CoAktivator (Clevers, H 2006) und bindet zusammen mit anderen Proteinen wie Bcl9 an den TCF/LEF-Transkriptionsfaktor, der dadurch aktiviert wird. TCF/LEF aktiviert wiederum eine RNA-Polymerase, die dann die Transkription verschiedener Zielgene bewirkt (siehe Abbildung 4b). Zu diesen gehören z. B. Myc und CyclinD1 (Reya, T und Clevers, H 2005), die in der Onkogenese eine bedeutende Rolle spielen. 

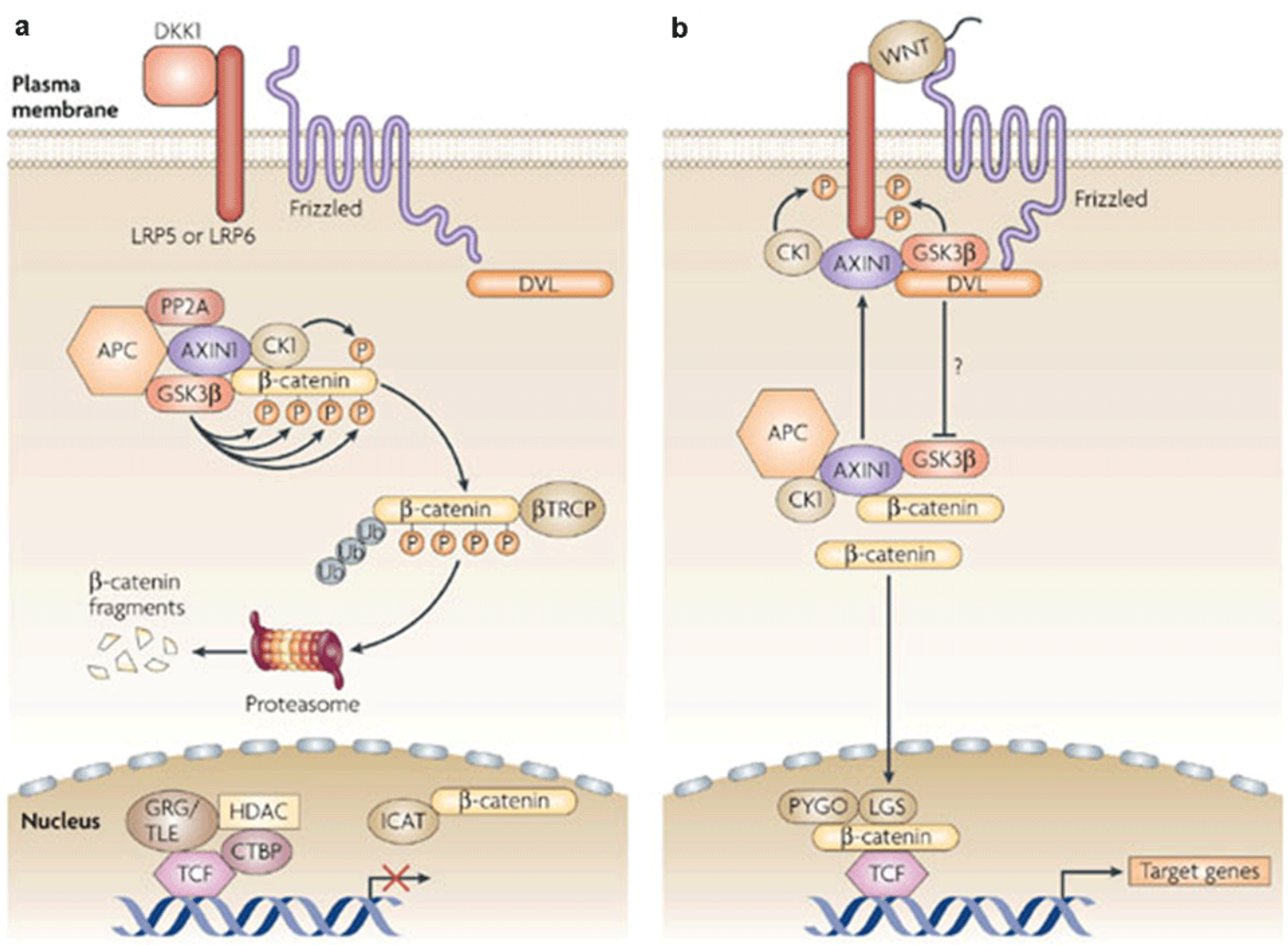

Abbildung 4: Der kanonische Wnt/ß-Catenin Signalweg. Bei Abwesenheit des Wnt-Liganden am Rezeptorkomplex wird ß-Catenin phosphoryliert und ubiquitiniert und durch das Proteasom degradiert (a). Durch Bindung der Wnt-Proteine am Rezeptorkomplex wird die Signalkaskade aktiviert. Die Aktivierung führt zur Stabilisierung und Translokation von ß-Catenin in den Nukleus. Dies resultiert in Transkription der Zielgene (b). Die Abbildung wurde aus Staal et al., Nature Reviews Immunology 8, 581-593, 2008 übernommen.

\subsubsection{Die nicht-kanonischen Wnt Signalwege}

\subsubsection{Der Wnt/JNK Signalweg}

Bei den beiden nicht-kanonischen Wnt Signalwegen wird der Wnt/JNK Signalweg (Boutros, $\mathrm{M}$ et al. 1998) vom $\mathrm{Ca}^{2+}$-abhängigen Signalweg (Kuhl, $\mathrm{M}$ et al. 2000) unterschieden.

Da der Wnt/JNK Signalweg Ähnlichkeiten zu dem Signalweg aufweist, der in Drosophila die planare Zellpolarität kontrolliert, wird er deshalb auch als PCP (planar cell polarity) Signalweg bezeichnet (Abbildung 5a). Die Aktivierung des Signalwegs wird über die Bindung von Wnt an den Fzd-Rezeptor über Ror1/2 als Co-Rezeptoren vermittelt (Hikasa, $\mathrm{H}$ et al. 2002). Dann erfolgt die Rekrutierung des cytoplasmatischen Proteins Dvl an den FzdRezeptor und die Aktivierung der beiden GTPasen Rho und Rac (Fanto, M et al. 2000; Habas, R et al. 2003). Daraus resultierend wird die c-Jun N-terminale Kinase JNK aktiviert, was wiederum zur Phosphorylierung und Aktivierung von c-Jun führt (Habas, R et al. 2003). 

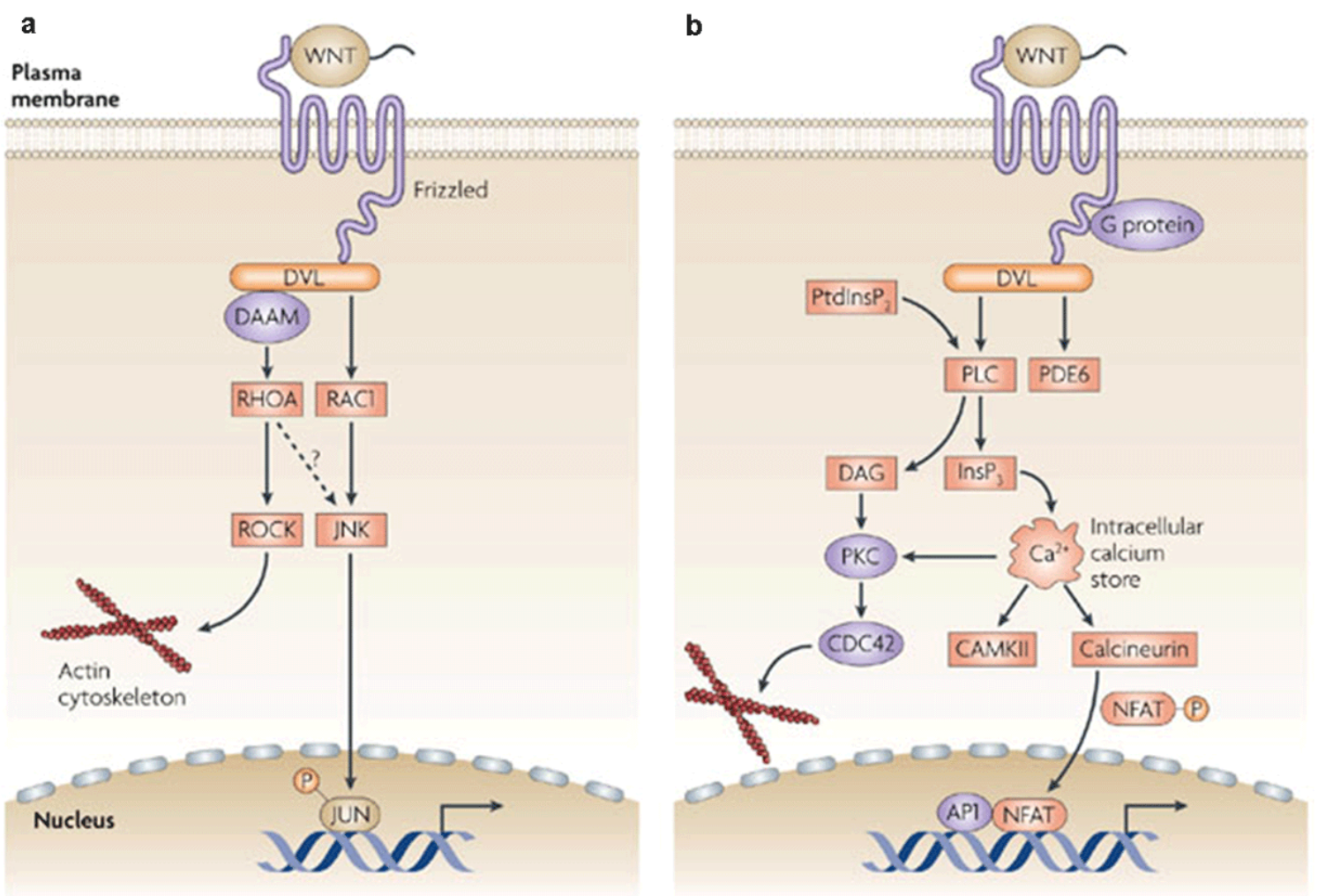

Abbildung 5: Die beiden nicht-kanonischen Wnt Signalwege. a) Der Wnt/JNK Signalweg führt durch Aktivierung von JNK und c-Jun zur Transkription von Zielgenen. b) Beim $\mathrm{Wnt} / \mathrm{Ca}^{2+}$ abhängigen Signalweg wird durch Anstieg der cytoplasmatischen Calciumkonzentration die Aktivierung der PKC, der CaMKIl sowie der Phosphatase Calcineurin vermittelt. Die Abbildung wurde aus Staal et al., Nature Reviews Immunology 8, 581-593, 2008 übernommen.

\subsubsection{Der Wnt/Ca ${ }^{2+}$ abhängige Signalweg}

Auch beim $\mathrm{Wnt} / \mathrm{Ca}^{2+}$ abhängigen Signalweg erfolgt die Signalweiterleitung zunächst durch Bindung von Wnt an den Fzd-Rezeptor (Abbildung 5b). Dadurch wird die membranständige Phospholipase $\mathrm{C}$ aktiviert und bewirkt die Freisetzung intrazellulärer $\mathrm{Ca}^{2+}$-lonen vom endoplasmatischen Reticulum ins Cytoplasma. Dies hat zur Folge, dass die $\mathrm{Ca}^{2+}$-abhängige Kinase Calmodulin-abhängige Kinase II (CaMKII) (Kuhl, M et al. 2000) und die Protein Kinase C (PKC) (Sheldahl, LC et al. 1999) aktiviert werden. Sowohl die CaMKIl als auch die PKC aktivieren verschiedene regulatorische Proteine sowie Transkriptionsfaktoren wie NF$\mathrm{kB}$ und Creb. Außerdem konnte gezeigt werden, dass auch der Calcium-abhängige Transkriptionsfaktor NFAT durch den Wnt/Ca ${ }^{2+}$ Weg aktiviert werden kann (Murphy, LL und Hughes, CC 2002; Saneyoshi, T et al. 2002; Pongracz, JE und Stockley, RA 2006). Darüber hinaus gibt es Hinweise, dass auch Dvl intrazelluläres $\mathrm{Ca}^{2+}$ freisetzen und somit Calciumsensitive Kinasen aktivieren kann (Sheldahl, LC et al. 2003). 


\subsection{Aktivierung der Wnt Signalwege durch Wnt5a}

Wnt5a kann als Ligand des kanonischen Wnt Signalwegs als auch der nicht-kanonischen Signalwege fungieren (Abbildung 6).

Seine aktivierende bzw. antagonisierende Funktion im kanonischen Signalweg ist vom jeweiligen Rezeptorkontext abhängig (Mikels, AJ und Nusse, R 2006). So wird der kanonische Wnt Signalweg aktiviert, wenn Wnt5a an die Rezeptorkombination Fzd4/LRP5 (Umbhauer, M et al. 2000; Mikels, AJ und Nusse, R 2006) oder an Fzd7 (Umbhauer, M et al. 2000) bindet. Auch durch Bindung an Fzd8 ist wahrscheinlich eine Wnt5a-vermittelte Aktivierung der Signalkaskade möglich (Itoh, K et al. 1998). Über den Rezeptor Fzd8 ist darüber hinaus bekannt, dass er vermehrt im BCC exprimiert wird (Asplund, A et al. 2008).

Eine Bindung von Wnt5a an Ror1/2 resultiert in der Aktivierung des Wnt/JNK Signalwegs ( $\mathrm{Li}$, L et al. 2009), wohingegen durch Bindung an die Rezeptoren Fzd2, 3, 4, 6 (He, $\mathrm{X}$ et al. 1997; Kuhl, M et al. 2000; Weeraratna, AT et al. 2002; Kohn, AD und Moon, RT 2005) oder Fzd5 (Blumenthal, A et al. 2006) der Wnt/Ca ${ }^{2+}$ abhängige Signalweg aktiviert wird. Die alternativen Wnt Signalwege sind sehr komplex und miteinander quervernetzt, wie der Abbildung $6 \mathrm{zu}$ entnehmen ist. Diese Interaktionen sind in Pukrop und Binder 2008 beschrieben.

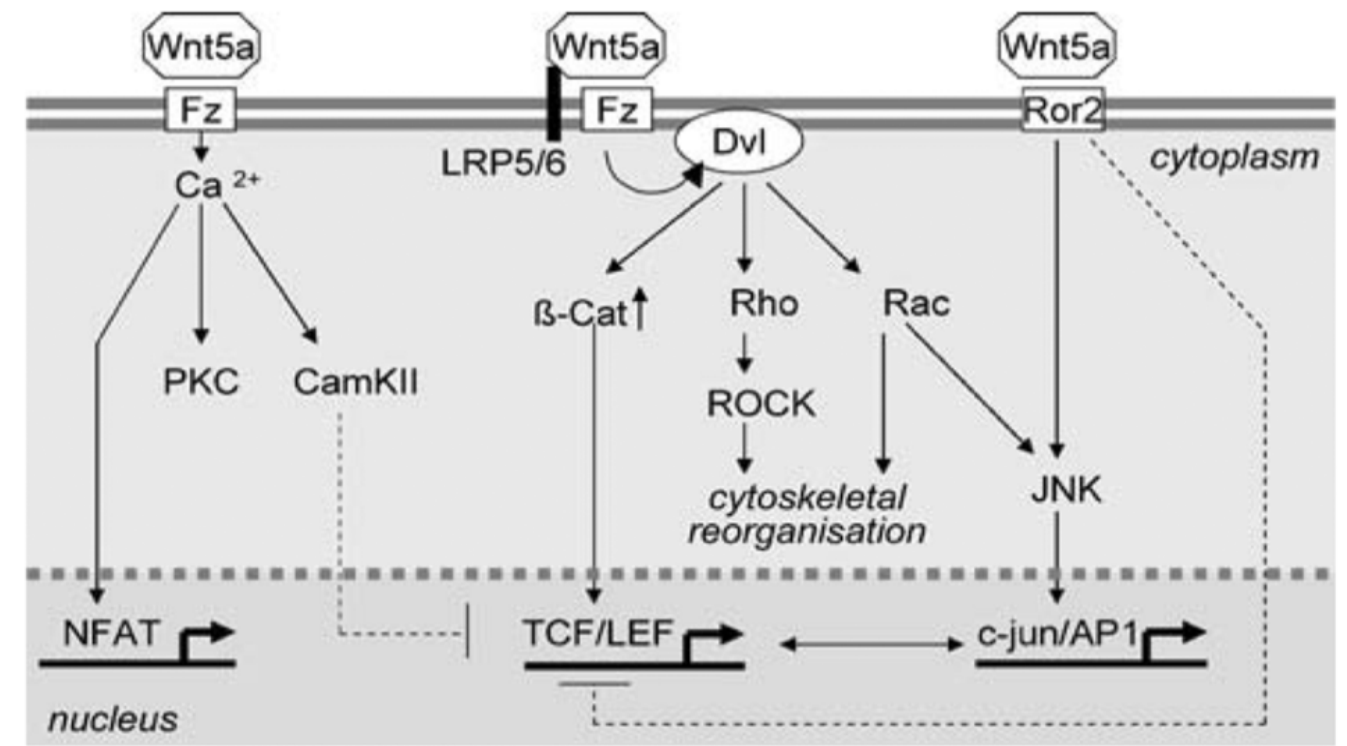

Abbildung 6: Darstellung der verschiedenen Wnt Signalwege aktiviert durch Wnt5a. Dargestellt sind sowohl der kanonische Wnt/ß-Catenin Signalweg als auch die beiden nicht kanonischen Wnt Signalwege (Wnt/JNK sowie Wnt/Ca ${ }^{2+}$ ) und deren Interaktionen. Die Abbildung wurde aus Pukrop und Binder, Journal of Molecular Medicine 86:259-266, 2008 übernommen.

\subsection{Die Rolle von Wnt5a bei Tumoren}

Generell wird die Rolle von Wnt5a in Tumoren kontrovers diskutiert. Mehrere Studien schreiben Wnt5a eine onkogene Funktion bei Tumoren zu. So konnte in soliden malignen Tumoren eine Überexpression von Wnt5a gezeigt werden (lozzo, RV et al. 1995). Auch beim 
malignen Melanom (Bittner, $M$ et al. 2000) ist Wnt5a ein zuverlässiger Marker für aggressives Tumorwachstum. Weiterhin ist gezeigt worden, dass eine Überexpression von Wnt5a sogar zur erhöhten Invasivität von Melanomzellen führt (Weeraratna, AT et al. 2002). Dies konnte auch für Brustkrebszellen gezeigt werden, wobei hier Wnt5a nicht tumorintrinsisch, sondern interessanterweise in tumorassoziierten Makrophagen (TAM, engl. tumor-associated macrophages) exprimiert wurde (Pukrop, T et al. 2006).

Dagegen zeigen einige Studien auch eine tumorsuppressorische Funktion von. So entwickeln hemizygote Wnt5a Knockout-Mäuse in ca. 25\% der Fälle B-Zell Lymphome und chronisch myeloische Leukämien (CML) (Liang, $\mathrm{H}$ et al. 2003). Weiterhin ist gezeigt worden, dass Wnt5a die Proliferation und Migration von Karzinomzellen der Schilddrüse hemmt (Kremenevskaja, $\mathrm{N}$ et al. 2005). Außerdem korreliert die Wnt5a Expression invers mit der Metastasierung und dem Überleben von Brustkrebspatienten (Jonsson, M et al. 2002). Schließlich konnte gezeigt werden, dass aggressive Brusttumoren generell nur wenig Wnt5a exprimieren (Leris, AC et al. 2005). Aufgrund der vorherrschenden Datengrundlage resultiert, dass die Funktion von Wnt5a vermutlich mit der einzelnen Tumorentität zusammenhängt und wahrscheinlich auch vom jeweiligen Rezeptorkontext abhängig ist.

\subsubsection{Bedeutung des Wnt5a Signalwegs beim BCC}

Neben dem Hh/Ptch Signalweg ist auch Wnt5a in die Pathogenese von Basalzellkarzinomen involviert. So konnte in allen bisher untersuchten BCC eine Überexpression von Wnt5a festgestellt werden (Bonifas, JM et al. 2001; Mullor, JL et al. 2001; Saldanha, G et al. 2004; Yang, SH et al. 2008). Deshalb wird diesem Gen eine wichtige Bedeutung bei der Entstehung und Progression von BCC zugeschrieben.

Wnt5a wird normalerweise in der Haut in der äußeren Wurzelscheide des Haares exprimiert. Zudem spielt Wnt5a eine wichtige Rolle bei der Haarfollikelmorphogenese und wird bei diesem Vorgang wahrscheinlich direkt durch den Hh/Ptch Signalweg reguliert (Reddy, S et al. 2001). Daher hat unsere Arbeitsgruppe zunächst untersucht, ob sich die Expression von Wnt5a in der BCC-Zelllinie ASZ001 durch Aktivierung der Hh/Ptch-Signalkaskade induzieren lässt. Mittels Transfektionsexperimenten konnte unsere Gruppe zeigen, dass dies jedoch nicht der Fall ist.

Weiterhin konnte bei einigen BCC eine nukleäre Lokalisation von ß-Catenin festgestellt werden (Saldanha, G et al. 2004). Deshalb wurde angenommen, dass Wnt5a über die Aktivierung des kanonischen Wnt/ß-Catenin Signalwegs zur Progression und vermehrter Proliferation dieser Tumoren führt. Auf der anderen Seite werden wichtige DownstreamTargets von ß-Catenin wie bsw. c-Myc in BCC nicht überexprimiert (Bonifas, JM et al. 2001). Daher ist die Funktion von kanonischem Wnt Signaling bei der Progression des Basalzellkarzinoms nicht eindeutig. Weiterhin zeigen in vivo Daten, dass kanonisches Wnt 
Signaling zumindest nicht mit der Initiation dieser Tumoren in Verbindung steht. So entwickeln transgene Mäuse, bei denen ß-Catenin in der Haut überexprimiert wird, keine Basalzellkarzinome, sondern Trichofollikulome und Pilomatrikome (Reya, T und Clevers, H 2005).

Unsere Arbeitsgruppe konnte nun zeigen, dass Wnt5a auch in BCC von Ptch floxfllox $E R T 2^{+/-}$ Mäusen exprimiert wird. Interessanterweise ist diese Expression nicht in den BCCVorläuferläsionen zu sehen (Abbildung 7, oben). Sie tritt erst in vollentwickelten BCC auf und bleibt während der Tumorregression bestehen. Dies führte zur Hypothese, dass Wnt5a mit der Tumorregression in Verbindung stehen könnte.

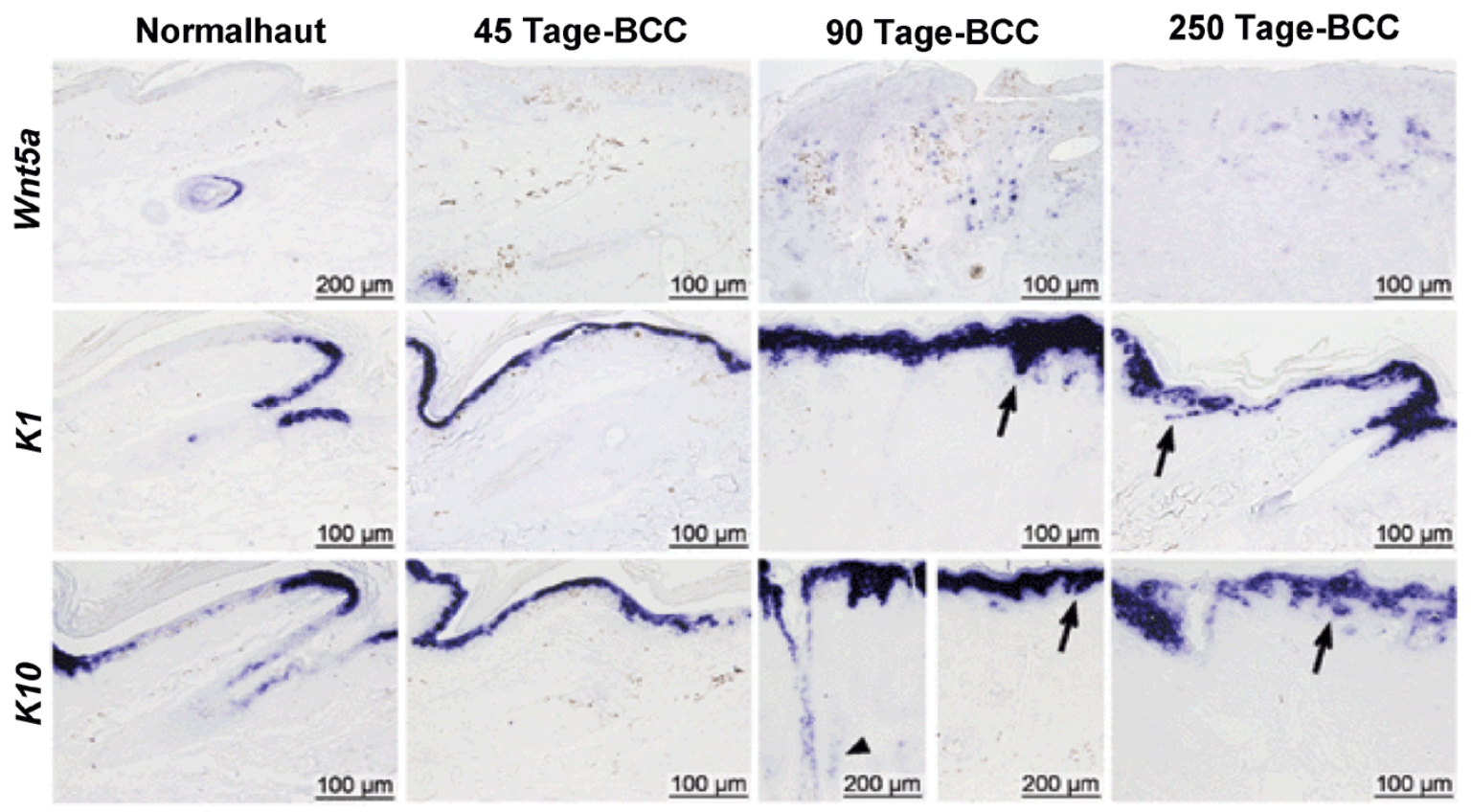

Abbildung 7: Darstellung von Normalhaut im Vergleich zu tumortragender Haut. Gezeigt ist die Expression von Wnt5a sowie der Differenzierungsmarker $K 1$ und $K 10$ in der Haut von Mäusen mittels in situ-Hybridisierung. Die jeweilige Expression wurde in Paraffinschnitten von Tamoxifen-behandelten Ptch $^{\text {floxfllox }}$ Mäusen (Normalhaut) und in BCC von Ptch flox/flox ERT2 ${ }^{+/-}$Mäusen zu unterschiedlichen Zeitpunkten nach Tumorinduktion nachgewiesen. Die Pfeile weisen auf $K 1$ sowie $K 10$ positive Areale in hyperproliferativer Haut bzw. tiefer gelegenen Hautschichten. Die Abbildung wurde aus Nitzki et al. (2010) übernommen.

Hochinteressant war dabei die Beobachtung, dass die Wnt5a Expression dabei lediglich auf das Stroma begrenzt war (Abbildung 8).

Weiterhin konnte unsere Arbeitsgruppe zeigen, dass die Spontanregression der Tumoren neben erhöhter stromaler Wnt5a Expression auch mit einer erhöhten tumorintrinsischen Expression der epidermalen Differenzierungsmarker $K 1$ und $K 10$ einhergeht (Abbildung 7 , Mitte und unten). 


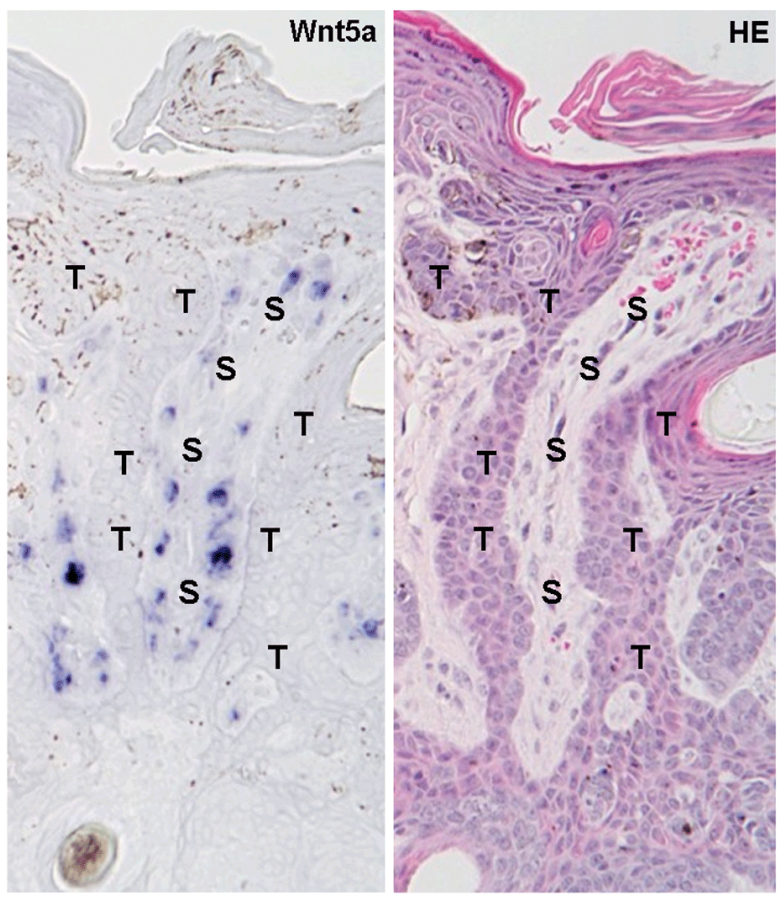

Abbildung 8: Wnt5a Expression und HE-Färbung von Haut einer Ptch ${ }^{f l o x / f l o x} E R T 2^{+/-}$Maus. Dargestellt sind direkt aneinander angrenzende Paraffinschnitte eines BCC 90 Tage nach Tumorinduktion in 200facher Vergrößerung. Der linke Ausschnitt der Abbildung zeigt die Wnt5a Expression mittels in situ-Hybridisierung und der rechte Ausschnitt eine entsprechende HE-Färbung des Gewebes. Abkürzungen: S, Stroma; T, Tumor.

Da angenommen wird, dass Wnt5a zur Aktivierung und nukleären Lokalisation von ßCatenin führen kann (siehe oben), hat unsere Arbeitsgruppe auch die Expression und Lokalisation von ß-Catenin sowie diejenige von Bcl9-2 in verschiedenen BCC Stadien der

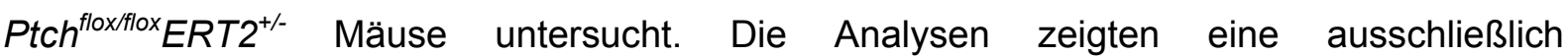
membranständige Färbung von ß-Catenin. Bcl9-2, welches normalerweise die Translokation von ß-Catenin aus dem Zelladhäsionskomplex an der Zellmembran in den Zellkern bewirkt um dort einen transkriptionell aktiven Komplex zu bilden, war nicht nachweisbar (Daten nicht gezeigt). Diese Daten zeigen, dass kanonisches Wnt Signaling wahrscheinlich eine

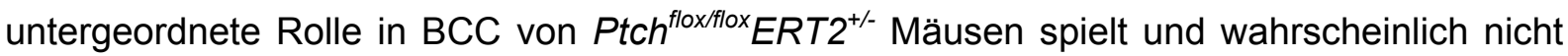
durch Wnt5a in diesem Modell aktiviert wird.

Unsere Arbeitsgruppe hat ebenfalls versucht, Hinweise über die Rolle von Wnt5a hinsichtlich der Aktivierung des Wnt/JNK und des Wnt/Ca ${ }^{2+}$ Signalwegs zu bekommen.

Zur Überprüfung der Aktivität des Wnt/JNK Signalwegs wurden verschiedene BCC Stadien

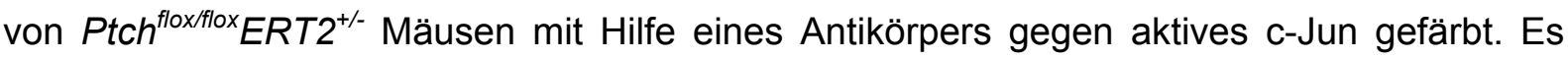
konnte gezeigt werden, dass die Expression heterogen und fokal lokalisiert war. Da die Expression von aktivem c-Jun jedoch nicht mit derjenigen von Wnt5a oder K10 korrelierte und in allen BCC Stadien gleich ausgeprägt war, war eine Aktivierung dieses Signalwegs durch Wnt5a eher unwahrscheinlich. 
Um auch einen Eindruck über die Aktivität des Wnt/Ca ${ }^{2+}$ abhängigen Signalwegs in BCC von $\mathrm{Ptch}^{\text {flox/flox}} \mathrm{ERT2}^{+/-}$Mäusen zu erlangen, hat unsere Arbeitsgruppe den Aktivierungsstatus von sowohl PKC als auch der CaMKII untersucht. Mittels Western Blot konnte gezeigt werden, dass sowohl PKC als auch die CaMKII in den vollausgebildeten und regredienten Tumoren gegenüber normaler Haut aktiver zu sein scheint.

Zusammengefasst zeigen diese Daten, dass Wnt5a in BCC von $\mathrm{Ptch}^{\text {floxflox }} E R T 2^{+/-}$Mäusen nicht tumorintrinsisch, sondern im BCC-Stroma exprimiert wird. Die stromale Expression wird hierbei erst in vollausgeprägten BCC-Stadien beobachtet. Sie bleibt auch in den regredienten Stadien bestehen und korreliert hierbei mit Differenzierungsvorgängen. Weiterhin ließen diese Daten vermuten, dass der Wnt/Ca ${ }^{2+}$ abhängige Signalweg während der BCC-Regression aktiv zu sein scheint. Ob die stromale Wnt5a Expression jedoch Wnt5a direkt mit den Differenzierungs-/ und Regressionsvorgängen, oder direkt mit der Aktvierung des Wnt/Ca ${ }^{2+}$ abhängigen Signalwegs im Zusammenhang stand, war zu Beginn dieser Arbeit unklar.

\subsection{Zielsetzung der Arbeit}

Das Basalzellkarzinom (BCC) ist der häufigste Tumor des Menschen. Ungefähr $20 \%$ aller BCC zeigen eine Spontanregression. Die Erforschung der zugrunde liegenden molekularen Mechanismen der Regression kann von besonderer Relevanz für neue Therapien des BCC sein.

Im Ptch floxfllox $E R T 2^{+/-}$Mausmodell können durch einmalige Gabe von Tamoxifen BCC induziert werden. Die Tumoren sind nach ca. 90 Tagen vollausgebildet und zeigen danach eine Spontanregression. Diese geht mit einer Differenzierung der Tumoren einher.

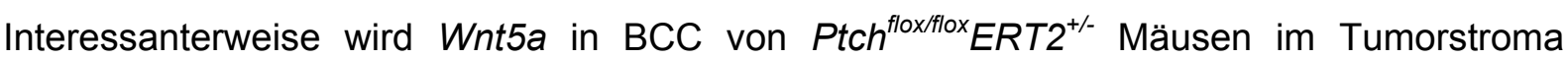
exprimiert und scheint mit der Tumorregression in Verbindung zu stehen. Außerdem scheint bei der Tumorregression der $\mathrm{Wnt} / \mathrm{Ca}^{2+}$ Signalweg aktiviert zu sein.

Im Rahmen dieser Dissertation sollte zunächst geklärt werden, ob der $\mathrm{Wnt} / \mathrm{Ca}^{2+}$ Signalweg durch Wnt5a aktiviert werden kann und ob dies im direkten Zusammenhang mit Differenzierungsvorgängen von BCC steht. Außerdem sollte untersucht werden, ob Wnt5a auch bei der Aktivierung des Wnt/ß-Catenin oder des Wnt/JNK Signalwegs eine Rolle spielt. Zudem sollte geklärt werden, welche stromale Zellpopulation für die Wnt5a Expression verantwortlich ist und ob die Wnt5a Expression durch BCC-Tumorzellen induziert werden kann.

Dann sollte geprüft werden, ob Wnt5a auch in vivo in die Tumorregression und/oder Differenzierung von BCC involviert ist. Hierzu sollte die Wnt5a Expression in der Haut von BCC-tragenden Ptch $^{\text {floxfllox }} E R T 2^{+/-}$Mäusen zum einen erhöht, und zum anderen vermindert werden. 
Zur Erhöhung der Wnt5a Expression sollte ein Wnt5a-Expressionsplasmid kloniert und in die BCC-tragende Haut injiziert werden. Außerdem wurde das Calcium-lonophor Ionomycin appliziert. Ionomycin sollte zur Erhöhung des $\mathrm{Ca}^{2+}$-Spiegels in der Haut führen. Dieses Experiment sollte somit Aufschluss über die potentielle Rolle von Calcium bei Differenzierung und Regression von BCC geben.

Zur Verminderung der Wnt5a Expression in der BCC-tragenden Haut wurden zunächst Wnt5a $^{+/-}$Mäuse in konditionelle Ptch floxflox ERT2 ${ }^{+/-}$Knockout-Mäuse eingekreuzt. Da sich im Laufe der Experimente zeigte, dass Wnt5a vorwiegend in BCC-assoziierten Makrophagen exprimiert ist, sollte das Wnt5a Level auch mittels Depletion der Wnt5a-exprimierende Makrophagen dezimiert werden. Hierzu wurde $\mathrm{Ptch}^{\text {flox/flox}} E R T 2^{+/-}$Knockout-Mäusen in Liposomen-verpacktes Clodronat (Clodrolip) appliziert. Zudem wurde versucht, das Knochenmark von Ptch ${ }^{\text {flox/flox}} E R T 2^{+/}$Mäusen durch Wnt5a-defizientes Knochenmark zu

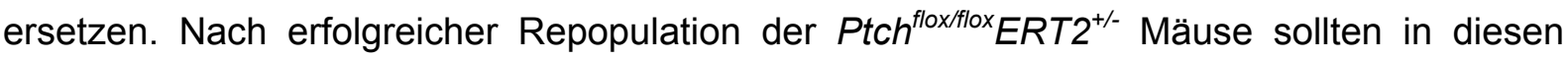
Tieren dann BCC induziert und das Wachstum der Tumoren verfolgt werden.

Da sich während der Experimente herausstellte, dass schon die alleinige Applikation von Leerliposomen einen Effekt auf Makrophagen und das Tumorwachstum in Ptch $^{\text {floxflox }} E R T 2^{+/}$ Mäusen hatte, wurde dieser unerwartete Liposomen-bedingte Effekt ebenfalls analysiert. 


\section{Material}

\subsection{Laborgeräte}

Tabelle 1: Auflistung der verwendeten Laborgeräte.

\begin{tabular}{|c|c|}
\hline Agarosegelelektrophorese-Kammern & peqlab Biotechnologie $\mathrm{GmbH}$, Erlangen \\
\hline Autoklav & W. Krannich GmbH \& Co KG, Göttingen \\
\hline BD FACSCalibur flow cytometer & BD Biosciences, Heidelberg \\
\hline BD LSR II flow cytometer & BD Biosciences, Heidelberg \\
\hline Blotapparaturen & Bio-Rad Laboratories $\mathrm{GmbH}$, München \\
\hline Begasungs-/Brutschränke (B6060, BBD 6220) & Heraeus Holding $\mathrm{GmbH}$, Hanau \\
\hline Crosslinker (Crosslinker CL-1) & Herolab GmbH, Wiesloch \\
\hline Digitale Fotokamera (PowerShot G10) & Canon Deutschland $\mathrm{GmbH}$, Krefeld \\
\hline Einkanal-Pipetten & Eppendorf, Hamburg \\
\hline Entwicklermaschine (Curix 60) & AGFA Vertriebsgesellschaft mbH \& Cie. KG, Köln \\
\hline Feinwaagen (Sartorius Basic plus) & Sartorius AG, Göttingen \\
\hline Filmkassetten & Sigma-Aldrich Chemie $\mathrm{GmbH}$, Steinheim \\
\hline Fluoreszenzmikroskop (BX60F5) & Olympus Optical Co. Ltd., Japan \\
\hline Gasbrenner (Gasprofi 2 scs) & WILD-TEC GmbH, Göttingen \\
\hline Gewebeeinbett und /-entwässerungsautomat (TP 1020) & Leica Mikrosysteme Vertrieb $\mathrm{GmbH}$, Bensheim \\
\hline Heizblock (Thermomixer) & Eppendorf, Hamburg \\
\hline Heizrührer (MR 3000/300) & Heidolph Instruments, Schwalbach \\
\hline Homogenisator (Miccra D-1) & ART-moderne Labortechnik e. K., Mühlheim \\
\hline Hybridisierungsofen (HB-1000 Hybridizer) & UVP, Inc., Upland, USA \\
\hline $\begin{array}{l}\text { Inverses Mikroskop mit Fluoreszenzfilter } \\
\text { (Axiovert 25, Filter Set 43,01,09) }\end{array}$ & Carl Zeiss Jena GmbH, Jena \\
\hline Kühlplatte (EG1150C) & Leica, Nussloch \\
\hline Kühlschrank $\left(4^{\circ} \mathrm{C}\right)$ & Robert Bosch $\mathrm{GmbH}$, Stuttgart \\
\hline Mikrowelle (Dimension 4) & Panasonic, Hamburg \\
\hline MilliQ-Anlage & Sartorius Stedim Biotech GmbH, Göttingen \\
\hline Mini-Zentrifuge & Carl Roth $\mathrm{GmbH}$, Karlsruhe \\
\hline Multi-Mod Microplate Reader (Synergy Mx) & BioTek Instruments, Inc., USA \\
\hline Multipipette & Eppendorf, Hamburg \\
\hline Paraffinspender, Ausgießstation (Dispenser PAG 12) & Medite Medizintechnik $\mathrm{GmbH}$, Burgdorf \\
\hline Paraffinstreckbad & Medax GmbH \& Co KG, Rendsburg \\
\hline pH-Meter I (inoLab ph Level 1) & WTW GmbH, Wien, Österreich \\
\hline Photometer (Biophotometer 6131) & Eppendorf, Hamburg \\
\hline Pipettierhilfe (Accu-jet) & Brand GmbH \& Co KG, Wertheim \\
\hline Präparierbesteck & Karl Hammacher $\mathrm{GmbH}$, Solingen \\
\hline Schlittenmikrotom (HN 40) & Leica Microsysteme Vertrieb $\mathrm{GmbH}$, Bensheim \\
\hline Schüttelwasserbad (1083) & GFL mbH, Burgwedel \\
\hline Sequenziergerät (ABI $3500 \mathrm{XL})$ & Applied Biosystems, Darmstadt \\
\hline Sterilbank (Euroflow Klasse IIA) & Clean Air Techniek bv, Woerden, Niederlande \\
\hline Stromquellen für Elektrophorese & peqlab Biotechnologie $\mathrm{GmbH}$, Erlangen \\
\hline Tank für Flüssigstickstoff & L'air liquide S.A., Paris Cedax, Frankreich \\
\hline TaqMan (ABI Prism 7900HT) & Applied Biosystems, Darmstadt \\
\hline Thermodrucker DPU-414 & Eppendorf, Hamburg \\
\hline Thermocycler & Eppendorf, Hamburg \\
\hline Tiefkühlschränke $\left(-20^{\circ} \mathrm{C}\right)$ & $\begin{array}{l}\text { Liebherr-Hausgeräte Ochsenhausen } \mathrm{GmbH} \text {, } \\
\text { Ochsenhausen und Robert Bosch } \mathrm{GmbH} \text {, Stuttgart }\end{array}$ \\
\hline Trans Blot, SD Semi Dry & Bio-Rad Laboratories $\mathrm{GmbH}$, München \\
\hline UV-Dokumentation (digital monochrome Printer P91D) & Mitsubishi, Ratingen \\
\hline Vortexer (Vortex-Genie 2) & Scientific Industries, Inc., Bohemia, USA \\
\hline Rotierender Plattformschüttler (Unimax 1010) & Heidolph Instruments, Schwalbach \\
\hline Zählkammer nach Neubauer (Assistent) & Brand GmbH \& Co KG, Wertheim \\
\hline Zentrifugen (Biofuge pico, fresco, primo, Multifuge 3L-R) & Heraeus Holding $\mathrm{GmbH}$, Hanau \\
\hline$-80^{\circ} \mathrm{C}$ Schrank & Sanyo Electric Co, Ltd, Japan \\
\hline
\end{tabular}




\subsection{Gebrauchswaren}

Tabelle 2: Auflistung der verwendeten Gebrauchswaren.

\begin{tabular}{|c|c|}
\hline Biopsie-Einbettkassetten & G. Kisker GbR, Steinfurt \\
\hline Blottingpapier & Inapa Tecno, Lissabon \\
\hline CL-XPosure Film & Thermo Fisher Scientific, Rockford, USA \\
\hline Companion-Platte (24-well-Format) & BD GmbH, Heidelberg \\
\hline Deckgläser & Menzel GmbH \& Co KG, Braunschweig \\
\hline Dispensionspipetten (Combitips plus) & Eppendorf, Hamburg \\
\hline EDTA-Röhrchen & Sarstedt AG \& Co., Nümbrecht \\
\hline Einwegspritzen (BD Plastipak und Micro-Fine) & BD GmbH, Heidelberg \\
\hline Faltenfilter & Sartorius Stedim Biotech $\mathrm{GmbH}$, Göttingen \\
\hline Glaswaren & Schott AG, Mainz \\
\hline Kanülen (Sterican $\varnothing 0,45 \times 12 \mathrm{~mm}$ ) & B. Braun Medical AG, Emmenbrücke \\
\hline Kryokonservierungsröhrchen & Greiner Bio-One GmbH, Frickenhausen \\
\hline Küvette (UVette & Eppendorf, Hamburg \\
\hline Luminometer Messplatten (96 well Assay Plate) & Costar, Corning Incorporated, Corning, USA \\
\hline Whatman-Papier (Nuclepore Track-Etched Membranes) & GE Healthcare, Whatman $\mathrm{GmbH}$, Dassel \\
\hline NuPAGE MES SDS Running buffer $20 x$ & Invitrogen $\mathrm{GmbH}$, Karlsruhe \\
\hline NuPAGE Novex Midi Gel & Invitrogen $\mathrm{GmbH}$, Karlsruhe \\
\hline Mikro-Hämatokrit-Kapillaren (Na-Heparin) & Brand GmbH \& Co.KG, Wertheim \\
\hline Objektträger (SuperFrost Plus, unbeschichtet) & Menzel GmbH \& Co.KG, Braunschweig \\
\hline Pasteurpipetten & Brand GmbH \& Co KG, Wertheim \\
\hline Paraffin zum Ausgießen (Paraplast Plus) & Thermo Fisher Scientific, Bonn \\
\hline PCR-Reaktionsgefäße und Deckel (ThermoFast 96) & 4titude ${ }^{(}$Ltd., Surrey, USA \\
\hline Petrischalen & Ochs $\mathrm{GmbH}$, Bovenden/Lenglern \\
\hline Pipettenspitzen, gestopft $(10 \mu \mathrm{l})$ & Sarstedt AG \& Co KG, Nümbrecht \\
\hline Pipettenspitzen, gestopft $(100 \mu \mathrm{l}, 200 \mu \mathrm{l}, 1000 \mu \mathrm{l})$ & G. Kisker GbR, Steinfurt \\
\hline Pipettenspitzen, ungestopft $(10 \mu \mathrm{l}, 200 \mu \mathrm{l})$ & Ochs $\mathrm{GmbH}$, Bovenden/Lenglern \\
\hline Pipettenspitzen, ungestopft $(1000 \mu \mathrm{l})$ & Sarstedt AG \& Co KG, Nümbrecht \\
\hline Nitrozellulose-Membran (Hybond-ECL, 0,2 $\mu \mathrm{M}$ ) & Amersham Biosciences Europe $\mathrm{GmbH}$, Freiburg \\
\hline Skalpellklingen (\#10, \#24) & Aesculap AG \& Co KG, Tuttlingen \\
\hline Sterilfilter $(0,2 \mu \mathrm{m}$ und $0,45 \mu \mathrm{m})$ & Th. Geyer GmbH \& Co KG, Renningen \\
\hline TaqMan Platten (384-well Optical Reaction Plate) & Thermo Fisher Scientific, Rockford, USA \\
\hline TaqMan Folien (Adhesive Clear Seals) & 4titude ${ }^{(B)}$ Ltd., Surrey, USA \\
\hline Zellkulturflaschen, $100 \mathrm{ml}$ & Sarstedt AG \& Co KG, Nümbrecht \\
\hline Zellkultur-Gewebeeinsätze (25mm) & Nunc GmbH \& Co KG, Wiesbaden \\
\hline Zellkultur-Membraneinsätze (Porengröße $8 \mu \mathrm{m}$ ) & BD GmbH, Heidelberg \\
\hline Zellkulturschalen, 100 mm, 35 mm (Nunclon Surface) & Nunc GmbH \& Co KG, Wiesbaden \\
\hline Zellschaber & Sarstedt, Inc., Newton, USA \\
\hline Zellsiebe $(40 \mu \mathrm{m}$ und $70 \mu \mathrm{m})$ & BD GmbH, Heidelberg \\
\hline 1,5 ml Reaktionsgefäße & Ochs $\mathrm{GmbH}$, Bovenden/Lenglern \\
\hline 2,0 ml Reaktionsgefäße & Sarstedt AG \& Co, Nümbrecht \\
\hline 15 ml Röhrchen & Greiner Bio-One GmbH, Frickenhausen \\
\hline 50 ml Röhrchen & Greiner Bio-One GmbH, Frickenhausen \\
\hline 6-Loch Platten (Tissue Culture Plate 6-well) & Sarstedt AG \& Co, Nümbrecht \\
\hline 96-Loch Platten (Tissue Culture Plate 96-well) & Nunc GmbH \& Co KG, Wiesbaden \\
\hline
\end{tabular}

\subsection{Chemikalien und Reagenzien}

Tabelle 3: Auflistung der verwendeten Chemikalien und Reagenzien.

\begin{tabular}{ll}
\hline Accutase & PAA Laboratories $\mathrm{GmbH}$, Cölbe \\
\hline Agar-Agar & Carl Roth GmbH \& Co. KG, Karlsruhe \\
\hline Agarose & Bio-Budget Technologie GmbH, Krefeld \\
\hline Albumin Fraktion V & Carl Roth GmbH \& Co. KG, Karlsruhe \\
\hline Ampuwa (steriles pyrogenfreies Wasser) & Fresenius Kabi Deutschland GmbH, Bad Homburg \\
\hline ß-Mercaptoethanol & Sigma-Aldrich, Chemie GmbH, Steinheim \\
\hline BLP (=Pam ${ }_{3}$ CSK $_{4}$ ) & InvivoGen San Diego, USA \\
\hline BM Purple AP-Substrat & Roche Diagnostics GmbH, Mannheim \\
\hline Borgal-Lösung & Virbac Tierarzneimittel GmbH, Bad Oldesloe \\
\hline Borsäure & MP Biochemicals, LLC, Frankreich \\
\hline
\end{tabular}


Material

\begin{tabular}{|c|c|}
\hline Calcein-AM & Sigma-Aldrich, Chemie GmbH, Steinheim \\
\hline Casein (I-Block) & Tropix, Bedford, USA \\
\hline Chelex 100 Resin Chelating Ion Exchanger Resin & BioRad Laboratories Inc., Hercules, USA \\
\hline Citronensäure-Monohydrat & Carl Roth GmbH \& Co. KG, Karlsruhe \\
\hline Collagenase Typ2 & Worthington Biochemical Corp., Lakewood, USA \\
\hline Deoxyribonukleotidtriphosphate (dNTP) & Bio-Budget Technologie $\mathrm{GmbH}$, Krefeld \\
\hline Diethyldicarbonat (DEPC) & Carl Roth GmbH \& Co. KG, Karlsruhe \\
\hline Dig RNA Labeling Mix, 10x conc. & Roche Diagnostics $\mathrm{GmbH}$, Mannheim \\
\hline Dimethylsulfoxid (DMSO) & Sigma-Aldrich, Chemie $\mathrm{GmbH}$, Steinheim \\
\hline Dithiothreitol (DTT) & Invitrogen $\mathrm{GmbH}$, Karlsruhe \\
\hline DNA-Größenstandard (1kb, 100bp und 50bp) & Invitrogen $\mathrm{GmbH}$, Karlsruhe \\
\hline Eosin $Y$ & Carl Roth GmbH \& Co. KG, Karlsruhe \\
\hline Essigsäureanhydrid & Carl Roth GmbH \& Co. KG, Karlsruhe \\
\hline Ethanol 99\%ig & J.T.Baker, Darmstadt \\
\hline Ethanol 99\%ig vergällt & Chemie-Vertrieb Hannover, Hannover \\
\hline Ethidiumbromid & inna-TRAIN-Diagnostics. Kronberg \\
\hline Ethylendiamintetraacetat (EDTA) & ICN Biochemicals Inc., Aurora, USA \\
\hline First strand buffer & Invitrogen $\mathrm{GmbH}$, Karlsruhe \\
\hline Formamid 99\% DNase, RNase frei & Acros Organics, Geel, Belgien \\
\hline Glutaraldehyd & Sigma-Aldrich, Chemie $\mathrm{GmbH}$, Steinheim \\
\hline Glycergel (Einbett-Medium) & Dako $\mathrm{GmbH}, \mathrm{Hamburg}$ \\
\hline Glycerol & Sigma-Aldrich, Chemie GmbH, Steinheim \\
\hline Hepes & Invitrogen $\mathrm{GmbH}$, Karlsruhe \\
\hline Ionomycin & Cell Signaling; NEB GmbH, Frankfurt/Main \\
\hline Lachsspermien-DNA (10mg/ml) & Invitrogen $\mathrm{GmbH}$, Karlsruhe \\
\hline Liquid Barrier Marker & Carl Roth GmbH \& Co. KG, Karlsruhe \\
\hline Ketanest S $(25 \mathrm{mg} / \mathrm{ml})$ & Pfizer Pharma GmbH, Karlsruhe \\
\hline KN-93 & ALEXIS Corporation, Lausen, Schweiz \\
\hline Mayers Hämalaunlösung & Merck KGaA, Darmstadt \\
\hline Methanol & Carl Roth GmbH \& Co. KG, Karlsruhe \\
\hline Milchpulver & Carl Roth GmbH \& Co. KG, Karlsruhe \\
\hline Natriumchlorid & AppliChem GmbH, Darmstadt \\
\hline Natriumdodecylsulfat (SDS) & Carl Roth GmbH \& Co. KG, Karlsruhe \\
\hline Nystatin & Sigma-Aldrich, Chemie $\mathrm{GmbH}$, Steinheim \\
\hline Paraformaldehyd & Carl Roth $\mathrm{GmbH} \&$ Co. KG, Karlsruhe \\
\hline PBS pH 7,4 (gebrauchsfertig) & GIBCO Invitrogen $\mathrm{GmbH}$, Karlsruhe \\
\hline PBS-Tabletten & GIBCO Invitrogen $\mathrm{GmbH}$, Karlsruhe \\
\hline Pertex Montagemedium & Medite Medizintechnik $\mathrm{GmbH}$, Burgdorf \\
\hline Pferdeserum (hitzeinaktiviert) & Invitrogen $\mathrm{GmbH}$, Karlsruhe \\
\hline Propidiumiodid & Invitrogen $\mathrm{GmbH}$, Karlsruhe \\
\hline Random Hexamer-Oligonukleotide & Invitrogen $\mathrm{GmbH}$, Karlsruhe \\
\hline RNase/DNase-freies destilliertes Wasser & GIBCO Invitrogen $\mathrm{GmbH}$, Karlsruhe \\
\hline RNAseZAp & Sigma-Aldrich, Chemie $\mathrm{GmbH}$, Steinheim \\
\hline Rompun $2 \%$ & Bayer Vital GmbH, Leverkusen \\
\hline rWnt5a (murines Protein) & R\&D Systems GmbH, Wiesbaden \\
\hline Salzsäure, rauchend $37 \%$ & Merck KGaA, Darmstadt \\
\hline Sephadex G-50 fine & Amersham Biosciences Europe $\mathrm{GmbH}$, Freiburg \\
\hline S.O.C. Medium & Invitrogen $\mathrm{GmbH}$, Karlsruhe \\
\hline Staurosporin & Sigma-Aldrich, Chemie $\mathrm{GmbH}$, Steinheim \\
\hline Tris & AppliChem GmbH, Darmstadt \\
\hline Triton $\mathrm{X}-100$ & Sigma-Aldrich, Chemie $\mathrm{GmbH}$, Steinheim \\
\hline TRIzol Reagent & Invitrogen $\mathrm{GmbH}$, Karlsruhe \\
\hline Trypanblau & Sigma-Aldrich, Chemie $\mathrm{GmbH}$, Steinheim \\
\hline Tween-20 & Scharlau Chemie S.A., Barcelona, Spanien \\
\hline Wasserstoffperoxid $30 \%$ & Merck KGaA, Darmstadt \\
\hline WST-1 & Roche Diagnostics $\mathrm{GmbH}$, Mannheim \\
\hline X-Gal & Carl Roth GmbH \& Co. KG, Karlsruhe \\
\hline Xylol & J. T. Baker B.V., Deventer, Holland \\
\hline
\end{tabular}




\subsection{Gebrauchsfertige Reaktionssysteme}

Bei Verwendung gebrauchsfertiger Reaktionssysteme wurde nach Herstellerangaben gearbeitet, eine alternative Vorgehensweise wurde bei Beschreibung der Methoden (Kapitel 3) entsprechend angeführt.

Tabelle 4: Auflistung verwendeter gebrauchsfertiger Reaktionssysteme.

\begin{tabular}{ll}
\hline Pierce $^{(8)}$ BCA Protein Assay Kit & Thermo Fisher Scientific, Rockford, USA \\
\hline Cell Proliferation ELISA, BrdU (chemiluminescence) & Roche Diagnostics GmbH, Mannheim \\
\hline Dako REAL ${ }^{\mathrm{IM}}$ EnVision ${ }^{\mathrm{IM}}$ Detection System & Dako Denmark A/S, Glostrup, Dänemark \\
\hline DNeasy Blood \& Tissue Kit & Qiagen $\mathrm{GmbH}$, Hilden \\
\hline Dual-Luciferase Reporter Assay System & Promega $\mathrm{GmbH}$, Mannheim \\
\hline Effectene Transfection Reagent Kit & Qiagen $\mathrm{GmbH}$, Hilden \\
\hline Enhanced chemoluminescence (ECL) Kit & Amersham Biosciences Europe GmbH, Freiburg \\
\hline High Pure PCR Cleanup Micro Kit & Roche Diagnostics GmbH, Mannheim \\
\hline pGEM-Teasy TA-cloning Kit & Promega GmbH, Mannheim \\
\hline PureLink HiPure Plasmid Midiprep Kit & Invitrogen $\mathrm{GmbH}$, Karlsruhe \\
\hline QuantiTect SYBR Green PCR & Qiagen GmbH, Hilden \\
\hline QuikChange II Site-Directed Mutagenesis Kit & Agilent Technologies Deutschland GmbH, \\
\hline RNeasy Fibrous Tissue Mini Kit & Böblingen \\
\hline RotiFect & Qiagen GmbH, Hilden \\
\hline SYBR Green Invitrogen & Carl Roth GmbH \& Co. KG, Karlsruhe \\
\hline
\end{tabular}

\subsection{Stammlösungen}

Zum Ansetzen und Verdünnen von Stammlösungen wurde $\mathrm{dd}_{2} \mathrm{O}$ aus der Milli-Q Anlage (Sartorius Stedim Biotech GmbH, Göttingen) verwendet.

Tabelle 5: Auflistung der verwendeten Stammlösungen.

\begin{tabular}{|c|c|c|c|}
\hline Binding Buffer (Annexin V) & $\begin{array}{l}0,1 \mathrm{M} \\
1,4 \mathrm{M} \\
25 \mathrm{mM} \\
\end{array}$ & $\begin{array}{l}\text { Hepes } \\
\mathrm{NaCl} \\
\mathrm{CaCl}_{2} \\
\end{array}$ & $\mathrm{pH} \mathrm{7,4}$ \\
\hline Blocking Puffer & $5 \%(w / v)$ & Milchpulver & $\begin{array}{l}\text { in } \\
\text { PBST }\end{array}$ \\
\hline Blotting Puffer & $\begin{array}{l}6 \%(\mathrm{w} / \mathrm{v}) \\
3 \%(\mathrm{w} / \mathrm{v}) \\
0,075 \% \\
20 \%(\mathrm{v} / \mathrm{v})\end{array}$ & $\begin{array}{l}\text { Tris Base } \\
\text { Glycin } \\
\text { SDS } \\
\text { Methanol }\end{array}$ & \\
\hline BSA/Azid-Lösung & $\begin{array}{l}0,1 \%(\mathrm{v} / \mathrm{v}) \\
0,02 \%(\mathrm{w} / \mathrm{v}) \\
2 \%(\mathrm{w} / \mathrm{v})\end{array}$ & $\begin{array}{l}\text { Tween-20 } \\
\text { Natriumazid } \\
\text { BSA }\end{array}$ & in PBS \\
\hline Citratpuffer $\mathrm{pH} 6,0$ & $10 \mathrm{mM}$ & Natriumcitrat & \\
\hline Cresol-Lösung & $0,1 \%(w / v)$ & $\begin{array}{l}\text { Cresol } \\
\text { gesättigte Sucroselösung }\end{array}$ & \\
\hline $\begin{array}{l}\text { Deoxyribonukleotidtriphosphat-Mix } \\
\text { (dNTPs) }\end{array}$ & $\begin{array}{l}10 \mathrm{mM} \\
10 \mathrm{mM} \\
10 \mathrm{mM} \\
10 \mathrm{mM}\end{array}$ & $\begin{array}{l}\text { dATP } \\
\text { dCTP } \\
\text { dGTP } \\
\text { dTTP }\end{array}$ & \\
\hline Eosin, $1 \%$ & $\begin{array}{l}1 \%(w / v) \\
80 \%(v / v)\end{array}$ & $\begin{array}{l}\text { Eosin Y } \\
\text { Ethanol }\end{array}$ & \\
\hline Glutaraldehyd/1xPBS & $0,2 \%(v / v)$ & Glutaraldehyd & in PBS \\
\hline
\end{tabular}




\begin{tabular}{|c|c|c|c|}
\hline Hämalaun nach Mayer & $\begin{array}{l}0,1 \%(w / v) \\
5 \%(w / v) \\
0,015 \%(w / v) \\
5 \%(w / v) \\
1 \%(w / v)\end{array}$ & $\begin{array}{l}\text { Hämatoxylin } \\
\text { Kaliumaluminiumsulfat } \\
\text { Natriumjodat } \\
\text { Trichloracethaldehydhydrat } \\
\text { Citronensäure }\end{array}$ & \\
\hline Hanks' Balanced Salt Solution (HBSS) & $\begin{array}{l}0,8 \%(\mathrm{w} / \mathrm{v}) \\
0,04 \%(\mathrm{w} / \mathrm{v}) \\
0,006 \%(\mathrm{w} / \mathrm{v}) \\
0,0048 \%(\mathrm{w} / \mathrm{v}) \\
0,15 \%(\mathrm{w} / \mathrm{v}) \\
0,1 \%(\mathrm{w} / \mathrm{v})\end{array}$ & $\begin{array}{l}\mathrm{NaCl} \\
\mathrm{KCl} \\
\mathrm{KH}_{2} \mathrm{PO}_{4} \\
\mathrm{Na}_{2} \mathrm{HPO}_{4} \\
\mathrm{MgSO}_{4} \\
\text { Glucose } \\
\end{array}$ & \\
\hline Hybridisierungspuffer Hyb F & $\begin{array}{l}40 \%(\mathrm{v} / \mathrm{v}) \\
10 \%(\mathrm{w} / \mathrm{v})\end{array}$ & $\begin{array}{l}\text { Formamid } \\
\text { Dextransulfat } \\
4 x \text { SSC } \\
\text { 1x Denhardts }\end{array}$ & $\mathrm{pH} 6,4$ \\
\hline Hybridisierungspuffer Hyb M & $\begin{array}{l}50 \%(\mathrm{v} / \mathrm{v}) \\
10 \%(\mathrm{w} / \mathrm{v}) \\
0,3 \mathrm{M} \\
20 \mathrm{mM} \\
5 \mathrm{mM} \\
10 \mathrm{mM} \\
\\
\\
\end{array}$ & $\begin{array}{l}\text { Formamid } \\
\text { Dextransulfat } \\
\mathrm{NaCl} \\
\text { Tris/HCl } \\
\text { EDTA } \\
\mathrm{NaPO}_{4} \\
\text { 1x Denhardts } \\
\text { Hefe-tRNA }\end{array}$ & $\mathrm{pH} 8,0$ \\
\hline LacZ-Puffer & $\begin{array}{l}2 \mathrm{mM} \\
0,02 \%(\mathrm{v} / \mathrm{v}) \\
0,01 \%(\mathrm{w} / \mathrm{v})\end{array}$ & $\begin{array}{l}\mathrm{MgCl}_{2} \\
\mathrm{NP}-40 \\
\text { Natrium Deoxycholat }\end{array}$ & in PBS \\
\hline LacZ-Färbepuffer & $\begin{array}{l}5 \mathrm{mM} \\
5 \mathrm{mM} \\
2 \mathrm{mM} \\
0,02 \%(\mathrm{v} / \mathrm{v}) \\
0,01 \%(\mathrm{w} / \mathrm{v}) \\
500 \mu \mathrm{g} / \mathrm{ml}\end{array}$ & $\begin{array}{l}\mathrm{K}_{3} \mathrm{Fe}(\mathrm{CN})_{6} \\
\mathrm{~K}_{4} \mathrm{Fe}(\mathrm{CN})_{6} \\
\mathrm{MgCl}_{2} \\
\mathrm{NP}-40 \\
\text { Natrium Deoxycholat } \\
\text { X-Gal-Stocklösung }\end{array}$ & in PBS \\
\hline LB-Medium (,Iysogeny broth”-Medium) & $\begin{array}{l}1 \%(\mathrm{w} / \mathrm{v}) \\
0,5 \%(\mathrm{w} / \mathrm{v}) \\
1 \%(\mathrm{w} / \mathrm{v})\end{array}$ & $\begin{array}{l}\text { Trypton } \\
\text { Hefeextrakt } \\
\mathrm{NaCl}\end{array}$ & $\mathrm{pH} 7,0$ \\
\hline $\begin{array}{l}\text { Lysepuffer (für Gewebe) } \\
\text { Protease-/ und Phosphataseinhibitoren: je } \\
1 \text { Tablette auf } 10 \mathrm{ml} \text { Lysepuffer }\end{array}$ & $\begin{array}{l}1 \%(\mathrm{v} / \mathrm{v}) \\
150 \mathrm{mM} \\
1 \mathrm{mM}\end{array}$ & $\begin{array}{l}\text { Triton X-100 } \\
\text { Hepes } \\
\text { EDTA }\end{array}$ & \\
\hline MBSTL-Puffer pH 7,5 & $\begin{array}{l}0,15 \mathrm{M} \\
0,1 \mathrm{M} \\
0,1 \%\end{array}$ & $\begin{array}{l}\mathrm{NaCl} \\
\text { Maleinsäure } \\
\text { Tween-20 }\end{array}$ & \\
\hline Neufuchsin-Chromogen & $\begin{array}{l}0,6 \%(\mathrm{v} / \mathrm{v}) \\
0,05 \%(\mathrm{w} / \mathrm{v}) \\
0,03 \%(\mathrm{w} / \mathrm{v}) \\
0,02 \%(\mathrm{w} / \mathrm{v}) \\
0,01 \%(\mathrm{w} / \mathrm{v})\end{array}$ & $\begin{array}{l}\text { N,N-Dimethylformamid } \\
\text { Levamisol } \\
\text { Naphtol As-Bi Phosphat } \mathrm{NaN}_{3} \\
\text { Neu-Fuchsin }\end{array}$ & $\begin{array}{l}\text { in TBS } \\
\mathrm{pH} 8,8\end{array}$ \\
\hline NT-Puffer & $\begin{array}{l}0,15 \mathrm{M} \\
0,1 \mathrm{M}\end{array}$ & $\begin{array}{l}\mathrm{NaCl} \\
\text { Tris/HCl }\end{array}$ & $\mathrm{pH} 7,5$ \\
\hline NTM-Puffer & $\begin{array}{l}0,1 \mathrm{M} \\
0,1 \mathrm{M} \\
50 \mathrm{mM}\end{array}$ & $\begin{array}{l}\mathrm{NaCl} \\
\mathrm{Tris} / \mathrm{HCl} \\
\mathrm{MgCl}_{2}\end{array}$ & $\mathrm{pH} 9,5$ \\
\hline NTMLT-Puffer & $\begin{array}{l}0,1 \mathrm{M} \\
0,1 \mathrm{M} \\
50 \mathrm{mM} \\
2 \mathrm{mM} \\
0,1 \%\end{array}$ & $\begin{array}{l}\mathrm{NaCl} \\
\text { Tris/HCl } \\
\mathrm{MgCl}_{2} \\
\text { Levamisol } \\
\text { Tween-20 }\end{array}$ & $\mathrm{pH} 9,5$ \\
\hline Paraformaldehyd-Lösung (PFA) & $4 \%(w / v)$ & Paraformaldehyd & in PBS \\
\hline PBST (Waschpuffer) & $0,1 \%(\mathrm{v} / \mathrm{v})$ & Tween-20 & in PBS \\
\hline
\end{tabular}




\begin{tabular}{|c|c|c|c|}
\hline $\begin{array}{l}\text { Phosphat-gepufferte Natriumchloridlösung, } \\
\text { 10x, pH 7,4 (PBS) }\end{array}$ & $\begin{array}{l}8 \%(w / v) \\
0,2 \%(w / v) \\
0,2 \%(w / v) \\
1,77 \%(w / v)\end{array}$ & $\begin{array}{l}\mathrm{NaCl} \\
\mathrm{KH}_{2} \mathrm{PO}_{4} \\
\mathrm{KCl} \\
\mathrm{Na}_{2} \mathrm{HPO}_{4} \times 2 \mathrm{H}_{2} \mathrm{O}\end{array}$ & \\
\hline Proteinase K-Puffer & $\begin{array}{l}50 \mathrm{mM} \\
5 \mathrm{mM} \\
40 \mu \mathrm{g} / \mathrm{ml}\end{array}$ & $\begin{array}{l}\text { Tris/HCl } \\
\text { EDTA } \\
\text { Proteinase K }\end{array}$ & $\mathrm{pH} 8,0$ \\
\hline RIPA Puffer (modifiziert) & $\begin{array}{l}50 \mathrm{mM} \\
150 \mathrm{mM} \\
1 \mathrm{mM}\end{array}$ & $\begin{array}{l}\text { Tris } \mathrm{HCl} \\
\mathrm{NaCl} \\
\text { EDTA }\end{array}$ & $\mathrm{pH} 7,4$ \\
\hline $\begin{array}{l}\text { Protease-/ und Phosphataseinhibitoren: je } \\
1 \text { Tablette auf } 10 \mathrm{ml} \text { Lysepuffer }\end{array}$ & $\begin{array}{l}1 \%(v / v) \\
0,25 \%(w / v)\end{array}$ & $\begin{array}{l}\text { NP-40 } \\
\text { Na-Deoxycholat }\end{array}$ & \\
\hline SDS Ladepuffer $6 x$ & $\begin{array}{l}35 \%(\mathrm{v} / \mathrm{v}) \\
9 \%(\mathrm{w} / \mathrm{v} \\
8,5 \%(\mathrm{w} / \mathrm{v}) \\
0,1 \%(\mathrm{w} / \mathrm{v})\end{array}$ & $\begin{array}{l}\text { Glycerol } \\
\text { SDS } \\
\text { DTT } \\
\text { Bromphenolblau }\end{array}$ & $\begin{array}{l}\text { in } \\
\text { Upper } \\
\text { Gel } \\
\text { Puffer }\end{array}$ \\
\hline $\begin{array}{l}\text { Standard Natriumcitrat Lösung (SSC), 20x, } \\
\mathrm{pH} 6,4\end{array}$ & $\begin{array}{l}0,3 \mathrm{M} \\
3 \mathrm{M} \\
\end{array}$ & $\begin{array}{l}\text { Natriumcitrat } \\
\mathrm{NaCl}\end{array}$ & \\
\hline STE-Puffer & $\begin{array}{l}50 \mathrm{mM} \\
100 \mathrm{mM} \\
1 \mathrm{mM} \\
1 \%(\mathrm{w} / \mathrm{v})\end{array}$ & $\begin{array}{l}\text { Tris } \mathrm{HCl} \\
\mathrm{NaCl} \\
\text { EDTA } \\
\text { SDS }\end{array}$ & $\mathrm{pH} 8,0$ \\
\hline STE-in situ-Puffer & $\begin{array}{l}10 \mathrm{mM} \\
5 \mathrm{mM} \\
0,5 \mathrm{M}\end{array}$ & $\begin{array}{l}\text { Tris/HCl } \\
\text { EDTA } \\
\mathrm{NaCl} \\
\end{array}$ & $\begin{array}{l}\mathrm{pH} 8,0 \\
\mathrm{pH} 8,0\end{array}$ \\
\hline Stop-Puffer & $\begin{array}{l}10 \mathrm{mM} \\
1 \mathrm{mM}\end{array}$ & $\begin{array}{l}\text { Tris/HCl } \\
\text { EDTA }\end{array}$ & $\mathrm{pH} 8$ \\
\hline Tris-EDTA Puffer pH 9,0 (TE) & $\begin{array}{l}10 \mathrm{mM} \\
1 \mathrm{mM}\end{array}$ & $\begin{array}{l}\text { Tris } \\
\text { EDTA }\end{array}$ & \\
\hline $\begin{array}{l}\text { Tris-Borsäure-EDTA Lösung, 10x (TBE) } \\
\text { Stammlösung, die für alle Anwendungen } \\
\text { 1:10 verdünnt wurde }\end{array}$ & $\begin{array}{l}890 \mathrm{mM} \\
730 \mathrm{mM} \\
12,5 \mathrm{mM} \\
\end{array}$ & $\begin{array}{l}\text { Tris/HCl } \\
\text { Borsäure } \\
\text { EDTA } \\
\end{array}$ & $\mathrm{pH} 8,0$ \\
\hline Tris-EDTA Puffer pH 9,0 (TE) & $\begin{array}{l}10 \mathrm{mM} \\
1 \mathrm{mM}\end{array}$ & $\begin{array}{l}\text { Tris } \\
\text { EDTA }\end{array}$ & \\
\hline $\begin{array}{l}\text { Tris-gepufferte Natriumchlorid-Lösung, 10x } \\
\text { (TBS) pH } 7,4 \text { bzw. } \mathrm{pH} 8,8 \\
\text { Stammlösung, die für alle Anwendungen } \\
\text { 1:10 verdünnt wurde }\end{array}$ & $\begin{array}{l}0,5 \mathrm{M} \\
1,5 \mathrm{M}\end{array}$ & $\begin{array}{l}\text { Tris/HCl } \\
\mathrm{NaCl}\end{array}$ & \\
\hline TBST (Waschpuffer) & $0,1 \%(v / v)$ & Triton $\mathrm{X}-100$ & In TBS \\
\hline Upper Gel Puffer & $\begin{array}{l}6 \%(\mathrm{w} / \mathrm{v}) \\
4 \%(\mathrm{v} / \mathrm{v})\end{array}$ & $\begin{array}{l}\text { Tris } \\
\text { SDS }\end{array}$ & $\mathrm{pH} 6,8$ \\
\hline X-Gal Stocklösung & $\begin{array}{l}40 \mathrm{mg} / \mathrm{ml} \\
100 \%\end{array}$ & $\begin{array}{l}\text { X-Gal } \\
\text { N,N-Dimethylsulfoxid } \\
\text { (DMSO) }\end{array}$ & \\
\hline
\end{tabular}

\subsection{Medien}

\subsubsection{Medien für die Bakterienkultur}

Bakterienkulturen (E. coli) wurden in LB-Medium kultiviert, das mit $\mathrm{ddH}_{2} \mathrm{O}$ angesetzt, autoklaviert und bei $4^{\circ} \mathrm{C}$ gelagert wurde. Unmittelbar vor Verwendung des Mediums erfolgte

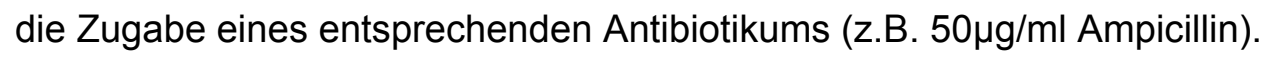




\subsubsection{Agarplatten}

Zur Herstellung von LB-Agarplatten wurde dem LB-Medium 1,5\% (w/v) Agar-Agar zugegeben, der Ansatz autoklaviert und auf $55^{\circ} \mathrm{C}$ abgekühlt. Danach wurde das entsprechende Antibiotikum zugegeben und der noch warme LB-Agar luftblasenfrei in $10 \mathrm{~cm}$ Petrischalen gegossen. Nach Erstarren des Agars wurden die Platten in sterilen Plastiktüten bei $4^{\circ} \mathrm{C}$ gelagert.

\subsubsection{Medien für die Kultur eukaryotischer Zelllinien}

Eukaryotische Zellen wurden in Dulbecco's Modified Eagle Medium (DMEM) oder in RPMI 1640 mit jeweils 10\% fötalem Kälberserum (Gibco, Invitrogen $\mathrm{GmbH}$, Karlsruhe) und 1\% Penicillin/Streptomycin (PAN Biotech $\mathrm{GmbH}$, Aidenbach) kultiviert. Die für die verschiedenen Zelllinien verwendeten Medien und Serumkonzentrationen sind in Tabelle 6 aufgeführt, abweichende Konzentrationen bzw. weitere Zusätze sind bei der Beschreibung der jeweiligen Experimente angegeben.

Zur Herstellung von $\mathrm{Ca}^{2+}$-chelatiertem FCS für das 154CF-Medium (Cascade Biologics ${ }^{\mathrm{TM}}$, Portland, USA) wurden zunächst $50 \mathrm{ml} \mathrm{FCS} \mathrm{für} 30 \mathrm{~min}$ bei $56^{\circ} \mathrm{C}$ hitzeinaktiviert. Nach Zugabe von 10g Chelex 100 Resin Chelating Ion Exchange Resin rührte das FCS für 60min bei RT auf dem Magnetrührer, wodurch dem Serum die $\mathrm{Ca}^{2+}$-Ionen entzogen wurden. Danach wurde die Mischung sowohl durch einen UV-Licht sterilisierten Faltenfilter als auch durch einen Sterilfilter $\left(0,2 \mu \mathrm{m}\right.$ Porengröße) filtriert. Das hitzeinaktivierte und $\mathrm{Ca}^{2+}$-chelatierte FCS wurde in $1 \mathrm{ml}$ Aliquots dauerhaft bei $-20^{\circ} \mathrm{C}$ gelagert.

\subsection{Bakterienstämme, eukaryotische Zelllinien und Primärzellen}

Zur Transformation und Amplifikation von Plasmid-DNA wurde der chemisch-kompetente Wirtsstamm E. coli DH5a (Invitrogen $\mathrm{GmbH}$, Karlsruhe) verwendet.

In Tabelle 6 sind die in dieser Arbeit verwendeten eukaryotischen Zelllinien und primär kultivierten Zellen aufgelistet. Alle Zellen wurden bei $37^{\circ} \mathrm{C}$ in einer konstanten $\mathrm{CO}_{2}$-haltigen Atmosphäre $\left(5 \% \mathrm{CO}_{2}\right)$ mit 95\% Luftfeuchtigkeit kultiviert. 
Tabelle 6: Auflistung der verwendeten Zelllinien. Spalte 1: Bezeichnung der Zelllinie; Spalte 2: Ursprungsspezies und Zelltyp; Spalte 3: verwendetes Medium; Spalte 4: Mediumzusätze (Serum-/ und Antibiotikakonzentration nur angegeben, sofern abweichend von 10\%FCS und 1\%P/S). Abkürzung: CM, konditioniertes Medium (engl. conditioned medium).

\begin{tabular}{|c|c|c|c|}
\hline 1 & 2 & 3 & 4 \\
\hline ASZ001 & $\begin{array}{l}\text { murine BCC-Zellinie aus } \\
\text { Ptch } 1^{\text {neo12/+ }} \text {-Mäusen }\end{array}$ & $154 \mathrm{CF}$ & $\begin{array}{l}2 \% \text { FCS (chelatiert) } \\
0,05 \mathrm{mM} \mathrm{CaCl}_{2}\end{array}$ \\
\hline B16F10 & murine Melanomzellen & RPMI 1640 & \\
\hline L929 & murine Fibroblasten & RPMI 1640 & \\
\hline NIH3T3 & embryonale murine Fibroblasten & DMEM & \\
\hline $\begin{array}{l}\text { NIH3T3- } \\
\text { Wnt5a }\end{array}$ & $\begin{array}{l}\text { embryonale murine Fibroblasten, } \\
\text { stabil transfiziert }\end{array}$ & DMEM & $400 \mu \mathrm{g} / \mathrm{ml} \mathrm{G} 418$ \\
\hline NIH3T3-lacZ & $\begin{array}{l}\text { embryonale murine Fibroblasten, } \\
\text { stabil transfiziert }\end{array}$ & DMEM & \\
\hline $\operatorname{Ptch}^{\text {flox/flox }}$ & adulte murine Fibroblasten & DMEM & \\
\hline \multirow{2}{*}{ BMDM } & \multirow{2}{*}{$\begin{array}{l}\text { bone marrow-derived } \\
\text { macrophages } \\
\text { (murin) }\end{array}$} & $\begin{array}{l}\text { DMEM } \\
\text { (Pluznikmedium; } \\
\text { zur } \\
\text { Differenzierung) }\end{array}$ & $\begin{array}{l}\text { 30\% L929-CM } \\
5 \% \text { Pferdeserum } \\
\text { 0,002\% ß-Mercaptoethanol }\end{array}$ \\
\hline & & $\begin{array}{l}\text { DMEM } \\
\text { (BMDM- } \\
\text { Kulturmedium; } \\
\text { zum Wachstum) }\end{array}$ & $15 \%$ L929-CM \\
\hline $\begin{array}{l}\text { Peritoneal- } \\
\text { Makrophagen }\end{array}$ & $\begin{array}{l}\text { mittels Peritoneallavage isolierte } \\
\text { murine Makrophagen }\end{array}$ & $154 \mathrm{CF}$ & $\begin{array}{l}2 \% \text { FCS (chelatiert) } \\
0,05 \mathrm{mM} \mathrm{CaCl}_{2}\end{array}$ \\
\hline
\end{tabular}

\subsection{Plasmide}

Für Klonierungen wurden die Plasmide pGEM-Teasy (Promega $\mathrm{GmbH}$, Mannheim), pcDNA3, pCR3.1 (Invitrogen GmbH, Karlsruhe) sowie pBluescript II-SK (Stratagene/Agilent Technologies $\mathrm{GmbH} \&$ Co. KG, Waldbronn) verwendet.

In Tabelle 7 sind alle in dieser Arbeit verwendeten Expressionsplasmide aufgelistet.

Tabelle 7: Plasmide. Spalte 1: Bezeichnung der Expressionsplasmide; Spalte 2: Bezeichnung der inserierten cDNA/Gen-Sequenz; Spalte 3: Bezeichnung des Promotors; Spalte 4: Referenz/Hersteller. Abkürzungen: $C M V$, Cytomegalie Virus.

\begin{tabular}{|c|c|c|c|}
\hline 1 & 2 & 3 & 4 \\
\hline CaMKIIT286D-CS2 & konstitutiv aktive CaMKII & CMV Promotor & $\begin{array}{l}\text { (Kuhl, M et al. } \\
2000)\end{array}$ \\
\hline CaMKII-K42M1-271-CS2 & Kinase-inaktive CaMKII & CMV Promotor & $\begin{array}{l}\text { (Kuhl, M et al. } \\
2000)\end{array}$ \\
\hline pCMV- $\beta G A L$ & $\beta$-Galaktosidase & CMV Promotor & $\begin{array}{l}\text { AG P.Burfeind, } \\
\text { Göttingen }\end{array}$ \\
\hline pCl-neo-b-catS33Y & $\begin{array}{l}\text { konstitutiv aktives } \\
\beta \text {-catenin }\end{array}$ & CMV Promotor & $\begin{array}{l}\text { (Morin, PJ et al. } \\
\text { 1997) }\end{array}$ \\
\hline SuperFOPFlash (FOP) & TCF/LEF Bindestellen & CMV Promotor & $\begin{array}{l}\text { (Korinek, V et al. } \\
\text { 1997) }\end{array}$ \\
\hline SuperTOPFlash (TOP) & $\begin{array}{l}\text { mutierte TCF/LEF } \\
\text { Bindestellen }\end{array}$ & CMV Promotor & $\begin{array}{l}\text { (Korinek, V et al. } \\
\text { 1997) }\end{array}$ \\
\hline pWnt5a(murin)-pcDNA3 & Wnt5a & CMV Promotor; & diese Arbeit \\
\hline mWnt5a-Kozak-pcDNA3 & Wnt5a & $\begin{array}{l}\text { CMV Promotor; Kozak- } \\
\text { Konsensus-Sequenz }\end{array}$ & diese Arbeit \\
\hline pEGFP-N1 & EGFP & CMV Promotor & $\begin{array}{l}\text { BD Bioscience } \\
\text { Clontech }\end{array}$ \\
\hline pRL-CMV & Renilla-Luziferase & CMV Promotor & Promega $\mathrm{GmbH}$ \\
\hline
\end{tabular}




\subsection{Synthetische DNA-Oligonukleotide}

Synthetische DNA-Oligonukleotide wurden von der Firma Eurofins MWG Operon, Ebersberg, bezogen und die Stammkonzentrationen mit RNase/DNase-freiem Wasser (GIBCO Invitrogen $\mathrm{GmbH}$, Karlsruhe) auf $100 \mu \mathrm{M}$ eingestellt. In der PCR wurden Stocklösungen von $10 \mu \mathrm{M}$ verwendet.

\subsubsection{DNA-Oligonukleotide zur Genotypisierung von Mäusen}

Die Genotypisierung von Mäusen ist unter 3.4.3 beschrieben und hierzu verwendete DNAOligonukleotide sind in Tabelle 8 aufgeführt.

Tabelle 8: Auflistung der DNA-Oligonukleotide zur Genotypisierung von Mäusen. Spalte 1: Bezeichnung der getesteten Mauslinie; Spalte 2: Fragmentgröße des wildtypischen (wt), gefloxten (flox) oder des deletierten (del) Ptch Allels, des mutierten Wnt5a (mut) Allels oder des entsprechenden Wildtyp (wt) Allels; Spalte 3: Bezeichnung der DNA-Oligonukleotide; Spalte 4: DNA-Oligonukleotidsequenz ( $\left.5^{\prime} \rightarrow 3^{\prime}\right)$; Spalte 5: Literaturreferenz. Abkürzungen: ${ }^{\text {wt }}$ Amplifikatlänge des Wildtyp-Allels; ${ }^{\text {mut }}$ Amplifikatlänge des mutanten Allels; ${ }^{\text {del }}$ Amplifikatlänge des Allels bei erfolgter Deletion durch Cre-Rekombinase vermittelte Rekombination.

\begin{tabular}{|c|c|c|c|c|}
\hline 1 & 2 & 3 & 4 & 5 \\
\hline $\operatorname{Ptch}^{\text {flox/flox }} E R T 2^{+/-}$ & $\begin{array}{l}150 \mathrm{bp}^{\text {flox }} \\
445 \mathrm{bp}^{\mathrm{wt}}\end{array}$ & $\begin{array}{l}\text { mPTCNx_f } \\
\text { mPTCNx_r } \\
\text { mPTCwt_r.2 }\end{array}$ & $\begin{array}{l}\text { TGGTAATTCTGGGCTCCCGT } \\
\text { CCGGTAGAATTAGCTTGAAGTTCCT } \\
\text { ACACAACAGGGTGGAGACCACT }\end{array}$ & $\begin{array}{l}\text { (Uhmann, A } \\
\text { et al. 2007) }\end{array}$ \\
\hline $\operatorname{Ptch}^{\text {flox/flox }} E R T 2^{+/-}$ & $950 \mathrm{bp}^{\mathrm{del}}$ & $\begin{array}{l}\text { Exon7-F } \\
\text { neo-R }\end{array}$ & $\begin{array}{l}\text { AGGAAGTATATGCATTGGCAGGAG } \\
\text { GCATCAGAGCAGCCGATTGTCTG }\end{array}$ & $\begin{array}{l}\text { (Uhmann, A } \\
\text { et al. 2007) }\end{array}$ \\
\hline $\operatorname{Ptch}^{\text {flox/flox }} E R T 2^{+/-}$ & $600 \mathrm{bp}$ & $\begin{array}{l}\text { Ella-Cre-F } \\
\text { Ella-Cre-R }\end{array}$ & $\begin{array}{l}\text { CCAGGCTAAGTGCCTTCTCTACA } \\
\text { AATGCTTCTGTCCGTTTGCCGGT }\end{array}$ & $\begin{array}{l}\text { (Uhmann, A } \\
\text { et al. 2007) }\end{array}$ \\
\hline$W n t 5 a^{+/-}$ & $\begin{array}{l}400 \mathrm{bp}^{\mathrm{mut}} \\
484 \mathrm{bp}^{\mathrm{wt}}\end{array}$ & $\begin{array}{l}\text { olMR7415 } \\
9261 \\
9260\end{array}$ & $\begin{array}{l}\text { GCCAGAGGCCACTTGTGTAG } \\
\text { CATCTCAACAAGGGCCTCAT } \\
\text { GAGGAGAAGCGCAGTCAATC }\end{array}$ & $\begin{array}{l}\text { (Yamaguchi, } \\
\text { TP et al. } \\
1999)\end{array}$ \\
\hline
\end{tabular}

\subsubsection{DNA-Oligonukleotide für Sequenzanalyse}

Die für die Analyse der murinen Wnt5a-Sequenz (siehe 3.1.5) verwendeten DNA-

Oligonukleotide sind in Tabelle 9 aufgelistet.

Tabelle 9: Auflistung der verwendeten DNA-Oligonukleotide für die DNA-Sequenzanalyse. Spalte 1: Bezeichnung des sequenzierten Plasmids; Spalte 2: Bezeichnung des DNA-Oligonukleotids; Spalte 3: DNA-Oligonukleotidsequenz $\left(5^{\prime} \rightarrow 3^{\prime}\right)$.

\begin{tabular}{lll}
\hline \multicolumn{1}{c}{$\mathbf{1}$} & \multicolumn{1}{c}{$\mathbf{2}$} & \multicolumn{1}{c}{$\mathbf{3}$} \\
\hline mWnt5a-Kozak- & mWnt5a-F.2 & TAAGCCCGGGAGTGGCTTTG \\
pcDNA3 & mWnt5a-R.2 & CCTGCCAGTTGGCTGCAGA \\
& Wnt5a-R & CAGCTTGCCCCGGCTGTTGA \\
& Wnt5a-Kozak-F & GGAATTCGCCACCATGAAGAAGCCCATTGGA \\
& Wnt5a-Kozak-R & AGTCCTTATCATCGTCGTCTTTGTAATC \\
& mWnt5a-SNP_F & CTTGGTGGTCTCTAGGTATGAATAACCCTGTTCAGAT \\
& mWnt5a-SNP_R & ATCTGAACAGGGTTATTCATACCTAGAGACCACCAAG \\
\hline
\end{tabular}




\subsubsection{DNA-Oligonukleotide für RT-PCR}

Der spezifische Nachweis von amplifizierten Transkripten erfolgte semiquantitativ über RTPCR an cDNA und den in Tabelle 10 aufgeführten DNA-Oligonukleotiden.

Tabelle 10: Auflistung der verwendeten DNA-Oligonukleotide für die RT-PCR. Spalte 1: Bezeichnung der Gentranskripte; Spalte 2: Fragmentgröße; Spalte 3: Bezeichnung der DNA-Oligonukleotide; Spalte 4: DNA-Oligonukleotidsequenz ( $\left.5^{\prime} \rightarrow 3^{\prime}\right)$; Spalte 5: Referenz.

\begin{tabular}{cccll}
\hline $\mathbf{1}$ & $\mathbf{2}$ & $\mathbf{3}$ & \multicolumn{1}{c}{$\mathbf{4}$} & $\mathbf{5}$ \\
\hline \multirow{2}{*}{ Gapdh } & \multirow{2}{*}{$576 \mathrm{bp}$} & $\begin{array}{l}\text { Gapdh-F } \\
\text { Gapdh-R }\end{array}$ & $\begin{array}{l}\text { ATCTTCTTGTGCAGTGCCAG } \\
\text { ATGACCACAGTCCATGCCAT }\end{array}$ & $\begin{array}{l}\text { (Uhmann, A et } \\
\text { al. 2005) }\end{array}$ \\
\hline \multirow{2}{*}{ Wif1 } & \multirow{2}{*}{$158 \mathrm{bp}$} & $\begin{array}{l}\text { mWif1-F } \\
\text { mWif1-R }\end{array}$ & $\begin{array}{l}\text { TCCTGTCAATATCCACTCCATGAA } \\
\text { CTGATGCCTTGTGAGGCACT }\end{array}$ & diese Arbeit \\
\hline
\end{tabular}

\subsubsection{DNA-Oligonukleotide für quantitative real time PCR (qRT-PCR)}

DNA-Oligonukleotide für die Messung von Genexpressionsniveaus mittels quantitativer real time PCR (qRT-PCR) mit SYBR Green sind in Tabelle 11 aufgelistet.

Tabelle 11: Auflistung der für die qRT-PCR verwendeten DNA-Oligonukleotide. Spalte 1: Bezeichnung der Gentranskripte; Spalte 2: Bezeichnung der DNA-Oligonukleotide; Spalte 3: DNA-Oligonukleotidsequenz $\left(5^{\prime} \rightarrow 3^{\prime}\right)$; Spalte 4: Referenz.

\begin{tabular}{|c|c|c|c|}
\hline 1 & 2 & 3 & 4 \\
\hline $18 S$ & $\begin{array}{l}\text { 18S-fwd } \\
\text { 18S-rev2 }\end{array}$ & $\begin{array}{l}\text { CGCAAATTACCCACTCCCG } \\
\text { TTCCAATTACAGGGCCTCGAA }\end{array}$ & $\begin{array}{l}\text { F. Nitzki; } \\
\text { AG Hahn }\end{array}$ \\
\hline$F 4 / 80$ & $\begin{array}{l}\mathrm{mF} 4 / 80 \mathrm{~F} .1 \\
\mathrm{mF} 4 / 80 \mathrm{R} .1\end{array}$ & $\begin{array}{l}\text { CGGAGTACCTAGACATCGAAAGCA } \\
\text { GGGGCCCCTGTAGATACTGATT }\end{array}$ & diese Arbeit \\
\hline$|v|-1$ & $\begin{array}{l}\text { Ivl-1-F1 } \\
\text { Ivl-1-R1 }\end{array}$ & $\begin{array}{l}\text { CCTCCTGTGAGTTTGTTTGGTCT } \\
\text { CTGAGGATATGATCTGGAGAAC }\end{array}$ & $\begin{array}{l}\text { A. Uhmann, } \\
\text { AG Hahn }\end{array}$ \\
\hline K1 & $\begin{array}{l}\mathrm{mK} 1-\mathrm{F} \\
\mathrm{mK} 1-\mathrm{R}\end{array}$ & $\begin{array}{l}\text { TCAACGTTGAGGTTGACCCTC } \\
\text { ACCTTCCTTCTGAGGATGCTG }\end{array}$ & $\begin{array}{l}\text { A. Zibat; } \\
\text { AG Hahn }\end{array}$ \\
\hline K10 & $\begin{array}{l}\mathrm{mK} 10-\mathrm{F} \\
\mathrm{mK} 10-\mathrm{R}\end{array}$ & $\begin{array}{l}\text { GGATGCTGAAGAGTGGTTCAA } \\
\text { TCTGTTTCTGCCAAGGAGGCT }\end{array}$ & $\begin{array}{l}\text { A. Zibat; } \\
\text { AG Hahn }\end{array}$ \\
\hline Loricrin & $\begin{array}{l}\text { Lor-F1 } \\
\text { Lor-R1 }\end{array}$ & $\begin{array}{l}\text { CACTCATCTTCCCTGGTGCTTC } \\
\text { GTCTTTCCACAACCCACAGGAG }\end{array}$ & $\begin{array}{l}\text { A. Uhmann, } \\
\text { AG Hahn }\end{array}$ \\
\hline Mac1 & $\begin{array}{l}\text { mMac1-F } \\
\text { mMac1-R }\end{array}$ & $\begin{array}{l}\text { GAGGCAACCATGGAATTCAGCC } \\
\text { CATAAGTGACAGTGCTCTGGATATC }\end{array}$ & diese Arbeit \\
\hline Tgm & $\begin{array}{l}\text { Tgm1-F } \\
\text { Tgm1-R }\end{array}$ & $\begin{array}{l}\text { GCAGTGGTGTAAATGCAGCTGG } \\
\text { ATGAGGAGCTCAAGGGCAATGC }\end{array}$ & $\begin{array}{l}\text { A. Uhmann, } \\
\text { AG Hahn }\end{array}$ \\
\hline Wif1 & $\begin{array}{l}\text { mWif1-F } \\
\text { mWif1-R }\end{array}$ & $\begin{array}{l}\text { TCCTGTCAATATCCACTCCATGAA } \\
\text { CTGATGCCTTGTGAGGCACT }\end{array}$ & diese Arbeit \\
\hline Wnt5a & $\begin{array}{l}\text { Wnt5a-F } \\
\text { Wnt5a-R }\end{array}$ & $\begin{array}{l}\text { TCCTATGAGAGCGCACGCAT } \\
\text { CAGCTTGCCCCGGCTGTTGA }\end{array}$ & $\begin{array}{l}\text { A. Zibat; } \\
\text { AG Hahn }\end{array}$ \\
\hline
\end{tabular}




\subsubsection{Sonden für in situ-Hybridisierung}

In Tabelle 12 sind die im Rahmen dieser Arbeit verwendeten Sonden für in situHybridisierungen aufgeführt.

Tabelle 12: Auflistung der verwendeten Sonden für in situ-Hybridisierung. Spalte 1: Bezeichnung der detektierten Gentranskripte; Spalte 2: Bezeichnung der verwendeten Plasmide; Spalte 3: Verwendete Restriktionsendonukleasen zur Linearisierung des Plasmids; Spalte 4: Größe des Inserts; Spalte 5: Eingesetzte Verdünnung und verwendeter Hybridisierungspuffer; Spalte 6: Referenz; Abkürzungen: as, antisense-Sonde; HybM, Hefe-tRNA enthaltender Hybridisierungspffer; HybF, Lachsspermien-DNA enthaltender Hybridisierungspuffer; sense, sense-Sonde.

\begin{tabular}{|c|c|c|c|c|c|}
\hline 1 & 2 & 3 & 4 & 5 & 6 \\
\hline$m S h h$ & pBluescript II-SK & $\begin{array}{l}\text { Not I (sense) } \\
\text { Hind III (as) }\end{array}$ & $642 \mathrm{bp}$ & 1:100 in HybF & $\begin{array}{l}\text { M Wijgerde; } \\
\text { Rotterdam }\end{array}$ \\
\hline$m W i f 1$ & pGEM-Teasy & $\begin{array}{l}\text { Spe I (Klon 6; sense) } \\
\text { Spe I (Klon 5; as) }\end{array}$ & $725 \mathrm{bp}$ & 1:350 in HybF & diese Arbeit \\
\hline$h W n t 5 a \_1$ & pGEM-Teasy & $\begin{array}{l}\text { Spe I (Klon 11; sense) } \\
\text { Spe I (Klon 10; as) }\end{array}$ & $514 \mathrm{bp}$ & 1:500 in HybM & diese Arbeit \\
\hline hWnt5a_2 & pGEM-Teasy & $\begin{array}{l}\text { Spe I (Klon 1; sense) } \\
\text { Spe I (Klon 2; as) }\end{array}$ & $540 \mathrm{bp}$ & 1:500 in HybM & diese Arbeit \\
\hline
\end{tabular}

\subsection{Enzyme}

Die in dieser Arbeit verwendeten Restriktionsendonukleasen wurden von den Firmen Invitrogen $\mathrm{GmbH}$, Karlsruhe, und New England Biolabs $\mathrm{GmbH}$, Frankfurt am Main, bezogen. Soweit nicht anders erwähnt wurde grundsätzlich nach Herstellerangaben gearbeitet. Alle weiteren verwendeten Enzyme sind in Tabelle 13 aufgelistet.

Tabelle 13: Auflistung der verwendeten Enzyme. Spalte 1: Bezeichnung des Enzyms; Spalte 2: Anwendung des Enzyms; Spalte 3: Hersteller; Abkürzungen: ISH, in situ-Hybridisierung; Taq, Thermus aquaticus.

\begin{tabular}{lll}
\hline \multicolumn{1}{c}{$\mathbf{1}$} & \multicolumn{1}{c}{$\mathbf{2}$} & \multicolumn{1}{c}{$\mathbf{3}$} \\
\hline Proteinase K & DNA-Isolierung; ISH & Carl Roth $\mathrm{GmbH}$, Karlsruhe \\
\hline Restriktionsendonukleasen & Restriktionshydrolyse & $\begin{array}{l}\text { Invitrogen } \mathrm{GmbH}, \text { Karlsruhe } \\
\text { New England Biolabs GmbH, } \\
\text { Frankfurt a. M. }\end{array}$ \\
\hline $\begin{array}{l}\text { Reverse Transkriptase } \\
\text { Super Script II }\end{array}$ & cDNA-Synthese & Invitrogen $\mathrm{GmbH}$, Karlsruhe \\
\hline RNase A & ISH; Zellzyklus-Analyse & Carl Roth GmbH, Karlsruhe \\
\hline Taq-DNA Polymerase & RT-PCR & Molzym GmbH \& Co.KG, Bremen \\
\hline T3 RNA Polymerase & Sonden-Herstellung für ISH & Promega GmbH, Mannheim \\
\hline T7 RNA Polymerase & Sonden-Herstellung für ISH & Promega GmbH, Mannheim \\
\hline
\end{tabular}

\subsection{Antikörper}

\subsubsection{Primäre Antikörper}

Die für proteinchemische Methoden (siehe 3.3) verwendeten primären Antikörper sind in Tabelle 14 aufgeführt. 
Tabelle 14: Auflistung der verwendeten primären Antikörper. Spalte 1: Bezeichnung des Antikörpers; Spalte 2: Ursprungsspezies des Antikörpers; Spalte 3: Verwendung; Spalte 4: Eingesetzte Verdünnung und verwendeter Puffer; Spalte 5: Hersteller. Abkürzungen: Cy, Indodikarbocyanin-Derivat; FACS, fluorescenceactivated cell sorting; FITC, Fluoresceinisothiocyanat; IHC, Immunhistochemie; mono, monoklonal; PE, Phycoerythrin; poly, polyklonal; WB, Western Blot.

\begin{tabular}{lllll}
\hline \multicolumn{1}{c}{$\mathbf{1}$} & \multicolumn{1}{c}{$\mathbf{2}$} & \multicolumn{1}{c}{$\mathbf{3}$} & \multicolumn{1}{c}{$\mathbf{4}$} & \multicolumn{1}{c}{$\mathbf{5}$} \\
\hline anti-Annexin V FITC & Ratte; mono & FACS & $1: 50$ in Binding Buffer & BD Pharmingen \\
\hline anti-B220 PE-Cy7 & Kaninchen; mono & FACS & $1: 50$ in PBS & BD Biosciences \\
\hline anti-CD4 FITC & Ratte; mono & FACS & $1: 50$ in PBS & BD Biosciences \\
\hline anti-CD8 PE-Cy7 & Ratte; mono & FACS & $1: 50$ in PBS & BD Biosciences \\
\hline anti-CD11b FITC & Ratte; mono & FACS & $1: 50$ in PBS & BD Biosciences \\
\hline anti-CD19 FITC & Ratte; mono & FACS & $1: 50$ in PBS & BD Biosciences \\
\hline anti-F4/80 & Ratte; mono & IHC & $\begin{array}{l}1: 100 \text { in 10\% } \\
\text { Casein/TBST }\end{array}$ & AbD Serotec \\
\hline anti-F4/80 Cy5 & Ratte; mono & FACS & $1: 50$ in PBS & eBioscience \\
\hline anti-Gr1 PE & Ratte; mono & FACS & $1: 50$ in PBS & BD Biosciences \\
anti-HSC 70 & Maus; mono & WB & $1: 10000$ in BSA/Azid- & Santa Cruz \\
\hline anti-Ki-67 & Maus; mono & IHC & $1: 50$ in TBS & BD Pharmingen \\
\hline anti-Wnt5a & Maus; poly & WB & $\begin{array}{l}1: 500 \text { in BSA/Azid- } \\
\text { Lösung }\end{array}$ & R\&D Systems \\
\hline
\end{tabular}

\subsubsection{Sekundäre Antikörper}

Die für proteinchemische Methoden (siehe 3.3) verwendeten sekundären Antikörper sind in Tabelle 15 aufgeführt. Für die Detektion des biotinylierten anti-Ratte Immunglobulins wurde StreptABComplex/AP (Dako GmbH, Hamburg) verwendet.

Tabelle 15: Auflistung der verwendeten sekundären Antikörper. Spalte 1: Bezeichnung des Antikörpers; Spalte 2: Ursprungsspezies des Antikörpers; Spalte 3: Verwendung; Spalte 4: eingesetzte Antikörperverdünnung; Spalte 5: Hersteller; Abkürzungen: AP, Alkalische Phosphatase; DB, Dot Blot; Fab, antigenbindendes Fragment; Ig, Immunglobulin; IHC, Immunhistochemie; ISH, in situ-Hybridisierung; HRP, horseradish peroxidase (Meerrettich-Peroxidase).

\begin{tabular}{lllll}
\hline \multicolumn{1}{c}{$\mathbf{1}$} & $\mathbf{2}$ & $\mathbf{3}$ & $\mathbf{4}$ & \multicolumn{1}{c}{$\mathbf{5}$} \\
\hline \multirow{2}{*}{ anti-Digoxigenin Fab; AP-konjugiert } & \multirow{2}{*}{ Schaf } & DB & $\begin{array}{l}1: 5000 \\
\text { ISH }\end{array}$ & $\begin{array}{l}\text { 1:500 } \\
\text { Moche Diagnostics GmbH, } \\
\end{array}$ \\
& Schaf & WB & $1: 5000$ & GE Healthcare, Dassel \\
\hline anti-Maus IgG; HRP-konjugiert & Ziege & IHC & gebrauchsfertig & Dako GmbH, Hamburg \\
\hline anti-Maus IgG; HRP-konjugiert & Kaninchen & IHC & $1: 50$ & Dako GmbH, Hamburg \\
\hline anti-Ratte IgG; biotinyliert & \multirow{2}{*}{ Esel } & WB & $1: 10000$ & $\begin{array}{l}\text { Pierce Biotechnology Inc, } \\
\text { Rockford, USA }\end{array}$ \\
\hline
\end{tabular}

\subsection{Datenbanken}

Ensembl

MGI Mouse Genome Informatics

National Center for Biotechnology Information (NCBI)

BasicLocalAlignmentSearchTool_BLAST (NCBI) http://www.ensembl.org/index.html http://www.informatics.jax.org/

http://www.ncbi.nlm.nih.gov/ http://blast.ncbi.nlm.nih.gov/Blast.cg 


\subsection{Software}

Tabelle 16: Auflistung der verwendeten Software.

\begin{tabular}{ll}
\hline ABI 3500 & Applied Biosystems, Darmstadt \\
\hline BD FACSDiva & BD Biosciences, Heidelberg \\
\hline cell $^{\mathrm{F}}$ & Olympus Europa GmbH, Hamburg \\
\hline Endnote & Thomson ISI ResearchSoft \\
\hline Excel 2007 & Microsoft Co., Redmont, USA \\
\hline FlowJo & Tree Star Inc., Ashland \\
\hline ImageJ & National Health Institute, Maryland, USA \\
\hline Intas GDC & Intas, Göttingen \\
\hline Photoshop 7.0 & Adobe Systems Incorporated, San Jose, USA \\
\hline Powerpoint 2007 & Microsoft Co., Redmont, USA \\
\hline SDS 2.1 & Applied Biosystems, Darmstadt \\
\hline Statistica 9 & StatSoft GmbH, Hamburg \\
\hline Word 2007 & Microsoft Co., Redmont, USA \\
\hline
\end{tabular}




\section{Methoden}

\subsection{Molekularbiologische Methoden}

\subsubsection{Isolierung und Aufreinigung von Nukleinsäuren}

\subsubsection{Plasmid DNA}

Die Transformation von Bakterienzellen erfolgte im Standardprotokoll an 50 $\mu$ l kompetenten Zellen (E. coli DH5a, Invitrogen $\mathrm{GmbH}$, Karlsruhe) mit 100ng reiner Plasmid-DNA oder aber

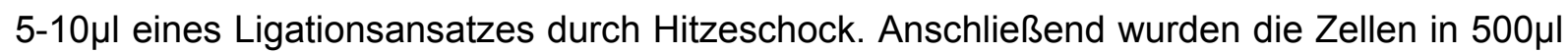
S.O.C.-Medium aufgenommen und unter leichtem Schütteln (900rpm) $1 \mathrm{~h}$ bei $37^{\circ} \mathrm{C}$ inkubiert.

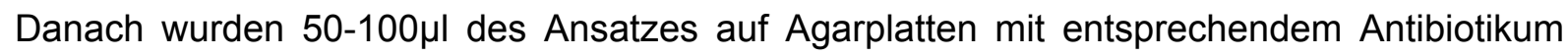
zur Selektion ausplattiert und über Nacht im Brutschrank bei $37^{\circ} \mathrm{C}$ inkubiert.

„Mini-Präparation“ von Plasmid-DNA erfolgte aus 1,5ml einer $2 \mathrm{ml}$-Übernachtkultur einer gepickten Einzelkolonie mit dem HiPure Plasmid DNA Purification Kit (Invitrogen GmbH, Karlsruhe) nach Herstellerangaben. Für eine „Maxi-Präparation“ von Plasmid-DNA wurde die DNA aus $100 \mathrm{ml}$ einer Übernachtkultur mit Hilfe des oben genannten Kits aufgereinigt.

Die DNA-Konzentration wurde am Photometer gegen einen Leerwert bestimmt.

Zur Überprüfung der aufgereinigten Plasmide erfolgten eine oder mehrere Restriktionshydrolysen an 100 bis 200ng DNA (siehe 3.1.8).

\subsubsection{Genomische DNA aus Gewebe und Blut}

\subsection{Isolierung genomischer DNA aus Schwanzbiopsien}

Das Gewebe wurde über Nacht bei $55^{\circ} \mathrm{C}$ in $400 \mu$ STE-Puffer mit $20 \mu$ l Proteinase $\mathrm{K}$ $(10 \mathrm{mg} / \mathrm{ml})$ inkubiert. Unverdautes Gewebe wurde $10 \mathrm{~min}$ bei $13000 \mathrm{rpm}$ abzentrifugiert und der klare Überstand in $99 \%$ Ethanol überführt. Durch kräftiges Schütteln der Reaktionsgefäße und anschließendes Zentrifugieren (25min, 13000rpm) erfolgte die Präzipitation der DNA. Das DNA-Pellet wurde mit 70\% Ethanol gewaschen, getrocknet und in $125 \mu \mathrm{l}$ Ampuwa aufgenommen. Nach dem Lösen des Pellets (10min, $42^{\circ} \mathrm{C}, 1400 \mathrm{rpm}$ ) erfolgte die Bestimmung der DNA-Konzentration am Photometer.

\subsection{Isolierung genomischer DNA aus murinen Föten}

Für die Transplantation fötaler Leberzellen in bestrahlte Mäuse (3.4.6) war es notwendig innerhalb kürzester Zeit den Genotyp der Föten bestimmen zu können. Zu diesem Zweck wurde ein fötales Vorderbein isoliert und mit $400 \mu$ STE-Puffer und $25 \mu$ l Proteinase $K$ für $6 \mathrm{~min}$ bei $55^{\circ} \mathrm{C}$ auf dem Schüttler (1400rpm) inkubiert. Nach anschließender Zentrifugation 
(4min, $13000 \mathrm{rpm}, 4^{\circ} \mathrm{C}$ ) wurden $300 \mu \mathrm{l}$ des Verdaus in $1 \mathrm{ml} 100 \%$ Ethanol überführt. Zur Präzipitation der DNA wurden die Reaktionsgefäße zunächst kräftig geschüttelt und danach für $9 \min \left(13000 \mathrm{rpm}, 4^{\circ} \mathrm{C}\right)$ abzentrifugiert. Das Pellet wurde mit $300 \mu \mathrm{l} 70 \%$ Ethanol gewaschen, $2 \mathrm{~min}$ bei zuvor genannten Bedingungen zentrifugiert und für $5 \mathrm{~min}$ bei $55^{\circ} \mathrm{C}$ über Kopf getrocknet. Die pelletierte DNA wurde schließlich in $125 \mu$ I Ampuwa aufgenommen und $10 \mathrm{~min}$ bei $47^{\circ} \mathrm{C}$ auf dem Schüttler (1400rpm) gelöst.

Für die sich anschließende Genotypisierungs-PCR wurden $2 \mu \mathrm{l}$ der Lösung eingesetzt.

\subsection{Isolierung genomischer DNA aus Blut}

Aus Mäuseblut wurde mit dem DNeasy Blood \& Tissue Kit (Qiagen, Hilden) nach Herstellerangaben DNA isoliert und diese wurde zur Amplifikation von Genen in der RT-PCR eingesetzt.

\subsubsection{Gesamt-RNA aus eukaryotischer Zellkultur oder Gewebe}

Zur Isolierung von Gesamt-RNA aus Zellen einer 6-Loch-Platte wurden diese mit PBS gewaschen und durch Zugabe von $1 \mathrm{ml}$ TRIzol Reagent durch mehrmaliges Auf-/und Abpipettieren von der Platte gelöst. Das Lysat wurde in ein steriles $2 \mathrm{ml}$ Reaktionsgefäß überführt. Durch 2-minütiges Vortexen (höchste Stufe) wurden die Zellen vollständig homogenisiert und anschließend sofort auf Eis gelagert.

Zur Isolierung von Gesamt-RNA aus Gewebe wurde das Organ zunächst mit einem sterilen Skalpell zerkleinert, möglichst zügig in $2 \mathrm{ml}$ TRIzol Reagent überführt und darin dann maximal $1 \mathrm{~min}$ auf Eis homogenisiert. Der Ansatz wurde für $10 \mathrm{~min}$ (10000rpm, $4^{\circ} \mathrm{C}$ ) abzentrifugiert, der Überstand in ein $2 \mathrm{ml}$ Reaktionsgefäß überführt und ebenfalls sofort auf Eis gelagert.

Die weitere Isolierung der Gesamt-RNA erfolgte für beide Ansätze in der gleichen Weise, indem die Lysate zunächst für 5 min bei RT inkubiert wurden. Nach Zugabe von $200 \mu l$ Chloroform wurde der Ansatz $15 \mathrm{sec}$ lang auf dem Vortexer geschüttelt und danach $3 \mathrm{~min}$ bei RT inkubiert. Die sich anschließende Zentrifugation bei $11000 \mathrm{rpm}$ für $10 \mathrm{~min}$ bei $4^{\circ} \mathrm{C}$ führte zur Phasentrennung, wobei die obere wässrige Phase in $1000 \mu l$ Isopropanol überführt wurde. Die Reaktionsgefäße wurden mehrfach invertiert und es folgte die Präzipitation der RNA über Nacht bei $-20^{\circ} \mathrm{C}$. Durch erneute Zentrifugation (12000rpm, $25 \mathrm{~min}, 4^{\circ} \mathrm{C}$ ) wurde die RNA pelletiert und es schloss sich zweimaliges Waschen mit 70\%igem Ethanol an, bevor das Pellet getrocknet und schließlich in $20 \mu \mathrm{l}$ RNase/DNase-freiem Wasser bei $50^{\circ} \mathrm{C}$ für $8 \mathrm{~min}$ auf dem Schüttler (900rpm) gelöst wurde. Nach Bestimmung der Konzentration am Photometer wurde die RNA bei $-80^{\circ} \mathrm{C}$ gelagert. 


\subsection{Isolierung von Gesamt-RNA aus Hautproben}

Eine Besonderheit stellte die Isolierung von RNA aus Hautproben dar, da diese mit Hilfe des RNeasy Fibrous Tissue Mini Kits (Qiagen, Hilden) isoliert wurde. Generell erfolgte die Isolierung nach Herstellerangaben. Jedoch wurde eine zusätzliche Behandlung mit der in diesem Kit enthaltenen DNase I und dem zugehörigen RDD-Puffer vorgenommen. Dazu wurden $20 \mu$ l Eluat mit $10 \%(v / v)$ RDD-Puffer und 2,7U DNase I versetzt und für $1 \mathrm{~h}$ bei $37^{\circ} \mathrm{C}$ inkubiert. Nach kurzer Zentrifugation schloss sich eine 5-minütige Inkubation bei $65^{\circ} \mathrm{C}$ an. Danach wurde zum Ansatz 99\% Ethanol gegeben und die RNA über Nacht bei $-20^{\circ} \mathrm{C}$ gefällt. Nach 30-minütiger Zentrifugation (12000rpm, $4^{\circ} \mathrm{C}$ ) wurde die RNA zweimal mit $70 \%$ Ethanol

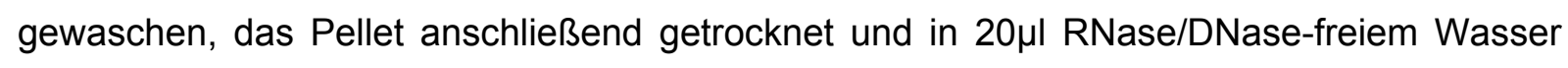
aufgenommen. Nach Bestimmung der Konzentration am Photometer wurde die RNA bei $-80^{\circ} \mathrm{C}$ gelagert.

\subsubsection{Konzentrationsbestimmung von Nukleinsäuren}

Die Konzentration von Nukleinsäuren wurde durch Messung der optischen Dichte (OD) bei 260nm mit Hilfe eines Spektralphotometers gegen einen Leerwert bestimmt. Durch Messung der Absorptionsmaxima von Proteinen (280nm) und niedermolekularen Salzen (230nm) konnte die Reinheit der Nukleinsäuren ermittelt werden.

Die Absorption der RNA für die Verwendung im RT Profiler PCR Array (SABiosciences, Qiagen, Hilden) wurde in 10mM Tris, pH 8,0 gemessen und musste folgenden Quotienten entsprechen:

- $\mathrm{A}_{260}: \mathrm{A}_{230}>1,7$

- $\mathrm{A}_{260}: \mathrm{A}_{280}=1,8$ bis 2,0

\subsubsection{Reverse Transkription}

Die reverse Transkription von $2 \mu \mathrm{g}$ Gesamt-RNA in cDNA erfolgte mit der reversen

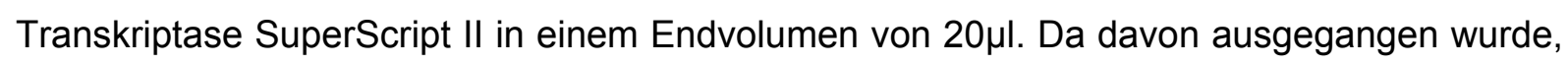
dass die Effizienz der reversen Transkription ca. 50\% beträgt, sollte die Endkonzentration der cDNA somit bei etwa 50ng/ $\mu$ l liegen.

Zuerst wurde zur Gesamt-RNA 250ng Hexamere gegeben und der Ansatz für 10min bei $70^{\circ} \mathrm{C}$ denaturiert. Nach Zugabe von Puffer (First Strand Buffer, Endkonzentration 1x), DTT (Endkonzentration $10 \mathrm{mM}$ ) und dNTPs (Endkonzentration 0,5mM) wurde der Ansatz für $10 \mathrm{~min}$ bei RT inkubiert und anschließend für $2 \mathrm{~min}$ bei $42^{\circ} \mathrm{C}$ angewärmt. Es folgte die Zugabe

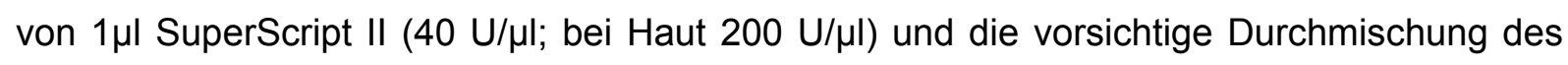
Ansatzes mit der Pipettenspitze. Die reverse Transkription erfolgte für $1 \mathrm{~h}$ bei $42^{\circ} \mathrm{C}$. Durch abschließende 10 -minütige Inkubation bei $70^{\circ} \mathrm{C}$ wurde die Reaktion abgestoppt. 


\subsubsection{Polymerase-Kettenreaktion (PCR)}

\subsubsection{Semiquantitative RT-PCR}

Zur semiquantitativen Analyse der Expression von Genen wurde die Amplifikation von DNA in Reaktionsvolumina von 10 bzw. $20 \mu \mathrm{l}$ pro Ansatz mit folgenden Reagenzien und Endkonzentrationen durchgeführt:

\begin{tabular}{l|l}
\hline $1 \mathrm{x}$ & Polymerase-Puffer \\
\hline $10 \%(\mathrm{v} / \mathrm{v})$ & Cresol-Lösung \\
\hline $0,5 \mu \mathrm{M}$ & sequenzspezifisches Vorwärts-DNA-Oligonukleotid \\
\hline $0,5 \mu \mathrm{M}$ & sequenzspezifisches Rückwärts-DNA-Oligonukleotid \\
\hline $0,2 \mathrm{mM}$ & dNTP-Mix \\
\hline $0,1 \mathrm{U}$ & Polymerase \\
\hline $10-100 \mathrm{ng}$ & Matrizen-DNA \\
\hline
\end{tabular}

Um die Amplifikatmengen untereinander vergleichen zu können, musste von allen Proben die gleiche Menge cDNA eingesetzt werden. Daher wurde zusätzlich in jeder zu messenden cDNA das Haushaltsgen Gapdh amplifiziert, das der Normalisierung diente. Außerdem wurden die PCR-Bedingungen den verwendeten synthetischen DNA-Oligonukleotiden und DNA-Polymerasen jeweils optimal angepasst. Ein typisches Programm für die RT-PCR beinhaltet folgende Schritte:

\begin{tabular}{llll}
\hline Denaturierung & $5-10 \mathrm{~min}$ & $95^{\circ} \mathrm{C}$ & \\
\hline Denaturierung & $0: 30-1: 00 \mathrm{~min}$ & $95^{\circ} \mathrm{C}$ & \\
Annealing & $0: 30-2: 00 \mathrm{~min}$ & $55-68^{\circ} \mathrm{C}$ & $25-35$ Zyklen \\
Elongation & $1-10 \mathrm{~min}$ & 68 oder $72^{\circ} \mathrm{C}$ & \\
\hline Elongation & $10-30 \mathrm{~min}$ & $72^{\circ} \mathrm{C}$ & \\
\hline
\end{tabular}

Je nach Weiterverwendung der PCR-Amplifikate wurde entweder der gesamte Ansatz oder nur ein Aliquot mittels Agarosegelelektrophorese analysiert.

\subsubsection{Quantitative real time PCR (qRT-PCR)}

Mittels quantitativer real-time PCR konnten Genexpressionsniveaus an verschiedener cDNA quantifiziert und untereinander verglichen werden. Dazu wurde ein Fluoreszenzfarbstoff (SYBR Green) verwendet, dessen Fluoreszenzsignal beim Interkalieren in die DNA quantifiziert wird und sich somit proportional zu der sich bildenden Amplifikatmenge verhält. Die Messung erfolgte in 10 $\mu$ l Reaktionsvolumen in einer PCR-384-Loch-Platte und jede zu analysierende Probe wurde in Triplikaten vermessen. Ein typischer qRT-PCR-Ansatz enthielt folgende Komponenten:

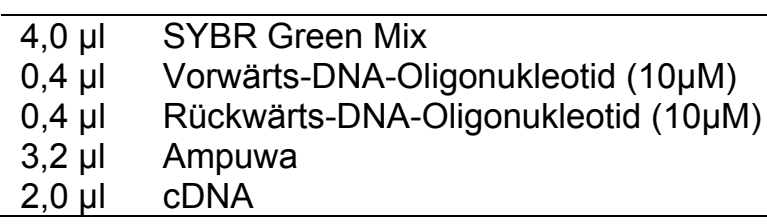


Für jedes zu quantifizierende Gen wurde eine entsprechende Standardkurve an einer speziellen cDNA als Matrize erstellt (Tabelle 17). Hierfür wurde die cDNA siebenmal (S1-S7) in jeweils 1:5 Verdünnungsschritten verdünnt. Außerdem wurde in jeder Probe die Expression von 18S rRNA zur Normalisierung vermessen.

Abhängig vom Hersteller des verwendeten SYBR Greens variierten die PCR-Programme, wobei die Amplifikatmenge immer über 40 Zyklen hinweg quantifiziert wurde. Nach Beendigung der Amplifiaktion wurde grundsätzlich eine Dissoziationskurve erstellt, um die Spezifität der verwendeten DNA-Oligonukleotide und die daraus resultierende Homogenität der Amplifikate zu überprüfen.

Die ermittelten Daten wurden mit der SDS 2.1 Software von Applied Biosystems und Microsoft Excel 2007 analysiert.

Tabelle 17: Auflistung verwendeter cDNA zur Erstellung von Standardkurven für die qRT-PCR verschiedener Gentranskripte. Spalte 1: Bezeichnung des analysierten Gentranskripts; Spalte 2: Ursprungsgewebe/zellen der cDNA zum Erstellen einer Standardkurve; Spalte 3: eingesetzte Menge an cDNA für Verdünnungsstufe S1 (in ng/ul);; Abkürzungen: BCC, Basalzellkarzinom; dpc, days post coitum.

\begin{tabular}{llc}
\hline \multicolumn{1}{c}{$\mathbf{1}$} & \multicolumn{1}{c}{$\mathbf{2}$} & $\mathbf{3}$ \\
\hline 18S rRNA & Mausembryo 12,5 dpc & 0,025 \\
\hline F4/80 & murine Milz & 50 \\
\hline Ivl-1 & murines BCC & 50 \\
\hline K1 & murines BCC & 50 \\
\hline K10 & murines BCC & 50 \\
\hline Loricrin & Normalhaut & 50 \\
\hline Mac1 & murine Milz & 50 \\
\hline Tgm & murines BCC & 50 \\
\hline Wif1 & murines BCC & 50 \\
\hline Wnt5a & Mausembryo 12,5 dpc & 50 \\
\hline
\end{tabular}

\subsubsection{RT Profiler PCR Array}

Mit RT Profiler PCR Arrays (SABiosciences) konnten im 384-Loch-Format innerhalb kurzer Zeit die Expressionsniveaus einer Vielzahl von Genen quantifiziert werden, die im Zusammenhang mit dem Wnt Signalweg stehen. Dazu wurden vom Hersteller empfohlene Kits zur Isolierung der RNA sowie zur Synthese der cDNA (RT' ${ }^{2}$ First Strand Kit) verwendet. Außerdem wurde das vom Hersteller empfohlene SYBR Green $\left(R T^{2} S Y B R\right.$ Green / ROX qPCR Master Mix) genutzt und es erfolgten die empfohlenen Überprüfungen von RNA und cDNA, um verlässliche Messergebnisse gewährleisten zu können.

Mit Hilfe dieser Methode wurden murine BCC zu unterschiedlichen Zeitpunkten nach Tumorinitiation analysiert. Zunächst wurde je $1 \mu \mathrm{g}$ RNA von sechs einzelnen BCC Proben oder sechs normalen Hautproben gepoolt und revers transkribiert. Die so erhaltene cDNA $(20 \mu \mathrm{l})$ wurde zunächst mit $91 \mu \mathrm{l}$ RNAse/DNase-freiem Wasser gemischt. 102 $\mu \mathrm{l}$ der cDNALösung wurde mit 550 $\mu$ l Mastermix gemischt. Jeweils $10 \mu l$ dieses Ansatzes wurden zur 
Expressionsanalyse jedes einzelnen Gens eingesetzt. Jedes Gen konnte pro Arrayplatte vierfach vermessen werden, so dass nach dieser Versuchsanordnung pro Arrayplatte die beiden zu untersuchenden Gruppen (BCC versus Normalhaut) in Duplikaten gemessen wurden. Danach wurde auf drei weiteren Arrayplatten die Genexpression in jeweils drei ausgewählten individuellen BCC bzw. Normalhaut RNA-Proben separat analysiert und miteinander verglichen.

In dieser Weise wurde die Genexpression von sowohl vollentwickelten als auch regredienten BCC untersucht (Beschreibung der unterschiedlichen Stadien der Tumorentwicklung, siehe Einleitung).

Alle Messungen wurden in dem Gerät ABI Prism 7900HT (Applied Biosystems, Darmstadt) durchgeführt. Die Datensätze wurden online mit Hilfe der von SABiosciences zur Verfügung gestellten Software ausgewertet (http://www.SABiosciences.com/pcrarraydataanalysis.php).

\subsubsection{DNA-Sequenzanalyse}

Die Sequenzierungs-PCR des Plasmids mWnt5a-Kozak-pcDNA3 wurde folgendermassen durchgeführt:

\begin{tabular}{ll}
\hline $1 \mathrm{x}$ & Sequenzierungspuffer \\
$1,0 \mu \mathrm{l}$ & BigDye ${ }^{\circledR}$ Terminator $\mathrm{v} 3.1 \mathrm{Ready}$ Reaction Mix \\
$1,0 \mu \mathrm{l}$ & DNA-Oligonukleotid $(10 \mu \mathrm{M})$ \\
$100 \mathrm{ng}$ & DNA \\
\hline add $10 \mu \mathrm{l}$ & Ampuwa \\
\hline
\end{tabular}

\begin{tabular}{lll}
$95^{\circ} \mathrm{C}$ & $1: 00 \min$ & \\
$95^{\circ} \mathrm{C}$ & $0: 30 \min$ & \multirow{2}{*}{30 Zyklen } \\
$60^{\circ} \mathrm{C}$ & $2: 30 \min$ & \\
$60^{\circ} \mathrm{C}$ & $5: 00 \min$ & \\
& &
\end{tabular}

Die DNA-Oligonikleotide für die Sequenzierung sind in Tabelle 9 gelistet.

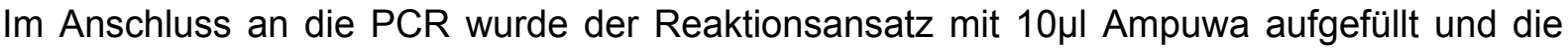
Amplifikate zunächst über Sephadex G50-Säulchen aufgereinigt. Dann wurden die Proben in eine MultiScreenHTS-HV Platte überführt und im ABI 3500 XL genetic analyser und der entsprechenden Software ABI 3500 data collection analysiert. Die Auswertung der erhaltenen Sequenzen erfolgte anhand des Sequenzchromatogramms und mit Hilfe eines BLAST-Programms des National Center for Biotechnology Information (NCBI).

\subsubsection{Gezielte Mutagenese}

Sequenzauffälligkeiten des Plasmids mWnt5a-Kozak-pcDNA3 (aggtaCgaata) wurden mit Hilfe des QuikChange II Site-Directed Mutagenesis Kits (Agilent Technologies Deutschland $\mathrm{GmbH}$ ) und den DNA-Oligonukleotiden mWnt5a-SNP_F und mWnt5a-SNP_R ausgebessert. 


\subsubsection{Agarosegelelektrophorese}

Je nach Größe der DNA-/ oder RNA-Fragmente wurden Gele von 0,5 bis 2,5\% (w/v) Agaroseanteil in TBE mit $0,2 \mu \mathrm{g} / \mathrm{ml}$ Ethidiumbromid verwendet. Die Auftrennung der Fragmente erfolgte in mit TBE gefüllten Gelelektrophoresekammern bei konstanter Spannung von 30 bis $100 \mathrm{~V}$. Für die Dokumentation wurde ein UV-Transilluminator (Intas, Göttingen) verwendet. Durch gleichzeitiges Auftrennen eines DNA-Größenstandards konnte sowohl die Fragmentgröße als auch die Konzentration der DNA durch vergleichendes Abschätzen mit dem Standard bestimmt werden.

\subsubsection{Klonierungen}

Die Klonierung von PCR-Produkten erfolgte mit Hilfe des pGEM-Teasy TA-Cloning Kits (Promega, Mannheim) nach Angaben des Herstellers. Die Ligation der Reaktionsansätze erfolgte über Nacht bei $4^{\circ} \mathrm{C}$.

Die erforderliche Restriktionshydrolyse von DNA erfolgte unter Zugabe von 2-3 Units eines jeweiligen Enzyms (pro $\mu \mathrm{g}$ DNA) in einem Volumen von 10 bis 50 $\mu$ l im optimalen Puffer. Wurden pro Restriktionsansatz mehrere Enzyme gleichzeitig verwendet, so wurde ein für alle Restriktionsendonukleasen optimaler Puffer gewählt. War dies jedoch nicht möglich, so erfolgte eine serielle Hydrolyse der DNA-Probe mit anschließender Ethanolfällung. Die Reaktionsansätze wurden jeweils für $1 \mathrm{~h}$ oder über Nacht bei optimaler Temperatur inkubiert. Nach Zugabe von $3 \mu \mathrm{l}$ Cresol-Lösung wurden die Fragmente auf einem Agarosegel über Gelelektrophorese aufgetrennt.

Aufzureinigende DNA-Fragmente wurden mit einem Skalpell unter UV-Licht aus dem Agarosegel geschnitten. Für die Aufreinigung der DNA wurde das Reaktionssystem High Pure PCR Cleanup Micro Kit (Roche Diagnostics GmbH, Mannheim) nach Herstellerangaben verwendet.

\subsection{Zellbiologische Methoden}

\subsubsection{Kultivierung eukaryotischer Zellen}

Eukaryotische Zellen wurden in Zellkulturschalen im Begasungsbrutschrank in einer Wasserdampf-gesättigten Atmosphäre mit $16 \% \mathrm{O}_{2}, 5 \% \mathrm{CO}_{2}$ bei $37^{\circ} \mathrm{C}$ kultiviert. Die verwendeten Medien sind in Tabelle 6 angegeben, abweichende Serumkonzentration bzw. Antibiotikazugabe wird bei Beschreibung der jeweiligen Experimente angegeben.

Ein Mediumwechsel wurde alle drei bis vier Tage durchgeführt. Bei Erreichen einer etwa 70\%igen Konfluenz wurden die Zellen passagiert. 
Zur Kryokonservierung von Zelllinien wurde das Medium abgenommen, die Zellen mit PBS gewaschen und mit 5ml Trypsin von der Zellkulturschale abgelöst. Nach der Zugabe von ebenfalls 5ml FCS-haltigem Medium (10\%) wurde durch vorsichtiges Auf-/ und Abziehen des Mediums eine Einzell-Suspension hergestellt. Diese wurde dann $5 \mathrm{~min}$ bei $300 \mathrm{xg}$ abzentrifugiert, der Überstand verworfen und das verbleibende Zellpellet in 10ml Medium mit 10\% DMSO resuspendiert. Die Zellsuspension wurde in Kryokonservierungsröhrchen zu je $1 \mathrm{ml}$ aliquotiert und zunächst für zwei Stunden bei $-20^{\circ} \mathrm{C}$ eingefroren. Danach wurden die Zellen über Nacht bei $-80^{\circ} \mathrm{C}$ gelagert, bevor sie zur Dauerkonservierung in flüssigen Stickstoff überführt wurden.

\subsubsection{Kokultivierung eukaryotischer Zellen}

ASZ001 wurden sowohl mit Ptch floxflox Fibroblasten als auch mit Peritonealmakrophagen kokultiviert. Die Experimente wurden in 6-Loch-Platten mit 25mm-Zellkulturgewebeeinsätzen (Nunc GmbH, Wiesbaden) durchgeführt. Für die Kokultivierung wurden 100.000 ASZ001/Loch in je $1 \mathrm{ml}$ 154CF-Medium $\left(0,05 \mathrm{mmol} / \mathrm{CaCl}_{2}, 2 \%\right.$ chelatiertes $\left.\mathrm{FCS}, 1 \% \mathrm{P} / \mathrm{S}\right)$ gesät. Pro Zellkulturgewebeeinsatz wurden 60.000 Fibroblasten in 1ml DMEM (10\% FCS, $1 \%$ P/S) gesät. Die Zellkultureinsätze

wurden in einer separaten Platte in einem Loch platziert, in dem bereits $1 \mathrm{ml}$ DMEM (10\% FCS, 1\% P/S) vorgelegt worden war. Am nächsten Tag wurde das Kulturmedium der Fibroblasten abgesaugt, die Zellen vorsichtig mit PBS gewaschen und der Gewebeeinsatz in eine Petrischale mit PBS überführt. Das 154CF-Medium der ASZ001-Zellen wurde erneuert und der Gewebeeinsatz mit den Fibroblasten luftblasenfrei auf die ASZ001 gesetzt. Die Kokultur der Zellen erfolgte in 154CF Medium $\left(0,05 \mathrm{mmol} / \mathrm{l} \mathrm{CaCl}_{2}, 2 \%\right.$ chelatiertes FCS, $1 \%$ $\mathrm{P} / \mathrm{S}$ ) für 72h. Dann wurden die Zellen mit PBS gewaschen und anschließend jeweils mit $1 \mathrm{ml}$ TRIzol Reagent zur Isolierung der RNA lysiert.

Zur Genexpressionsanalyse von ASZ001, die mit Peritonealmakrophagen kokultiviert worden waren, wurden die aus einer Maus isolierten Peritonealmakrophagen nach der Zentrifugation in $2 \mathrm{ml} 154 \mathrm{CF}-M e d i u m\left(0,05 \mathrm{mmol} / / \mathrm{CaCl}_{2}, 2 \%\right.$ chelatiertes $\left.\mathrm{FCS}, 1 \% \mathrm{P} / \mathrm{S}\right)$ resuspendiert. Jeweils $350 \mu \mathrm{l}$ der Zellsuspension wurden auf Zellkulturgewebeeinsätze gegeben, die im Loch einer 6-Loch-Platte hingen und bereits $1 \mathrm{ml}$ 154CF-Medium $\left(0,05 \mathrm{mmol} / / \mathrm{CaCl}_{2}, 2 \%\right.$ chelatiertes FCS, 1\% P/S) enthielt. Am folgenden Tag wurden die Zellen für die $72 \mathrm{~h}$ andauernde Kokultivierung luftblasenfrei zusammengesetzt (siehe experimentelles Vorgehen zur Kokultur von Fibroblasten). Danach wurden die ASZ001 mit 1ml TRIzol Reagent zur Isolierung von RNA lysiert.

Um die Genexpression der kokultivierten Makrophagen zu analysieren, wurde das experimentelle Design umgekehrt. So wurden die Peritonealmakrophagen direkt in die 6Loch-Platte und die ASZ001 in die Gewebeeinsätze gesät. 


\subsubsection{Transfektion eukaryotischer Zellen}

Die Transfektion von Zelllinien wurde mit dem Transfektionsmedium RotiFect (Carl Roth $\mathrm{GmbH}$, Karlsruhe) durchgeführt. Dazu wurde nach Herstellerangaben gearbeitet und pro

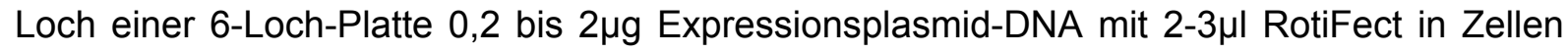
transfiziert. Die Inkubation der Zellen mit dem Nukleinsäure/Lipidkomplex betrug $3 \mathrm{~h}$.

Ein von diesem Protokoll abweichendes Vorgehen war für die Transfektion von ASZ001Zellen notwendig, die mit dem Effectene Transfection Reagent (Qiagen, Hilden) nach Herstellerangaben transfiziert wurden. Hierzu wurden 200.000 Zellen in 154CF-Medium $\left(0,05 \mathrm{mmol} / / \mathrm{CaCl}_{2}, 2 \%\right.$ chelatiertes $\left.\mathrm{FCS}, 1 \% \mathrm{P} / \mathrm{S}\right)$ pro Loch einer 6-Loch-Platte gesät. Am nächsten Tag wurde die zu transfizierende Plasmid-DNA (in einem 1,5ml Reaktionsgefäß)

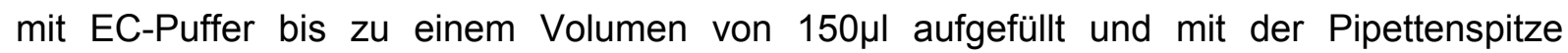
gemischt. Dann wurde $8 \mu$ l Enhancer zugegeben und der Ansatz kurz auf dem Vortexer

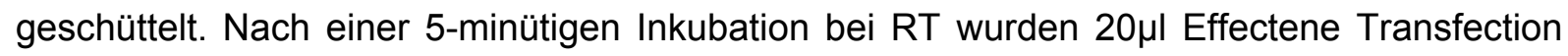
Reagent dazugegeben und zum Durchmischen auf-/ und abpipettiert. Während der darauffolgenden Inkubation des Transfektionsansatzes für 10min bei RT wurden die ASZ001

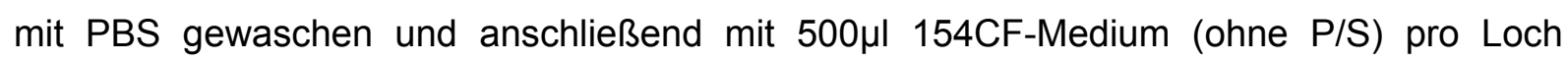

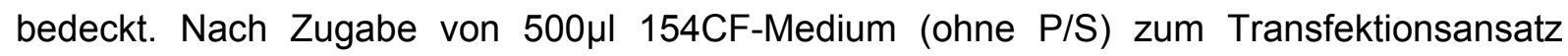
wurde dieser auf die Zellen gegeben. Während der Liposomen-vermittelten Transfektion sollte aufgrund verminderter Effizienz auf die Zugabe von Antibiotika verzichtet werden. Nach einer 8-stündigen Inkubation bei $37^{\circ} \mathrm{C}$ wurde das Medium abgesaugt und die Zellen anschließend wie gewohnt in 154CF-Medium $\left(0,05 \mathrm{mmol} / \mathrm{l} \mathrm{CaCl}_{2}, 2 \%\right.$ chelatiertes FCS, $1 \%$ $\mathrm{P} / \mathrm{S})$ für $48 \mathrm{~h}$ kultiviert.

Eine in parallel dazu durchgeführte Transfektion mit $2 \mu \mathrm{g}$ pEGFP-N1 diente als Kontrolle, wobei die Transfektionseffizienz nach $24 \mathrm{~h}$ mit einem Fluoreszenzmikroskop überprüft wurde.

\subsubsection{Isolierung und Kultivierung von peritonealen Makrophagen und BMDM}

Zur Isolierung peritonealer Makrophagen wurde eine Maus auf einem Präparationsbrett fixiert und mit 70\%igem Ethanol desinfiziert. Dann erfolgte eine Peritoneallavage. Dazu wurde das desinfizierte Bauchfell vorsichtig mit der Pinzette angehoben, eingeschnitten und mit der Schere vom Peritoneum abgelöst. Nach erneuter Desinfektion mit 70\%igem Ethanol wurden $10 \mathrm{ml}$ steriles PBS mit Hilfe einer Spritze in die Peritonealhöhle injiziert. Dies sollte mit viel Druck erfolgen, um schon beim Einspritzen eine Durchmischung der intraperitonealen Flüssigkeit zu erzielen. Dann wurde das Präparationsbrett mit der darauf fixierten Maus geschwenkt, um die Zellen möglichst effektiv vom Peritoneum abzulösen. Anschließend wurde das PBS mit einer Spritze lateral abgesaugt. Dabei musste sehr sorgsam vorgegangen werden, um das Ansaugen etwaiger Darm-/ und Fettzellen zu vermeiden. Nach Entfernen der Kanüle von der Spritze wurde die Flüssigkeit (etwa 8ml) 
vorsichtig in ein $15 \mathrm{ml}$ Röhrchen gespritzt und sofort auf Eis gelagert. Nach erfolgter Zentrifugation ( $4 \mathrm{~min}, 300 \mathrm{xg}, 4^{\circ} \mathrm{C}$ ) wurde der Überstand verworfen.

Für FACS-Analysen wurden die Zellen in $5 \mathrm{ml}$ sterilem PBS und für die Kultivierung in Zellkultur in $2 \mathrm{ml} 154 \mathrm{CF}-$ Medium $\left(0,05 \mathrm{mmol} / \mathrm{l} \mathrm{CaCl}_{2}, 2 \%\right.$ chelatiertes $\left.\mathrm{FCS}, 1 \% \mathrm{P} / \mathrm{S}\right)$ resuspendiert. Die genaue Beschreibung der weiteren Kultivierung dieser Primärzellen ist im Abschnitt zur Kokultivierung eukaryotischer Zellen (siehe 3.2.1.1) beschrieben.

Um BMDM (engl. bone marrow-derived macrophages) zu isolieren wurde zunächst die Haut entlang des Femurs vom darunter liegenden Gewebe gelöst. Mit Nadeln wurde die Felldecke dann seitlich fixiert, so dass die Muskeln besser von den Knochen präpariert werden konnten. Anschließend wurde der Femur entfernt und solange auf Eis gelagert bis auch der zweite Knochen auf die oben beschriebene Weise aus der Maus isoliert war. Nachdem die beiden Knochen unter Zuhilfenahme steriler Gaze gründlich von Gewebe befreit waren, wurden sie an beiden Enden mit einer Schere eröffnet. Mit einer Spritze wurde dann jeder Knochen mit 2,5ml Pluznikmedium (siehe Tabelle 6) durchspült und in einer beschichteten Nunc-Petrischale aufgefangen. Nach Zugabe von weiteren $5 \mathrm{ml}$ Pluznikmedium wurde durch mehrmaliges Auf-/und Abziehen des Mediums mit einer 10ml Pipette eine EinzellSuspension hergestellt.

Die so gewonnenen Zellen wurden über Nacht $\left(37^{\circ} \mathrm{C}, 5 \% \mathrm{CO}_{2}, 95 \%\right.$ Luftfeuchtigkeit) inkubiert. Die BMDM setzen sich in dieser kurzen Zeit nicht auf der beschichteten Petrischale und konnten am nächsten Tag aus dem Medium durch eine 10-minütige Zentrifugation bei 1200rpm zurückgewonnen werden. Die pelletierten Zellen wurden in 40ml Pluznikmedium aufgenommen und dann auf vier unbeschichtete, sterile Sarstedt-Petrischalen á $10 \mathrm{ml}$ aufgeteilt. Nur die BMDM konnten auf der unbeschichteten Oberfläche adhärieren und nach drei Tagen wurde das verbrauchte Pluznikmedium durch $10 \mathrm{ml}$ frisches ersetzt. Vier Tage später (also eine Woche nach Isolierung der Zellen) waren die BMDM soweit ausdifferenziert, dass sie für weiterführende Versuche genutzt werden konnten.

Dazu wurden die Zellen mit $2 \mathrm{ml}$ Accutase pro Platte für $5 \mathrm{~min}$ im Brutschrank abgelöst und in 10ml DMEM (inklusive 10\% FCS) aufgenommen. Nach einer 10-minütigen Pelletierung bei 1200rpm wurden die Zellen in 15ml BMDM-Kultmedium (sieher Tabelle 6) aufgenommen und in einer Neubauer-Zählkammer ausgezählt.

\subsubsection{Herstellung konditionierter Medien (CM, engl: conditioned medium)}

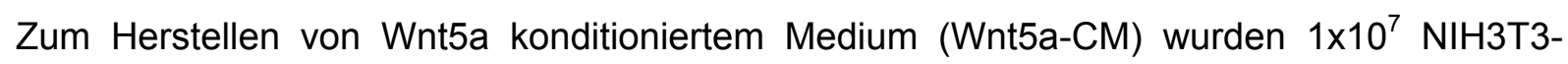
Wnt5a-Zellen in $10 \mathrm{ml}$ Medium in $10 \mathrm{~cm}$ Petrischalen ausgesät und über Nacht bei $37^{\circ} \mathrm{C}$ inkubiert. Das gleiche erfolgte mit NIH3T3-lacZ-Zellen, die der Gewinnung von konditioniertem Kontrollmedium (lacZ-CM) dienten. Beide Zelllinien wurden zum Anwachsen 
in DMEM (10\% FCS, 1\% P/S) kultiviert, wobei das Medium der NIH3T3-Wnt5a-Zellen

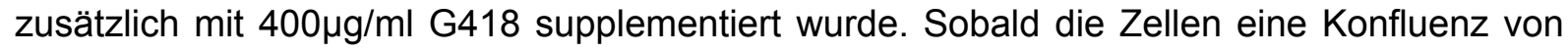
$70 \%$ erreicht hatten (meistens schon am nächsten Tag), wurden sie mit $5 \mathrm{ml}$ PBS gewaschen und anschließend in 10ml 154CF-Medium $\left(0,05 \mathrm{mmol} / \mathrm{CaCl}_{2}\right.$, nur $0,5 \%$ chelatiertes $\mathrm{FCS}, 1 \%$ $\mathrm{P} / \mathrm{S}$ ) für $24 \mathrm{~h}$ inkubiert. Dann wurde das Medium mit einer $10 \mathrm{ml}$-Spritze aufgezogen, sterilfiltriert (Porengröße $0,2 \mu \mathrm{m}$ ) und im $50 \mathrm{ml}$ Reaktionsgefäß aufgefangen. Die so gewonnenen konditionierten Medien konnten mehrere Wochen bei $4^{\circ} \mathrm{C}$ gelagert werden und wurden für die Versuche unverdünnt für 24h auf ASZ001 gegeben (siehe 3.2.4).

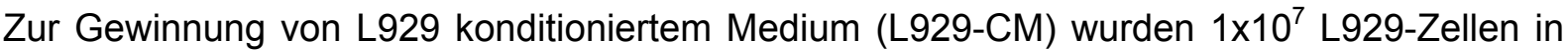
100ml RPMI1640 (10\% FCS, 1\% P/S) in Zellkulturflaschen gesät und bei standardisierten Kultivierungsbedingungen für eine Woche kultiviert. Das konditionierte Medium wurde in $50 \mathrm{ml}$ Reaktionsgefäße überführt und $10 \mathrm{~min}$ bei $300 \mathrm{rpm}$ abzentrifugiert. Dadurch wurden die im Medium befindlichen toten Zellen entfernt und es folgte die Sterilfiltration (Porengröße $0,2 \mu \mathrm{m}$ ) des gewonnenen Überstands. Das L929-CM wurde bei $-20^{\circ} \mathrm{C}$ gelagert und wurde für die Ausdifferenzierung sowie Kultivierung von BMDM benötigt (vgl. 3.2.2).

\subsubsection{Stimulation von ASZ001 mit Wnt5a-CM und rWnt5a}

Für die Stimulationsexperimente wurden 100.000 ASZ001 in $1 \mathrm{ml}$ 154CF-Medium $\left(0,05 \mathrm{mmol} / / \mathrm{CaCl}_{2}, 2 \%\right.$ chelatiertes $\left.\mathrm{FCS}, 1 \% \mathrm{P} / \mathrm{S}\right)$ in 6-Loch-Platten gesät. Am folgenden Tag wurde das Medium entweder durch $1 \mathrm{ml}$ Wnt5a-CM (bzw. lacZ-CM), oder durch $1 \mathrm{ml}$ 154CF-Medium (0,05mmol/l $\mathrm{CaCl}_{2}$, nur 0,5\% chelatiertes FCS, $\left.1 \% \mathrm{P} / \mathrm{S}\right) \mathrm{mit} 50 \mathrm{ng} / \mathrm{ml} \mathrm{rWnt5a}$ (bzw. dem Lösungsmittel PBS) ersetzt.

Nach 24h Inkubation wurden die Zellen mit PBS gewaschen und mit $1 \mathrm{ml}$ TRIzol Reagent für Genexpressionsanalysen lysiert.

\subsubsection{Bestimmung der Zellviabilität}

Die Viabilität von BMDM nach Stimulation mit 100ng/ml BLP oder 100 $\mathrm{gg} / \mathrm{ml}$ Liposomen

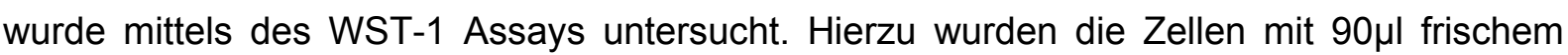
Kulturmedium und $10 \mu \mathrm{l}$ WST-1-Lösung (Roche Applied Science, Mannheim) für $3 \mathrm{~h}$ bei $37^{\circ} \mathrm{C}$ inkubiert. Das Tetrazoliumsalz WST-1 (engl. water soluble tetrazolium) wurde während der Inkubation durch mitochondriale Dehydrogenasen der noch stoffwechselaktiven Zellen zu Formazan reduziert (orange-farbene Verbindung). Die Menge an gebildetem Farbstoff korrelierte mit der Anzahl lebender Zellen und konnte mittels Absorptionsmessung bei einer Wellenlänge von 450nm in einem Microplate Reader (BioRad, München) quantifiziert werden. 


\subsubsection{Untersuchung des Migrationsverhaltens von Zellen}

Zur Untersuchung des Einflusses von BLP und Liposomen auf das Migrationsverhalten von BMDM wurden am nächsten Tag $0,75 \times 10^{5}$ BMDM pro Zellkultur-Membraneinsatz $(8 \mu \mathrm{m}$ Porengröße, von BD) in 300 $\mu$ BMBM-Kulturmedium ausgesät. Die Einsätze wurden in der 24-Loch-Platte platziert und nun für $18 \mathrm{~h}$ in mit 100ng/ml BLP oder $100 \mu \mathrm{g} / \mathrm{ml}$ Liposomen supplementiertem Medium inkubiert.

Zur Untersuchung des Migrationsverhaltens von mit Tumorzellen kokultivierten BMDM wurden 50.000 MCF-7 (in DMEM, 10\%FCS, 1\% P/S) oder 50.000 B16F10 (in RPMI1640, $10 \% \mathrm{FCS}, 1 \% \mathrm{P} / \mathrm{S}$ ) pro Loch einer 24-Loch-Platte ausgesät. Am nächsten Tag wurden die

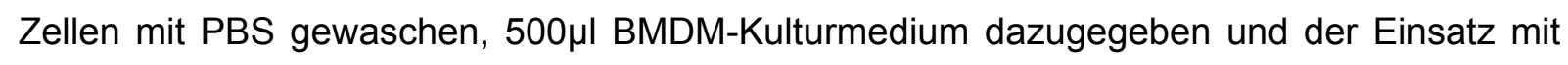
den daraufgesäten BMDM aufgesetzt.

In beiden Experimenten wurden die Einsätze (18h nach Inkubation mit BLP oder Liposomen; 18h nach Kokultivierung mit Tumorzellen) in eine neue 24-Loch-Platte überführt und in 500 $\mu \mathrm{l}$ $5 \mu \mathrm{M}$ Calcein-Lösung (verdünnt in Medium) für $1 \mathrm{~h}$ bei $37^{\circ} \mathrm{C}$ inkubiert. Danach wurden die nicht durch die Membran gewanderten BMDM mit handelsüblichen Wattestäbchen von der Oberseite der Membran entfernt. Jede Membran wurde 2x mit 300 $\mu$ PBS gewaschen und erneut mit Wattestäbchen gereinigt. Nach einem weiteren Waschschritt wurden

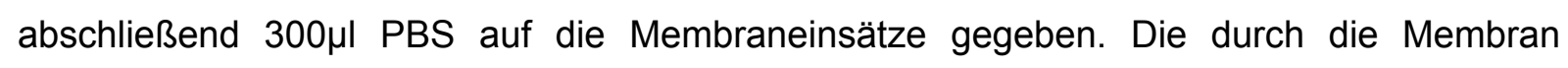
gewanderten und an der Unterseite anheftenden BMDM wurden dann unter dem Mikroskop ausgezählt. Dazu wurden pro Membran sieben sich aneinander anschließende Fotos in 100facher Vergrößerung gemacht und die Zellen mit der Software ImageJ ausgezählt.

\subsubsection{5-Bromo-2-Deoxyuridin Assay}

Zur Analyse der Proliferation von BMDM und ASZ001 wurde der 5-Bromo-2-Deoxyuridin Assay (Cell Proliferation ELISA/BrdU-Kit von Roche Diagnostics GmbH, Mannheim) durchgeführt und das Produkt nach Herstellerangaben verwendet. Es basiert auf dem namensgebenden Pyrimidinanalogon Bromdeoxyuridin (BrdU), das während der Replikation anstelle von Thymidin in die DNA eingebaut wird. Dadurch verhält sich die Menge an gebundenem BrdU proportional zur Proliferationsrate der Zellen. Für den Assay wurden in

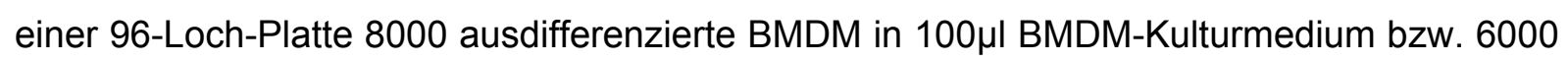

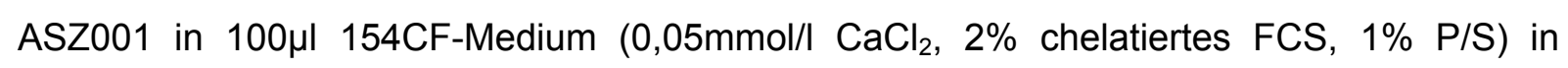
Triplikaten ausgesät. Am nächsten Tag wurde das Medium erneuert und mit 100ng/ml BLP oder $100 \mu \mathrm{g} / \mathrm{ml}$ Liposomen bzw. dem entsprechenden Lösungsmittel supplementiert. Die Zellen wurden für $72 \mathrm{~h}$ mit den Substanzen inkubiert und das angereicherte Medium wurde täglich erneuert. Beim letzten Mediumwechsel wurden zusätzlich 10 $\mu$ BrdU für die folgenden

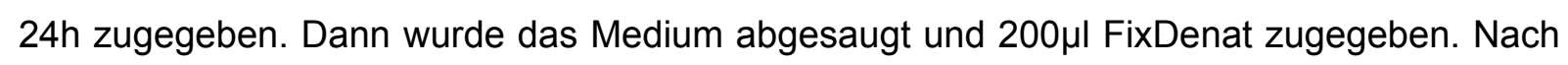
30-minütiger Inkubation bei RT wurde die Lösung abgesaugt. Nach einer kurzen

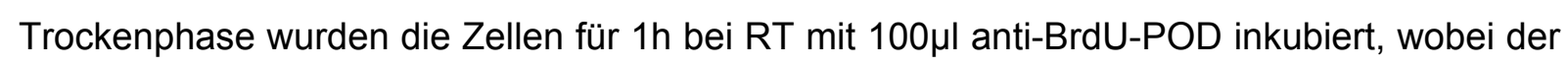


Antikörper zuvor 1:100 in Medium verdünnt wurde. Anschließend wurde das Medium wieder abgesaugt und die Zellen für 10min mit 300 $\mu$ Waschpuffer inkubiert, der 1:10 mit $\mathrm{ddH}_{2} \mathrm{O}$ verdünnt wurde. Dieser Waschschritt wurde 3fach wiederholt, der Puffer letztlich abgesaugt und die Platte kurz getrocknet. Schließlich wurde die BrdU-Inkorporation am Luminometer bestimmt, wobei die Zugabe des Peroxidase-Substrats (1:100 in Substratpuffer verdünnt) erst unmittelbar vor der Messung über eine Schlauchverbindung erfolgte.

\subsubsection{Isolierung und Kultivierung von Hautstanzen}

Die in Zellkultur inkubierten Hautstanzen stammten von $P_{t c h}{ }^{f l o x f l o x} E R T 2^{+/-}$Mäusen. In den

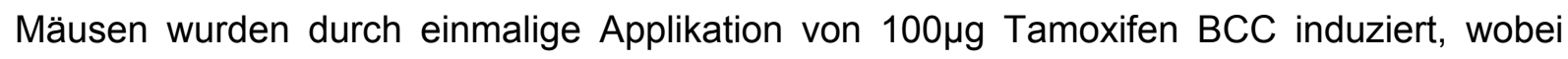
eine Maus ohne Cre-Rekombinase als Normalhaut-Kontrolle verwendet wurde. Für den Versuch wurde die Haut 45 Tage nach Tumorinduktion isoliert, so dass sie bereits Vorläuferläsionen aufwies. Durch diese Art der Kultivierung von Gewebe wurde ein System geschaffen, das den in vivo Konditionen eher ähnelte als die Analysen mit der stabilen BCCZelllinie ASZ001.

Um eine keimfreie Kultivierung des Gewebes zu gewährleisten, wurden die Tiere 48h vor Isolierung der Hautstanzen mit Ketanest $S$ und Rompun (siehe 3.4.5.6) anästhesiert. Dann wurde auf den Schwanz handelsübliche Enthaarungscreme appliziert, die nach einer Inkubation von $20 \mathrm{~min}$ mit Leitungswasser wieder abgespült wurde. Am folgenden Tag wurde

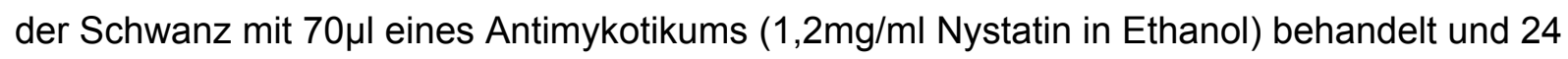
Stunden später wurden die Tiere durch zervikale Dislokation abgetötet. Die Schwanzhaut wurde mit 70\%igem Ethanol desinfiziert und mit einem sterilen Skalpell vorsichtig vom subkutanen Binde-/ und Stützgewebe abgelöst. Nach Überführen in eine Petrischale mit PBS wurde sie in $1 \mathrm{~mm}^{2}$ große Stücke geschnitten. Anschließend wurden jeweils fünf Hautstanzen mit der Dermis nach unten auf einen sterilen Milliporefilter gelegt, welcher auf der Oberfläche von $2 \mathrm{ml}$ Kulturmedium (DMEM, 2\% FCS, 1\% P/S) schwamm. Die Biopsien wurden sieben Tage lang mit oder ohne 50ng/ml rekombinantem Wnt5a oder $20 \mu \mathrm{mol} / \mathrm{l} \mathrm{KN}-93 \mathrm{bzw}$. den entsprechenden Lösungsmitteln (PBS oder DMSO) in einer 24-Loch-Platte kultiviert. Das Medium wurde jeden zweiten Tag teilweise erneuert, indem $1 \mathrm{ml}$ des verbrauchten Mediums abgenommen und durch $1 \mathrm{ml}$ frisches ersetzt wurde.

Danach wurden jeweils drei der Biopsien bei $-80^{\circ} \mathrm{C}$ weggefroren, um molekularbiologisch analysiert zu werden. Die beiden anderen Hautstanzen wurden für zwei Tage in 4\%iger PFALösung fixiert, dann in Paraffin eingebettet und anschließend histologisch analysiert. 


\subsection{Immunhistochemie und Immunzytochemie}

\subsubsection{Dualer Luciferase Assay}

Die Analyse der Aktivität des kanonischen Wnt Signalwegs in BCC-Zellen erfolgte mittels Quantifizierung der Luciferaseaktivität mit dem Dual-Luciferase Reporter Assay System von Promega nach Herstellerangaben.

Dazu wurden 200.000 ASZ001 im 6-Loch-Format in 154CF-Medium $\left(0,05 \mathrm{mmol} / / \mathrm{CaCl}_{2}, 2 \%\right.$ chelatiertes FCS, 1\% P/S) ausgesät und am nächsten Tag transfiziert (vgl.3.2.1.2). Die Aktivitätsmessung des SuperTOPFlash-Expressionsplasmids (TOP hat 8 TCF/LEFBindestellen zur Aktivierung der Expression des Luciferasegens) bzw. des Kontrollvektors SuperFOPFlash (FOP hat 8 mutierte TCF/LEF-Bindestellen) erfolgte 48h nach Transfektion.

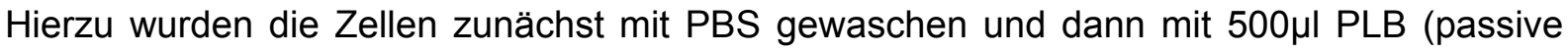
lysis buffer; im Luciferase-Kit enthalten) für 20min auf dem Schüttler lysiert. Dann wurden $20 \mu l$ des Lysats in eine 96-Loch-Platte überführt und im Luminometer nach zeitversetzter Zugabe von je 100 $\mu$ LAR II und Stop\&Glo quantifiziert. Das Zellysat wurde dann für etwaige weitere Analysen bei $-80 \mathrm{C}$ gelagert.

Normalisiert wurden die gemessenen Werte auf die Aktivität der vom RenillaReporterplasmid konstitutiv exprimierten Renilla-Luciferase aus Renilla reniformis. Die Werte wurden als Änderung der RLU (relative light units) graphisch dargestellt.

\subsubsection{ELISA}

Mit Hilfe kommerziell erworbener Testsysteme (enzyme-linked immunosorbent Assay, ELISA) wurde der Überstand von mit BLP oder Liposomen stimulierten BMDM hinsichtlich Cytokinfreisetzung analysiert.

Dazu wurden 15.000 Zellen in einer 96-Loch-Platte in BMDM-Kulturmedium inkubiert. Am folgenden Tag wurde das Medium erneuert und mit 100ng/ml BLP oder 100 $\mu \mathrm{g} / \mathrm{ml}$ Liposomen supplementiert. Die Zellen wurden nun für $6 \mathrm{~h}, 12 \mathrm{~h}$ oder $24 \mathrm{~h}$ inkubiert. Danach wurde der Überstand in ein $1,5 \mathrm{ml}$ Reaktionsgefäß pipettiert und $10 \mathrm{~min}$ bei $13000 \mathrm{rpm}$ abzentrifugiert. Der Überstand wurde in ein neues Reaktionsgefäß überführt und bis zur Analyse bei $-20^{\circ} \mathrm{C}$ gelagert. Die Level von IL-6, IL-10, CCL2 (monocyte chemoattractant protein, MCP-1), CCL3

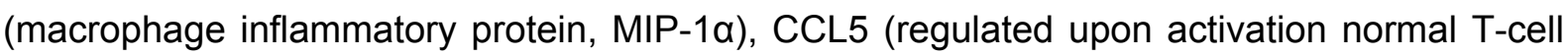
expressed and presumably secreted, RANTES) und CXCL1 (KC, mouse equivalent of human GROa) wurden mit DuoSet ELISA Development Kits (R\&D Systems GmbH, Wiesbaden) bestimmt. Das Level von TNF- $\alpha$ wurde mit dem ELISA-Kit von BioLegend (San Diego, CA, USA) quantifiziert und das von IL-12p40 wurde mit dem ELISA-Kit von eBioscience (San Diego, CA, USA) bestimmt. Es wurde nach Herstellerangaben gearbeitet 
und die nach Substratzugabe entstandene chromogene Verbindung wurde photometrisch bei 450nm in einem Microplate Reader von BioRad, München gemessen.

\subsubsection{Immunhistologische Antikörperfärbungen}

\subsubsection{Gewebeentnahme und /-fixierung}

Gewebe von Mäusen wurde entweder sofort auf Trockeneis für die Kryokonservierung weggefroren (zur Dauerlagerung bei $-80^{\circ} \mathrm{C}$ ) oder in $4 \%$ iger PFA-Lösung für mindestens zwei Tage (Haut zwei Wochen) bei $4^{\circ} \mathrm{C}$ fixiert. Die weitere Fixierung des Gewebes für die Einbettung in Paraffinblöcke erfolgte maschinell im Universitätsklinikum Göttingen, Abteilung Neuropathologie. Dann wurde das Gewebe manuell luftblasenfrei in eine Einbettungsform überführt und mit Hilfe einer erhitzten Pinzette ausgerichtet. Zum Auffüllen der Einbettungsform wurde flüssiges Paraplast zugefügt. Nach dem Erkalten konnten die Blöcke aus den Einbettungsformen gelöst und bei Raumtemperatur dauerhaft gelagert werden.

\subsubsection{Herstellung von Paraffinschnitten von Geweben}

Die Paraffinblöcke wurden auf einer Kühlplatte gekühlt. Dann wurden Schnitte (etwa $3 \mu \mathrm{m}$ dick) am Schlittenmikrotom hergestellt. Für Färbungen wurden sie in einem $50^{\circ} \mathrm{C}$ heißen Wasserbad gestreckt. Für immunhistologische Antikörperfärbungen und in situHybridisierungen wurden die Schnitte auf Superfrost-Objektträger gezogen und über Nacht bei $37^{\circ} \mathrm{C}$ getrocknet. Für HE-Färbungen wurden die Schnitte auf unbeschichtete Objektträger aufgezogen und für $20 \mathrm{~min}$ bei $80^{\circ} \mathrm{C}$ getrocknet.

\subsubsection{Hämatoxylin/Eosin (HE)-Färbung, Vermessung des Tumorareals und Antikörperfärbungen}

Für die HE-Färbung wurde das Gewebe zunächst durch Inkubation in Xylol (2x10min) entparaffiniert und anschließend mittels einer absteigenden Ethanolreihe (je $2 \mathrm{~min}$ in $100 \%$ (2x), 96\% und $70 \%$ Ethanol) rehydriert. Nach ausgiebigem Spülen in $\mathrm{ddH}_{2} \mathrm{O}$ wurden die Schnitte für 15min in Hämalaun nach Meyer inkubiert. Die anschließende Farbentwicklung fand unter fließendem, lauwarmem Leitungswasser für mindestens 5 min statt. Dann wurden die Schnitte für 20sec in 1\%ige Eosin-Lösung getaucht, in die unmittelbar zuvor einige Tropfen Eisessig $(0,5 \%$ v/v) gegeben wurde. Anschließend wurden die Schnitte kurz in $\mathrm{ddH}_{2} \mathrm{O}$ gespült und mittels einer aufsteigenden Ethanolreihe dehydriert (je $1 \mathrm{~min}$ in $70 \%$, 96\%, 100\% Ethanol). Vor dem Eindeckeln des Gewebes mit Pertex wurden die Objektträger zur vollständigen Dehydrierung kurz in Xylol geschwenkt. Die Aushärtung des Montagemediums erfolgte durch Inkubation der Präparate bei $55^{\circ} \mathrm{C}$ für mindestens $15 \mathrm{~min}$. 
Die gefärbten Schnitte wurden am Mikroskop analysiert und mit einer Digitalkamera dokumentiert.

Anhand der oben beschriebenen HE-gefärbten Schnitte wurde die Größe von BCC am Mikroskop mit der cell ${ }^{\mathrm{F}}$ Software quantifiziert.

Für immunhistologische Antikörperfärbungen wurden die Epitope der entparaffinierten und rehydrierten Schnitte falls notwendig demaskiert (siehe Tabelle 18). Dann wurden die Schnitte 2x in TBS gespült und zur Inhibierung endogener Peroxidasen für 20min mit 3\%iger $\mathrm{H}_{2} \mathrm{O}_{2}$-Lösung (verdünnt in TBS) auf dem Schüttler inkubiert. Die Reaktion wurde durch intensives Spülen mit dd $\mathrm{H}_{2} \mathrm{O}$ gestoppt, die Schnitte anschließend kurz in TBS gespült und das Gewebe für 20min mit 5\% FCS/10\% BSA in TBS geblockt. Danach wurden die Schnitte mit primärem Antikörper (siehe Tabelle 14, für Verdünnung) jeweils $1 \mathrm{~h}$ bei RT oder über Nacht bei $4^{\circ} \mathrm{C}$ in einer feuchten Kammer inkubiert. Zur Visualisierung der Signale wurde das EnVision Detection System von Dako verwendet. Dazu wurden die Schnitte zunächst für 30min mit dem gebrauchsfertigen Sekundärantikörper (HRP-konjugiert) inkubiert, danach zweimal mit TBS gewaschen und für 10min in DAB-Chromogen (1:50 verdünnt) entwickelt. Zum Abstoppen der Reaktion wurden die Schnitte intensiv mit $\mathrm{ddH}_{2} \mathrm{O}$ gespült und zur besseren Übersicht mit Hämalaun gegengefärbt.

Die immunhistologischen Färbungen mit dem anti-Ki67 Antikörper wurden anschließend am Mikroskop ausgewertet. Hierzu wurden 1000Zellen/Gewebeschnitt gezählt und der prozentuale Anteil positiver Zellen berechnet.

Tabelle 18: Antigen-Demaskierung und Verdünnung der verwendeten primären Antikörper. Spalte 1: Bezeichnung des Antigens; Spalte 2: Antigendemaskierung; Spalte 3: eingesetzte Verdünnung und verwendeter Puffer.

\begin{tabular}{lll}
\hline \multicolumn{1}{c}{$\mathbf{1}$} & \multicolumn{1}{c}{$\mathbf{2}$} & \multicolumn{1}{c}{$\mathbf{3}$} \\
\hline anti-F4/80 & ohne Vorbehandlung & $1: 100$ in $10 \%$ Casein/TBST \\
\hline anti-Ki67 & Citratpuffer pH6; $16 \min 100^{\circ} \mathrm{C}$ & $1: 50$ in TBS \\
\hline
\end{tabular}

\subsubsection{In situ-Hybridisierung}

Zum Nachweis von mRNA-Transkripten in Gewebeschnitten wurde die Methode der in situHybridisierung durchgeführt. Um eine RNA-Degradation zu verhindern, wurden mit Ausnahme von 0,1 M Triethanolamin pH 8,0, STE-in situ-Puffer, MBSTL-Puffer und NTMTLPuffer sämtliche benötigten Lösungen und Puffer vor der Verwendung mit Diethylpyrocarbonat (DEPC) behandelt. Dazu wurden die Lösungen/Puffer mit 0,03\% DEPC $(\mathrm{v} / \mathrm{v})$ versetzt, über Nacht bei Raumtemperatur inkubiert und anschließend zur DEPCInaktivierung autoklaviert. Verwendete Pinzetten wurden mit RNaseZap behandelt und danach mit $0,03 \%$ DEPC- $\mathrm{H}_{2} \mathrm{O}$ abgespült. Darüber hinaus wurden die für in situ- 
Hybridisierung verwendeten Küvetten nach jedem Einsatz mit $\mathrm{ddH}_{2} \mathrm{O}$ gespült und anschließend gebacken.

\subsubsection{Herstellung Digoxigenin-markierter Sonden}

Zur Herstellung Digoxigenin-markierter RNA-Sonden für die in situ-Hybridisierung wurden $10 \mu \mathrm{g}$ Plasmid mit $20 \mathrm{U}$ eines geeigneten Restriktionsenzyms in einem $50 \mu \mathrm{l}$-Ansatz für $2 \mathrm{~h}$ bei $37^{\circ} \mathrm{C}$ linearisiert. Die DNA wurde dann in $600 \mu \mathrm{l} 100 \%$ igem Ethanol für $30 \mathrm{~min}$ bei $13000 \mathrm{rpm}$ $\left(4^{\circ} \mathrm{C}\right)$ gefällt, das Pellet mit $70 \%$ igem Ethanol gewaschen und anschließend in $20 \mu \mathrm{l}$ RNase/DNAse-freiem Wasser aufgenommen. Zur Quantifizierung der DNA-Menge wurde $1 \mu \mathrm{l}$ mittels Agarosegelelektrophorese aufgetrennt und durch vergleichendes Abschätzen mit dem DNA-Größenstandard die Konzentration ermittelt.

Für die Markierungsreaktion wurden folgende Reagenzien eingesetzt:

$1 \mu \mathrm{g}$ linearisiertes Plasmid

1x DIG RNA Labeling Mix

1x Transcription Buffer

10 mM DTT

1 U RNA Polymerase (T3 bzw. T7)

Der Reaktionsansatz wurde für $1,5 \mathrm{~h}$ bei $37^{\circ} \mathrm{C}$ inkubiert, danach wurde die Reaktion für eine weitere Stunde bei $37^{\circ} \mathrm{C}$ nach Zugabe folgender Reagenzien wiederholt:

1x DIG RNA Labeling Mix

1x Transcription Buffer

10 mM DTT

1 U RNA Polymerase (T3 bzw. T7)

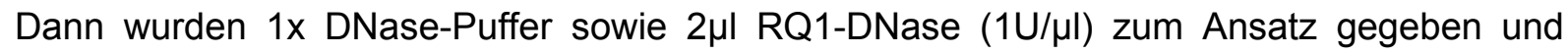
dieser für $8 \mathrm{~min}$ bei $37^{\circ} \mathrm{C}$ inkubiert. Nach Zugabe von $10 \mu$ l Stop-Puffer erfolgte die Aufreinigung der RNA-Sonde über Sephadex-G50-Säulchen. Zur Überprüfung der RNASonde wurde $1 \mu \mathrm{l}$ Sonde für $45 \mathrm{~min}$ bei $37^{\circ} \mathrm{C}$ mit $1 \mu \mathrm{l}$ RNase $A(10 \mathrm{mg} / \mathrm{ml})$ verdaut und neben $1 \mu l$ unverdauter RNA-Sonde auf ein Agarosegel aufgetragen. Nur die unbehandelte Sonde darf im Gel sichtbar werden.

Mittels eines sogenannten Dot Blots wurde die Markierungseffizienz der RNA-Sonde überprüft. Dafür wurde eine serielle 1:10 Verdünnungsreihe (fünf Verdünnungsstufen) der Sonde mit $6 x$ SSC hergestellt. Je $1 \mu$ der Verdünnungen wurde auf eine Nylonmembran pipettiert und mittels UV-Licht (Cross-Linker, $125 \mathrm{~mJ}$ ) auf dieser fixiert. Danach wurden überschüssige Bindungsstellen der Membran für 5 min mit $55^{\circ} \mathrm{C}$ warmen $4 \%$ igem BSA in NTPuffer abgesättigt. Nach kurzem Waschen der Membran in NT-Puffer wurde sie für $7 \mathrm{~min}$ in Antikörperlösung (1:5000 anti-Digoxigenin Fab Fragments/AP in NT-Puffer) gelegt. Die Membran wurde $3 \times 2 \mathrm{~min}$ in NT-Puffer gewaschen und anschließend für $3 \mathrm{~min}$ in NTM-Puffer 
umgepuffert. Die Entwicklung erfolgte mit NBT/BCIP im Dunkeln bis zur gewünschten Farbintensität (10-20 min). Abschließend wurde die Membran intensiv mit $\mathrm{ddH}_{2} \mathrm{O}$ gespült.

Nach erfolgreichem Testen wurde der Sondenansatz mit RNase/DNase-freiem Wasser versehen und zur Stabilisierung 1:1 mit Formamid aufgefüllt. Das Volumen wurde nach Abschätzen der Konzentration im Dot Blot so gewählt, dass sense-/ und antisense-Sonden gleich stark konzentriert waren. Danach wurden die Sonden aliquotiert und bei $-80^{\circ} \mathrm{C}$ gelagert.

\subsubsection{Durchführung der in situ-Hybridisierung}

Die auf Superfrost Objektträger aufgezogenen Paraffinschnitte wurden wie beschrieben entparaffiniert und rehydriert. Es folgten 5 min Inkubation in PBS und 0,83\% $\mathrm{NaCl}$-Lösung und danach eine Fixierung in 4\%iger PFA-Lösung (in PBS) für 20min auf Eis. Nach erneutem Waschen in PBS wurden die Gewebeschnitte in Proteinase K-Puffer für 7,5 min permeabilisiert. Die Schnitte wurden kurz mit PBS gewaschen, erneut in 4\%iger PFA-Lösung (in PBS) für 5min auf Eis fixiert und zunächst in 0,1M Triethanolamin, $\mathrm{pH} 8,0$, und dann für 10 min in 0,25\% (v/v) Essigsäureanhydrid überführt. Danach wurden die Schnitte mit PBS und $0,83 \% \mathrm{NaCl}$-Lösung gewaschen und schließlich in einer aufsteigenden Ethanolreihe dehydriert.

Die Schnitte wurden an der Luft getrocknet und noch am gleichen Tag für die Hybridisierung verwendet. Der näher zum Mattrand hin aufgezogene Gewebeschnitt fungierte als Negativkontrolle (sense-Sonde) und wurde vor der Hybridisierung mittels Liquid Barrier Marker vom anderen Gewebeschnitt abgegrenzt. Die sense-/ und antisense-Sonden wurden im entsprechenden Hybridisierungspuffer verdünnt (siehe Tabelle 12 ), für $2 \mathrm{~min}$ bei $80^{\circ} \mathrm{C}$ denaturiert und sofort auf Eis gestellt. Zum Hybridisierungspuffer F wurde zusätzlich $50 \mu \mathrm{g} / \mathrm{ml}$ Lachsspermien-DNA gegeben, die zuvor für 10 min bei $95^{\circ} \mathrm{C}$ denaturiert worden war. Dann wurden $100 \mu l$ der jeweiligen Probe auf das Gewebe gegeben und luftblasenfrei mit einem autoklavierten Deckgläschen abgedeckt. Für die Hybridisierung wurden die Objektträger über Nacht bei $59^{\circ} \mathrm{C}$ in einer feuchten Kammer inkubiert, deren Boden mit $50 \%$ Formamid/5xSSC bedeckt war.

Am nächsten Tag wurden die Objektträger zum Entfernen der Deckgläschen in eine Küvette mit 5xSSC gestellt. Anschließend wurden die Schnitte für $30 \mathrm{~min}$ in $5 \times \mathrm{SSC}(\mathrm{pH} 6,4)$ bei $55^{\circ} \mathrm{C}$ inkubiert und für weitere $30 \mathrm{~min}$ in $50 \%$ Formamid, $2 x S S C(\mathrm{pH} 6,4)$ bei $63^{\circ} \mathrm{C}$ im SchüttelWasserbad gewaschen. Es folgten ein Waschschritt bei RT und 3 Waschschritte bei $37^{\circ} \mathrm{C}$ in STE-in situ-Puffer für jeweils $10 \mathrm{~min}$. Nach einer Inkubation mit $8 \mathrm{ng} / \mathrm{ml}$ RNase A in STE-in situ-Puffer für $30 \mathrm{~min}$ bei $37^{\circ} \mathrm{C}$ und einem 15 -minütigen Spülen mit STE-in situ-Puffer bei $37^{\circ} \mathrm{C}$ erfolgte eine erneute Inkubation für 30min in $50 \%$ Formamid, $2 \times S S C(p H 6,4)$ bei $63^{\circ} \mathrm{C}$ im Schüttel-Wasserbad. Dann wurden die Objektträger für $15 \mathrm{~min}$ bei RT in 2xSSC (pH 6,4) 
und danach für 10min bei RT in NT-Puffer überführt. Anschließend wurden sie $3 \times 5 \mathrm{~min}$ mit MBSTL-Puffer gewaschen. Danach wurde 0,2\% Casein in PBS zur Blockade unspezifischer Bindungsstellen auf die Gewebeproben gegeben und die Objektträger für $1 \mathrm{~h}$ in einer feuchten Kammer bei RT inkubiert. Der Antikörper Anti-Digoxigenin Fab fragments/AP wurde $1: 500$ in $0,02 \%$ Casein in MBSTL-Puffer verdünnt. 80 $\mu$ dieser Verdünnung wurde auf die Gewebeschnitte gegeben und über Nacht bei $4^{\circ} \mathrm{C}$ in einer feuchten Kammer inkubiert.

Am folgenden Tag wurden die Objektträger $6 x$ für $15 \mathrm{~min}$ bei RT in MBSTL-Puffer (in einer Küvette) und danach $3 \times 5 \mathrm{~min}$ in NTMLT-Puffer (in feuchter Kammer, direkt auf dem Objektträger) gewaschen. Anschließend wurde das gebrauchsfertige Substrat BM-Purple (Roche Diagnostics $\mathrm{GmbH}$, Mannheim) auf die Schnitte gegeben und die Objektträger bei RT solange im Dunkeln inkubiert bis eine ausreichende Signalintensität erreicht war. In Abhängigkeit von der verwendeten Sonde dauerte dieser Vorgang meist mehrere Tage, wobei täglich frisches BM-Purple auf die Gewebeschnitte gegeben wurde. Zum Abstoppen der Färbereaktion wurden die Objektträger kurz in Stop-Puffer inkubiert und danach in PBS überführt. Es folgte die Fixierung der Färbung für mindestens $1 \mathrm{~h}$ in $4 \%$ PFA $0,2 \%$ Glutaraldehyd (in PBS), dann wurde intensiv mit PBS gewaschen und abschließend das Gewebe mit Glycergel (Dako GmbH, Hamburg) eingedeckt.

\subsubsection{Durchflusszytometrische Analysen (FACS)}

Für die Analyse der Apoptose mittels Annexinfärbung wurden 240.000 ausdifferenzierte BMDM in 1ml BMDM-Kulturmedium bzw. die gleiche Anzahl ASZ001 in 1ml 154CF-Medium in 6-Loch-Platten (in Duplikaten) gesät und über Nacht bei $37^{\circ} \mathrm{C}$ inkubiert. Am nächsten Tag wurde das Medium durch mit 100ng/ml BLP oder 100 $\mathrm{mg} / \mathrm{ml}$ Liposomen supplementiertem Medium ersetzt. Als Positivkontrolle wurde der Proteinkinase-Inhibitor Staurosporin eingesetzt. Die Zellen wurden für $72 \mathrm{~h}$ mit den Substanzen kultiviert, wobei das Medium täglich erneuert wurde. Dann wurden die Zellen mit PBS gewaschen und mit $1 \mathrm{ml}$ Accutase (von PAA) $5 \mathrm{~min}$ bei $37^{\circ} \mathrm{C}$ abgelöst. Die Zellen wurden in $15 \mathrm{ml}$ Röhrchen gegeben, in dem bereits $2 \mathrm{ml}$ Medium vorgelegt worden war. Dann wurden sie $5 \mathrm{~min}\left(300 \mathrm{xg}, 4^{\circ} \mathrm{C}\right)$ abzentrifugiert, mit PBS gewaschen und erneut pelletiert. Danach wurden die Zellen in 100 $\mu$ l Binding Buffer von BD Pharmingen (1:10 verdünnt in $\mathrm{ddH}_{2} \mathrm{O}$ ) resuspendiert und nach Zugabe von $2 \mu$ l Annexin V-FITC für 10min im Dunkeln bei RT inkubiert. Danach wurde $1 \mu \mathrm{l}$ To-Pro-3 lodid (von Invitrogen) zugegeben. Nach einer Inkubation von $5 \mathrm{~min}$ im Dunkeln erfolgte die Zugabe von 200 $\mu$ 1xBinding Buffer, und die Proben wurden innerhalb einer Stunde am BD FACSCalibur gemessen.

Für Zellzyklus-Analysen wurden ebenfalls 240.000 ausdifferenzierte BMDM in 1ml BMDMKulturmedium in 6-Loch-Platten gesät und über Nacht bei $37^{\circ} \mathrm{C}$ inkubiert. Am nächsten Tag 
wurden die Zellen für $72 \mathrm{~h}$ entweder mit Liposomen $(0,1 \mathrm{mg} / \mathrm{ml})$ oder mit dem entsprechenden Lösungsmittel PBS behandelt. Das Medium mit den Zusätzen wurde täglich gewechselt. Nach drei Tagen wurden die Zellen mit PBS gewaschen, mit $1 \mathrm{ml}$ Accutase von der Platte gelöst und in ein $15 \mathrm{ml}$ Röhrchen (mit $2 \mathrm{ml}$ Medium) überführt. Die Zellen wurden für $5 \mathrm{~min}$ (1000rpm, $4^{\circ} \mathrm{C}$ ) pelletiert und in $1 \mathrm{ml}$ PBS resuspendiert. Anschließend wurde die Zellsuspension mit viel Druck in 10ml 100\% Ethanol gespritzt, der zuvor für mindestens 2 Stunden bei $-80^{\circ} \mathrm{C}$ lagerte. Das $15 \mathrm{ml}$ Röhrchen wurde invertiert, sofort auf Trockeneis gelagert und die Zellen für mindestens $2 \mathrm{~h}$ bei $-20^{\circ} \mathrm{C}$ fixiert. Für die Färbung wurden die Zellen zunächst für $5 \mathrm{~min}\left(1500 \mathrm{prm}, 4^{\circ} \mathrm{C}\right.$ ) pelletiert, dann mit $2 \mathrm{ml} 100 \%$ Ethanol gewaschen und erneut abzentrifugiert. Das Zellpellet wurde danach in 500 $\mu$ Propidiumiodid-Lösung $(10 \mu \mathrm{g} / \mathrm{ml}$ Propidiumiodid und $100 \mu \mathrm{g} / \mathrm{ml}$ RNaseA in PBS) resuspendiert und für $30 \mathrm{~min}$ bei $37^{\circ} \mathrm{C}$ inkubiert. Direkt im Anschluss an die Inkubation wurden die Zellen am BD LSR II flow cytometer analysiert.

Für die durchflusszytometrische Analyse von Blutzellen erfolgte die Blutabnahme aus dem retroorbitalen Venenplexus (siehe 3.4.5.5). Es wurden $49 \mu$ les Vollbluts mit $1 \mu$ I Antikörper für 20min auf Eis inkubiert. Daran schloss sich eine Erythrozytenlyse an, indem der Ansatz mit $1 \mathrm{ml}$ gebrauchsfertigem Lyse-Puffer (BD Pharmingen) für 10min auf Eis inkubiert wurde. Danach wurden die Zellen für $4 \mathrm{~min}\left(300 \mathrm{xg} ; 4^{\circ} \mathrm{C}\right)$ abzentrifugiert und zweimal mit $2 \mathrm{ml}$ PBS gewaschen. Zum Schluss wurden die Zellen in $300 \mu \mathrm{l}$ PBS resuspendiert und bis zur Messung auf Eis gelagert (maximal 1h).

Zur FACS Analyse von Milzzellen wurde dieses Organ in $10 \mathrm{ml}$ PBS in einer Petrischale

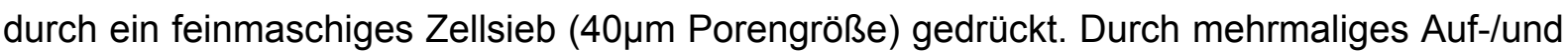
Abziehen wurde mit einer Spritze und einer feinen Kanüle eine Einzell-Suspension hergestellt.

Für FACS-Analysen von Hautzellen wurden Ohren isoliert, mit einem Skalpell in sehr kleine Stücke gehackt und in $2 \mathrm{ml}$ HBSS mit $0,2 \%$ Collagenase Typ II (von Worthington) für $1 \mathrm{~h}$ bei $37^{\circ} \mathrm{C}$, 1000rpm inkubiert. Diese Suspension wurde dann durch ein Zellsieb $(70 \mu \mathrm{m}$ Porengröße) filtriert. Durch die Zugabe von 10\% FCS (in PBS) erfolgte die Inaktivierung der Collagenase.

Die isolierten Zellen aus Milz, Haut und Peritoneallavage wurden dann für $4 \mathrm{~min}\left(300 \mathrm{xg}, 4^{\circ} \mathrm{C}\right)$ abzentrifugiert und die jeweiligen Pellets in 5ml PBS resuspendiert. Nach Quantifizierung in der Neubauer-Zählkammer wurden pro durchflusszytometrischer Färbung $1 \times 10^{6}$ Zellen eingesetzt.

Die Färbungen mit den jeweiligen Antikörpern (1:50 in PBS; siehe auch Tabelle 14) erfolgten in einem Volumen von $50 \mu \mathrm{l}$ in lichtundurchlässigen $1,5 \mathrm{ml}$ Reaktionsgefäßen für 20 Minuten

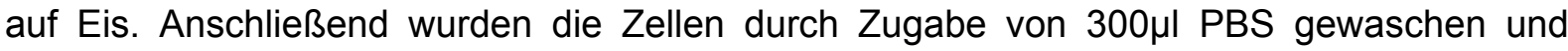


abzentrifugiert (300xg; $4^{\circ} \mathrm{C}, 4 \mathrm{~min}$ ). Danach wurde das Zellpellet in $300 \mu \mathrm{l}$ PBS resuspendiert und bis zur Messung auf Eis gelagert (maximal $1 \mathrm{~h}$ ).

Alle durchflusszytometrischen Messungen wurden am BD LSR II flow cytometer durchgeführt. Die Software BD FacsDiva ${ }^{\mathrm{TM}}$ diente zur Dokumentation der Daten, die dann mit der Software FlowJo ausgewertet wurden.

\subsubsection{Western Blot}

Zur Isolierung von Proteinen aus Haut wurde diese zunächst mit dem Skalpell zerkleinert und anschließend mit dem Homogenisator in Lyse-Puffer (für Gewebe) in 15ml Röhrchen homogenisiert. Danach wurde das Gewebe für $10 \mathrm{~min}$ (13000rpm, $4^{\circ} \mathrm{C}$ ) abzentrifugiert, das Proteinlysat in ein $1,5 \mathrm{ml}$ Reaktionsgefäß überführt und bei $-80^{\circ} \mathrm{C}$ gelagert.

Um Proteine aus Zellen (Kultivierung in 6-Loch-Platten) zu isolieren, wurden sie zunächst mit PBS gewaschen und dann in $200 \mu \mathrm{l}$ modifiziertem RIPA-Puffer aufgenommen. Mit Hilfe eines Zellschabers wurden noch anhaftende Zellen von der Petrischale gelöst und es folgte die Inkubation des Lysats für $10 \mathrm{~min}$ bei RT. Dann wurden die Zellen für $10 \mathrm{~min}\left(13000 \mathrm{rpm}, 4^{\circ} \mathrm{C}\right.$ ) pelletiert, der Überstand in ein neues $1,5 \mathrm{ml}$ Reaktionsgefäß überführt und schließlich bei $80^{\circ} \mathrm{C}$ gelagert.

Die Proteinkonzentration wurde mit dem BCA Protein Assay Kit (Pierce Biotechnology, Rockford, USA) nach Herstellerangaben bestimmt und für die Analyse wurden $18 \mu \mathrm{g}$ Protein eingesetzt.

Vor Laden des Gels wurde das Volumen der Proteinlysate (entsprechend 18$\mu \mathrm{g}$ Protein) mit

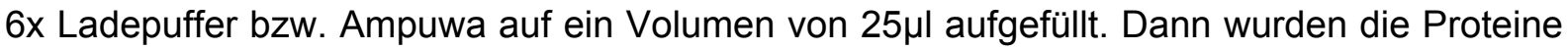
für 5 min bei $96^{\circ} \mathrm{C}$ denaturiert und mittels eines NuPAGE Novex Midi Gels (Gradient von 4\%$12 \%$ ) bei 160 Volt aufgetrennt. Danach wurden die Proteine innerhalb von anderthalb Stunden bei 120mA mittels Semi-Dry Blot (Trans Blot SD Semi-Dry; Bio-Rad Laboratories $\mathrm{GmbH}$ ) auf eine Nitrozellulosemembran übertragen. Anschließend wurde die Membran für 1h in Blocking Puffer auf dem Schüttler inkubiert, um unspezifische Bindungsstellen vor Zugabe des primären Antikörpers abzusättigen. Dann wurde die Membran 3x10min in PBST gewaschen. Anschließend folgte die Inkubation mit primärem Antikörper in BSA/Azid-Lösung über Nacht bei $4^{\circ} \mathrm{C}$. Am nächsten Tag wurde die Membran zunächst $3 \times 10$ min mit PBST gewaschen und dann mit dem Sekundärantikörper (verdünnt in Blocking Puffer) für $1 \mathrm{~h}$ bei RT inkubiert. Nach drei weiteren Waschschritten á 10min wurde das ECL Plus Western Blotting Detection System (Amersham) nach Herstellerangaben gemischt und gleichmäßig auf der Membran verteilt. Nach Inkubation von etwa $2 \mathrm{~min}$ im Dunkeln wurde das ECLGemisch wieder von der Membran entfernt. Dann wurde die Membran luftblasenfrei mit Folie 
bedeckt, um vor Austrocknung geschützt zu sein. Die Entwicklung erfolgte in der Dunkelkammer unter Verwendung von Filmkassetten.

Die eingesetzten Verdünnungen der verwendeten primären und sekundären Antikörper sind in Tabelle 14 und 15 aufgeführt.

\subsubsection{X-Gal-Färbung von Hautbiopsien}

Die isolierte Haut wurde in 1x PBS auf Eis gewaschen und dann für mindestens $2 \mathrm{~h}$ in $4 \%$ iger Paraformaldehyd-Lösung ( $\mathrm{pH} 7,8$ ) auf Eis fixiert. Nach dem Waschen (3x 20min in 1x PBS auf Eis) wurde die Haut solange in 25\%iger Sucrose-Lösung (in 1xPBS) auf Eis inkubiert, bis das Gewebe auf den Boden des Reaktionsgefäßes sank. Dann wurde die Haut in LacZPuffer $3 x 5 \mathrm{~min}$ bei RT äquilibriert. Anschließend wurde das Gewebe über Nacht bis hin zu 5 Tage in LacZ-Färbepuffer bei $30^{\circ} \mathrm{C}$ im Brutschrank inkubiert, wobei bei mehrtägiger Färbedauer der Puffer täglich erneuert wurde. Abschließend wurde die Haut 3x 20min mit 1xPBS gewaschen und für die lichtmikroskopische Untersuchung in einer aufsteigenden Glycerolreihe (15\%, 30\%, 50\%, 80\% in $1 \times$ PBS) für je $12 \mathrm{~h}$ bei $4^{\circ} \mathrm{C}$ äquilibriert. Das Material kann nach erfolgter Behandlung bei $4^{\circ} \mathrm{C}$ jahrelang gelagert werden.

\subsection{Tierexperimentelle Methoden}

\subsubsection{Mauslinien}

Wildtypmäuse des Inzuchtstamms C57BL/6N wurden von Charles River Laboratories (Sulzfeld, Deutschland) erworben und im Tierstall des Instituts für Humangenetik (Universität Göttingen) gezüchtet.

Ptch $^{\text {floxflox }} E R T 2^{+/-}$Mäuse (Uhmann, A et al. 2007) waren im Labor zur Induktion und Untersuchung von Basalzellkarzinomen (BCC) bereits vorhanden. In Ptch ${ }^{\text {floxfllox }}$ Mäusen sind die Exone 8 und 9 des Ptch Gens von Erkennungssequenzen für die Cre-Rekombinase flankiert („gefloxt“). Durch eine Kreuzung mit Rosa26CreERT2 Mäusen, die eine tamoxifeninduzierbare Cre-Rekombinase ERT2 unter der Kontrolle des Rosa26 Promotors exprimieren, kann dann ein Ptch Knockout (und damit BCC) induziert werden. Die Induktion der BCC in den Ptch floxfllox ERT2 ${ }^{+/-}$Mäusen wird in Kapitel 3.4.5.1 detailliert beschrieben.

Wnt5a ${ }^{+/-}$Mäuse wurden vom Jackson Laboratory (Bar Harbor, USA) über R. Smits (Medical Center Rotterdam, Niederlande) bezogen.

Im Rahmen dieser Arbeit wurde durch Verpaarung der beiden zuletzt genannten Mauslinien eine neue Mauslinie Ptch floxfllox ERT2 ${ }^{+/-} W n t 5 a^{+/-}$generiert (siehe Tabelle 19). Diese Mäuse waren zum einen heterozygot für Wnt5a und zum anderen konnte durch Induktion der PtchDeletion BCC hervorgerufen werden. 
In Tabelle 19 sind die genetisch manipulierten Mauslinien aufgelistet. Die Zucht und Haltung sowie tierexperimentelle Methoden werden im Folgenden beschrieben.

Tabelle 19: Auflistung der verwendeten Mauslinien. Spalte 1: Bezeichnung der Mauslinie; Spalte 2: Genetischer Hintergrund; Spalte 3: Art der genetischen Veränderung; Spalte 4: Literaturreferenz.

\begin{tabular}{|c|c|c|c|}
\hline 1 & 2 & 3 & 4 \\
\hline A) $P t c h^{f l o x / f l o x} E R T 2^{+/-}$ & $\begin{array}{l}\text { 129Sv / } \\
\text { C57BL/6N }\end{array}$ & $\begin{array}{l}\text { konditionelles Ptch } \\
\text { Knockout kombiniert mit } \\
\text { einem ERT2 Transgen }\end{array}$ & $\begin{array}{l}\text { (Uhmann, A et al. } \\
\text { 2007) }\end{array}$ \\
\hline B) $\mathrm{Wnt}^{+} \mathrm{a}^{+/-}$ & C57BL/6N & $\begin{array}{l}\text { konventionelles Wnt5a } \\
\text { Knockout }\end{array}$ & $\begin{array}{l}\text { (Yamaguchi, TP et } \\
\text { al. 1999) }\end{array}$ \\
\hline $\begin{array}{l}\text { C) } \\
\text { Ptch } \\
\text { flox/flox } E R T 2^{+/-} W n t 5 a^{+/-}\end{array}$ & & Kombination von A) und B) & diese Arbeit \\
\hline
\end{tabular}

\subsubsection{Maushaltung}

Die verwendeten Mausstämme wurden im institutseigenen Tierstall (Institut für Humangenetik, Universität Göttingen) gehalten und gezüchtet. Die Tierhaltung erfolgte in Makrolonkäfigen Typ II und III, bei einem zwölfstündigen Hell-Dunkel-Rhythmus, einer Temperatur von $20 \pm 2^{\circ} \mathrm{C}$ und einer relativen Luftfeuchtigkeit von $50 \pm 10 \%$. Pelletiertes Trockenfutter sowie Leitungswasser standen den Mäusen ständig zur Verfügung.

Im Falle von Knochenmarkstransplantationen erhielten die Tiere eine Woche vor bis 6 Wochen nach Transplantation über das Trinkwasser eine antibiotische Behandlung (3x wöchentlich 0,12\% Borgallösung).

Für die im Rahmen dieser Arbeit durchgeführten tierexperimentellen Analysen lagen die entsprechenden genehmigten Tierversuchsanträge vor.

\subsubsection{Genotypisierung von Mäusen}

Ohrlochmarkierung zur Kennzeichnung und die Entnahme von Schwanzbiopsien (ca. 0,2cm der Schwanzspitze) von drei Wochen alten Mäusen wurden von Tierpflegern des Instituts vorgenommen.

Nach Isolierung von DNA aus den Schwanzbiopsien wurde der Genotyp der Mäuse mittels PCR bestimmt bestimmt. Die verwendeten DNA-Oligonukleotide sind in Tabelle 8 aufgeführt.

\subsubsection{Bestimmung des Kopulationszeitpunktes und der Trächtigkeit}

Um Embryonen für die Transplantation fötaler Leberzellen (siehe 3.4.6) an Tag 14,5 nach Befruchtung isolieren zu können, wurden die Weibchen aus Verpaarungen früh morgens auf eine erfolgte Kopulation hin untersucht. Durch Koagulation der Samenflüssigkeit kann bis zu $24 \mathrm{~h}$ nach erfolgter Ejakulation ein fester Vaginalplaque entstehen. Die Sichtung des Vaginalplaques wurde als Tag 0,5 nach erfolgter Kopulation definiert (days post coitum; dpc). 
Ob die vaginalplaque-positiven Weibchen tatsächlich tragend waren, konnte visuell erst nach 9,5 bis 10,5 Tagen bestätigt werden.

\subsubsection{Applikation von Medikamenten und Blutabnahme}

\subsubsection{Intramuskuläre Injektion von Tamoxifen}

Zunächst wurde eine $100 \mathrm{mg} / \mathrm{ml}$ Tamoxifen-Lösung (Sigma-Aldrich, Chemie $\mathrm{GmbH}$, Steinheim) in $96 \%$ Ethanol hergestellt. Diese Lösung wurde dann in sterilem Sonnenblumenöl (Sigma-Aldrich Chemie $\mathrm{GmbH}$, Steinheim) 1:10 verdünnt. Diese Emulsion $(10 \mathrm{mg} / \mathrm{ml})$ wurde bis zur Verwendung bei $-20^{\circ} \mathrm{C}$ gelagert.

Zur Induktion der Cre-Rekombinase in den Mauslinien $\mathrm{Ptch}^{\text {floxflox }} \mathrm{ERT2}^{+/-}$und $\mathrm{Ptch}^{\text {flox/flox }} \mathrm{ERT2}^{+/-} \mathrm{Wnt}^{+a^{+-}}$wurden 6-9 Wochen alte Mäuse im Genick fixiert und einmalig

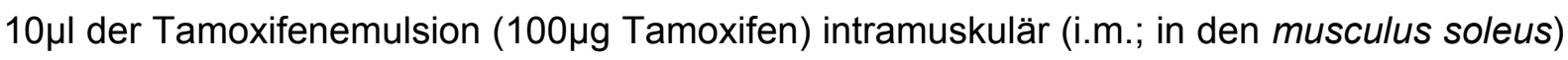
injiziert. Im Rahmen dieser Arbeit wurde auch allen Kontrollmäusen ohne Cre-Rekombinase $100 \mu g$ Tamoxifen i.m. gespritzt.

\subsubsection{Topische Applikation von Ionomycin}

Zur Erhöhung von $\mathrm{Ca}^{2+}$ in der Haut wurden $\mathrm{Ptch}^{\text {floxfllox }} \mathrm{ERT2}^{+/-}$Mäuse zu unterschiedlichen

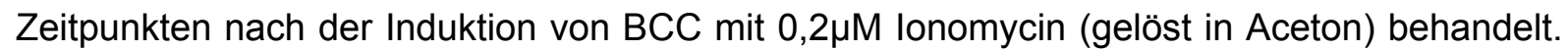
Kontrollen wurde nur das Lösungsmittel appliziert. Darüber hinaus wurden auch Mäuse ohne BCC mit Ionomycin behandelt, um einen generellen Einfluss der Substanz auf die Haut zu überprüfen.

Die Behandlung der Tiere erfolgte $5 x$ wöchentlich. Hierzu wurde die Maus im Genick fixiert und der gesamte Schwanz kurz in lonomycin-Lösung getaucht. Die Maus blieb zum Verdampfen des Lösungsmittels noch für weitere $30 \mathrm{sec}$ fixiert. Die Behandlung erfolgte in drei unabhängigen Kohorten. Dazu wurde entweder unmittelbar, 15 oder 45 Tage nach Tamoxifen-Injektion (und damit BCC Induktion) mit der Applikation begonnen und endete jedes Mal an Tag 90 der Tumorentwicklung.

\subsubsection{Subkutane Injektion eines Expressionsplasmids}

Zur Überexpression von nackter Plasmid-DNA in vivo wurde in Vorversuchen durch Applikation eines ßGal-Expressionsplasmids zunächst ein geeignetes Spritzschema etabliert. Dann wurde ein Wnt5a-Expressionsplasmid sowie PBS (als Kontrolle) in WildtypMäuse subkutan injiziert, wobei das Experiment zukünftig mit Basaliom-tragenden Mäusen durchgeführt werden soll. 


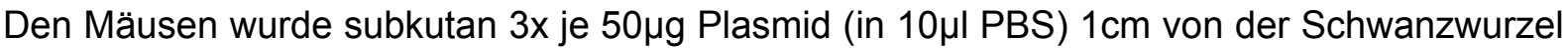
entfernt gespritzt. Zwischen den Injektionen wurde jeweils ein Tag pausiert. 24h bzw. sieben Tage nach der letzten Dosis folgte das schmerzfreie Abtöten der Tiere. An der isolierten ßGalaktosidase-gespritzten Haut wurde eine X-Gal-Färbung durchgeführt (siehe 3.3.7) und aus den Wnt5a-gespritzten Hautarealen wurden Proteine zur Analyse im Western Blot isoliert.

\subsubsection{Intraperitoneale Injektion von Clodrolip, Leerliposomen und BLP}

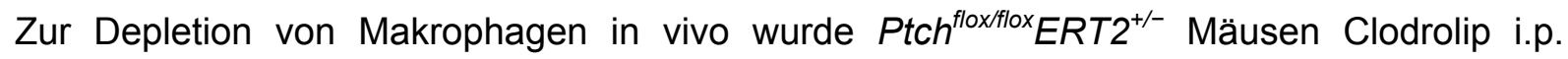
injiziert, als Kontrolle dienten Leerliposomen. Die Substanzen wurden freundlicherweise von R. Schwendener, Schweiz zur Verfügung gestellt. Die Injektion erfolgte in einem Volumen von $120 \mu \mathrm{l}$ PBS (erste Dosis 2mg/20g; folgende Dosen $1 \mathrm{mg} / 20 \mathrm{~g}$ ) jeden vierten Tag. Um einen Einfluss der Makrophagendepletion auf die Tumorgröße zu untersuchen, wurde die Behandlung an Tag 15 nach der BCC-Initiation begonnen und wurde für 75 Tage fortgesetzt.

Außerdem wurde den Ptch $^{\text {floxfllox} E R T 2 ~}{ }^{+-}$Mäusen der TLR1/2-Agonist BLP $\left(\mathrm{Pam}_{3} \mathrm{CSK}_{4}\right)$ i.p gespritzt. Die Konzentration betrug $25 \mu \mathrm{g} /$ Tier in einem Volumen von $120 \mu \mathrm{l}$ PBS und die Injektion wurde jeden vierten Tag appliziert. Kontrolltieren wurde die gleiche Menge PBS i.p. gespritzt. Die erste Injektion erfolgte 15 Tage nach Tumorinduktion und wurde bis zum Tag 90 nach Induktion fortgeführt.

\subsubsection{Blutabnahme aus dem retroorbitalen Venenplexus}

Durch festes Fixieren der Maus im Genick wurde das Blut im Plexus gestaut, um es mit einer angebrochenen Mikro-Hämatokrit-Kapillare aus dem retroorbitalen Venenplexus zu entnehmen. Das zu analysierende Blut lief direkt in ein EDTA-Röhrchen, das sofort kräftig geschüttelt wurde. Die Blutproben wurden bis zur Analyse bei $4^{\circ} \mathrm{C}$ gelagert.

Die Isolierung von DNA aus Blut ist im Abschnitt 3.1.1.2.3 und die weitere Behandlung des Blutes für FACS-Analysen in Abschnitt 3.3.5 beschrieben.

\subsubsection{Narkotisierung von Mäusen}

Zur Narkotisierung wurde den Mäusen i.p. $64 \mu \mathrm{g}$ Ketanest $S$ und $12 \mu \mathrm{g}$ Rompun pro $1 \mathrm{~g}$ Körpergewicht injiziert. Um eine Austrocknung der Augen während der Narkose zu verhindern, wurden sie mit einer 0,9\%igen $\mathrm{NaCl}$-Lösung bedeckt. 


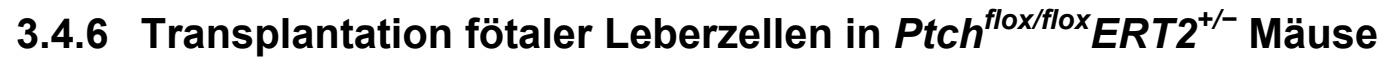

Zur Isolierung fötaler Leberzellen von 14,5 Tage alten Mausembryonen wurden zunächst heterozygote $\mathrm{Wnt}_{5 a^{+/}}$Mäuse miteinander verpaart. Am folgenden Morgen wurden die Weibchen aus den Verpaarungen auf Vaginalplaques hin untersucht (siehe Abschnitt 3.4.4). Am Tag 14,5 dpc wurden die tragenden Weibchen durch zervikale Dislokation schmerzfrei getötet, der Uterus isoliert und die Embryonen auf Eis in 1x PBS aus dem Uterusgewebe präpariert. Dann wurde der Embryo an Kopf und Schwanz auf einem Präparationsbrett fixiert und zunächst ein Vorderbein zur Isolierung von DNA für die Genotypisierung (siehe 3.1.1.2.1) entfernt. Dann wurde die Bauchhaut des Embryos eröffnet, mit einer Pinzette die fötale Leber entnommen und in 5ml PBS auf Eis bis zur Weiterverarbeitung aufbewahrt.

Nach erfolgter Genotypisierung wurden die Lebern entsprechend ihres Genotyps (Wnt5a ${ }^{+/+}$

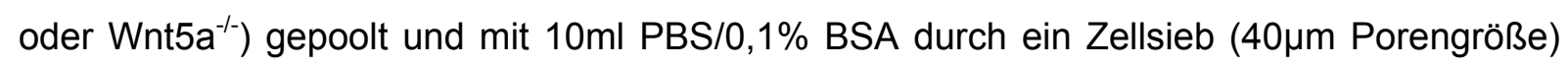
gedrückt. Anschließend wurden die Zellen $7 \mathrm{~min}\left(300 \mathrm{xg}, 4^{\circ} \mathrm{C}\right)$ pelletiert und vorsichtig in $1 \mathrm{ml}$ PBS $/ 0,1 \%$ BSA resuspendiert. Dann wurden sie mittels Trypanblau auf ihre Viabilität geprüft und bis zur Injektion ständig auf Eis gelagert.

Die zu transplantierenden 12-15 Wochen alten $\operatorname{Ptch}^{\text {floxflox }} E R T 2^{+/-}$Mäuse, die einen Tag vor der Transplantation mit einer letalen Dosis (10Gy) im Universitätsklinikum Göttingen, Abteilung Radiologie bestrahlt worden waren, wurden etwa 5 min vor Transplantation unter eine Rotlicht-Wärmelampe gesetzt und anschließend in einer Plexiglasröhre fixiert. Dann wurden den bestrahlten Mäusen $2 \times 10^{6}$ fötale Leberzellen in $200 \mu l$ sterilem PBS i.v. gespritzt, wobei ein Kontrolltier kein Transplantat erhielt.

\subsubsection{Präparation von Tumoren und Geweben}

Nach zervikaler Dislokation wurde die Maus auf dem Präparationsbrett fixiert und mit $70 \%$ Ethanol desinfiziert. Dann wurde das Abdomen entlang der Mittellinie eröffnet, die Bauchaorta freigelegt und durchtrennt, um das Tier ausbluten zu lassen.

Die Isolierung der Schwanzhaut erfolgte mit einem Skalpell, indem sie längs mit zwei sich gegenüberliegenden Schnitten aufgeschnitten wurde. Die eine Hälfte der Schwanzhaut wurde vorsichtig vom subkutanen Binde-/ und Stützgewebe abgetragen und für weitere Analysen bei $-80^{\circ} \mathrm{C}$ gelagert. Die andere Hälfte der Haut wurde am Knochen belassen und auf diese Weise für 2 Wochen in 4\%iger PFA-Lösung für histologische Analysen fixiert.

Die histologische Abklärung aller Tumoren erfolgte anhand von HE-gefärbten Gewebeschnitten durch den erfahrenen Neuropathologen der Universitätsklinik Göttingen, PD. Dr. W. Schulz-Schaeffer. 


\subsubsection{Statistische Auswertungsverfahren}

Alle statistischen Auswertungen erfolgten mit Hilfe der Software Statistica und dem Microsoft-Programm Excel. Die Graphiken wurden in Box-Whisker-Plots dargestellt, um Streuung und Spannweite einer Verteilung inklusive möglicher Ausreißer in einem Bild zusammenzufassen. Die Box umfasst die mittleren 50\% der Verteilung und der Median der Einzelwerte wird durch einen horizontalen Strich an entsprechender Stelle in der Box dargestellt. Die Signifikanz von Unterschieden und Gleichheit einzelner Gruppen wurde durch einen t-Test für unabhängige Gruppen (Mann-Whitney-U-Test) ermittelt. Hierbei werden Unterschiede mit $p$-Werten von $p<0,05$ als signifikant und $p>0,05$ als nicht-signifikant bezeichnet. 


\section{Ergebnisse}

\subsection{Expression und Funktion von Wnt5a in der BCC-Zelllinie ASZ001 und BCC-tragenden Hautstanzen}

In unserer Arbeitsgruppe waren bereits vor Beginn dieser Doktorarbeit murine Basalzellkarzinome intensiv analysiert worden. Auch gab es bereits Vorarbeiten zur Rolle von Wnt5a bei der Regression dieser Tumorentität. Wie bereits ausführlich beschrieben, war bekannt, dass die Regressionsvorgänge mit einer Wnt5a Expression im Tumorstroma einhergehen (siehe Einleitung und (Nitzki, F et al. 2010)).

Gleichzeitig werden Differenzierungsmarker der Haut ( $K 1$ und $K 10)$ überexprimiert.

Weiterhin gab es Hinweise, dass der Wnt/Ca ${ }^{2+}$ Signalweg, nicht aber der Wnt/ß-Catenin oder Wnt/JNK Signalweg, eine Rolle bei der Regression von BCC spielt.

Diese Tatsachen legen die Vermutung nahe, dass Wnt5a im BCC direkt die Wnt/Ca ${ }^{2+}$ Signalkaskade aktiviert und über die Induktion von Differenzierungsmarkern mit der Regression der Tumoren in Verbindung stehen könnte.

Um diese Hypothesen und Ergebnisse zu verifizieren, wurden Untersuchungen an der BCCZelllinie ASZ001 und an BCC-tragenden Hautstanzen durchgeführt.

Zunächst wurde jedoch untersucht, welche stromale Zellpopulation für die Wnt5a Expression im BCC verantwortlich sein könnte.

\subsubsection{ASZ001 induzieren die Expression von Wnt5a in kokultivierten Makrophagen}

Aus der Literatur von anderen Tumorentitäten war bekannt, dass die Wnt5a Expression in tumorassoziierten Makrophagen (TAM, engl. tumor-associated macrophages) induziert werden kann (Pukrop, T et al. 2006). Da aber Fibroblasten ebenfalls zu Zellen des Tumorstromas gehören, wurden für den Versuch auch murine Fibroblasten untersucht. Beide Zellsubpopulationen wurden mit der BCC-Zelllinie ASZ001 kokultiviert. Nach einer Kokultivierung von $72 \mathrm{~h}$ wurde die Wnt5a Expression in beiden Zelltypen mittels qRT-PCR analysiert. Außerdem wurden die Makrophagen bzw. Fibroblasten ohne Tumorzellen für $72 \mathrm{~h}$ unter ansonsten gleichen Bedingungen kultiviert. Auf diese Kontrollen wurden die ermittelten Expressionsniveaus der stromalen Zellen nach Kokultur normalisiert. Wie in Abbildung $9 \mathrm{zu}$ sehen, konnte die Wnt5a Expression tatsächlich in den Makrophagen induziert werden. Das Wnt5a Expressionslevel wurde dabei um das ca. 2-fache induziert. Ein solcher Anstieg konnte in den Fibroblasten nicht gemessen werden. Vielmehr nahm die Wnt5a Expression in diesen Zellen sogar ab. 


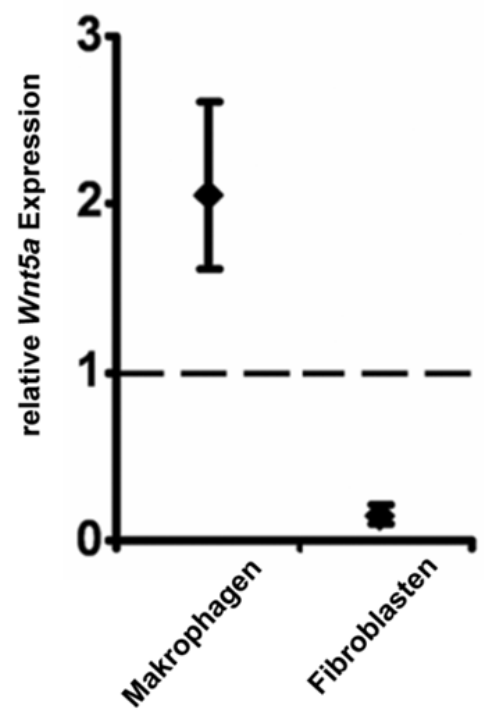

\begin{abstract}
Abbildung 9: Analyse der Wnt5a Expression in Makrophagen und Fibroblasten nach Kokultivierung mit ASZ001. Die gezeigten Daten repräsentieren sechs (Makrophagen) und drei (Fibroblasten) unabhängige Experimente, die jeweils in Triplikaten vermessen wurden. Dargestellt sind die Mittelwerte (+/Konfidenzintervall) der Experimente in Relation zur Wnt5a Expression in den entsprechenden nichtkokultivierten Zellen, deren Expression auf 1 gesetzt wurde (gestrichelte Linie).
\end{abstract}

Zusammengefasst zeigen die Daten, dass eine Wnt5a Expression nur in Makrophagen nach Kokultivierung mit ASZ001 induziert werden konnte. In Fibroblasten war dies hingegen nicht der Fall.

\title{
4.1.2 Wnt5a hat keinen Einfluss auf den kanonischen Wnt Signalweg in ASZ001
}

Um zu untersuchen, ob Wnt5a den kanonischen Wnt/ß-Catenin Signalweg induzieren kann, wurden ASZ001 mit SuperTOPFlash (TOP hat 8 TCF/LEF-Bindestellen zur Aktivierung der Expression des Luciferasegens) oder SuperFOPFlash (FOP hat 8 mutierte TCF/LEFBindestellen) transfiziert, siehe Kapitel 3.3.1. Die Kotransfektion von pCl-neo-b-catS33Y (S33Y) diente in dem Experiment als Positivkontrolle, da das durch diesen Vektor exprimierte konstitutiv aktive ß-Catenin zur Aktivierung des kanonischen Signalwegs führt. $24 \mathrm{~h}$ vor Lyse der Zellen wurden die transfizierten Zellen mit 50ng/ml rWnt5a bzw. dem entsprechenden Volumen PBS (als Kontrolle) inkubiert. Dann wurde die Luciferase-Aktivität gemessen. Die Luciferase-Werte nach Transfektion des TOP-Vektors wurden $=1$ gesetzt. Die anderen Werte wurden auf diesen Wert normalisiert.

In der Abbildung 10 ist erkennbar, dass die Transfektion des TOP-Vektors und zusätzliche Kotransfektion von $\mathrm{pCl}$-neo-b-catS33Y die Aktivierung des Luciferasegens induziert und zu einer fast 6-fachen Änderung der Luciferase-Aktivität führt. Damit zeigt das Ergebnis, dass der Assay generell sehr gut funktioniert. Die Inkubation mit rWnt5a führt zwar zu einer 
leichten Induktion des TOP-Vektors im Vergleich zur Kontrolle, allerdings ist dieser Effekt nicht stärker als die Induktion des FOP-Vektors durch die aktive Form von ß-catenin (S33Y). Diese Daten zeigen, dass Wnt5a keinen Einfluss auf den kanonischen Wnt Signalweg in ASZ001 Zellen hat.

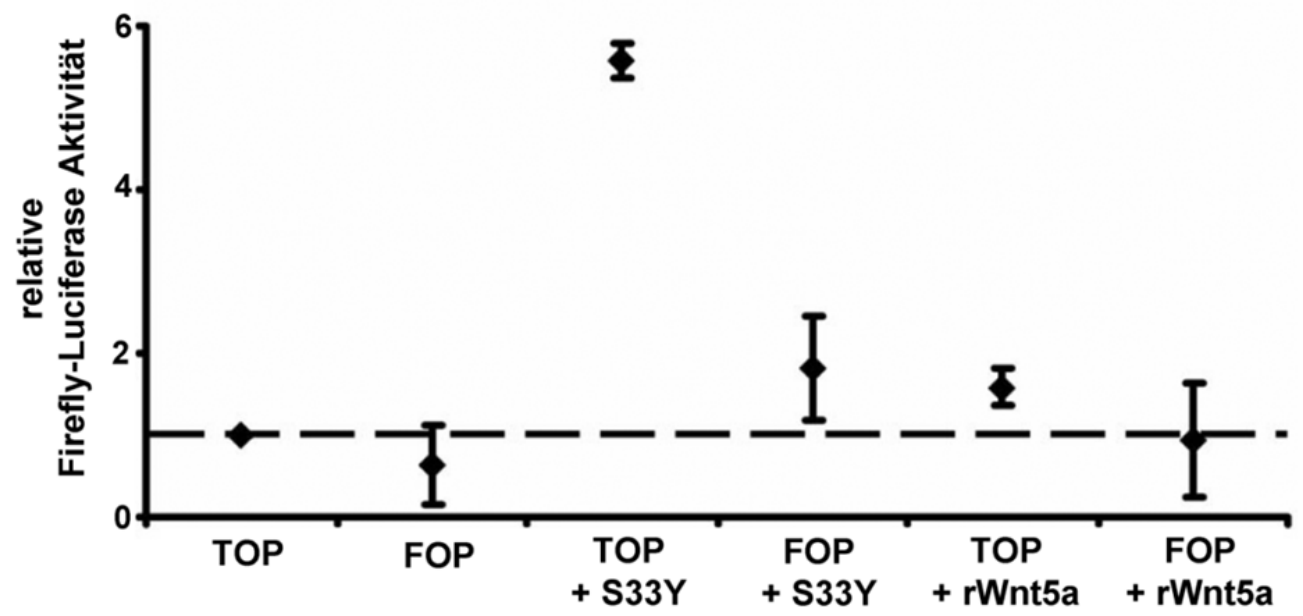

Abbildung 10: TOP/FOP Luciferase Reporter Assay in der BCC-Zelllinie ASZ001 nach Inkubation mit Wnt5a. Die gezeigten Daten repräsentieren jeweils vier unabhängige Experimente, die in Duplikaten vermessen wurden und als Änderung der Luciferase-Aktivität dargestellt sind. Die Luciferaseaktivität der TOP Kontrolle (transfiziert mit SuperTOPFlash) wurde auf 1 gesetzt (gestrichelte Linie). Die Luciferaseaktivität aller weiteren Transfektionen ist relativ zu diesem Wert dargestellt. Abkürzungen: FOP, Transfektion mit SuperFOPFlash; S33Y, Transfektion mit pCl-neo-b-catS33Y. Auf die Inkubation der Zellen mit rWnt5a wird entsprechend hingewiesen.

Zusammengefasst zeigen die Daten, dass Wnt5a den kanonischen Wnt Signalweg in ASZ001 nicht induzieren kann.

\subsubsection{Wnt5a induziert die K10 Expression in ASZ001}

Um zu untersuchen, ob Wnt5a tatsächlich in der Lage ist, die $K 1$ oder K10 Expression in BCC-Zellen zu beeinflussen, wurden ASZ001 mit rWnt5a $(50 \mathrm{ng} / \mathrm{ml})$ oder mit Wnt5a-CM (konditioniertes Medium aus Wnt5a-exprimierenden Fibroblasten, siehe Kapitel 3.2.3) für 24h inkubiert. Zudem wurden die ASZ001 mit Makrophagen kokultiviert, da Makrophagen unter diesen Bedingungen Wnt5a exprimieren (siehe Kapitel 3.2.1.1). Im Anschluss wurde die Expression der beiden Differenzierungsmarker $K 1$ und $K 10$ mittels qRT-PCR in den ASZ001 gemessen und die Expression jeweils auf die Expressionsniveaus der mit PBS oder konditioniertem Medium aus Kontrollzellen behandelten Ansätze normalisiert. Da $K 1$ in den ASZ001 weder exprimiert noch nach Inkubation mit Wnt5a reguliert wurde, sind die Daten hier nicht gezeigt. Interessanterweise wurde jedoch die Expression von $K 10$ durch Inkubation mit rWnt5a etwa 3-fach und durch Wnt5a-CM 2-fach induziert. Auch nach Kokultivierung mit 
Wnt5a-exprimierenden Makrophagen wurde eine ca. 3-fache Induktion der K10 Expression gemessen (Abbildung 11).

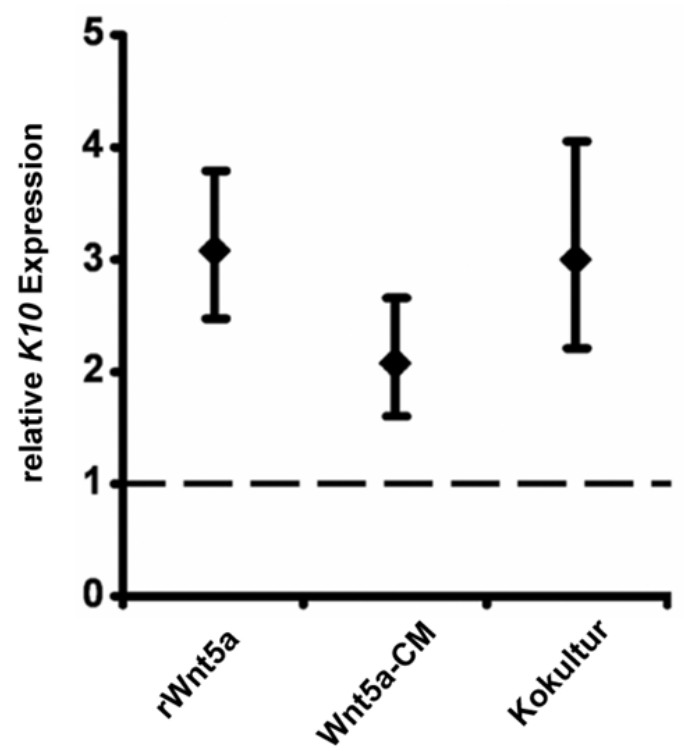

Abbildung 11: K10 Expression in ASZ001 nach Inkubation mit Wnt5a oder Kokultur mit Wnt5aexprimierenden Makrophagen. Gezeigt ist die K10 Expression in der BCC-Zelllinie ASZ001 nach Inkubation mit rekombinantem Wnt5a (rWnt5a), Wnt5a-konditioniertem Medium (Wnt5a-CM) oder nach Kokultivierung mit Peritonealmakrophagen (Kokultur). Dargestellt sind die Mittelwerte (+/-Konfidenzintervall) in Relation zur K10 Expression von unbehandelten Makrophagen, deren Expression auf 1 gesetzt wurde (gestrichelte Linie). Die gezeigten Daten repräsentieren die Ergebnisse von neun (rWnt5a), drei (Wnt5aCM) bzw. zwei (Kokultur) unabhängigen Experimenten, die jeweils in Triplikaten vermessen wurden.

Diese Daten belegen, dass Wnt5a die K10 Expression in BCC-Zellen induzieren kann.

\subsubsection{Wnt5a und Aktivierung des $\mathrm{Wnt} / \mathrm{Ca}^{2+}$ Signalwegs induziert die $\mathrm{K} 10$ Expression in BCC in Zellkultur}

Da die Differenzierung von epidermalen Zellen $\mathrm{Ca}^{2+}$ abhängig verläuft (Hennings, $\mathrm{H}$ et al. 1980) wurde nun untersucht, ob die Wnt5a-induzierte K10 Expression in BCC-Zellen durch den $\mathrm{Ca}^{2+}$-abhängigen Wnt Signalweg vermittelt wird.

Wie andere Mitglieder unserer Arbeitsgruppe zeigen konnten, ließ sich die Wnt5a-induzierte K10 Expression durch KN-93, nicht aber durch Dkk-1, BIM (ein spezifischer Inhibitor der PKC) oder SP600125 (ein spezifischer Inhibitor der JNK) hemmen (Nitzki, F et al. 2010). Dies zeigt, dass die Wnt5a-vermittelte $K 10$ Induktion in den ASZ001 über den $\mathrm{Ca}^{2+}$ abhängigen Wnt Signalweg in Abhängigkeit der CaMKII induziert wird. 


\subsubsection{Einfluss der CaMKII auf die K10 Expression in ASZ001}

Die Abhängigkeit der K10 Expression von der CaMKII wurde nochmals mit Hilfe eines Transfektionsexperiments von ASZ001 verifiziert.

Hierzu wurden die Zellen mit CaMKII-T286D-CS2 (konstitutiv aktive CaMKII) und mit einem Kinase-inaktiven Plasmid (CaMKII-K42M1-271-CS2) transfiziert. 48h nach Transfektion wurden die Proben hinsichtlich ihrer K10 Expression mittels qRT-PCR analysiert. Die Daten wurden auf ermittelte Werte nach Transfektion mit dem Kontrollvektor pcS2 normalisiert. Wie man der Abbildung 12 entnehmen kann, stieg die K10 Expression durch die Expression von konstitutiv aktiver CaMKII im Vergleich zu inaktiver CaMKII in ASZ001 fast 3,5-fach an.

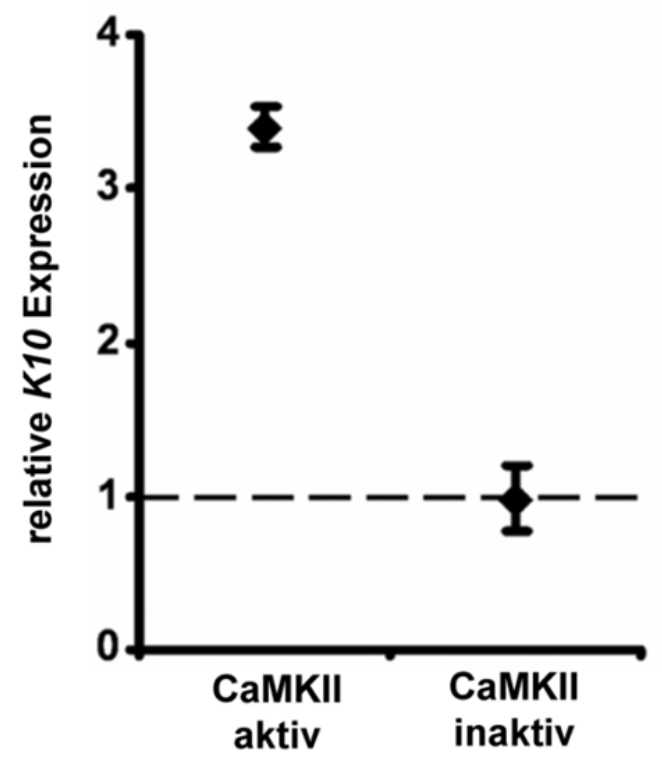

Abbildung 12: Einfluss der CaMKII auf die K10 Expression in ASZ001. Gezeigt ist die K10 Expression in der BCC-Zellinie ASZ001 nach Transfektion mit CaMKII-T286D-CS2 (aktive CaMKII) oder CaMKIIK42M1-271-CS2 (inaktive CaMKII). Dargestellt sind die Mittelwerte (+/-Konfidenzintervall) in Relation zur K10 Expression von mit pcS2 (Kontrollvektor) transfizierten ASZ001, deren Expression auf 1 gesetzt wurde (gestrichelte Linie). Die Daten repräsentieren die Ergebnisse von zwei unabhängigen Experimenten, vermessen in Duplikaten.

Zusammengefasst lassen die Daten darauf schließen, dass die Wnt5a-vermittelte $K 10$ Expression in der BCC-Zelllinie ASZ001 über den $\mathrm{Ca}^{2+}$-abhängigen Wnt Signalweg in Abhängigkeit von der CaMKII induziert wird.

\subsubsection{Einfluss von Wnt5a und dem CaMKII Inhibitor KN-93 auf die K10 Expression in BCC-tragenden Hautstanzen}

Um die oben beschriebene Abhängigkeit der K10 Expression von Wnt5a und CaMKII zu

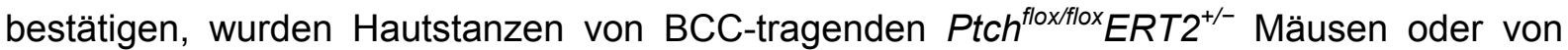
tumorlosen $P t c h^{\text {flox/flox }}$ Mäusen für sieben Tage in der Zellkultur kultiviert. Das Kulturmedium wurde entweder mit rekombinantem Wnt5a $(50 \mathrm{ng} / \mathrm{ml})$ oder mit dem CaMKII-Inhibitor KN-93 
(20 $\mu \mathrm{mol} / \mathrm{l})$ supplementiert. Ein etwaiger Einfluss der Substanzen bzw. ihrer Lösungsmittel auf Normalhaut konnte durch histologische Analyse der HE-Schnitte ausgeschlossen werden (Daten nicht gezeigt). In den BCC-tragenden Hautstanzen konnte gezeigt werden, dass die Inkubation mit rWnt5a im Gegensatz zur Lösungsmittelkontrolle zu einer etwa 7-fachen Erhöhung der K10 Expression führt (Abbildung 13). Dagegen wird die K10 Expression durch den CaMKII-Inhibitor KN-93 um das etwa 0,05-fache im Vergleich zu den Lösungsmittelkontrollen inhibiert.

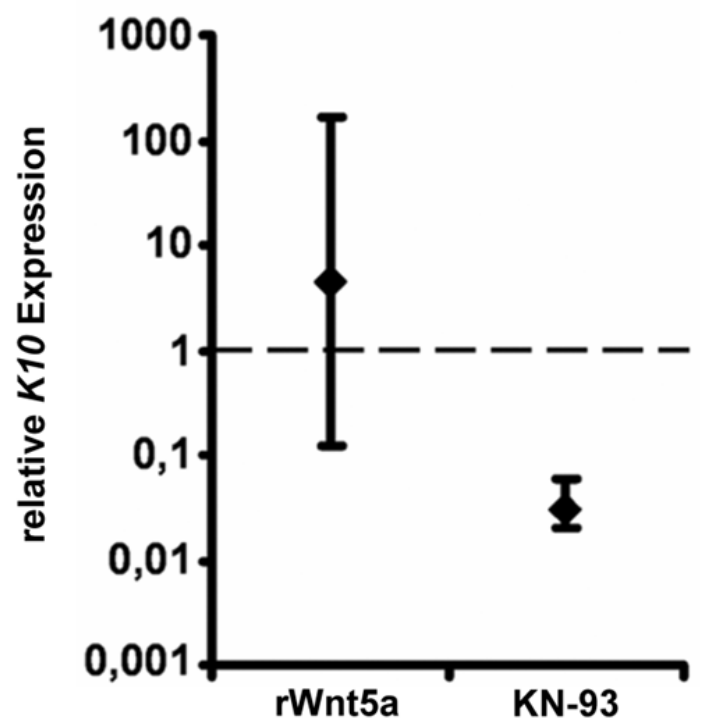

Abbildung 13: Einfluss von Wnt5a oder KN-93 auf die K10 Expression in BCC-tragenden Hautstanzen. Die Hautstanzen wurden entweder mit rWnt5a oder dem CaMKII-Inhibitor KN-93 für sieben Tage inkubiert. Dargestellt sind die Mittelwerte (+/-Konfidenzintervall) in Relation zur K10 Expression von Lösungsmittel-behandelten Stanzen, deren Expression auf 1 gesetzt wurde (gestrichelte Linie). Die Daten repräsentieren die Ergebnisse von drei und sechs unabhängigen Experimenten, die jeweils in Duplikaten analysiert wurden.

Zusammengefasst bestätigen diese Daten, dass KN-93 die K10 Expression inhibiert und Wnt5a die K10 Expression induziert.

\subsubsection{Wnt5a oder CaMKII Inhibitor KN-93 haben keinen Einfluss auf die BCC Proliferation in BCC-tragenden Hautstanzen}

Um einen Anhaltspunkt zu bekommen, ob die Differenzierung (sprich K10 Expression) direkt mit einer Proliferationshemmung der BCC in Verbindung steht, wurden die Hautstanzen histologisch begutachtet und mit dem Proliferationsmarker Ki67 gefärbt.

Wie man der Abbildung 14 entnehmen kann, konnten keine eindeutigen Unterschiede hinsichtlich der Tumorgröße in den mit Wnt5a, KN-93 oder Lösungsmittel-behandelten Hautstanzen festgestellt werden. 

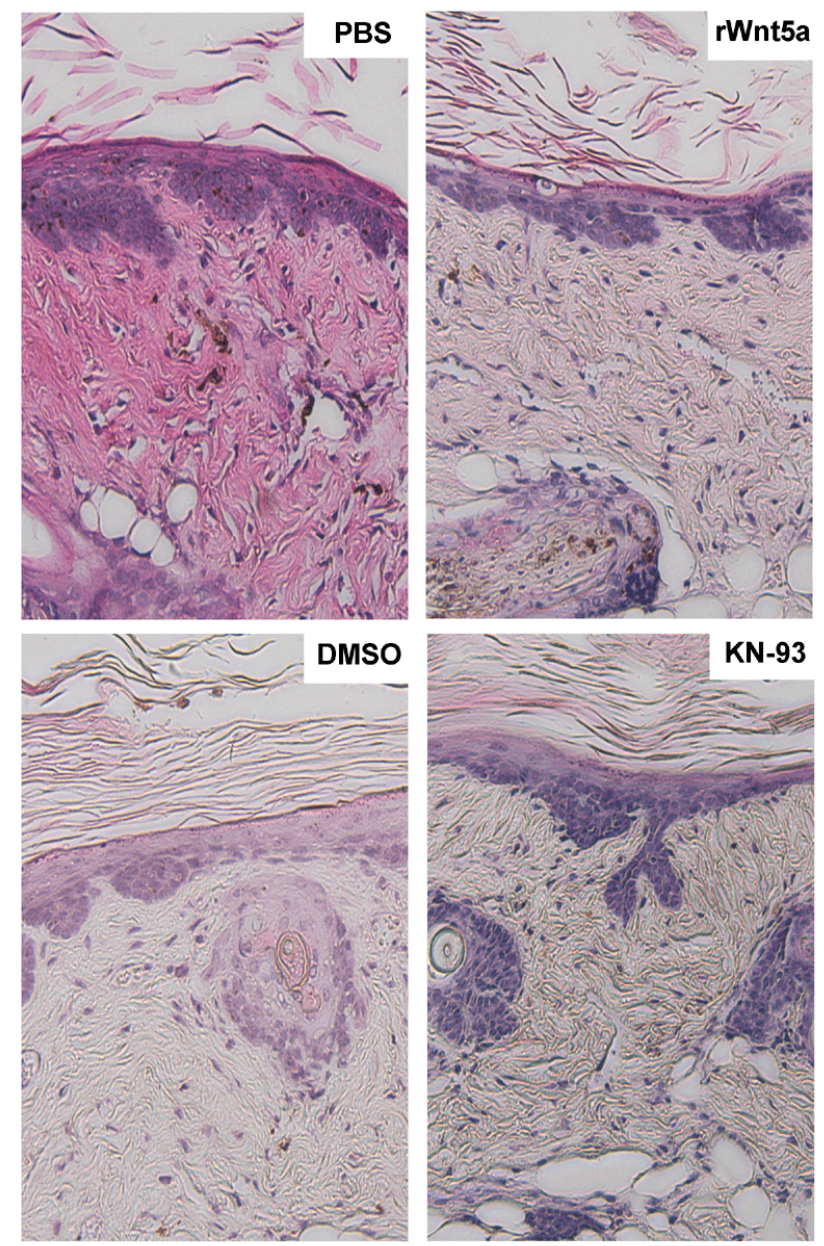

Abbildung 14: Tumorgröße von mit Wnt5a, KN-93 oder Lösungsmittel behandelten BCC-tragenden Hautstanzen. Gezeigt sind die HE-gefärbten Schnitte von repräsentativen Hautstanzen, die für sieben Tage mit rWnt5a, dem Lösungsmittel PBS, dem CaMKII-Inhibitor KN-93 oder dem Lösungsmittel DMSO inkubiert wurden. Die Aufnahme der Fotos erfolgte bei 200facher Vergrößerung.

Eine immunhistochemische Färbung für den Proliferationsmarker Ki67 ist für repräsentative Hautstanzen in Abbildung 15 gezeigt. Eine Quantifizierung des Anteils Ki67 positiver Zellen war aufgrund der zu kleinen Stanzen nicht möglich. Durch intensives Vergleichen der Färbungen wurde subjektiv festgelegt, dass sich die Proliferationsrate nach Inkubation der Gewebestücke mit den Substanzen eher nicht unterscheidet. 


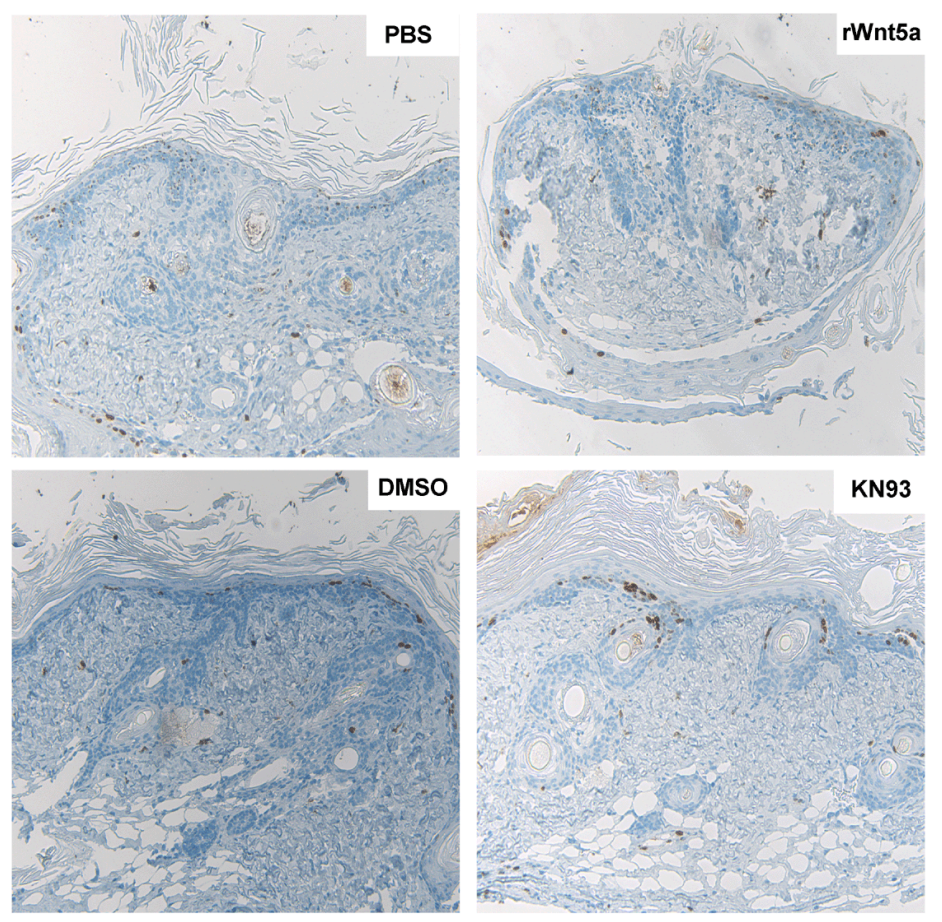

Abbildung 15: Ki67 Expression in BCC-tragenden Hautstanzen nach Behandlung mit Wnt5a, KN-93 oder Lösungsmittel. Gezeigt sind immunhistochemische Färbungen für den Proliferationsmarker Ki67 an Hautstanzen, die für sieben Tage mit rWnt5a, dem Lösungsmittel PBS, dem CaMKII-Inhibitor KN-93 oder dem Lösungsmittel DMSO inkubiert wurden. Die Aufnahmen sind bei 100facher Vergrößerung gemacht worden.

Zusammenfassend kann man festhalten, dass die Hemmung der $K 10$ Expression in den Hautstanzen nicht direkt mit einer Proliferationshemmung assoziiert ist und auch in keiner eindeutigen Änderung der Tumorgröße resultiert.

\subsubsection{Bedeutung anderer Komponenten des Wnt Signalwegs im BCC}

Weiterhin wurden mit Hilfe von RT Profiler PCR Arrays noch weitere Gene des Wnt Signalwegs identifiziert, die in vollentwickelten und regredienten BCC reguliert zu sein scheinen (für die qRT-PCR Analysen wurde die Genexpression von normaler Haut mit derjenigen von vollentwickelten und regredienten BCC miteinander verglichen). Allerdings steht die Validierung der Array-Ergebnisse für viele der Gene noch aus. Für Wnt5a entsprach das ermittelte Genexpressionsmuster jedoch den bereits mehrfach gezeigten Ergebnissen: So konnte auch in der Arrayanalyse gezeigt werden, dass die Wnt5a Expression in den vollentwickelten Tumoren gegenüber der normalen Haut stark ansteigt und auch in den regredienten Stadien erhalten bleibt.

Ein weiteres interessantes und etwas näher untersuchtes Gen, das bei den Arrayanalysen entdeckt wurde, ist der „Wnt inhibitory factor 1“ Wif1. Wif1 interagiert mit Wnt Liganden und blockiert sie dadurch (Hsieh, JC et al. 1999). Allerdings ist bislang unbekannt, ob Wif1 die Inhibierung über den kanonischen oder einen der nichtkanonischen Wnt Signalwege 
vermittelt. Ebenso wie für Wnt5a wird auch die Rolle von Wif1 beim Tumorwachstum kontrovers diskutiert. So wird zum einen berichtet, dass Wif1 in malignen Tumoren wie dem Glioblastom nicht exprimiert wird (Lambiv, WL et al. ; Wissmann, C et al. 2003) und im Melanom epigenetisch abgeschaltet ist (Lin, YC et al. 2007). Andere Studien zeigen dagegen, dass Wif1 in intestinalen Adenomen und beim Kolonkarzinom überexprimiert ist (Cebrat, M et al. 2004).

In den qRT-Profiler Analysen von BCC-Proben schien Wif1 in den vollentwickelten Tumorstadien im Vergleich zur Normalhaut etwa 20-fach überexprimiert zu sein. Obwohl die Expression in regredienten Tumoren abnahm, war sie jedoch gegenüber der normalen Haut immer noch stark erhöht (Daten nicht gezeigt).

Mittels in situ-Hybridisierungen konnte daraufhin gezeigt werden, dass sich die Lokalisation der Wif1 Expression im Laufe der BCC-Entwicklung verändert. So scheint Wif1 in vollentwickelten BCC tumorintrinsisch exprimiert zu werden. Hingegen wird Wif1 bei Regression der Tumoren im Stroma exprimiert (siehe Abbildung 16). Möglicherweise wird auch Wif1 - ähnlich wie Wnt5a - in den regredienten Tumoren in tumorassoziierten Makrophagen exprimiert. Allerdings zeigen die Wif1 exprimierenden Stromazellen keine Makrophagen-ähnliche Morphologie.
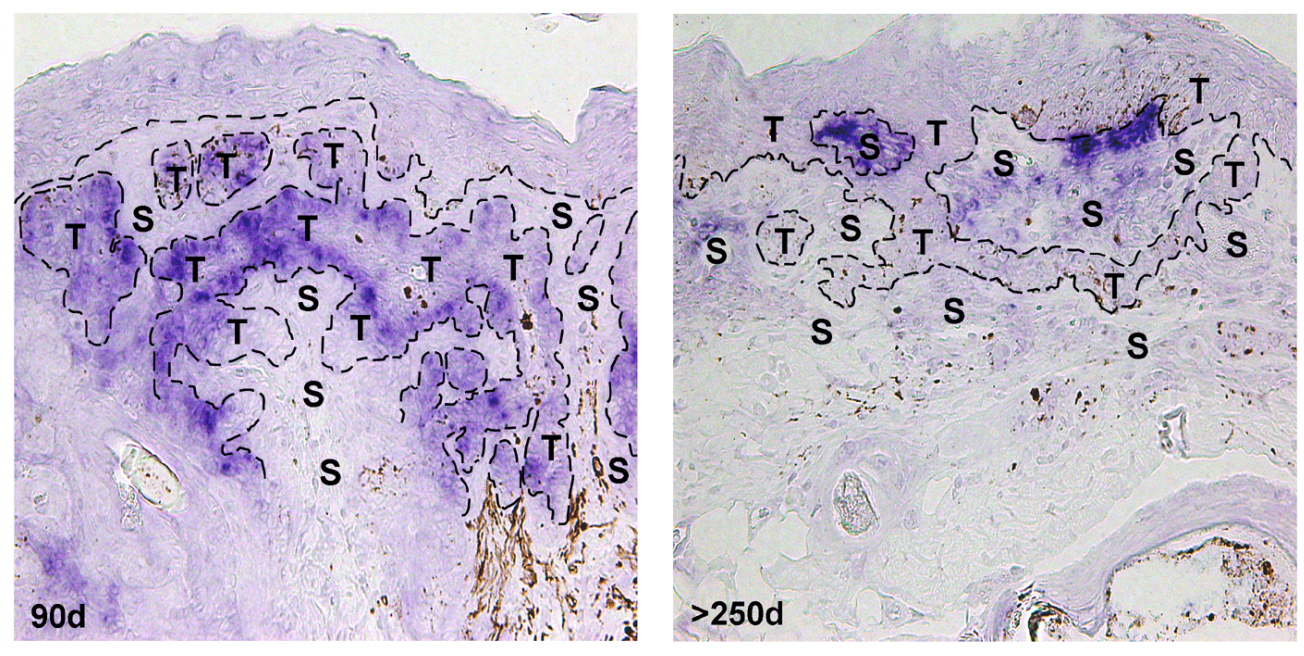

Abbildung 16: Lokalisation der Wif1 Expression verändert sich mit dem Zeitpunkt nach BCCInduktion. Gezeigt sind in situ-Hybridisierungen für Wif1 an einem vollentwickelten (90d) sowie regredienten (>250d) BCC von Ptch floxfflox $E R T 2^{+/-}$Mäusen. Die gestrichelte Linie grenzt den Tumor (T) vom Stroma (S) ab, die Aufnahmen entsprechen einer 200fachen Vergrößerung.

Da sich das Expressionsmuster von Wif1 in vollentwickelten und regredienten BCC so stark unterscheidet, ist die Vermutung naheliegend, dass Wif1 in diesen BCC-Stadien eine völlig unterschiedliche Funktion hat. Es wäre denkbar, dass stromales Wif1 in regredienten BCC möglicherweise Wnt Liganden inhibiert und dadurch das Wnt Signaling im Tumor unterbindet. Die Funktion von Wif1 und seine Rolle bei Progression bzw. Regression des $\mathrm{BCC}$ soll daher in kommenden Folgearbeiten näher charakterisiert werden. 


\subsection{Untersuchung der Effekte von $\mathrm{Ca}^{2+}$ und Wnt5a Überexpression auf BCC im Mausmodell}

\subsubsection{Das Calcium-lonophor lonomycin induziert die BCC-Differenzierung im Mausmodell}

Aus den im vorigen Abschnitt beschriebenen Zellkulturexperimenten geht hervor, dass die Wnt5a-vermittelte $\mathrm{K} 10$ Induktion in ASZ001 über den $\mathrm{Ca}^{2+}$-abhängigen Wnt Signalweg erfolgen könnte. Da dieses Erkenntnis nur auf in vitro Analysen basiert wurde daraufhin untersucht, ob Wnt5a auch in vivo eine Differenzierung der BCC hervorrufen kann. Auch sollte untersucht werden, ob die Differenzierung direkt mit antiproliferativen Vorgängen in Verbindung stehen könnte.

Da man davon ausgehen kann, dass eine Behandlung mit dem Calcium-lonophor lonomycin zur $\mathrm{Ca}^{2+}$ Erhöhung in der Haut führt (Perchellet, EM et al. 1990), wurden $\mathrm{Ptch}^{\text {floxflox }} \mathrm{ERT2}^{+/-}$

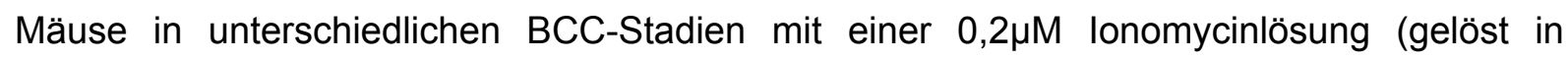
Aceton) behandelt. Kontrollen wurde nur das Lösungsmittel appliziert. Die Behandlung der Tiere erfolgte $5 x$ wöchentlich an drei Kohorten. Dazu wurde entweder unmittelbar (Kohorte 1), 15 Tage (Kohorte 2) oder 45 Tage (Kohorte 3) nach BCC-Induktion durch Tamoxifen (siehe Einleitung) mit der lonomycin-Applikation begonnen. Die Behandlung endete am Tag 90 nach der Tumorinduktion. Die Kontrolltiere erhielten über denselben Zeitraum das Lösungsmittel Aceton.

Alle Tumoren wurden nun histologisch und molekularbiologisch untersucht.

\subsubsection{1 lonomycin hat keinen Einfluss auf die Tumorgröße}

Die Tumorgröße der BCC wurde an HE-Färbungen von Paraffinschnitten mittels der Software cell $^{F}$ bestimmt. Die Abbildung 17 zeigt, dass sich die Tumorgröße zwischen Lösungsmittel-/ und lonomycin-behandelten Tieren in allen drei Kohorten nicht signifikant voneinander unterscheidet.

Somit hat lonomycin offenbar keinen direkten Einfluss auf die Tumorgröße. 


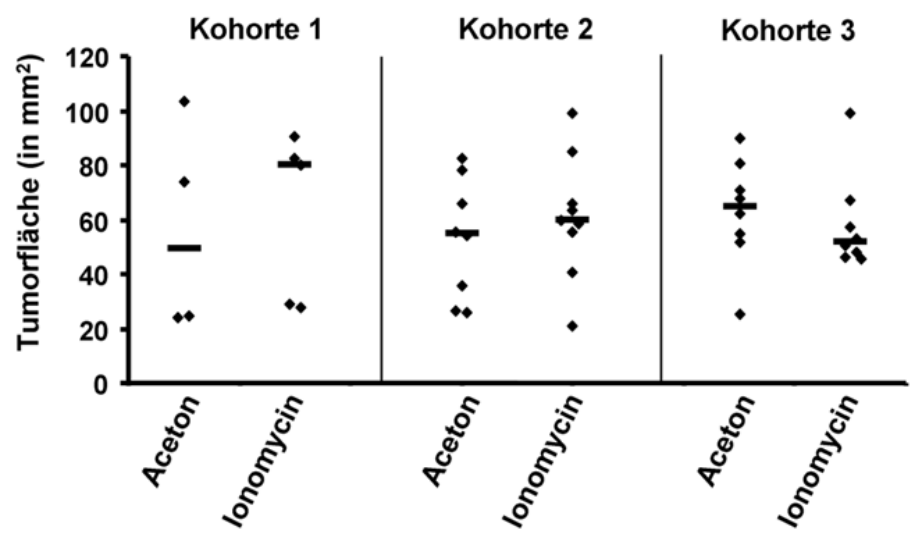

Abbildung 17: Tumorfläche nach Behandlung der Haut mit lonomycin. BCC-tragende $P_{t c h}{ }^{f l o x}$ flox $E R T 2^{+/-}$Mäuse wurden mit $0,2 \mu \mathrm{M}$ lonomycin bzw. dem Lösungsmittel Aceton behandelt. Die Tumorfläche wurde mittels der cell ${ }^{\mathrm{F}}$ Software berechnet und ist in $\mathrm{mm}^{2}$ angegeben. Kohorte 1: Behandlungsbeginn unmittelbar nach BCC-Induktion (Ionomycin $n=5$; Lösungsmittel $n=4$ ); Kohorte 2: Behandlungsbeginn 15 Tage nach BCC-Induktion (Ionomycin $n=9$; Lösungsmittel $n=8$ ) oder Kohorte 3 : Behandlungsbeginn 45 Tage nach BCC-Induktion (lonomycin $n=8$; Lösungsmittel $n=8$ ). Alle Tumoren wurden am Tag 90 nach Tumorinduktion untersucht. Dargestellt sind die analysierten Tumoreinzelwerte und der errechnete Median (-). * signifikant ( $p<0,05$ im t-Test für unabhängige Variablen) gegenüber der Lösungsmittelkontrolle.

\subsubsection{Keine eindeutige Verringerung proliferierender BCC-Zellen durch lonomycin}

Zur Bestimmung der Proliferation wurde mittels immunhistologischer Antikörperfärbung die Expression des Proliferationsmarkers Ki67 quantifiziert. Abbildung 18 zeigt, dass der Proliferationsindex der mit Ionomycin-behandelten Tumoren in Kohorte 1 und Kohorte 3 niedriger ist als der der Lösungsmittel-behandelten BCC. Für die Kohorte 3 ist dieser Effekt sogar signifikant. In der Kohorte 2 konnte keine Änderung des Anteils Ki67 positiver Zellen festgestellt werden.

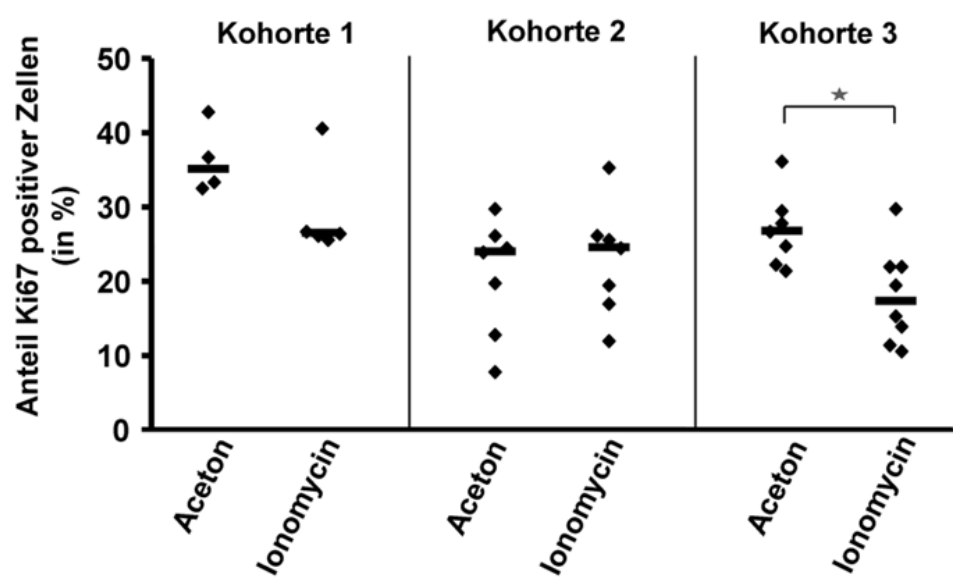

Abbildung 18: Darstellung des Proliferationsindex nach lonomycin-Applikation. BCC-tragende

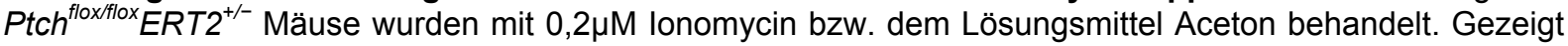
ist der prozentuale Anteil Ki67 positiver Tumorzellen für die drei Kohorten (siehe Text). Alle BCC wurden am Tag 90 nach Tumorinduktion untersucht. Dargestellt sind die analysierten Tumoreinzelwerte und der errechnete Median (-). * signifikant $(p<0,05 \mathrm{im}$ t-Test für unabhängige Variablen) gegenüber der Lösungsmittelkontrolle. 
Diese Ergebnisse zeigen, dass Ionomycin die BCC-Proliferation bzw. die Zahl Ki67 positiver Zellen in BCC tendenziell verringert, wobei die Ergebnisse jedoch nur teilweise signifikant sind.

\subsubsection{3 lonomycin induziert die Expression von Differenzierungsmarkern in BCC}

Eine potentielle Induktion von Differenzierungsmarkern durch lonomycin wurde in BCC der Kohorte 1 analysiert. Diese Kohorte war am längsten mit lonomycin behandelt worden, da die Applikation unmittelbar nach Tumorinduktion begonnen und für 90 Tage fortgeführt wurde.

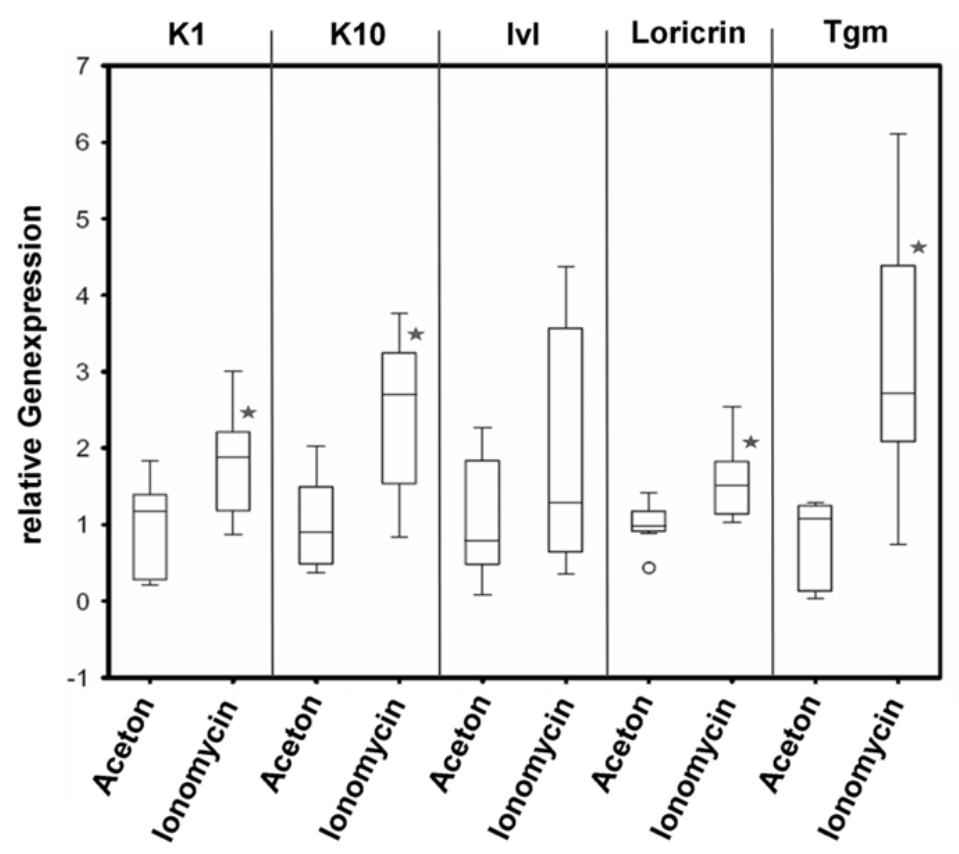

Abbildung 19: Expression von Differenzierungsmarkern in BCC-tragender Haut nach lonomycinApplikation. Untersucht wurde die Expression in Ionomycin $(n=5)$ und Lösungsmittel behandelten $(n=4)$ BCC-Proben der Kohorte 1 mittels qRT-PCR. Die genspezifische Expression wurde zunächst auf die Expression von 18sRNA normalisiert. Die Messung pro Einzelprobe erfolgte in Triplikaten. Alle Messungen sind als Box-Whisker-Plot und in Relation zur Lösungsmittel-Kontrolle, deren mittlere Expression auf 1 gesetzt wurde, dargestellt. * signifikant $(p<0,05$ im t-Test für unabhängige Variablen) gegenüber der Lösungsmittelkontrolle. Legende: $\circ$ Ausreißer.

Es wurde sowohl die Expression der frühen Differenzierungsmarker $K 1$ und $K 10$, als auch die der späten Differenzierungsmarker Involucrin (IVl), Loricrin und Transglutaminase (Tgm) untersucht. Wie die Abbildung 19 zeigt wird für alle getesteten Marker in den lonomycinbehandelten Tumoren eine erhöhte Genexpression gemessen. Mit Ausnahme von Involucrin ist dieser Effekt signifikant.

Aus dieser Analyse geht eindeutig hervor, dass Ionomycin die Expression von Differenzierungsmarkern im BCC induzieren kann. 
Zusammengefasst lässt sich sagen, dass lonomycin zur Expression von Differenzierungsmarkern im BCC führt. Wenn man davon ausgeht, dass die durch lonomycin bedingten Effekte durch eine $\mathrm{Ca}^{2+}$ Erhöhung hervorgerufen werden, wird $K 10$ tatsächlich durch $\mathrm{Ca}^{2+}$ induziert. Dies würde auch die im Kapitel 4.1.4 aufgestellte Hypothese, dass $K 10$ durch den $\mathrm{Wnt} / \mathrm{Ca}^{2+}$ Signalweg induziert werden kann, unterstützen. Jedoch hat lonomycin gleichzeitig keinen direkten Einfluss auf Größe und Proliferation der Tumoren. Daher zeigen diese Daten, dass Differenzierungsvorgänge eher nicht in die Regression des BCC involviert sind.

\subsubsection{Einfluss einer Wnt5a Überexpression auf BCC: Vorarbeiten}

Um den Einfluss von Wnt5a auf BCC im Mausmodell zu untersuchen, sollte Wnt5a durch Spritzen einer nackten Plasmid-DNA in der Haut überexprimiert werden. Die sich anschließenden Analysen in Hinblick auf Größe und Differenzierung der Tumoren können Aufschluss über die Rolle von Wnt5a bei der Regression von BCC geben.

Dass die Überexpression von nackter Plasmid-DNA in vivo möglich ist, konnte bereits vor über einem Jahrzehnt gezeigt werden (Hengge, UR et al. 1996). Zur Etablierung der Methode in unserem Labor wurde zunächst ein ßGalaktosidase-kodierendes Plasmid in der Haut exprimiert. Um ein geeignetes Spritzschema zu etablieren, wurde den Mäusen

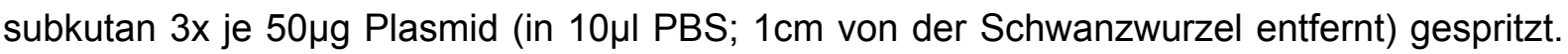
Den Kontrollen wurde das gleiche Volumen PBS injiziert. Zwischen den Injektionen wurde jeweils ein Tag pausiert. 24h bzw. sieben Tage nach der letzten Applikation wurde dann eine X-Gal-Färbung des behandelten Hautareals durchgeführt.
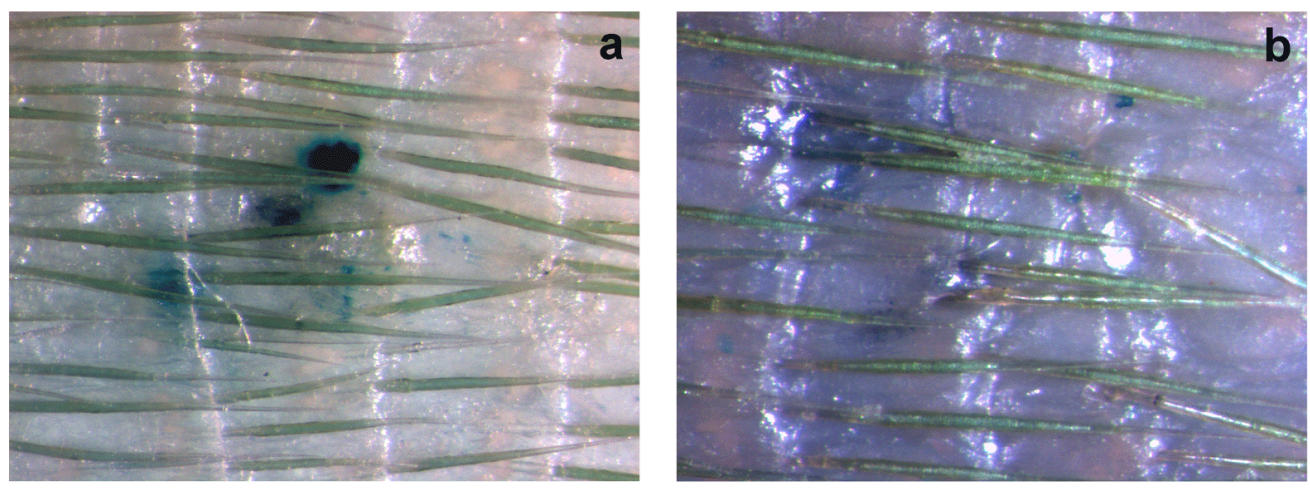

Abbildung 20: ßGalaktosidase-Aktivität in Haut nach Injektion eines ßGalaktosidase-exprimierenden Plasmids. Gezeigt ist die ßGalaktosidase-Aktivität in Plasmid-gespritzter Schwanzhaut mittels X-Gal-

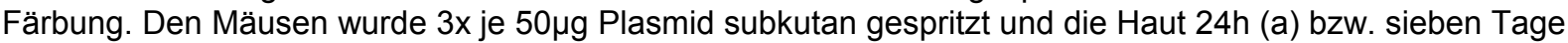
(b) nach der letzten Injektion isoliert. Die Aufnahme der Fotos erfolgte bei 10facher Vergrößerung.

Mittels X-Gal-Färbung war es möglich die Aktivität der ßGalaktosidase im Gewebe sichtbar zu machen (Abbildung 20). Dazu wurde die Haut vier Tage in der Färbelösung inkubiert, PBS-gespritzte Kontrollen zeigten dagegen keinerlei Färbung (Daten nicht gezeigt). 
Die ßGalaktosidase-Aktivität war lediglich auf das Plasmid-gespritzte Areal limitiert. Die Abbildung 20 lässt vermuten, dass $24 \mathrm{~h}$ nach der letzten Injektion eine etwas höhere ßGalaktosidase-Aktivität vorliegen könnte (Abbildung 20, a).

Nach der Etablierung der Methode sollte dann versucht werden, Wnt5a in der Haut überzuexprimieren. Hierzu wurde zunächst das pWnt5a(murin)-pcDNA3 Plasmid eingesetzt. Die Ergebnisse zeigten jedoch, dass sich dieses Plasmid nicht in der Haut exprimieren ließ (Daten nicht gezeigt).

Daher wurde ein neues Wnt5a-Expressionsplasmid (mWnt5a-Kozak-pcDNA3) kloniert. Dieses neue Plasmid enthielt zusätzlich eine Kozak-Konsensus-Sequenz, welche die Expression von cDNAs verbessern kann. Um mögliche weitere Fehlerquellen in den zukünftigen in vivo Versuchen auszuschließen, erfolgte die Sequenzierung des neuen Plasmids. Tatsächlich wurde dabei ein SNP entdeckt, der jedoch mit anschließender zielgerichteter Mutagenese (site-directed mutagenesis) wieder ausgetauscht wurde. Das Plasmid wurde dann in NIH3T3-Zellen exprimiert. Hierzu wurden $2 \mu \mathrm{g}$ des Plasmids bzw. des Kontrollvektors transfiziert. Die Isolierung der Zellen erfolgte 48h nach der Transfektion und die Proteinlysate wurden im Western Blot analysiert.

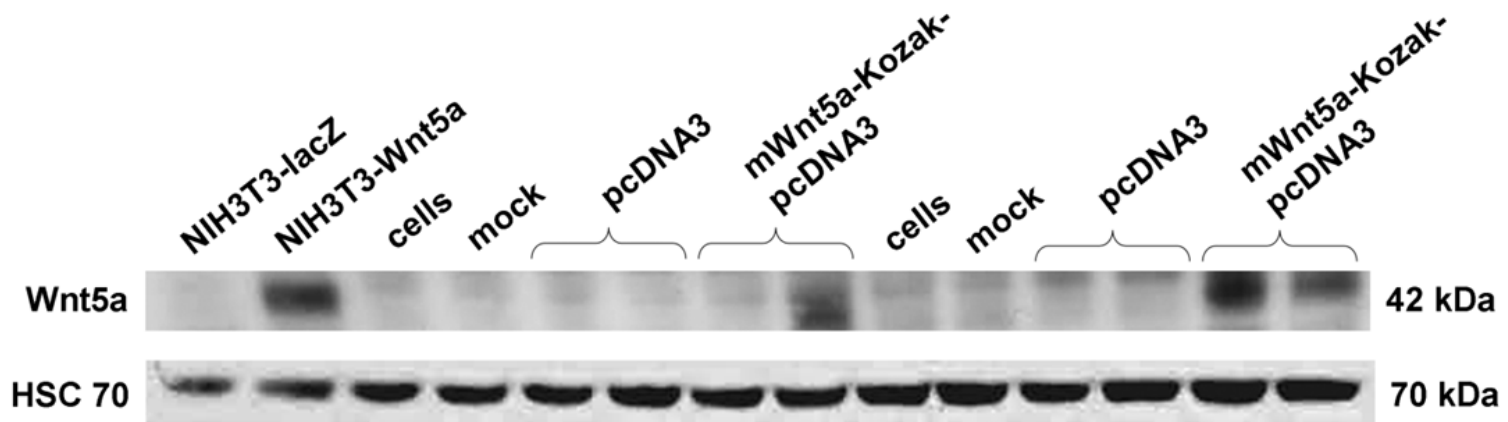

Abbildung 21: Analyse der Wnt5a Expression nach Transfektion des mWnt5a-Kozak-pcDNA3 Plasmids in NIH3T3-Zellen. Gezeigt ist die Proteinexpression von Wnt5a mittels Western Blot nach Transfektion von NIH3T3 mit $2 \mu \mathrm{g}$ Wnt5a-Expressionsplasmid (mWnt5a-Kozak-pcDNA3) bzw. dem entsprechenden Kontrollvektor (pcDNA3). Als Positivkontrolle wurden NIH3T3-Wnt5a und als Negativkontrolle NIH3T3-lacZ eingesetzt. Die Konzentration der aufgetragenen Proteinlysate betrug $18 \mu \mathrm{g}$. Die Analyse von HSC70 (housekeeper) diente der Verifizierung gleicher Proteinmengen. Abkürzungen: cells, unbehandelte NIH3T3; mock, mit Transfektionsreagenz behandelte NIH3T3.

Der in Abbildung 21 dargestellte Western Blot zeigt, dass im Proteinlysat der NIH3T3-Wnt5a (Positivkontrolle) eindeutig Wnt5a überexprimiert wird. Weiterhin wird Wnt5a in den mit Wnt5a-Expressionsplasmid transfizierten Zellen exprimiert. In den entsprechenden Kontrolllysaten ( $p c D N A 3)$ wird dagegen kein Wnt5a-Signal detektiert. In einem der vier analysierten Proteinlysate (mit Wnt5a-Expressionsplasmid transfizierte Zellen) kann keine Wnt5a Überexpression nachgewiesen werden, wobei dies jedoch mit mangelnder Transfektionseffizienz zusammenhängen könnte. 
Aufgrund dieser Analysen kann das Expressionsplasmid mWnt5a-Kozak-pcDNA3 zukünftig in BCC-tragenden Ptch flox/flox ERT2 ${ }^{+-}$Mäusen zur Überexpression von Wnt5a in vivo genutzt werden. Leider war dies aufgrund von Zeitmangel im Rahmen dieser Dissertation nicht möglich.

\subsection{Untersuchung der Effekte einer verminderten Wnt5a Expression auf BCC im Mausmodell}

Um den Einfluss von Wnt5a auf BCC in vivo zu untersuchen, wurde versucht die Wnt5a Expression im Mausmodell zu vermindern. Falls unsere Hypothese, dass Wnt5a im BCC als Tumorsuppressor agiert, zutreffen sollte, müssten BCC der Maus nach Verminderung der Wnt5a Expression ein verstärktes Wachstum zeigen. Um die Wnt5a Expression zu reduzieren, wurden drei verschiedene experimentelle Ansätze verfolgt. Hierbei handelt es

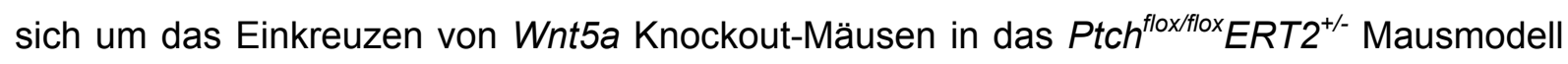
als genetischer Ansatz, das Ersetzen von wildtypischen Makrophagen durch Wnt5a-/Makropagen, und die Depletion von Wnt5a-exprimierenden Makrophagen durch eine systemische Gabe von Clodrolip.

\subsubsection{Genetischer Ansatz zur Reduzierung der Wnt5a Expression im BCC- Mausmodell}

Um die Expression von Wnt5a in vivo zu vermindern, wurden Ptch $^{f l o x / f l o x} E R T 2^{+/-}$Mäuse mit heterozygoten Wnt5a+/- Knockout-Mäusen verpaart. Da Wnt5a-/- Knockout-Mäuse perinatal sterben (Yamaguchi, TP et al. 1999), konnten nur $\mathrm{Ptch}^{\text {floxfllox}} E R T 2^{+/-} W_{n t 5 a^{+/-}}$generiert werden. In den Ptch flox/flox ERT2 ${ }^{+/-} W n t 5 a^{+/-}$Mäusen wurden dann mittels Tamoxifeninjektion BCC induziert. Als Kontrollen wurden BCC in Ptch ${ }^{\text {floxflox }} E R T 2^{+/-}$Mäusen induziert.

Die BCC wurden dann zu drei unterschiedlichen Zeitpunkten nach Tumorinduktion analysiert: nach 45 Tagen (Kohorte1 Wnt5a+/- $n=11$; Wnt5a+/+ $n=10$ ), nach 90 Tagen (Kohorte2 Wnt5a+/- n=10; Wnt5a+/+ n=10) und nach 250 Tagen (Kohorte 3 Wnt5a+/- n=10; Wnt5a+/+ n=12). Die entsprechenden Tumoren wurden hinsichtlich ihrer Wnt5a Expression sowie der generellen Tumorgröße analysiert. Darüber hinaus wurde die gesamte Haut auf etwaige hyperplastische Veränderungen untersucht. 


\subsubsection{Keine signifikante Reduzierung der Wnt5a Expression in Ptch $^{\text {flox/flox }}$ ERT2 $^{+/-}$Wnt5a $^{+-}$Mäusen}

Eine qRT-PCR Analyse zeigte, dass die Wnt5a Expression in den $\mathrm{Ptch}^{\text {floxflox }} E R T 2^{+/-} \mathrm{Wnt}_{5 a^{+-}}$ Mäusen in allen drei untersuchten Kohorten keine signifikanten Unterschiede im Vergleich zu $\mathrm{Ptch}^{\text {flox/flox }} \mathrm{ERT2}^{+/-}$Mäusen aufwies (Abbildung 22).

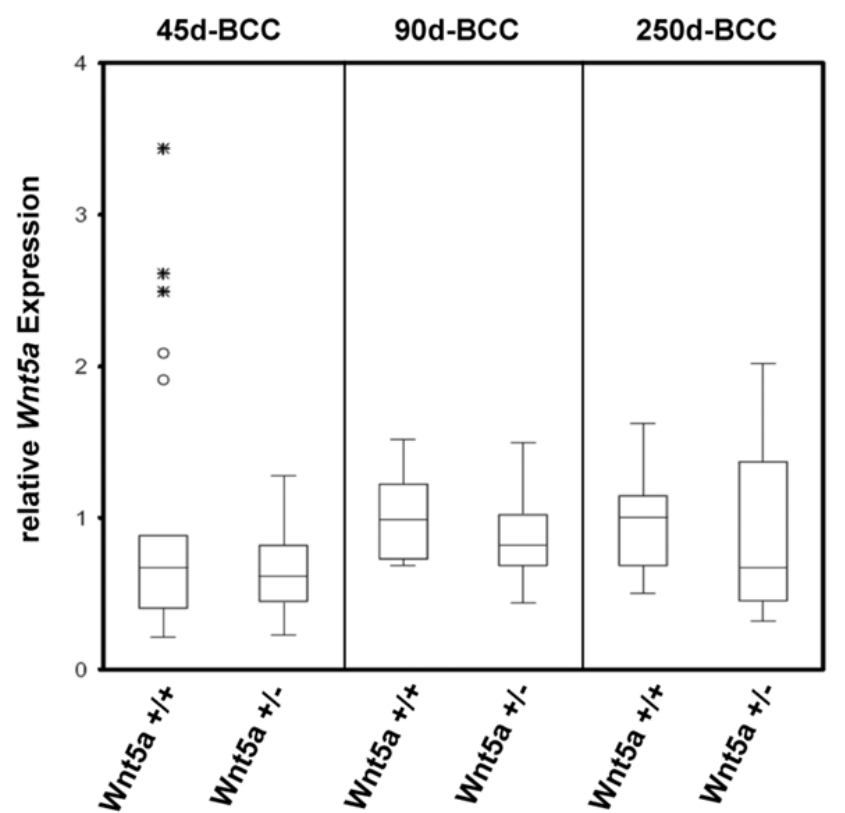

Abbildung 22: Analyse der Wnt5a Expression in verschiedenen BCC-Stadien in

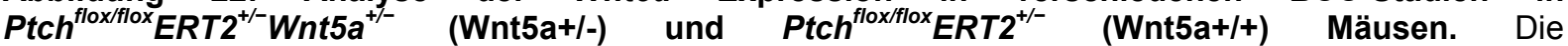
Genexpressionsanalyse wurde in drei verschiedenen BCC-Stadien (45, 90 und 250 Tage nach BCC Induktion) durchgeführt. Untersucht wurde die Expression in BCC von Wnt5a+/+ und Wnt5a+/- Mäusen (Anzahl, siehe Text) mittels qRT-PCR. Die genspezifische Expression wurde zunächst auf die Expression von 18sRNA normalisiert. Die Messung pro Einzelprobe erfolgte in Triplikaten und alle Messungen sind als Box-Whisker-Plot und in Relation zur Kontrolle dargestellt. Abkürzungen/Legende: $d$, Tage; * signifikant $(p<0,05$ im t-Test für unabhängige Variablen) gegenüber der Kontrolle; $\circ$ Ausreißer; * Extremwert.

\subsubsection{Keine signifikante Veränderung der BCC-Größe in Ptch $^{\text {flox/flox }}$ ERT2 $^{+/-}$Wnt $a^{+/-}$Mäusen}

Wie der Abbildung $23 \mathrm{zu}$ entnehmen ist, zeigt das Tumorareal in keiner der drei analysierten Kohorten einen signifikanten Unterschied zwischen $\mathrm{Ptch}^{\mathrm{flox} / \mathrm{flox}} \mathrm{ERT2}^{+/-} \mathrm{Wnt}_{5} \mathrm{a}^{+/-}$und

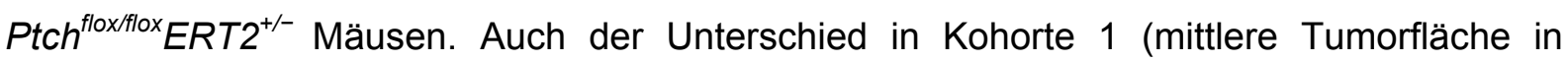

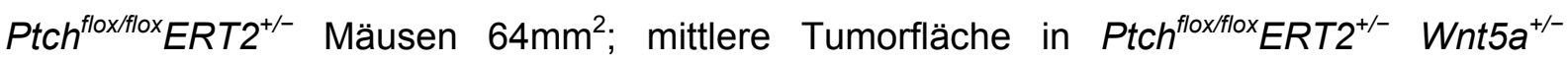
Mäusen $44 \mathrm{~mm}^{2}$ ) ist nicht signfikant. Zudem wird deutlich, dass die berechnete Tumorfläche der vollentwickelten BCC (Kohorte 2, mittlere Tumorfläche etwa $86 \mathrm{~mm}^{2}$ ) im Vergleich zu denen der regredienten BCC (Kohorte 3 , mittlere Tumorfläche $30 \mathrm{~mm}^{2}$ ) sehr groß ist. Da sich hierbei Ptch $^{\text {floxfflox}} E R T 2^{+/-}$Kontrollmäuse nicht von Ptch floxfflox $E R T 2^{+/-} W_{n t 5 a^{+/-}}$Mäusen 
unterscheiden, kann man davon ausgehen, dass eine Wnt5a Heterozygotie keinen Einfluss auf die Regression von BCC hat

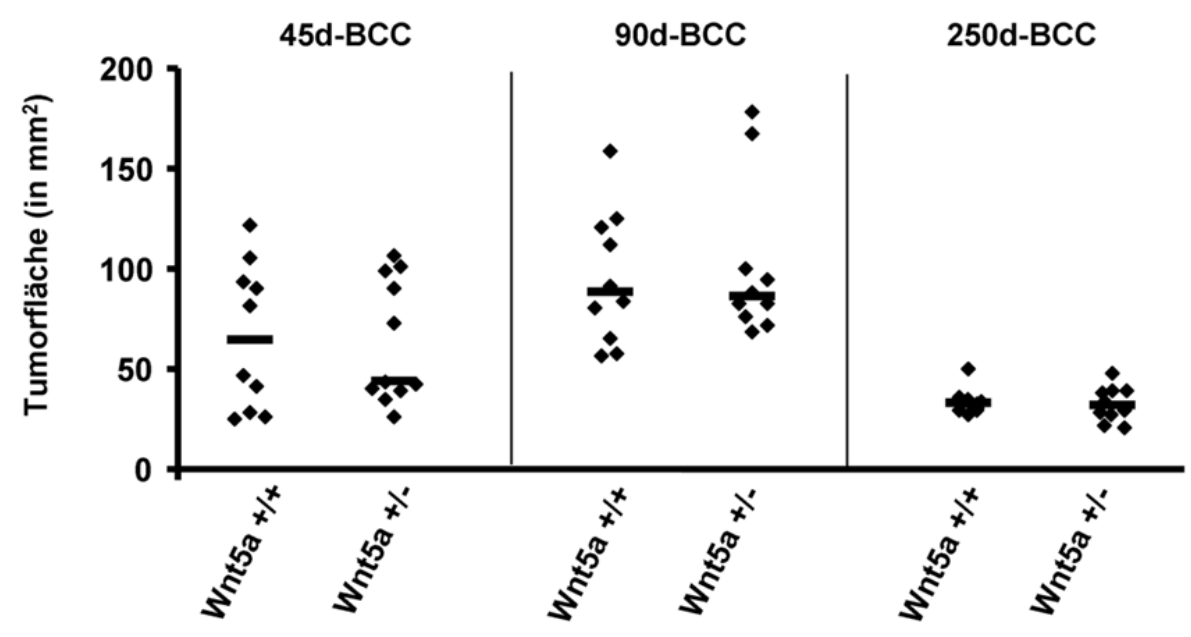

Abbildung 23: Vergleich der Tumorgröße zwischen Ptch $^{\text {flox/flox } E R T 2^{+/-} W_{n t 5 a} a^{+-}}($Wnt5a+/-) und Ptch $^{\text {flox/flox }}$ ERT2 $^{+/-}$(Wnt5a+/+) Mäusen. Die Tumoren wurden zu drei unterschiedlichen Zeitpunkten (45, 90 und 250 Tage nach BCC Induktion) analysiert. Dargestellt sind die ermittelten Tumoreinzelwerte (Anzahl analysierter BCC: Kohorte 1, n=21; Kohorte 2, n=20 und Kohorte 3, n=22) und ihr errechneter Median (-). * signifikant $(p<0,05$ im t-Test für unabhängige Variablen) gegenüber der Kontrolle.

Zusammengefasst zeigen die Daten, dass sich in keiner der drei analysierten Kohorten die Tumorgröße der $\mathrm{Ptch}^{\text {floxfllox}} \mathrm{ERT2}^{+/-} \mathrm{Wnt}_{5 \mathrm{a}^{+/-}}$Mäuse signifikant von der BCC-Größe der

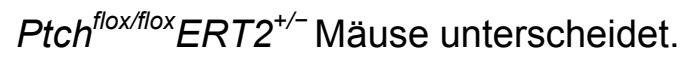

\subsubsection{Epidermale Hyperplasien in Ptch ${ }^{\text {flox/flox }} \mathrm{ERT2}^{+/-}$Wnt5a $^{+/-}$Mäusen}

Eine der Ptch ${ }^{f l o x / f l o x} E R T 2^{+/} W_{n t 5 a^{+-}}$Mäuse der Kohorte 3 wurde drei Monate nach Tumorinduktion phänotypisch auffällig. So zeigte die Maus im Nacken blutig-schorfige Bereiche auf, die nicht abheilten, erhaben waren und sich vergrößerten. Das Tier wurde bis zum Abtöten regelmäßig observiert, zeigte jedoch keine weiteren Auffälligkeiten. 250 Tage nach Tumorinduktion wurden die auffälligen Hautareale histologisch analysiert.

Die Abbildung 24a zeigt den auffälligen Nackenbereich. In Abbildung 24b ist der entsprechende Nackenbereich im HE-gefärbten Paraffinschnitt gezeigt. Neben einer abnorm verdickten Epidermis weisen die Areale eine papillomartige Struktur auf. Es handelt sich jedoch weder um ein BCC noch um ein Plattenepithelkarzinom. Papillomartige

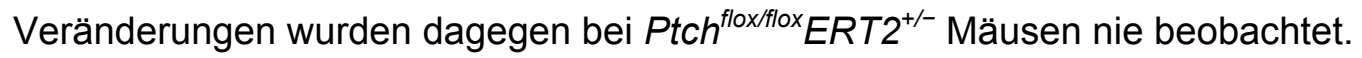



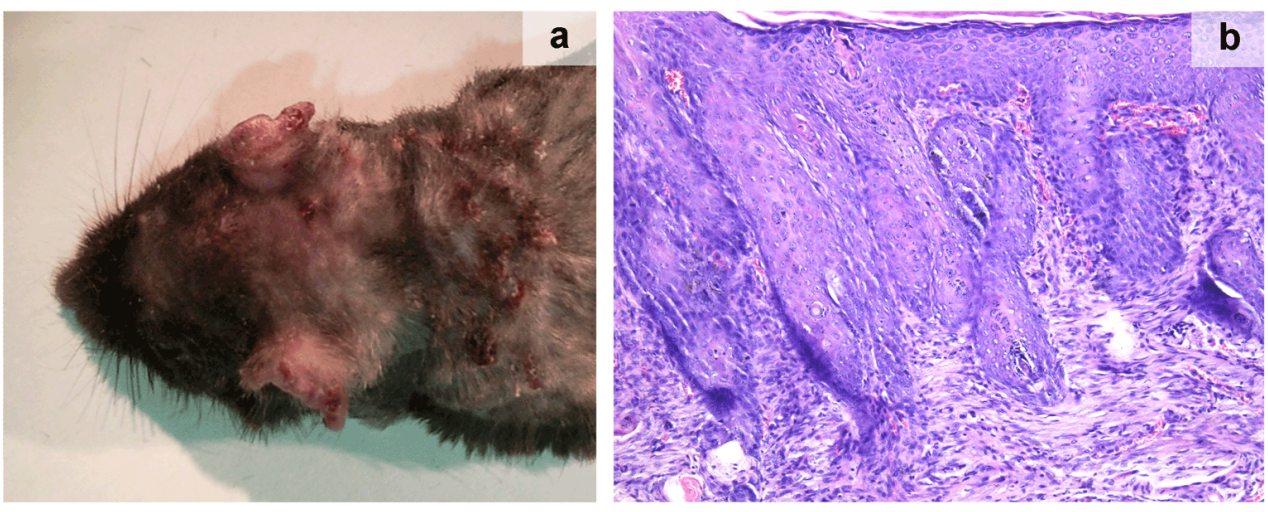

Abbildung 24: Papillomartige Veränderungen der Haut in einer Ptch ${ }^{\text {flox/flox }} E_{R T 2^{+/}}$Wnt5a $^{+/-}$Maus. Dargestellt sind die phänotypische Erscheinung (a) sowie der HE-gefärbte Paraffinschnitt der Haut (b, 100fache Vergrößerung) einer Ptch flox/flox $E R T 2^{+/}$Wnt5a $^{+-}$Maus 250 Tage nach Tumorinduktion.

Kleinere hyperproliferative Hautareale konnten jedoch sowohl in $\mathrm{Ptch}^{\text {floxflox }} E R T 2^{+/-} \mathrm{Wnt}_{5 a^{+/-}}$ Mäusen als auch in Ptch floxfflox ERT2 ${ }^{+/-}$Mäusen der Kohorte 3 detektiert werden (Abbildung

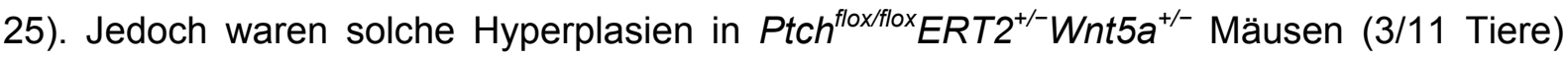

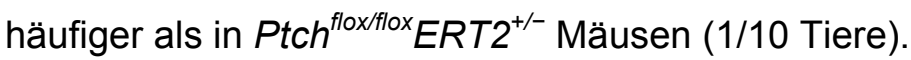
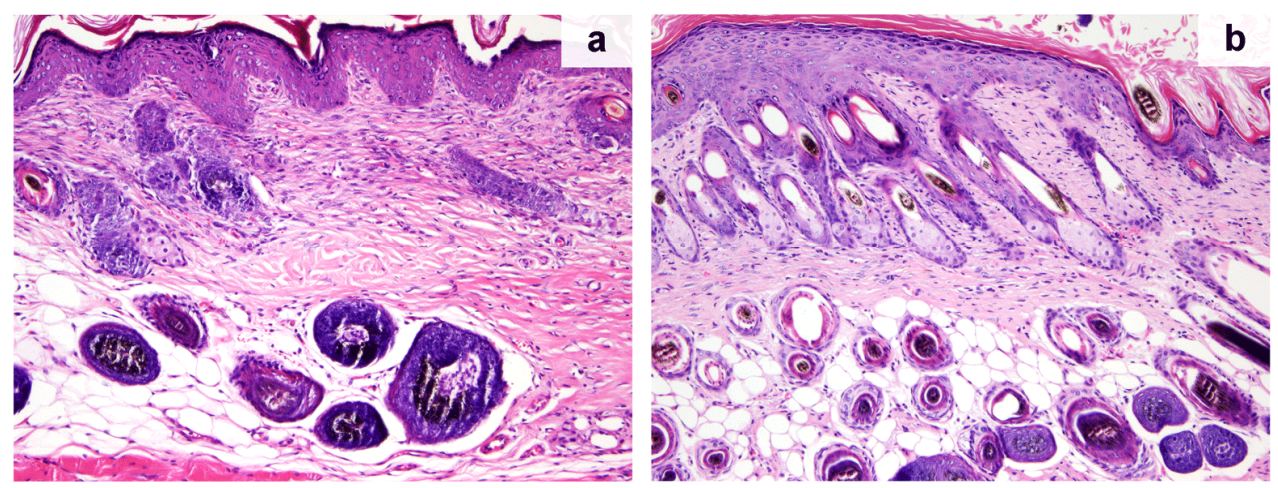

Abbildung 25: Hyperproliferative Bereiche behaarter Haut von Ptch $^{\text {flox/flox }}$ ERT2 $^{+/-}$Wnt5a $^{+/-}\left(\mathrm{Wnt}^{\mathrm{a}} \mathrm{a}^{+/-}\right)$ und Ptch flox/flox ERT2 ${ }^{+/-}($Wnt5a+/+) Mäusen. Dargestellt sind HE-gefärbte Paraffinschnitte von der Rückenhaut einer Wnt5a+/- Maus (a) und von der Nackenhaut einer Wnt5a+/+ Maus (b) 250 Tage nach Tumorinduktion. Die Fotos wurden bei 100facher Vergrößerung aufgenommen.

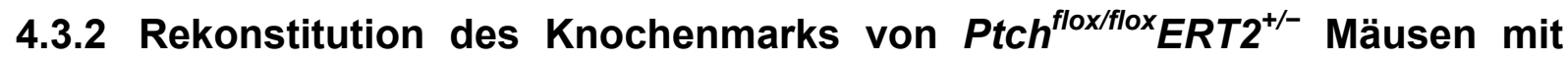 Wnt5a-defizienten Zellen}

Wie in der Einleitung beschrieben, ist die spontane Regression der BCC mit der Induktion von Wnt5a in Makrophagen assoziiert. Daher sollte in einem weiteren experimentellen Ansatz versucht werden, Wnt5a-exprimierende Makrophagen durch Wnt5a-defiziente zu ersetzen.

Dazu wurden Ptch $^{\text {floxflox }} E R T 2^{+/-}$Mäuse mit einer letalen Dosis bestrahlt. Am nächsten Tag wurden sie mit Leberzellen aus Wnt5a-defizienten (Wnt5a-/-) Embryonen transplantiert. 
Kontrollen erhielten Leberzellen aus wildtypischen Embryonen (Wnt5a+/+). Das genaue Vorgehen ist in Kapitel 3.4.6 beschrieben.

Nach mehreren vergeblichen Versuchen, konnten schließlich alle Mäuse erfolgreich transplantiert werden. Sechs Wochen nach der Transplantation der Leberzellen wurden die Tiere auf eine erfolgreiche Rekonstitution des Immunsystems untersucht. Dazu wurden B-I und T-Zellen im Blut der Mäuse mittels FACS analysiert. Alle 14 bestrahlten bzw. transplantierten Mäuse haben innerhalb der sechs Wochen wieder ein intaktes Immunsystem mit normaler Lymphozytenanzahl aufgebaut (Daten nicht gezeigt).

Weiterhin wurde das Blut und die DNA von Körperzellen (isoliert aus Schwanzbiopsien) der

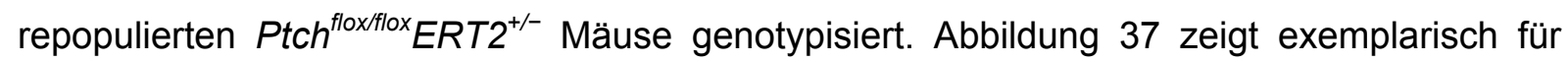
vier der Tiere die DNA-Analyse des Blutes und der Schwanzhaut hinsichtlich der Expression wichtiger Gene, die zum Nachweis der erfolgreichen Substitution des Knochenmarks bedeutsam sind.

Alle vier Ptch floxfllox ERT2 ${ }^{+/-}$Mäuse zeigen bei der Analyse somatischer DNA die Wnt5a Wildtyp-Bande (Abbildung 26a, oben). Diese Wildtyp-Bande findet sich auch in der Analyse des Blutes für die Tiere \#1 und \#2, denen Leberzellen aus wildtypischen Embryonen injiziert wurden. Hingegen erhielten die Tiere \#3 und \#4 Leberzellen aus Wnt5a-defizienten Embryonen. Bei diesen Tieren wird in Blut-DNA tatsächlich das Wnt5a Knockout-Allel detektiert (Abbildung 26b, oben).

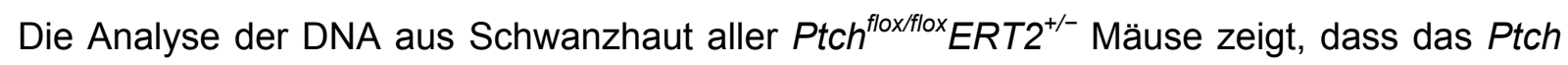
Allel gefloxt ist und auch die Cre-Rekombinase vorhanden ist. Bei der Analyse des Blutes wird jedoch deutlich, dass die Tiere nach erfolgreicher Repopulation durch die fötalen Leberzellen (unabhängig vom Genotyp der transplantierten Zellen) wieder wildtypisch für

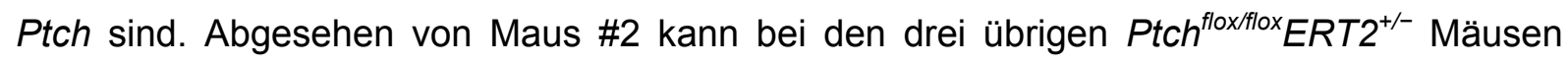
nach der Repopulation keine Cre-Rekombinase im Blut mehr detektiert werden. Auch kann das gefloxte Ptch Allel nicht mehr nachgewiesen werden. Maus \#2 dagegen zeigt neben dem Wildtyp Ptch Allel auch das gefloxte Allel. Weiterhin kann in dieser Maus auch die CreRekombinase in der Blut-DNA nachgewiesen werden. Dies bedeutet, dass in diesem Tier das Knochenmark durch die Bestrahlung nicht vollständig eliminiert wurde. Ein solcher Chimärismus konnte bei 5/14 Mäusen nachgewiesen werden. 


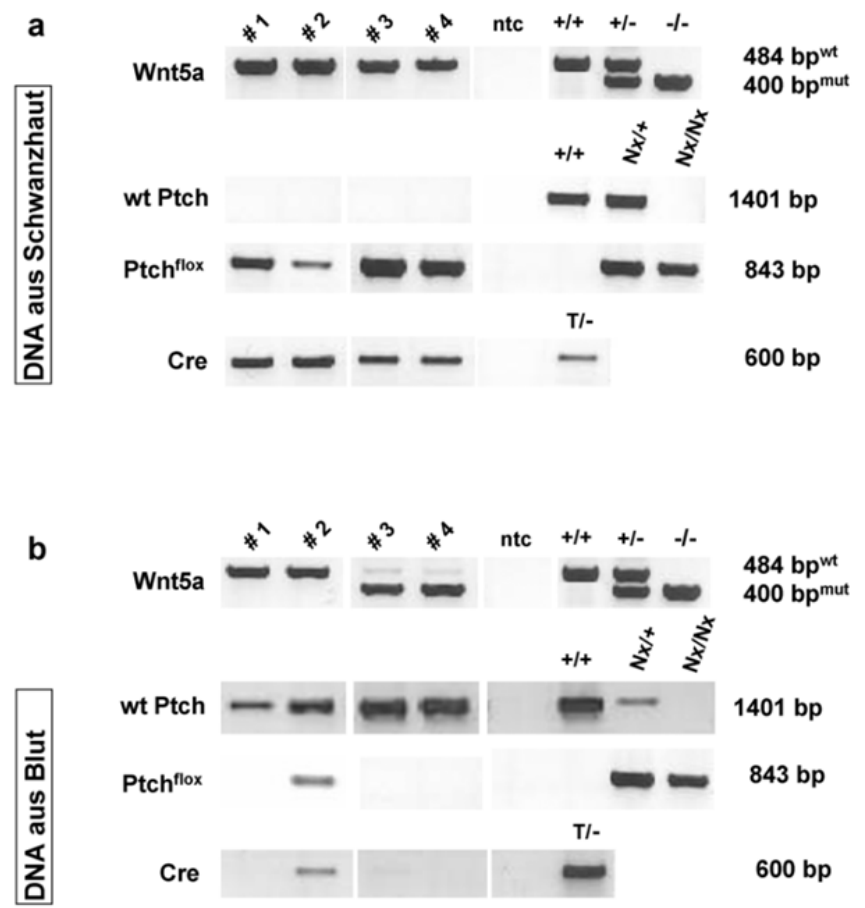

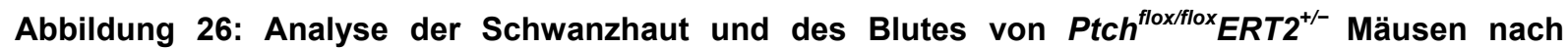
Transplantation mit fötalen Leberzellen. Gezeigt sind RT-PCR-Analysen an DNA von Schwanzbiopsien und des Blutes von Ptch floxflox ERT2 $2^{+-}$Mäusen nach erfolgreicher Repopulation des Knochenmarks durch Leberzellen aus wildtypischen Embryonen (Maus \#1 und Maus \#2) oder Wnt5a-defizienten Leberzellen (Maus \#3 und Maus \#4). Die Analysen wurden sechs Wochen nach erfolgter Transplantation der fötalen Leberzellen durchgeführt. Abkürzungen: ntc, Negativkontrolle (engl. no template control).

Nach dieser Überprüfung wurde den Tieren Tamoxifen zur Induktion von BCC injiziert. Die Tumoren werden 90 Tage nach Tumorinitiation hinsichtlich ihrer Größe, Proliferation und des Differenzierungsstatus analysiert. Das Experiment konnte leider vor Abgabe dieser Doktorarbeit nicht abgeschlossen werden.

\subsubsection{Applikation von Clodrolip zur Depletion von Wnt5a-exprimierenden Makrophagen}

Wie bereits mehrfach erwähnt, wird die Spontanregression der BCC in Ptch $^{\text {floxflox }} \mathrm{ERT2}^{+/-}$ Mäusen mit der Wnt5a Expression in Makrophagen in Verbindung gebracht. In einem weiteren experimentellen Ansatz wurde daher versucht, diese Wnt5a-exprimierenden Makrophagen im BCC-Stroma zu depletieren. Diese Depletion erfolgte durch Applikation von Clodrolip, das freundlicherweise von R. Schwendener (Institut für Molekulare Krebsforschung, Universität Zürich, Schweiz) zur Verfügung gestellt wurde. Bei Clodrolip handelt es sich um in Liposomen-verpacktes Clodronat, ein Bisphosphonat. Bisphosphonate sind Medikamente, die normalerweise für diagnostische und therapeutische Zwecke bei Knochen-/ sowie Calciumstoffwechselkrankheiten eingesetzt werden. Sie haben eine hohe Affinität zu anorganischen Calciumverbindungen, binden also an Knochensubstanz. 
Bisphosphonate, wie Clodronat, werden in der Klinik gegen Knochenmetastasen und wegen der hohen Endocytosekapazität von Osteoklasten gegen Knochenresorption eingesetzt (Henneman, ZJ et al. 2008).

BCC wurden in Ptch floxflox ERT2 ${ }^{+/}$Mäusen durch Tamoxifengabe induziert. Am Tag 15 nach BCC-Induktion wurden die Tiere dann mit Clodrolip $(n=7)$ bzw. Leerliposomen $(n=4)$ behandelt. Die Applikation erfolgte jeden vierten Tag (erste Dosis $2 \mathrm{mg} / 20 \mathrm{~g}$; folgende Dosen $1 \mathrm{mg} / 20 \mathrm{~g}$ - siehe auch Kapitel 3.4.5.4). Dieses Schema wurde gewählt, damit jegliche einsetzende Wnt5a Expression in der Haut von Beginn an verhindert wird. Durch in situHybridisierungen in verschiedenen Tumorstadien war ja bekannt, dass in den Vorläuferläsionen (45 Tage nach Tumorinduktion) noch kein Wnt5a exprimiert wird. Somit wird durch die rechtzeitige Applikation von Clodrolip (also an Tag 15 nach Tumorinduktion) die mögliche Wnt5a Expression sogleich unterbunden. Die Behandlung endete nach 75 Tagen.

Auch wurden drei Ptch ${ }^{\text {floxflox }}$ Mäuse ohne BCC mit Clodrolip behandelt, um einen Einfluss der Substanz auf Normalhaut zu überprüfen. Analysen von HE-gefärbten Hautschnitten der letzteren Tiere zeigten jedoch keine Auffälligkeiten.

\subsubsection{Effiziente Depletion von Makrophagen in Milz und Haut durch Clodrolip} Nach 75tägiger Behandlung der Ptch floxflox ERT2 ${ }^{+/-}$Mäuse mit Clodrolip bzw. Leerliposomen (Kontrolle) wurde zunächst geprüft, ob die erstgenannte Substanz tatsächlich in einer Depletion der Makrophagen in vivo resultiert. Dazu wurde zunächst an den isolierten Milzen eine immunhistologische Antikörperfärbung gegen den Makrophagenmarker F4/80 durchgeführt. Die Milzen der Clodrolip-behandelten Mäuse wiesen deutlich weniger F4/80positive Zellen auf (Daten nicht gezeigt). Zusätzlich wurde die Expression von F4/80 als auch Mac1 (ein weiterer Makrophagenmarker) mittels qRT-PCR untersucht. Wie man in Abbildung 27 sieht, ist sowohl die F4/80 als auch die Mac1 Expression in der Milz nach Applikation von Clodrolip signifikant gegenüber der Leerliposomenkontrolle vermindert. 


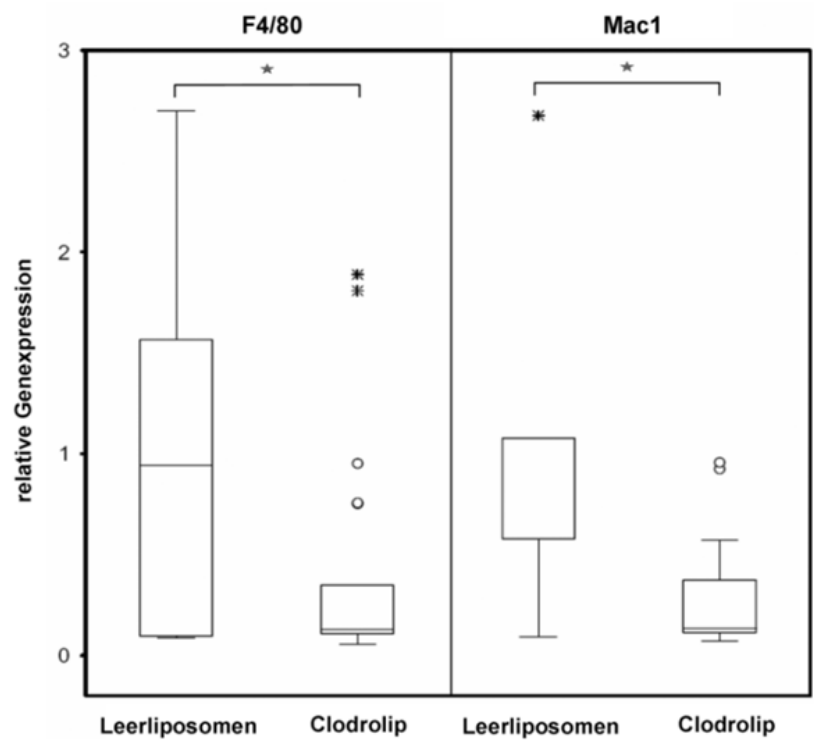

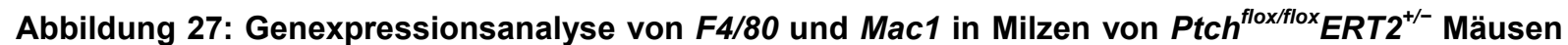
nach 75tägiger Applikation von Clodrolip. Gezeigt ist die Genexpression der beiden Makrophagenmarker F4/80 sowie Mac1 in Milzen von mit Clodrolip-behandelten Mäusen. Jede Probe wurde in Triplikaten vermessen. Alle gemessenen Werte sind als Box-Whisker-Plot dargestellt und in Relation zur Leerliposomen-behandelten Kontrolle dargestellt. Legende: * signifikant ( $p<0,05$ im t-Test für unabhängige Variablen) gegenüber der Kontrolle; $\circ$ Ausreißer; * Extremwert.

Um zu untersuchen, ob die Clodrolipbehandlung auch in der Haut der BCC-tragenden

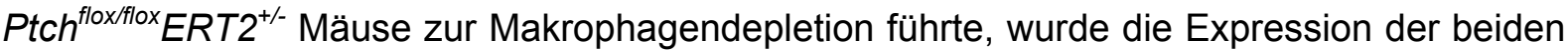
Makrophagenmarker auch in der Schwanzhaut analysiert. Wie man Abbildung 28 entnehmen kann, ist sowohl die Expression von F4/80 als auch von Mac1 nach Clodrolipapplikation in der Haut signifikant reduziert.

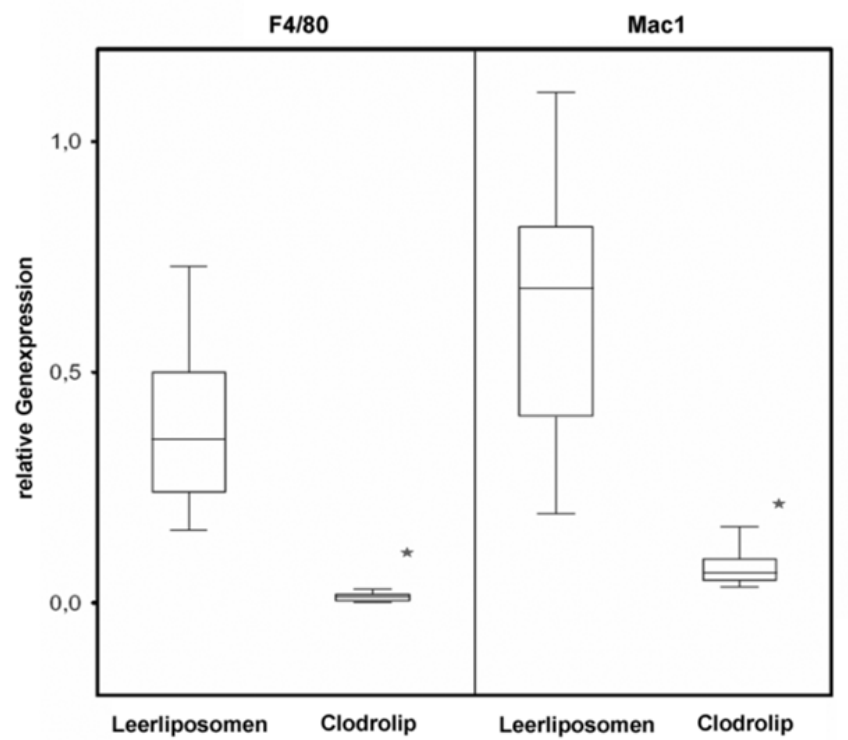

Abbildung 28: Genexpressionsanalyse von F4/80 und Mac1 in Haut von Ptch ${ }^{\text {flox/flox }}{ }^{\text {ERT2 }}{ }^{+/-}$Mäusen nach 75tägiger Applikation von Clodrolip. Gezeigt ist die Genexpression der beiden Makrophagenmarker F4/80 sowie Mac1 in Haut von mit Clodrolip-behandelten Mäusen. Jede Probe wurde in Triplikaten vermessen und alle gemessenen Werte sind dann als Box-Whisker-Plot dargestellt.* signifikant ( $p<0,05$ im t-Test für unabhängige Variablen) gegenüber der Kontrolle. 
Die erfolgreiche Depletion von Makrophagen durch Clodrolip in Milz und Haut konnte auch über FACS-Analysen bestätigt werden. Wie man Tabelle 20 entnehmen kann, war der prozentuale Anteil an Mac1, F4/80 und Gr1-positiver Zellen in Relation zur Gesamtpopulation nach Applikation von Clodrolip in beiden Geweben deutlich reduziert.

Tabelle 20: FACS-Analysen der Milz-/ und Hautzellen von Ptch $^{\text {flox/flox }}$ ERT2 $^{\text {+/- }}$ Mäusen nach 75 tägiger Applikation von Clodrolip. Gezeigt ist der prozentuale Anteil F4/80 positiver Zellen in Relation zur Gesamtpopulation in Milz und Haut sowie Gr1 positiver Zellen der Haut nach 75tägiger Applikation von Leerliposomen (Kontrolle) oder Clodrolip.

\begin{tabular}{|c|c|c|c|}
\hline \multirow{2}{*}{ Leerliposomen } & Milz & \multicolumn{2}{|c|}{ Haut } \\
\cline { 2 - 4 } & $\mathbf{F 4 / 8 0 ~ ( \% )}$ & Gr1 (\%) & $\mathbf{F 4 / 8 0 ~ ( \% ) ~}$ \\
\hline Maus \# 1 & 3,76 & 7,91 & 8,28 \\
\hline Maus \# 2 & 2,06 & 8,00 & 6,47 \\
\hline Maus \# 3 & 1,14 & 4,91 & 4,63 \\
\hline Mittelwert & $\mathbf{2 , 3 2}$ & $\mathbf{6 , 9 4}$ & $\mathbf{6 , 4 6}$ \\
\hline \hline Clodrolip & Milz & \multicolumn{2}{|c|}{ Haut } \\
\cline { 2 - 4 } & $\mathbf{F 4 / 8 0 ~ ( \% )}$ & Gr1 (\%) & F4/80 (\%) \\
\hline Maus \# 4 & 0,11 & 1,73 & 1,4 \\
\hline Maus \# 5 & 0,12 & 6,68 & 5,62 \\
\hline Maus \# 6 & 0,12 & 3,33 & 2,37 \\
\hline Mittelwert & $\mathbf{0 , 1 2}$ & $\mathbf{3 , 9 1}$ & $\mathbf{3 , 1 3}$ \\
\hline
\end{tabular}

Zusammengefasst belegen diese Daten, dass die 75tägige Applikation von Clodrolip zur signifikanten Depletion von Makrophagen in Milz und Haut der BCC-tragenden $P t c h^{\text {flox/flox }} E R T 2^{+/-}$Mäuse führt.

\subsubsection{Signifikante Abnahme der Wnt5a Expression in der Haut nach Clodrolipbehandlung}

Um zu untersuchen, ob durch die Clodrolipbehandlung, die ja zur effizienten Makrophagendepletion in der Haut der BCC-tragenden $\mathrm{Ptch}^{\text {floxflox }} E R T 2^{+/}$Mäuse geführt hatte, tatsächlich mit einer Reduzierung der Wnt5a Expression einhergeht, wurde eine qRTPCR Analyse durchgeführt. Wie die Abbildung 29 zeigt, resultiert die 75tägige Applikation von Clodrolip in einer signifikant verminderten Wnt5a Expression gegenüber der Leerliposomenkontrolle.

Da laut unserer Hypothese das Wnt5a Level im direkten Zusammenhang mit der Induktion des Differenzierungsmarkers K10 stehen könnte, wurde zusätzlich die Expression von $K 10$ in den Proben untersucht. Falls Wnt5a tatsächlich die K10 Expression induzieren sollte, müsste die Abnahme von Wnt5a mit einer verminderten K10 Expression korrelieren. Wie man Abbildung 29 entnehmen kann, hatte Clodrolip keinen signifikanten Einfluss auf die K10 Expression in den BCC-tragenden Hautproben. 


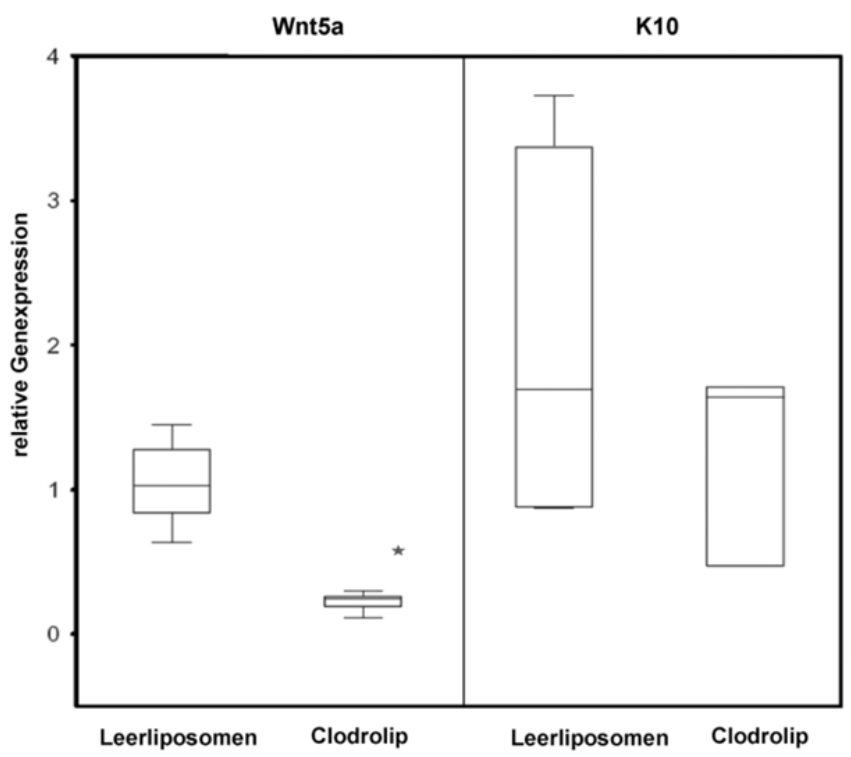

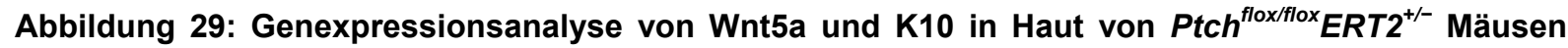
nach 75tägiger Applikation von Clodrolip. Gezeigt ist die Genexpression von Wnt5a sowie K10 in Haut von mit Clodrolip-behandelten Mäusen. Jede Probe wurde in Triplikaten vermessen und alle gemessenen Werte sind als Box-Whisker-Plot dargestellt. * signifikant $(p<0,05$ im t-Test für unabhängige Variablen) gegenüber der Kontrolle.

Zusammengefasst zeigen diese Versuche, dass die Applikation von Clodrolip in vivo zur signifikanten Depletion von Makrophagen in der Milz und Haut führt. Dies korreliert mit einer signifikanten Verminderung der Wnt5a Expression in der Haut der BCC-tragenden $\mathrm{Ptch}^{\text {floxflox }} \mathrm{ERT2}^{+/}$Mäuse. Zudem lassen die Analysen vermuten, dass Wnt5a nicht in die Regulation bzw. Induktion des Differenzierungsmarkers $K 10$ involviert ist.

\subsubsection{Zunahme der Größe und des proliferativen Verhaltens von BCC nach Clodrolipapplikation}

Es konnte gezeigt werden, dass nach Applikation von Clodrolip die Wnt5a Expression in der Haut signifikant herunterreguliert wurde. Laut unserer Hypothese sollte die Reduzierung von Wnt5a mit aggressiverem Tumorwachstum einhergehen und letztlich in größeren BCC resultieren. Daher wurden die BCC der mit Clodrolip-/ und Leerliposomen-behandelten Tiere hinsichtlich ihres Proliferationsstatus und hinsichtlich ihrer Größe analysiert.

In Abbildung 30a ist zu sehen, dass die Applikation von Clodrolip den Anteil proliferierender Zellen erhöht. Dieser Effekt ist zwar nicht signifikant, jedoch ist der prozentuale Anteil der Ki67 positiven Zellen nach Clodrolipbehandlung um ca. 5\% höher im Vergleich zur Leerliposomenkontrolle. Die Berechnung des Tumorareals zeigt weiterhin, dass die Applikation von Clodrolip zum signifikanten Anstieg der Tumorgröße im Vergleich zur Leerliposomenkontrolle geführt hat (Abbildung 30b). So beträgt der Median der Tumorfläche nach Behandlung mit Leerliposomen $45 \mathrm{~mm}^{2}$, wogegen dieser nach Clodrolipbehandlung $82 \mathrm{~mm}^{2}$ beträgt. 


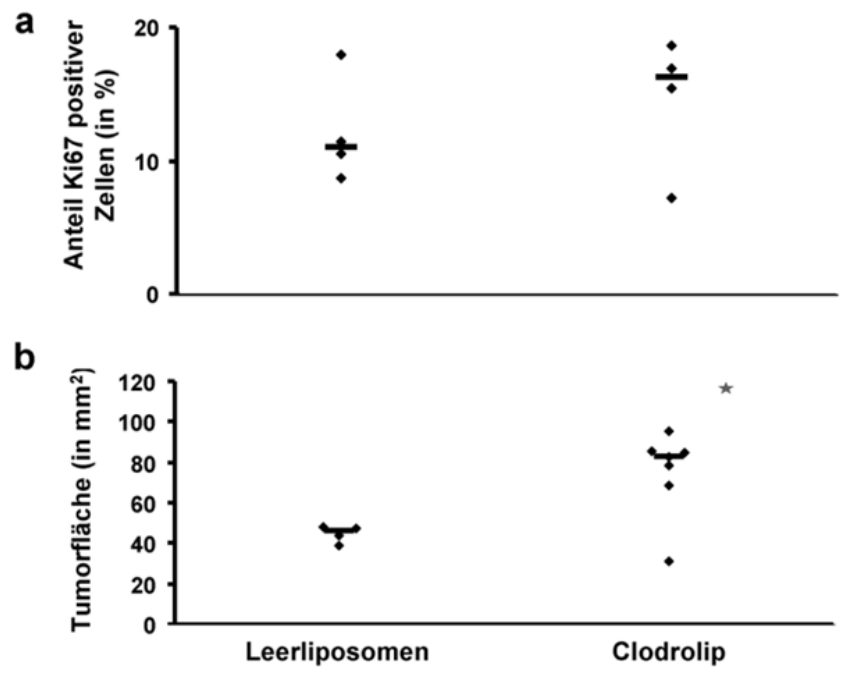

\begin{abstract}
Abbildung 30: Proliferationsindex und Tumorgröße von Ptch $^{\text {flox/flox }} E R T 2^{+/-}$Mäusen nach Applikation von Clodrolip. Gezeigt sind der prozentuale Anteil Ki67 positiver BCC-Zellen (a) sowie die gemessene Tumorgröße (b) nach 75tägiger Behandlung der Mäuse mit Clodrolip bzw. Leerliposomen (Kontrolle). Der Anteil Ki67 positiver Zellen wurde in \% angegeben. Die Daten repräsentieren in a) je 4 Proben und in b) 4 bzw. 6 BCC. * signifikant ( $p<0,05$ im t-Test für unabhängige Variablen) gegenüber der Kontrolle.
\end{abstract}

Diese Daten zeigen, dass die stromale Wnt5a Expression im BCC der Ptch floxflox $E R T 2^{+/-}$ Mäuse tatsächlich auf Makrophagen zurückzuführen ist. Außerdem wird bestätigt, dass eine Verminderung der Wnt5a Expression in der Haut zu aggressiverem Tumorwachstum führt und schließlich in größeren BCC resultiert. Entgegen der ursprünglichen Hypothese zeigen die Daten weiterhin, dass K10 weder durch Wnt5a reguliert wird noch eine Rolle beim BCCWachstum spielt (siehe auch voriges Kapitel, vgl. 4.3.3.2)

\title{
4.4 Einfluss von Liposomen auf das Wachstum von BCC
}

Obwohl Clodrolip im Vergleich zu Liposomen eindeutig zur Depletion von Makrophagen, Verminderung der Wnt5a Expression in der Haut und schließlich zu aggressiverem Tumorwachstum führt, fiel dennoch auf, dass die BCC sowohl nach Clodrolip-/ als auch Liposomenapplikation extrem viel kleiner waren als sonst gesehene BCC in unserer Arbeitsgruppe.

Ein Vergleich zwischen einem völlig unbehandelten und einem mit Liposomen-behandelten BCC ist in Abbildung 31 dargestellt. Man erkennt, dass der unbehandelte Tumor (Abbildung 31a) wesentlich größer ist als der liposomenbehandelte (Abbildung 31b). 

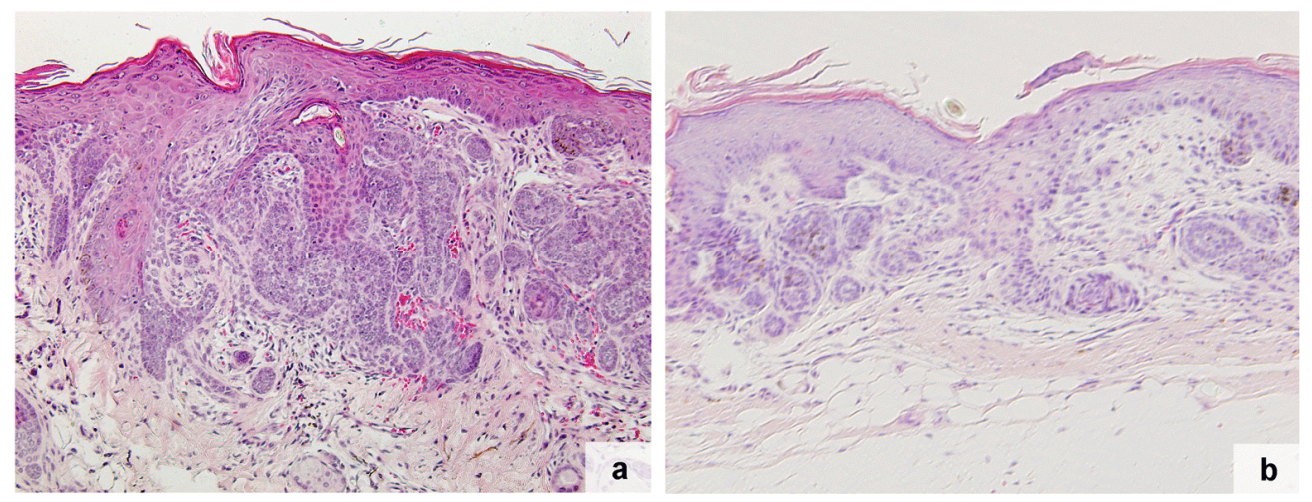

Abbildung 31: Einfluss von Liposomen auf das BCC-Wachstum in vivo. Gezeigt sind HE-gefärbte Schnitte von BCC 90 Tage nach Tumorinduktion in 100facher Vergrößerung. (a) zeigt ein unbehandeltes BCC, (b) zeigt ein über 75 Tage mit Liposomen-behandeltes BCC.

\subsubsection{Wirkung von Liposomen und BLP auf das BCC-Wachstum im Mausmodell}

Wie soeben beschrieben, wurde im Rahmen der mit Clodrolip und Leerliposomen durchgeführten Experimente auffällig, dass auch die Applikation von Leerliposomen in $P t c h^{f l o x f l o x} E R T 2^{+/-}$Mäusen zu kleineren Tumoren führte (Abbildung 31). Da diese Aussage jedoch auf Tumoren beruhte, die nicht aus derselben Studie stammten (bei der Applikation von Clodrolip wurden lediglich Liposomenkontrollen, nicht aber unbehandelte Kontrollen, mitgeführt) wurde der Einfluss von Liposomen auf das BCC-Wachstum nochmals genauer in einem weiteren Experiment untersucht.

In diesem Experiment wurden in allen $P$ tch $^{\text {floxfflox}} E R T 2^{+/-}$Mäusen BCC induziert. 15 Tage nach der Tumorinduktion wurden die Tiere über 75 Tage entweder mit PBS ( $n=4)$, mit Liposomen $(n=4)$ oder mit BLP $(n=5)$ behandelt. Behandlungszeitraum und /-schema entspricht demjenigen des ersten Experiments (siehe Kapitel 4.3.3).

Bei BLP $\left(\mathrm{Pam}_{3} \mathrm{CSK}_{4}\right)$ handelt es sich um einen TLR1/2-Agonisten. Von BLP ist bekannt, dass es zu einer dosisabhängigen Verkleinerung von Melanomen in vivo führt (Zhang, $Y$ et al. 2011). In Anlehnung an die Publikation von Zhang et al. wurde den Mäusen BLP in einer Dosis von $25 \mu \mathrm{g} / \mathrm{Tier}$ jeden vierten Tag i.p. gespritzt.

\subsubsection{Liposomen und BLP hemmen das Tumorwachstum}

Nach der Behandlung wurden alle Tumoren isoliert und hinsichtlich der Tumorgröße analysiert. In Abbildung 32 ist gezeigt, dass sowohl eine Applikation von Liposomen als auch von BLP, verglichen mit den PBS-behandelten Kontrollen, zu einer signifikanten Hemmung des BCC-Wachstums führt. 


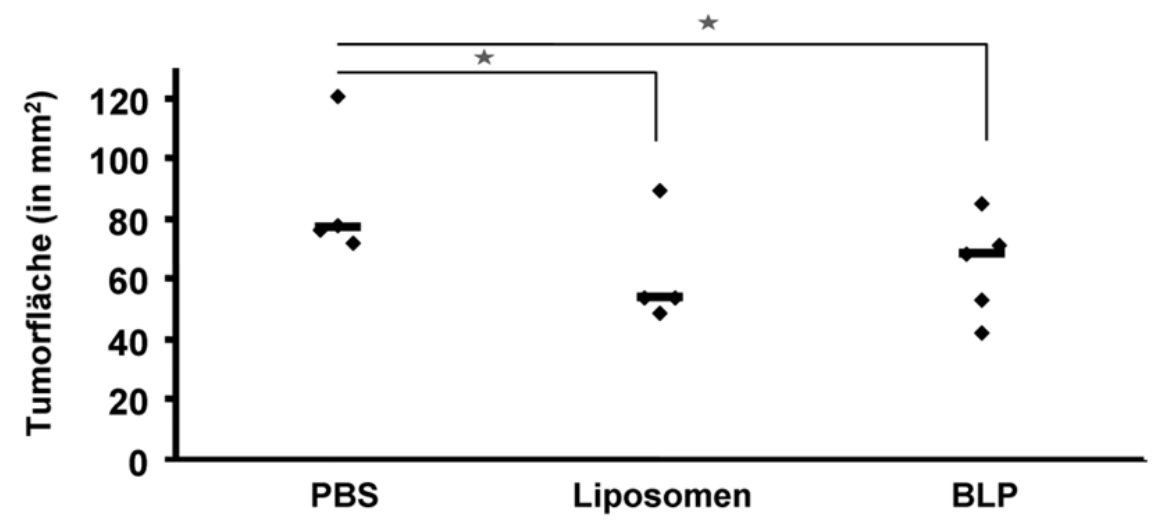

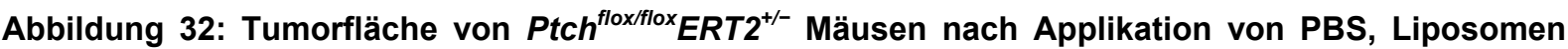
oder BLP. Gezeigt ist die gemessene Tumorfläche nach 75tägiger Behandlung der Mäuse mit PBS $(n=4)$, Liposomen $(n=4)$ oder BLP $(n=5)$. Alle Tumoren wurden am Tag 90 nach Tumorinduktion untersucht. Dargestellt sind die analysierten Tumoreinzelwerte und der errechnete Median (-). * signifikant ( $p<0,05 \mathrm{im}$ t-Test für unabhängige Variablen) gegenüber der Kontrolle.

\subsubsection{Liposomen und BLP induzieren K10 Expression in der BCC-tragenden Haut}

Die Tumoren wurden außerdem hinsichtlich ihrer Differenzierung untersucht. Hierzu wurde mittels qRT-PCR die Expression des Differenzierungsmarkers $K 10$ gemessen. In Abbildung 33 ist die auf PBS-behandelte Tumoren normalisierte Genexpression dargestellt. Sowohl nach Behandlung der Tiere mit Liposomen als auch mit BLP steigt die K10 Expression in den analysierten BCC signifikant an.

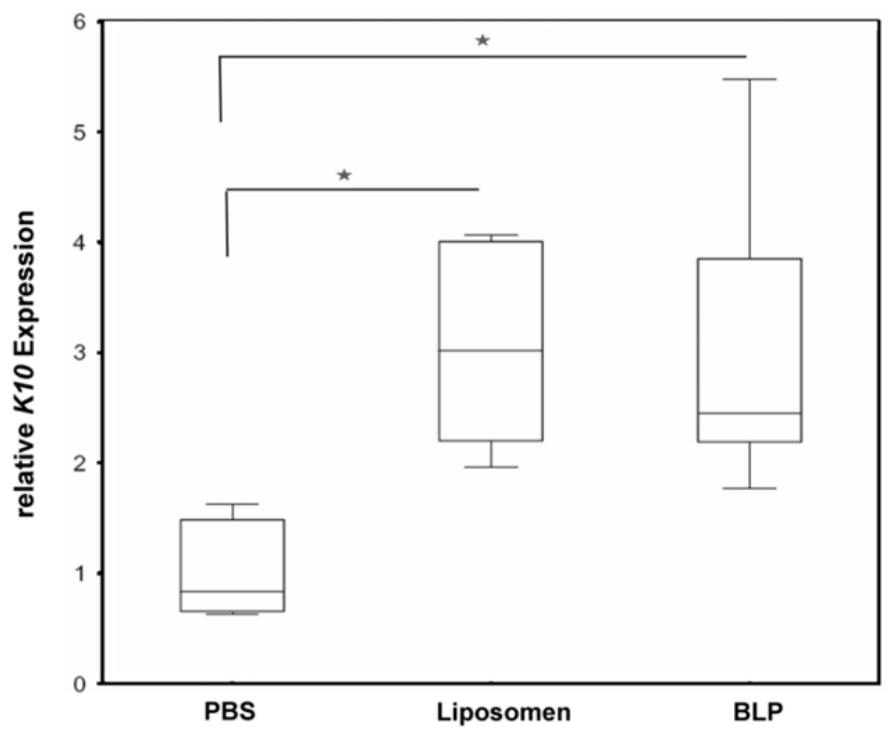

Abbildung 33: K10 Expression in BCC nach in vivo Applikation von Liposomen oder BLP. Gezeigt ist die $K 10$ Expression in BCC-tragender Haut von Ptch $^{f l o x f f l o x} E R T 2^{+/-}$Mäusen nach Behandlung mit PBS $(\mathrm{n}=4)$, Liposomen $(n=4)$ oder BLP $(n=5)$. Die gemessenen Werte sind als Box-Whisker-Plot dargestellt und der Mittelwert der Lösungsmittelkontrolle wurde $=1$ gesetzt. Die $K 10$ Expression der anderen Gruppen ist relativ zu diesem Wert dargestellt. * signifikant ( $p<0,05$ im t-Test für unabhängige Variablen) gegenüber der Kontrolle. 
Zusammengefasst zeigen diese Versuche, dass die Applikation von Liposomen und BLP in vivo sowohl zur signifikanten Verringerung der BCC-Größe als auch zur signifikant höheren K10 Expression in der Haut von BCC-tragenden Ptch $^{\text {floxfllox}} E R T 2^{+/-}$Mäuse führt.

\subsubsection{Liposomen verringern die Makrophagenzahl in der Peritonealhöhle, der Milz und der Haut}

Auch bei diesem Versuch wurde direkt nach dem Isolieren der Tumoren der prozentuale Anteil an Makrophagen in Peritoneallavage, Milz und Haut mittels FACS-Analysen bestimmt (Abbildung 34).

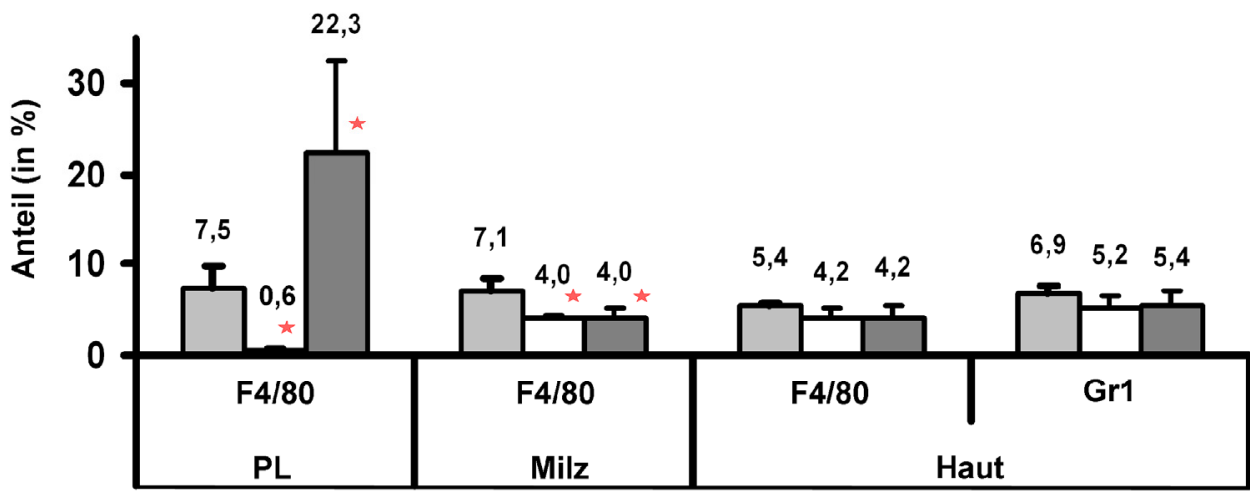

口PBS $\square$ Liposomen $\square$ BLP

Abbildung 34: Makrophagensubgruppen in Ptch $^{\text {flox/flox }} \mathrm{ERT2}^{+-}$Mäusen nach Behandlung mit PBS, Liposomen oder BLP. Gezeigt ist der über FACS ermittelte prozentuale Anteil an F4/80 bzw. Gr1 positiven

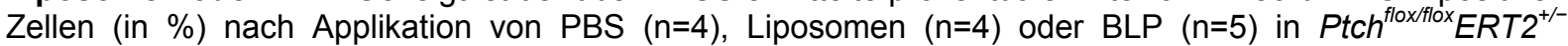
Mäusen. Der prozentuale Anteil des Makrophagenmarkers F4/80 wurde sowohl für Zellen der Peritoneallavage (PL), der Milz sowie der Haut bestimmt. In der Haut wurde zusätzlich der prozentuale Anteil des Makrophagenmarkers Gr1 analysiert. Aufgetragen wurde der Mittelwert der Messwerte mit entsprechender Standardabweichung.

Der Anteil F4/80 positiver Zellen nimmt nach Behandlung der Tiere mit Liposomen im Vergleich zu PBS-behandelten Mäusen in der Peritoneallavage signifikant ab. Dagegen steigt nach Applikation von BLP der Anteil F4/80 positiver Zellen im Vergleich zur PBSKontrolle in der Lavage signifikant an. In Milz und Haut nimmt der prozentuale Anteil an Makrophagen sowohl nach Applikation von Leerliposomen als auch BLP im Vergleich zu den PBS-Kontrollen ab. Dieser Effekt ist in der Milz, nicht aber in der Haut, signifikant. In der Haut wurde daher noch der Anteil Gr1 positiver Zellen bestimmt. Wie man sieht nimmt der prozentuale Anteil auch dieser Makrophagenpopulation sowohl nach Applikation von Leerliposomen als auch BLP im Vergleich zu den PBS-Kontrollen ab. Jedoch ist dieser Effekt ebenfalls nicht signifikant.

Zusammenfassend kann man sagen, dass sowohl Liposomen als auch BLP einen bedeutenden Einfluss auf die Anzahl von Makrophagen in der Peritonealhöhle und der Milz nehmen. 


\subsubsection{Wirkung von Liposomen und BLP auf BMDM und ASZ001}

Die bisherigen Experimente zeigen, dass Liposomen und BLP einen Einfluss auf das BCCWachstum und auf die Anzahl der Makrophagen in Ptch $^{\text {floxflox }} E R T 2^{+/-}$Mäusen haben. Um diese Wirkung näher zu charakterisieren, wurden Zellkulturexperimente mit BMDM (bone marrow-derived macrophages) und der BCC-Zelllinie ASZ001 durchgeführt.

Da BLP in vivo genauso wie Liposomen a) zur Wachstumshemmung der BCC führt und b) die Anzahl der Makrophagen vermindert, wurde diese Substanz auch für die in vitro Experimente als Kontrollsubstanz verwendet.

\subsubsection{Wirkung von Liposomen und BLP auf BMDM}

\subsection{Liposomen und BLP ändern die Morphologie von BMDM}

Schon eine 24stündige Inkubation der BMDM mit Liposomen oder BLP führte zu einer deutlichen Veränderung der Morphologie dieser Zellen (Daten nicht gezeigt). Die in Abbildung 35 dargestellten Aufnahmen zeigen BMDM nach 72stündiger Inkubation mit den Substanzen. Nach Inkubation mit BLP erscheinen die BMDM abgeflacht. Dagegen sind die Zellen nach Inkubation mit Liposomen abgekugelt. Die Lösungsmittelkontrollen zeigen nach 72stündiger Inkubation die gleiche Morphologie wie unbehandelte BMDM.

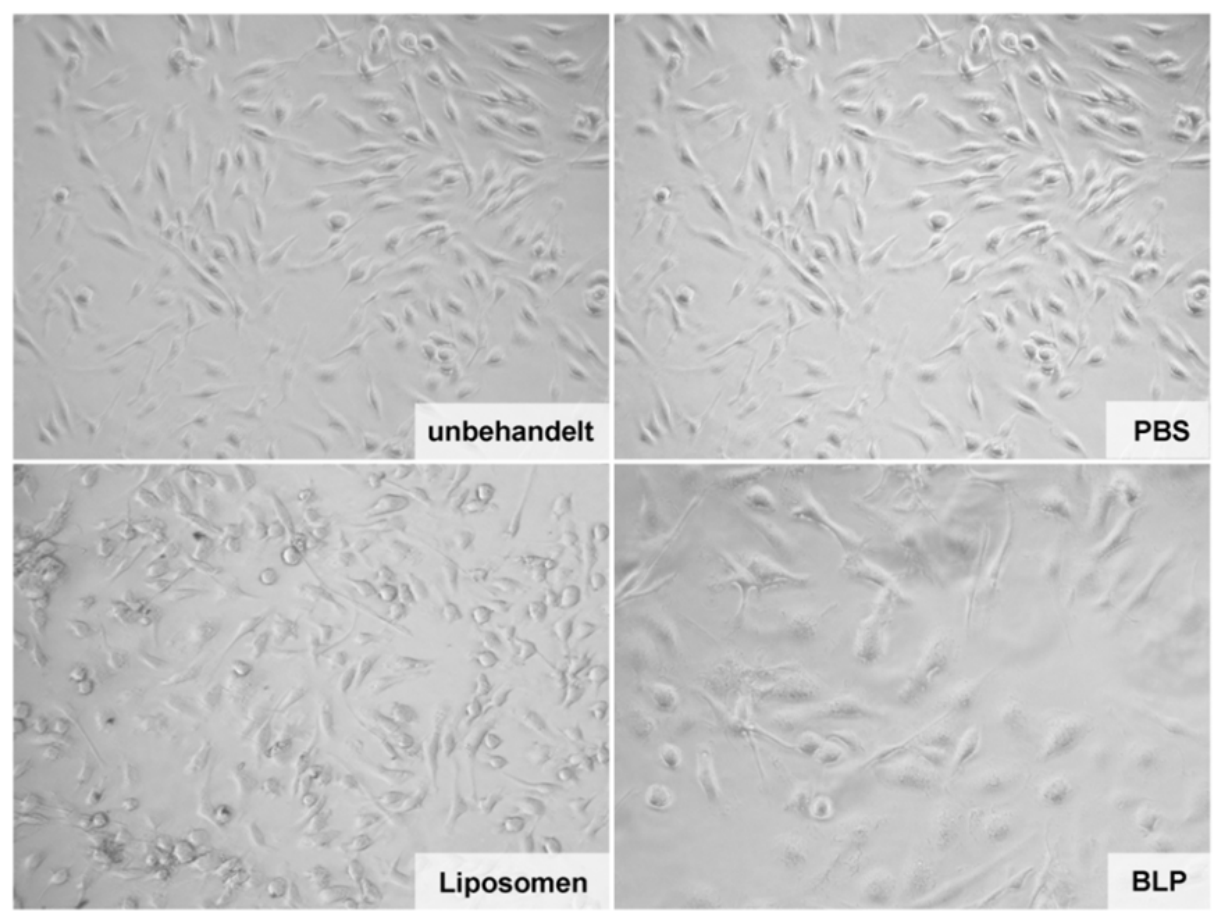

Abbildung 35: Morphologie von BMDM nach Inkubation mit Liposomen oder BLP. Gezeigt sind BMDM nach 72stündiger Inkubation mit Liposomen oder BLP im Vergleich zu unbehandelten und Lösungsmittel-behandelten (PBS) BMDM. 


\subsection{Keine toxische Wirkung von Liposomen und BLP auf BMDM}

Um eine eventuelle toxische Wirkung der beiden Substanzen auf die BMDM zu untersuchen, wurde die Zellviabilität mittels WST-1 Assay untersucht. Bei diesem Experiment wurden die Zellen für 6, 12, 24 und 72 Stunden mit den Substanzen inkubiert. In Abbildung 36 sind die Ergebnisse für die 72stündige Inkubation dargestellt. Wie man der Abbildung entnehmen kann, hat sogar eine solch lange Inkubationsdauer mit Liposomen keinen Einfluss auf die Zellviabilität (Daten für 6, 12, 24stündige Inkubation nicht gezeigt). BLP scheint hingegen sogar die Stoffwechselaktivität der BMDM signifikant anzuregen.

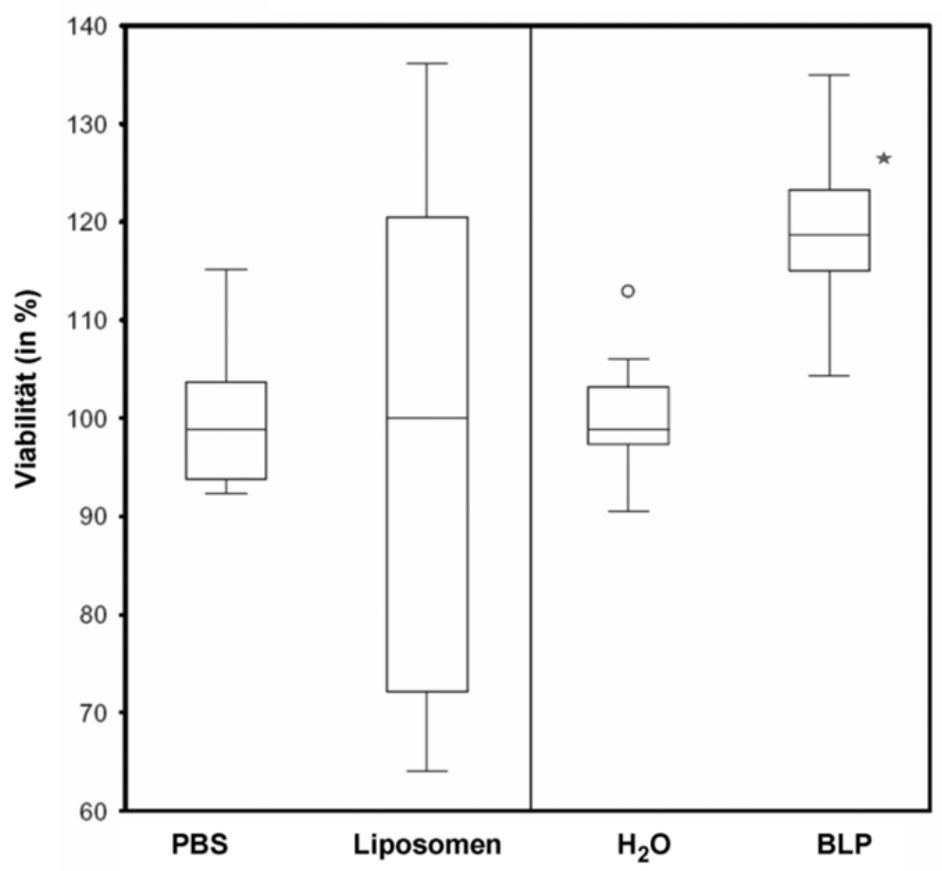

Abbildung 36: WST-1 Assay von BMDM nach Inkubation mit Liposomen oder BLP. Gemessen wurde nach 72stündiger Inkubation der BMDM mit Liposomen, BLP oder den entsprechenden Lösungsmitteln (PBS, $\mathrm{H}_{2} \mathrm{O}$ ) die Absorptionsänderung von WST-1. Die ermittelten Werte sind als Box-Whisker-Plot dargestellt. Der Mittelwert der jeweiligen Lösungsmittelkontrollen wurde $=100 \%$ gesetzt. Die Messwerte der Behandlungsgruppen sind relativ zu diesem Wert dargestellt. Die Daten zeigen die Auswertung von vier unabhängigen Experimenten. Legende: * signifikant ( $p<0,05 \mathrm{im}$ t-Test für unabhängige Variablen) gegenüber der Kontrolle; ○ Ausreißer.

\subsection{BLP, nicht aber Liposomen, führen zur Cytokinfreisetzung aus BMDM}

Weiterhin wurde der Einfluss von Liposomen und BLP auf die Cytokinproduktion von BMDM untersucht. Die in Abbildung 37 dargestellte Graphik zeigt den im Medium gemessenen Cytokingehalt von acht verschiedenen Cytokinen nach Inkubation der Zellen mit Liposomen oder BLP.

Für alle analysierten Zeitpunkte (6, 12, 24 Stunden Inkubation) ist deutlich erkennbar, dass Liposomen keinen Effekt haben. Dagegen führt eine Inkubation mit BLP zur Freisetzung der Cytokine IL-6, MIP-1 $\alpha / C C L 3$, Rantes/CCL5, TNF- $\alpha$, KC/CXCL1, und MCP-1/CCL2 ins 
Medium. Bis auf MCP-1, das erst nach 24h ansteigt, steigt der Gehalt der genannten Cytokine dabei proportional zur Inkubationszeit an. Auffällig ist jedoch, dass auch durch eine Inkubation mit BLP die Cytokine IL-10 und IL-12p40 nicht beeinflusst werden.

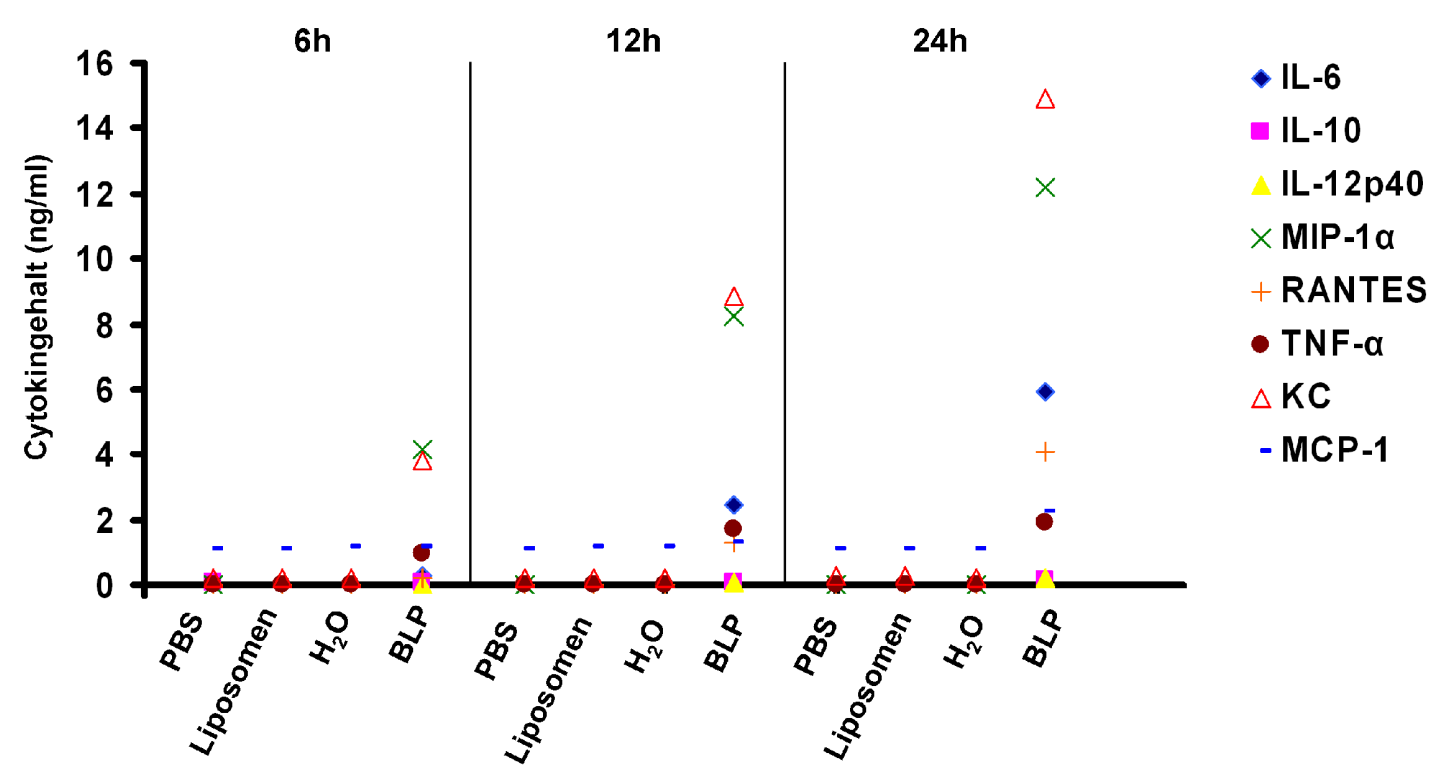

Abbildung 37: Cytokinfreisetzung aus BMDM nach Inkubation mit Liposomen bzw. BLP. Gezeigt ist der absolute Cytokingehalt nach 6,12 und 24stündiger Inkubation von BMDM mit Liposomen, BLP oder den entsprechenden Lösungsmitteln (PBS, $\mathrm{H}_{2} \mathrm{O}$ ). Der Cytokingehalt wurde im Überstand des Mediums mittels ELISA vermessen.

Zusammengefasst kann man sagen, dass Liposomen (im Gegensatz zu BLP) keine Produktion von IL-6, MIP-1 $\alpha / C C L 3$, Rantes/CCL5, TNF- $\alpha$, KC/CXCL1, und MCP-1/CCL2 in BMDM anregen können. Allerdings führt auch BLP zu keiner Produktion von IL-10 und IL12p40 in BMDM.

\subsection{Liposomen und BLP führen zu vermehrter Migration von BMDM}

Zur Untersuchung des Einflusses von Liposomen und BLP auf das Migrationsverhalten von BMDM wurden die Zellen in mit Liposomen oder BLP supplementiertem Medium inkubiert. Dazu wurden $0,75 \times 10^{5}$ BMDM in Zellkultur-Membraneinsätze ausgesät und in einer 24-LochPlatte platziert. Nach einer 18stündigen Inkubation wurden durch die Membran migrierte Zellen mit Calcein gefärbt und am Mikroskop ausgezählt (siehe Kapitel 3.2.6). Der Zeitraum der Inkubation sollte maximal 18h andauern, da die Zellen besonders direkt nach Stimulation mit vermehrter Migration reagieren und längere Inkubationszeiten so möglicherweise das Ergebnis verfälschen. Ist die Inkubation dagegen länger als 18h, können die bereits migrierten Zellen von der Membran abfallen und damit ebenfalls das Ergebnis verfälschen. 
Wie in Abbildung 38 gezeigt, ist der Anteil gewanderter Zellen sowohl nach Inkubation der Zellen mit Liposomen als auch mit BLP im Vergleich zur jeweiligen Kontrolle signifikant erhöht.

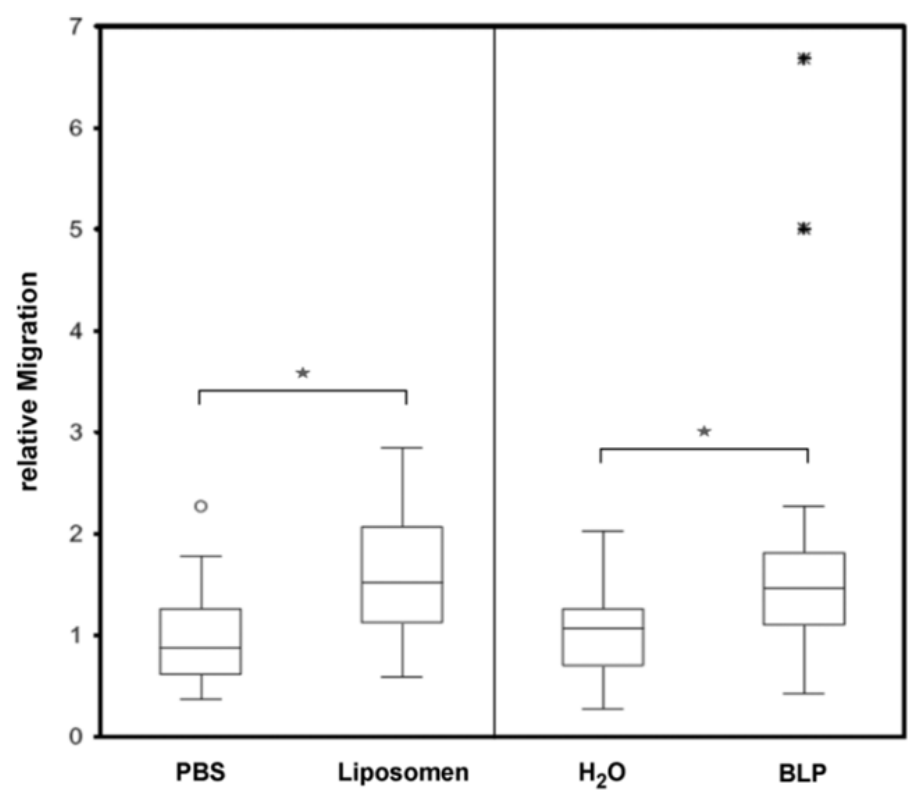

Abbildung 38: Migration von BMDM nach Inkubation mit Liposomen oder BLP. Gezeigt ist die relative Migration von BMDM nach 72stündiger Inkubation mit Liposomen, BLP oder den entsprechenden Lösungsmitteln. Die gemessenen Werte sind als Box-Whisker-Plot dargestellt und der Mittelwert der jeweiligen Lösungsmittelkontrollen wurde $=1$ gesetzt. Die Messwerte der anderen Gruppen sind relativ zu diesem Wert dargestellt. Die Daten zeigen die Auswertung von je fünf unabhängigen Experimenten, wobei jedes Experiment in Triplikaten durchgeführt wurde. Legende: * signifikant $(p<0,05$ im t-Test für unabhängige Variablen) gegenüber der Kontrolle; ○ Ausreißer; * Extremwert.

\subsection{Liposomen und BLP vermindern die Proliferation von BMDM}

Die in vivo Versuche zur Applikation von Liposomen und BLP in den Ptch $^{\text {floxflox }}$ ERT2 $^{+/-}$ Mäusen haben gezeigt, dass beide Substanzen die Anzahl von Makrophagen deutlich beeinflussen (siehe Abbildung 34).

Da die verminderte Anzahl der Makrophagen in Peritonealhöhle, Milz und Haut auch durch eine Proliferationshemmung zustande gekommen sein könnte, wurde der Einfluss von Liposomen und BLP auf die BMDM mittels BrdU-Assay untersucht. Hierzu wurden in einer 96-Loch-Platte 8000 BMDM ausgesät und das Medium am nächsten Tag mit Liposomen bzw. BLP supplementiert. Die Zellen wurden für $72 \mathrm{~h}$ mit den Substanzen inkubiert. Für die letzten 24h wurde das Medium mit BrdU angereichert. Die BrdU-Inkorporation wurde am Luminometer bestimmt (siehe Kapitel 3.2.7). 


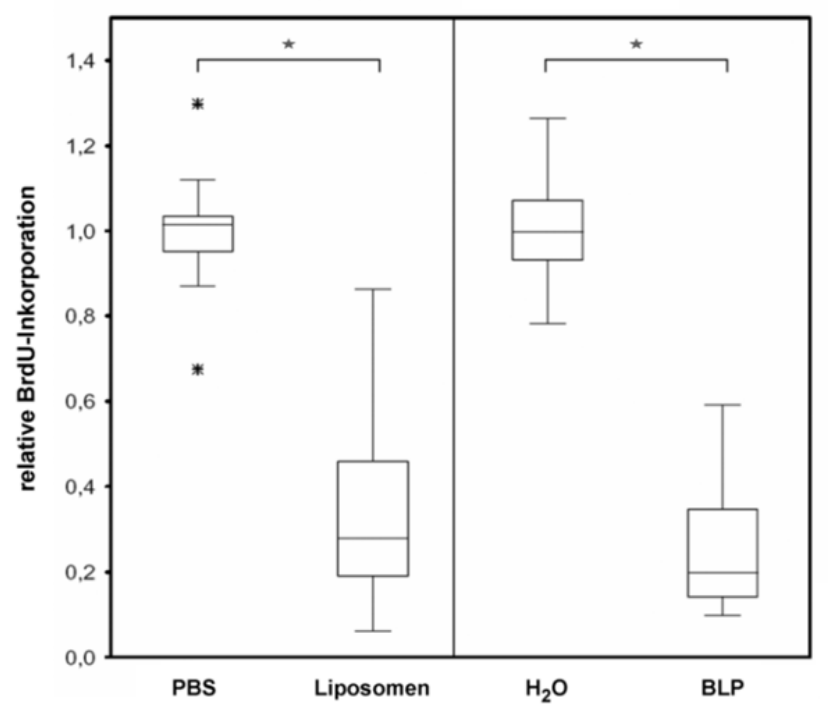

Abbildung 39: Relative Proliferationsrate von BMDM nach Inkubation mit Liposomen oder BLP. Gezeigt ist die relative BrdU-Inkorporation von BMDM nach 72stündiger Inkubation mit Liposomen, BLP oder den entsprechenden Lösungsmitteln. Die gemessenen Werte sind als Box-Whisker-Plot dargestellt und der Mittelwert der Lösungsmittelkontrolle wurde $=1$ gesetzt und die Messwerte der anderen Gruppe sind relativ zu diesem Wert dargestellt. Die Daten zeigen die Auswertung von drei unabhängigen Experimenten, wobei jedes in Triplikaten durchgeführt wurde. Legende: * signifikant $(p<0,05 \mathrm{im} \mathrm{t}$-Test für unabhängige Variablen) gegenüber der Lösungsmittelkontrolle; * Extremwert.

Wie man Abbildung 39 entnehmen kann, inhibieren sowohl BLP als auch Liposomen die Proliferation der BMDM. Im Vergleich zum entsprechenden Lösungsmittel ist dieser Effekt signifikant.

\subsection{Liposomen führen in BMDM zum Zellzyklusarrest in der G0/G1-Phase}

Wie aus den Experimenten deutlich hervorgeht, inhibieren Liposomen die Proliferation von BMDM. In einem weiteren Schritt wurde daher analysiert, zu welchem Zeitpunkt des Zellzyklus diese Hemmung stattfindet. Hierzu wurden die Zellen für $72 \mathrm{~h}$ mit Liposomen oder dem Lösungsmittel PBS inkubiert, danach mit Propidiumiodid gefärbt und anschließend über FACS analysiert (siehe Kapitel 3.3.5).

Wie man in Abbildung 40 sieht, führt die 72stündige Inkubation der BMDM mit Liposomen zu einem Zellzyklusarrest in der G0/G1-Phase. So steigt der Anteil der Zellen nach Inkubation mit Liposomen um etwa $8 \%$ gegenüber der Lösungsmittelkontrolle an. Hingegen nimmt der Anteil der in der S-Phase befindlichen Zellen um ca. $8 \%$ gegenüber der Lösungsmittelkontrolle ab.

In Abbildung 41 ist der prozentuale Anteil an BMDM in der jeweiligen Zellzyklus-Phase zusätzlich als Box-Whisker-Plot dargestellt. Anhand dieser Graphik ist erkennbar, dass der sich in der G0/1-Phase befindliche Zellanteil durch Inkubation mit Liposomen im Vergleich zu den PBS-behandelten Zellen signifikant ansteigt. Dagegen verringert sich der prozentuale Anteil der sich in der S-Phase befindlichen Zellen signifikant im Vergleich zur Kontrolle. 
Zellen der G2/M-Phase bleiben durch eine Inkubation mit Liposomen im Vergleich zur Kontrolle nahezu unverändert.
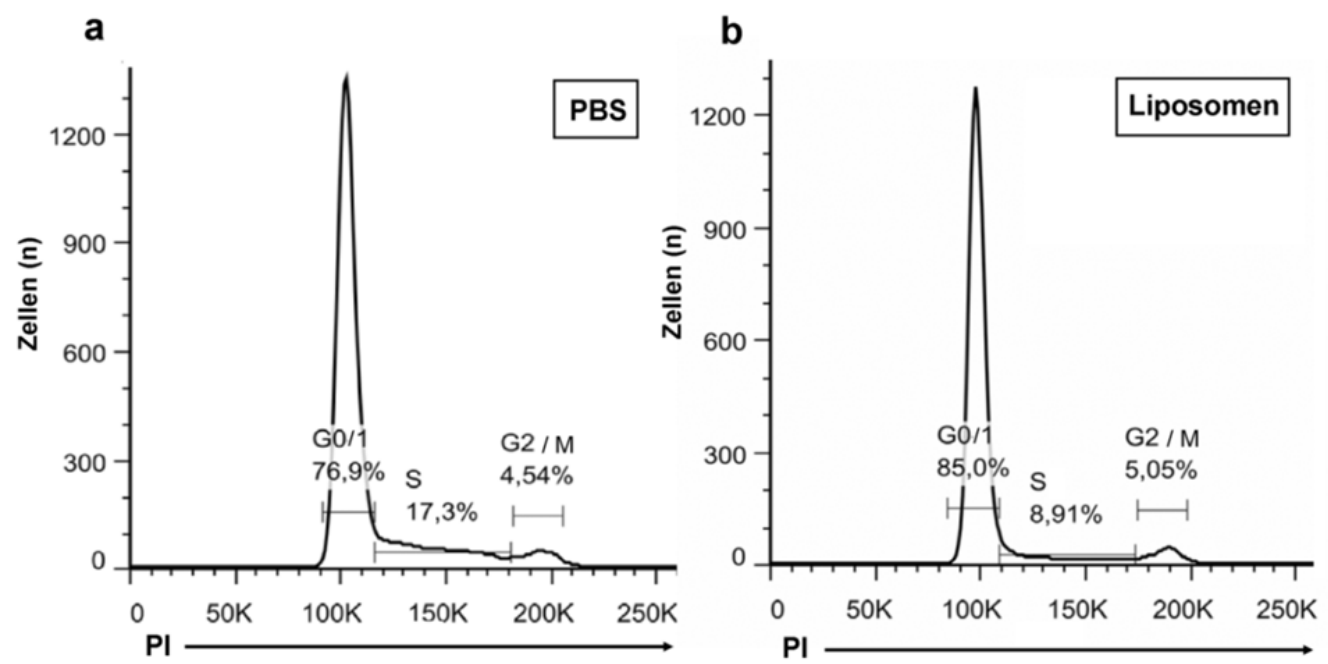

Abbildung 40: Zellzyklus von BMDM nach Inkubation mit PBS oder Liposomen. BMDM wurden für 72 Stunden mit PBS (a) oder Liposomen (b) inkubiert. Nach Färbung der Zellen mit Propidiumiodid (PI), folgte die Analyse mittels FACS. Im FACS-Histogramm sind die verschiedenen Stadien des Zellzyklus markiert. Es wird die G0/G1-Phase (Ruhephase (G0) und postmitotische Phase oder Präsynthesephase (G1)) von der S-Phase (Synthesephase) und der G2/M-Phase (prämitotische Phase oder Postsynthesephase (G2) und Mitosephase (M)) unterschieden. Die relativen prozentualen Anteile der Zellen in der jeweiligen Phase des Zellzyklus sind in Prozent angegeben.

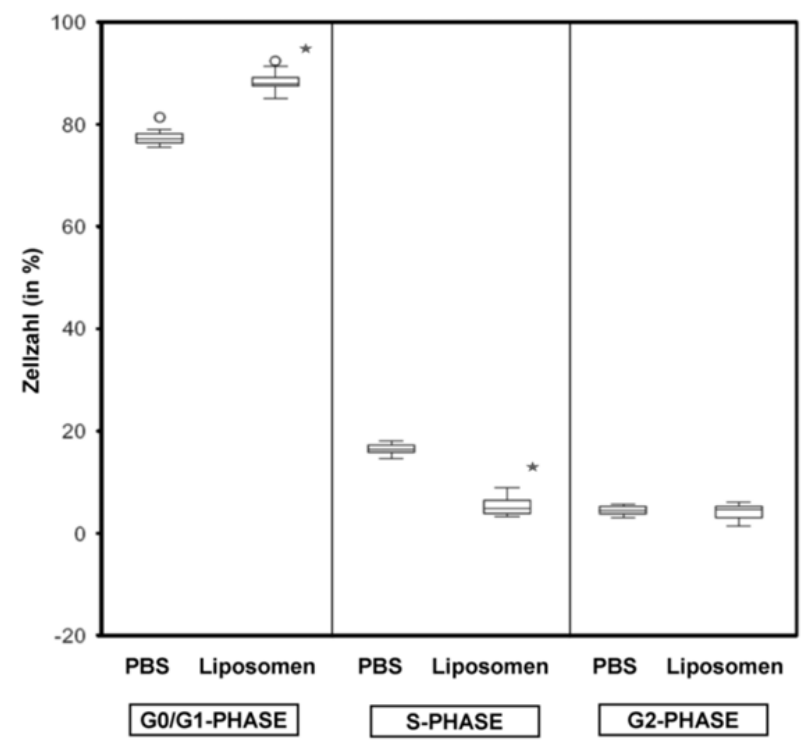

Abbildung 41: Zellzyklus von BMDM nach Inkubation mit PBS oder Liposomen. Dargestellt ist der prozentuale Anteil an BMDM nach 72stündiger Inkubation mit Liposomen oder dem Lösungsmittel PBS in verschiedenen Phasen des Zellzyklus. Die über FACS ermittelten Daten (vgl. Abbildung 40) sind als BoxWhisker-Plot dargestellt. In die Analyse flossen die Daten aus zwei unabhängig voneinander durchgeführten Experimenten ein (PBS, $n=4$; Liposomen, $n=10)$. Legende: * signifikant ( $p<0,05 \mathrm{im}$ t-Test für unabhängige Variablen) gegenüber der Lösungsmittelkontrolle; $\circ$ Ausreißer.

Die obigen Ergebnisse belegen, dass eine 72stündige Inkubation mit Liposomen zum Zellzyklusarrest von BMDM in der G0/G1-Phase führt. 


\subsection{Liposomen und BLP induzieren Apoptose in BMDM}

Darüber hinaus wurde untersucht, ob Liposomen und BLP das Apoptoseverhalten von BMDM beeinflussen. Hierzu wurden die Zellen für 72 Stunden mit den Substanzen inkubiert und die Zellen anschließend mit FITC-gelabeltem Annexin sowie To-Pro-3 lodid gefärbt (siehe Kapitel 3.3.5). Die Bestimmung der Anzahl apoptotischer Zellen erfolgte über FACSAnalyse und wurde als prozentualer Anteil an der Gesamtzellzahl berechnet. Wie in Abbildung 42 deutlich zu sehen, führt die Inkubation von BMDM mit Liposomen im Vergleich zur PBS-Kontrolle zum signifikanten Anstieg apoptotischer Zellen. So steigt der mittlere Anteil von etwa $7 \%$ auf $13 \%$. Gleichermaßen führt auch die Inkubation der BMDM mit BLP zum signifikanten Anstieg apoptotischer Zellen, ihr mittlerer Anteil steigt von ebenfalls $7 \%$ auf sogar über $30 \%$.

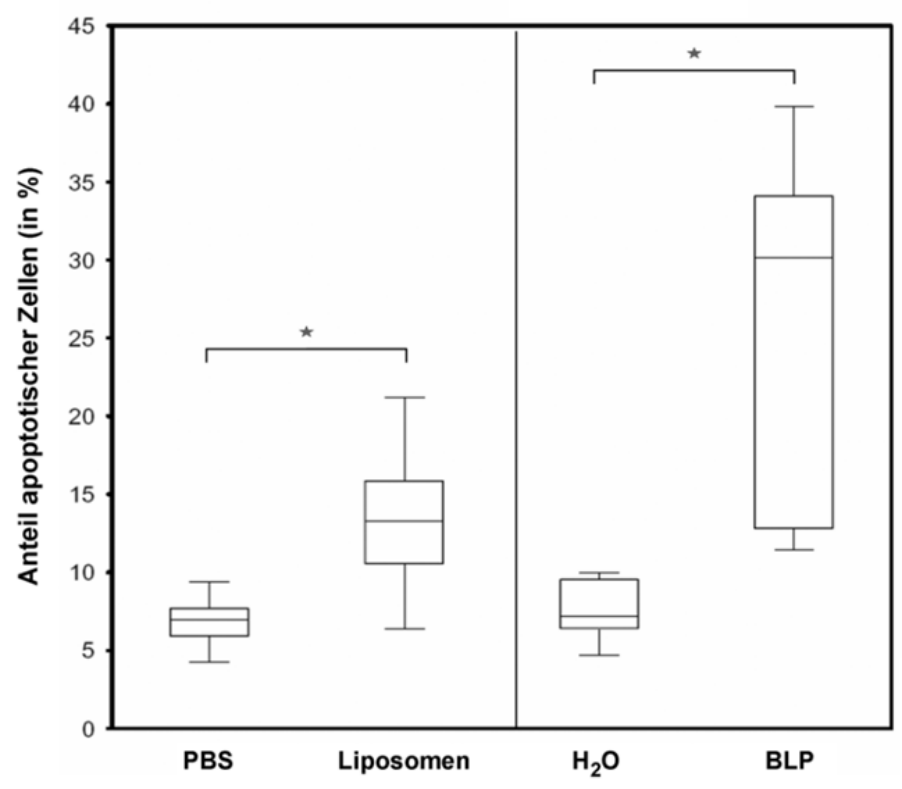

Abbildung 42: Anteil Annexin-/ und To-Pro-3 lodid positiver BMDM nach Behandlung mit Liposomen oder BLP. Dargestellt ist der prozentuale Anteil apoptotischer Zellen nach 72stündiger Inkubation von BMDM mit Liposomen, BLP oder den entsprechenden Lösungsmitteln. Die über FACS ermittelten Daten sind als Box-Whisker-Plot dargestellt. In die Analyse flossen die Daten aus drei unabhängig voneinander durchgeführten Experimenten ein, die Apoptose wurde pro Behandlung in Duplikaten gemessen. * signifikant ( $p<0,05$ im t-Test für unabhängige Variablen) gegenüber der Lösungsmittelkontrolle.

Diese Analyse zeigt, dass sowohl Liposomen als auch BLP die Apoptose in BMDM induzieren.

Zusammengefasst zeigen die erhobenen in vitro Daten, dass Liposomen und BLP einen vergleichbaren Einfluss auf BMDM haben. Beide Substanzen verändern die Morphologie der BMDM, sie führen zu vermehrter Migration, sie vermindern die Proliferation der Zellen und induzieren Apoptose. Ein Unterschied besteht jedoch darin, dass Inkubation der BMDM mit BLP, nicht aber mit Liposomen, in einer Cytokinfreisetzung resultiert. Es muss außerdem betont werden, dass sowohl Liposomen als auch BLP keine toxische Wirkung auf die Zellen 
haben. Deshalb sind alle hier analysierten Effekte hinsichtlich Proliferation und Apoptose nicht durch Toxizität der beiden Substanzen bedingt.

\subsubsection{Wirkung von Liposomen oder BLP auf ASZ001}

Die bisherigen in vitro Experimente zeigen, dass Liposomen und auch BLP einen deutlichen Einfluss auf BMDM haben. Um zu untersuchen, ob Liposomen oder BLP auch eine antiproliferative oder proapoptotische Wirkung auf BCC-Zellen haben, wurde die BCCZelllinie ASZ001 mit den Substanzen behandelt.

\subsection{Keine Proliferationshemmung von ASZ001 durch Liposomen oder BLP}

Zunächst wurden die Tumorzellen nach Inkubation mit Liposomen bzw. BLP hinsichtlich ihrer Proliferation im BrdU-Assay analysiert. Hierzu wurden in einer 96-Loch-Platte 6000 ASZ001Zellen ausgesät und das Medium am nächsten Tag mit Liposomen bzw. BLP supplementiert. Die Zellen wurden für $72 \mathrm{~h}$ mit den Substanzen inkubiert. Für die letzten $24 \mathrm{~h}$ wurde BrdU zugegeben. Die Auswertung der BrdU-Inkorporation erfolgte am Luminometer (siehe Kapitel 3.2.7).

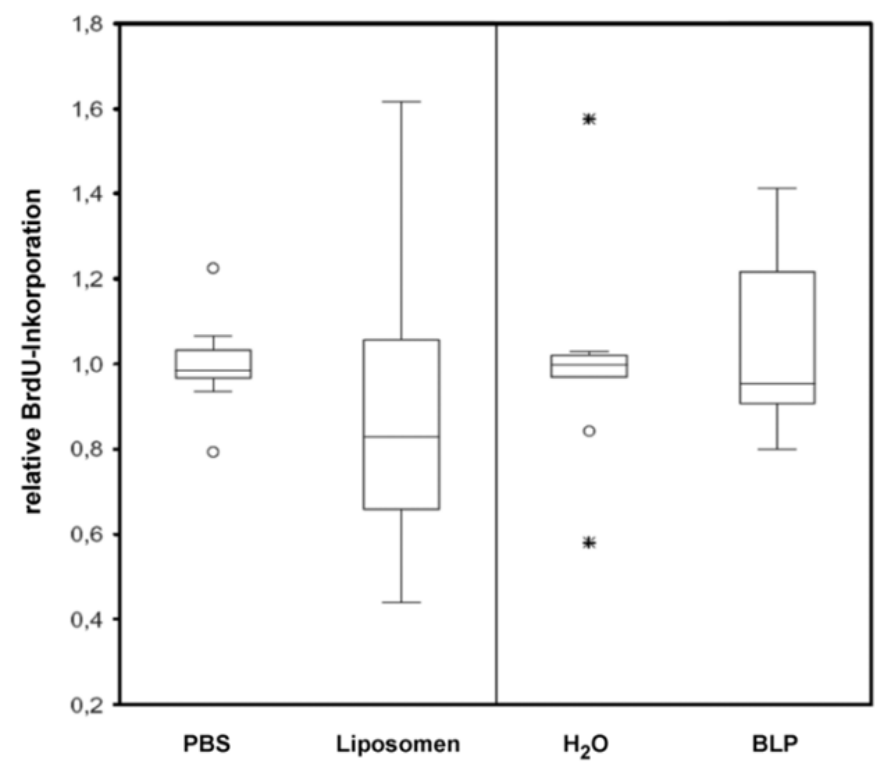

Abbildung 43: Relative Proliferationsrate von ASZ001 nach Inkubation mit Liposomen oder BLP. Gezeigt ist die relative BrdU-Inkorporation von ASZ001 nach 72stündiger Inkubation mit Liposomen, BLP oder den entsprechenden Lösungsmitteln. Die gemessenen Werte sind als Box-Whisker-Plot dargestellt. Der Mittelwert der Lösungsmittelkontrolle wurde =1 gesetzt und die Messwerte der anderen Gruppe sind relativ zu diesem Wert dargestellt. Die Daten zeigen die Auswertung von zwei unabhängigen Experimenten, wobei jedes Experiment in Triplikaten durchgeführt wurde. Legende: * signifikant $(p<0,05 \mathrm{im}$ t-Test für unabhängige Variablen) gegenüber der Lösungsmittelkontrolle; o Ausreißer, * Extremwert.

Aus der Abbildung 43 geht hervor, dass eine Inkubation der ASZ001 mit Liposomen oder BLP keinen signifikanten Einfluss auf die BrdU-Inkorporation hat. 


\subsection{Keine Stimulation der Apoptose von ASZ001 durch Liposomen oder BLP}

Weiterhin wurde analysiert, ob die Inkubation der ASZ001 mit Liposomen bzw. BLP das Apoptoseverhalten der Zellen beeinflusst. Dazu wurden die Zellen für 72 Stunden mit den beiden Substanzen inkubiert und die Zellen anschließend mit FITC-gelabeltem Annexin sowie To-Pro-3 lodid gefärbt (siehe Kapitel 3.3.5). Die Bestimmung der Anzahl apoptotischer Zellen erfolgte über FACS-Analyse und wurde als prozentualer Anteil an der Gesamtzellzahl berechnet.

In der Abbildung 44 ist erkennbar, dass eine Inkubation der Zellen mit Liposomen den Anteil apoptotischer Zellen nicht signifikant verändert. Die Werte zeigen jedoch eine sehr hohe Varianz. Nach Inkubation der Tumorzellen mit BLP wird die Zahl apoptotischer Zellen im Mittel von etwa $43 \%$ auf 38\% vermindert. Dieser Effekt ist jedoch nicht signifikant.

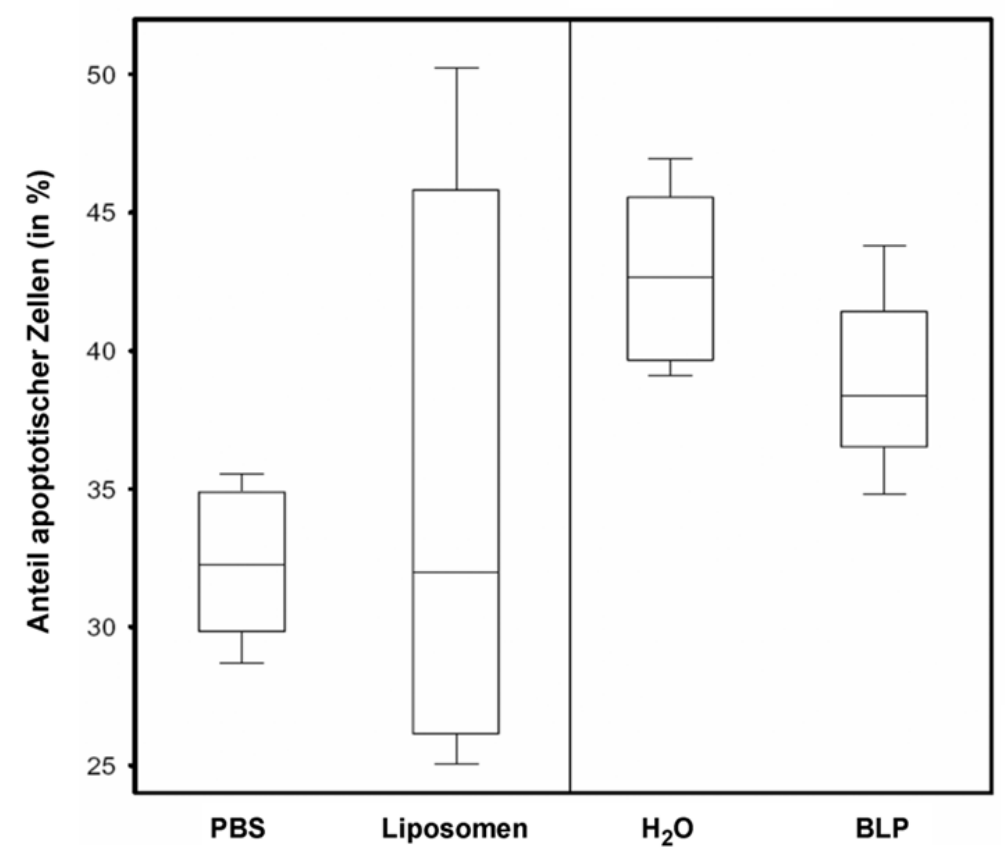

Abbildung 44: Anteil Annexin-I und To-Pro-3 lodid positiver ASZ001 nach Behandlung mit Liposomen oder BLP. Dargestellt ist der prozentuale Anteil apoptotischer Zellen nach 72stündiger Inkubation von ASZ001 mit Liposomen, BLP oder den entsprechenden Lösungsmitteln. Die über FACS ermittelten Daten sind als Box-Whisker-Plot dargestellt. In die Analyse flossen die Daten aus drei unabhängig voneinander durchgeführten Experimenten ein, die Apoptose wurde pro Behandlung in Duplikaten gemessen. * signifikant $(p<0,05$ im t-Test für unabhängige Variablen) gegenüber der Lösungsmittelkontrolle.

Zusammenfassend ist festzuhalten, dass weder Liposomen noch BLP die Proliferation oder das Apoptoseverhalten von BCC-Zellen beeinflussen. 


\section{Diskussion}

\subsection{Expression und Funktion von Wnt5a in der BCC-Zelllinie ASZ001 und BCC-tragenden Hautstanzen}

In unserer Arbeitsgruppe wurden murine Basalzellkarzinome bereits intensiv analysiert und es wurde damit begonnen die Rolle von Wnt5a in dieser Tumorentität zu charakterisieren. Mit Hilfe des konditionellen Ptch ${ }^{\text {floxfllox}} E R T 2^{+/}$Knockout-Mausmodells (siehe Einleitung und (Uhmann, A et al. 2007)) wurde dokumentiert, dass die Tumoren im Laufe der Zeit histologisch einen stärker differenzierten Phänotyp aufwiesen und etwa 200-250 Tage nach Tumorinduktion eine Spontanregression zeigten, was mit einer verminderten Proliferationsrate der Tumoren einherging.

\subsubsection{Wnt5a wird von BCC-assoziierten Makrophagen exprimiert}

Die Wnt5a Expression setzte in vivo interessanterweise erst im vollentwickelten Tumor, also etwa 90 Tage nach Tumorinduktion, ein und blieb auch in den regredienten Tumorstadien bestehen. In den frühen Vorläuferläsionen war die Wnt5a Expression auf den Haarfollikel limitiert und entsprach dem Status wie in normaler Haut (Reddy, S et al. 2001; Reddy, ST et al. 2004). Daher schien Wnt5a nicht mit der Initiation von BCC in Verbindung zu stehen. Vorversuche unserer Arbeitsgruppe zeigten außerdem, dass die Wnt5a Expression im BCC nur auf das Stroma beschränkt war. Die stärkste Wnt5a Expression schien hierbei in den stromalen Zellen zu sein, die mit hyperproliferativen Bereichen der Epidermis assoziiert waren und welche ein besonders hohes Level der Differenzierungsmarker $K 1$ und $K 10$ exprimierten. Dieses Ergebnis stützte die Annahme, dass Wnt5a mit der Differenzierung und möglicherweise auch der Regression der Tumoren in Verbindung stehen könnte. Es stellte sich dann aber noch die Frage, welche stromale Zellpopulation für die Wnt5a Expression verantwortlich war. Dazu wurden immunhistochemische Analysen an Paraffinschnitten von BCC gegen Fibroblasten (Vimentin-Antikörper) und Makrophagen (F4/80-Antiköper) durchgeführt. Das Stroma war für beide Marker positiv. Aufgrund des Fehlens eines geeigneten Wnt5a-Antikörpers war es uns somit leider nicht möglich immunhistochemische Ko-Färbungen auf dem gleichen Schnitt durchzuführen. Folglich konnte auch keine eindeutige Aussage über die stromale Wnt5a-exprimierende Zellpopulation gemacht werden. Um herauszufinden, welche Zellen für die stromale Wnt5a Expression verantwortlich waren, wurden deshalb sowohl Fibroblasten als auch Makrophagen mit der BCC-Zelllinie ASZ001 kokultiviert. In dieser Versuchsanordnung wurde eine erhöhte Wnt5a Expression in den Tumorzellen lediglich durch Makrophagen induziert. Diese Tatsache wurde auch durch 
weitere Analysen unserer Arbeitsgruppe unterstützt. So korrelierte die erhöhte Wnt5a Expression in vollentwickelten und regredienten Tumoren mit einer erhöhten F4/80 Expression in diesen Tumorstadien (Nitzki, F et al. 2010).

Es war bereits bekannt, dass tumorassoziierte Makrophagen (TAM, engl. tumor-associated macrophages) Wnt5a exprimieren können. So konnten Pukrop et al. zeigen, dass die Expression von Wnt5a in TAM zur Tumorprogression beim Brustkrebs beitrug (Pukrop, T et al. 2006). Auch in der vorliegenden Arbeit konnte gezeigt werden, dass mit Tumorzellen kokultivierte Makrophagen Wnt5a exprimierten. Im Gegensatz zum Brustkrebs schien beim BCC die Makrophagen-assoziierte Wnt5a Expression eher mit Tumorregression in Verbindung zu stehen. Dies passte zu der bereits beschriebenen Tatsache, dass Zellen des Immunsystems und Cytokine mit der spontanen Regression von BCC assoziiert waren (Hunt, MJ et al. 1994).

Die Kokultur-Versuche von Makrophagen und ASZ001 wurden zusätzlich mit dem spezifischen Hh-Signalweg-Inhibitor Cyclopamin durchgeführt. Hierdurch sollte untersucht werden, ob die Wnt5a Expression in den Makrophagen durch parakrines Hh Signaling der ASZ001 induziert wurde. Da Cyclopamin jedoch die durch Kokultivierung hervorgerufene Wnt5a Expression in den Makrophagen nicht hemmen konnte, kann man davon ausgehen, dass die Expression von Wnt5a in Makrophagen durch einen bisher unbekannten Faktor der Tumorzellen induziert wird und unabhängig vom $\mathrm{Hh} / \mathrm{Ptch}$ Signalweg ist.

\subsubsection{Wnt5a induziert die BCC Differenzierung über den $\mathrm{Wnt} / \mathrm{Ca}^{2+}$ Signalweg in Abhängigkeit der CaMKII}

Es war bekannt, dass Wnt5a sowohl als Ligand des kanonischen Wnt Signalwegs als auch der nicht-kanonischen Signalwege fungieren kann. Dies ist jeweils vom Rezeptorkontext

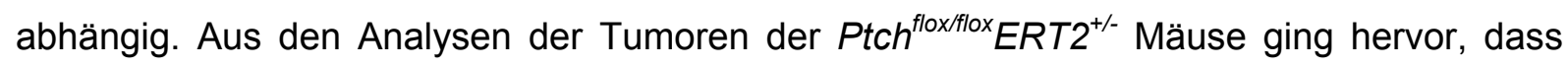
Wnt5a im Stroma von vollentwickelten und regredienten BCC exprimiert wird. Gleichzeitig konnte gezeigt werden, dass in diesen Tumorstadien die Differenzierungsmarker $K 1$ und $K 10$ hochreguliert wurden. Diese Tatsache legte die Vermutung nahe, dass Wnt5a direkt mit der Differenzierung der Tumoren in Verbindung steht. Das konnten die Versuche mit der BCCZelllinie ASZ001 bestätigen. So wurde sowohl nach Inkubation der ASZ001 mit rWnt5a, Wnt5a-CM als auch nach Kokultivierung mit Wnt5a-exprimierenden Makrophagen die K10 Expression in den Tumorzellen induziert. Im Rahmen dieser Arbeit sollte nun geklärt werden, über welchen der drei alternativen Signalwege (siehe Einleitung) Wnt5a die K10 Expression induziert. Dazu wurden qRT-PCR Analysen, immunhistochemische Analysen und Western Blots durchgeführt. Darüber hinaus wurde versucht die Aktivität der Signalwege mit der 
beobachteten Erhöhung der Wnt5a Expression in vollentwickelten und regredienten BCC zu korrelieren.

Analysen von ß-Catenin, seines Partners Bcl9-2 und seines Targets Axin2 in vollausgebildeten nodulären murinen und humanen BCC ergaben keinen Anhaltspunkt für eine Aktivierung des kanonischen Wnt Signalwegs. Weiterhin zeigten zellkulturbasierte Assays, dass rWnt5a den kanonischen Wnt Signalweg in der BCC-Zelllinie ASZ001 nicht aktivieren kann. Alle diese Daten legen daher die Vermutung nahe, dass der kanonische Wnt

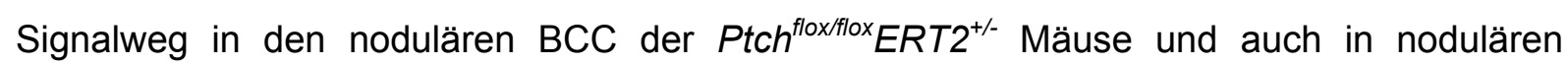
humanen BCC eine untergeordnete Rolle spielt und zudem nicht durch Wnt5a aktiviert werden kann. Diese Annahme steht im Gegensatz zu einer Publikation von Yang et al., die belegt, dass kanonisches Wnt Signaling in transgenen M2SMO Mäusen und in humanen superfiziellen BCC bei der Initiierung der BCC eine Rolle spielt (Yang, SH et al. 2008). Zusammend mit unseren Daten kann man daher vermuten, dass die Aktivität des kanonischen Wnt Signalwegs offenbar nur bei der BCC Initiation, nicht aber bei vollausgebildeten BCC, und vor allem nicht bei der BCC-Regression, eine Rolle spielt. Außerdem ist es möglich, dass der kanonische Signalweg mit speziellen histologischen BCC-Subtypen assoziiert ist. So waren die BCC in der Studie von Yang et al. einheitlich vom superfiziellen Subtyp, wogegen diejenigen unserer Studie ausschließlich vom nodulären Subtyp waren. Möglicherweise spielt der kanonische Signalweg auch noch eine Rolle bei infiltrativen BCC sowie bei anderen Hauttumoren wie z.B. Pilomatrikulomen, da auch in diesen Tumoren eine nukleäre Expression von ß-Catenin nachgewiesen werden konnte (Doglioni, C et al. 2003; El-Bahrawy, M et al. 2003; Palmer, HG et al. 2008).

Die Aktivität des Wnt/JNK Signalwegs wurde in den nodulären BCC der Ptch floxfllox $E R T 2^{+/-}$ Mäuse unter Verwendung eines anti-phospho-c-Jun Antikörpers analysiert, wobei das Expressionsmuster von phospho-c-Jun sehr heterogen war. Die Expression war nicht auf Tumorzellen beschränkt, sondern war auch im Stroma und Zellen der Epidermis zu finden. Außerdem wurde phospho-c-Jun in allen Tumorstadien exprimiert. Darüber hinaus korrelierte das Expressionsmuster von phospho-c-Jun ebenfalls nicht mit dem erhöhten Expressionslevel von Wnt5a in vollentwickelten und regredienten BCC. Daher ist

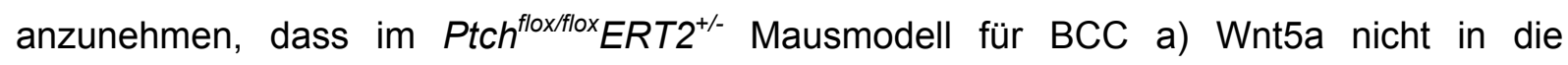
Aktivierung des Wnt/JNK Signalwegs involviert ist und b) der Wnt/JNK Signalweg nicht an der BCC-Regression beteiligt ist.

Die Aktivität des Wnt/Ca ${ }^{2+}$ Signalwegs wurde zunächst mittels eines Antikörpers untersucht, der die aktive Form der PKC detektierte. Hierbei zeigte sich, dass die PKC sowohl in den 


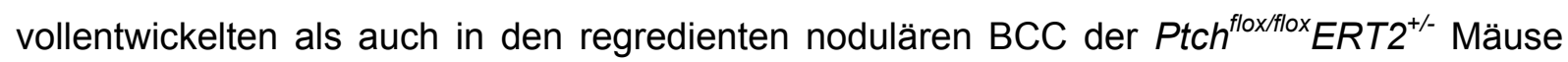
aktiviert war. Dies war der erste Hinweis, dass Wnt5a den Wnt/Ca ${ }^{2+}$ Signalweg in den BCC induzieren konnte.

Interessanterweise ist auch die Differenzierung von epidermalen Zellen $\mathrm{Ca}^{2+}$-abhängig (Fan, $\mathrm{H}$ und Khavari, PA 1999). Da eine Differenzierung wiederum zur Regression von BCC beitragen kann und da unsere Daten zeigten, dass Wnt5a die K10 Expression in BCC-Zellen induzierte, wurde nun untersucht, ob die Wnt5a-vermittelte $K 10$ Expression durch Aktivierung des $\mathrm{Ca}^{2+}$-abhängigen Wnt Signalwegs zustande kommen kann.

Wie andere Mitglieder unserer Arbeitsgruppe zeigen konnten, ließ sich die Wnt5a-induzierte K10 Expression in ASZ001 nur durch den CaMKII-spezifischen Inhibitor KN-93, nicht aber durch spezifische Inhibitoren der anderen Wnt Signalwege hemmen (Nitzki, F et al. 2010). Dies zeigt, dass die Wnt5a-induzierte $K 10$ Expression tatsächlich den Wnt/Ca ${ }^{2+}$ Signalweg involviert. Der Zusammenhang zwischen $\mathrm{Ca}^{2+}$ und $\mathrm{K} 10$ Expression wurde durch eine Inkubation von ASZ001 mit dem Calcium-lonophor lonomycin deutlich. Hierdurch wurde ebenfalls eine $K 10$ Expression induziert. Außerdem zeigten Transfektionsversuche, dass die konstitutiv aktive CaMKII-T286D zur Zunahme der K10 Expression in ASZ001 führte, das Kinase-inaktive CaMKII-Plasmid vermochte dies jedoch nicht.

Basierend auf all diesen Versuchen kann man schließen, dass Wnt5a in BCC von Ptch $^{\text {flox/llox }} E R T 2^{+/-}$Mäusen den $\mathrm{Wnt} / \mathrm{Ca}^{2+}$ Signalweg aktiviert. Diese Aktivierung führt zu einer erhöhten K10 Expression in Abhängigkeit der CaMKII.

Um die oben beschriebene Abhängigkeit der K10 Expression von Wnt5a und CaMKII zu bestätigen, wurden Hautstanzen von BCC-tragenden $\mathrm{Ptch}^{\text {floxflox }} \mathrm{ERT2}^{+/-}$Mäusen oder von Kontrollmäusen mit rWnt5a oder dem CaMKII-Inhibitor KN-93 kultiviert. Dadurch wurde ein System geschaffen, das den in vivo Konditionen eher ähnelt als die bisherigen Analysen mit der BCC-Zelllinie ASZ001. Auch diese Analysen zeigten, dass die Inkubation mit rWnt5a zu einem Anstieg der K10 Expression führt, welche sich durch Inkubation mit KN-93 rückgängig machen lässt. Somit zeigte auch dieser Versuch, dass der $\mathrm{Wnt} / \mathrm{Ca}^{2+}$ Signalweg bei der Wnt5a-vermittelten $\mathrm{K} 10$ Induktion im BCC involviert ist.

Da die Inkubationszeit in Zellkultur wahrscheinlich zu kurz war, um die Tumorgröße oder aber die Proliferationsrate der BCC-Stanzen zu beeinflussen (eine längere Inkubation der Hautstanzen führte allerdings zur Nekrose des Gewebes, was im Vorfeld dieses Versuchs ausgetestet worden war), sollten die Effekte von $\mathrm{Ca}^{2+}$ und Wnt5a auf das BCC-Wachstum nun in Ptch $^{\text {floxfllox}}$ ERT2 $^{+/-}$Mäusen in vivo untersucht werden (siehe Kapitel 4.2 und 4.3). 


\subsubsection{Modell für die Funktion von Wnt5a in BCC-Entwicklung und /-Regression}

Bevor zur Diskussion der in vivo Versuche übergegangen wird, soll zunächst das bis zu diesem Zeitpunkt aufgestellte Modell zu der Rolle von Wnt5a in der BCC-Entwicklung sowie /-Regression erklärt werden (Abbildung 45).

In frühen, vollentwickelten und regredienten nodulären BCC ist die Hh/Ptch Signalkaskade aktiv. Dies wird durch die Expression von Markergenen wie beispielsweise Gli1 deutlich. Die spontane Regression der Tumoren scheint in unserem Mausmodell durch Wnt5a ausgelöst zu werden, dessen Expression in stromalen Zellen durch unbekannte, von den Tumorzellen sezernierte lösliche Faktoren induziert werden. Stromales Wnt5a induziert in den Tumorzellen unter Aktivierung der CaMKII den Wnt/Ca ${ }^{2+}$ Signalweg. Das wiederum resultiert in einer erhöhten K10 Expression der Tumorzellen und schließlich in der Differenzierung der Tumoren. Daher kann die Abnahme der Proliferation und Zunahme der K10 Expression trotz bestehender $\mathrm{Hh} / \mathrm{Ptch}$ Signalwegsaktivität in vollentwickelten und regredienten BCC mit einem nichtzell-autonomen Szenario erklärt werden, das Tumor-Stroma-Interaktionen über den Wnt5a Signalweg vermittelt.

Diese Daten sind in Nitzki et al., 2010 in Cancer Research veröffentlicht worden (Nitzki, F et al. 2010).

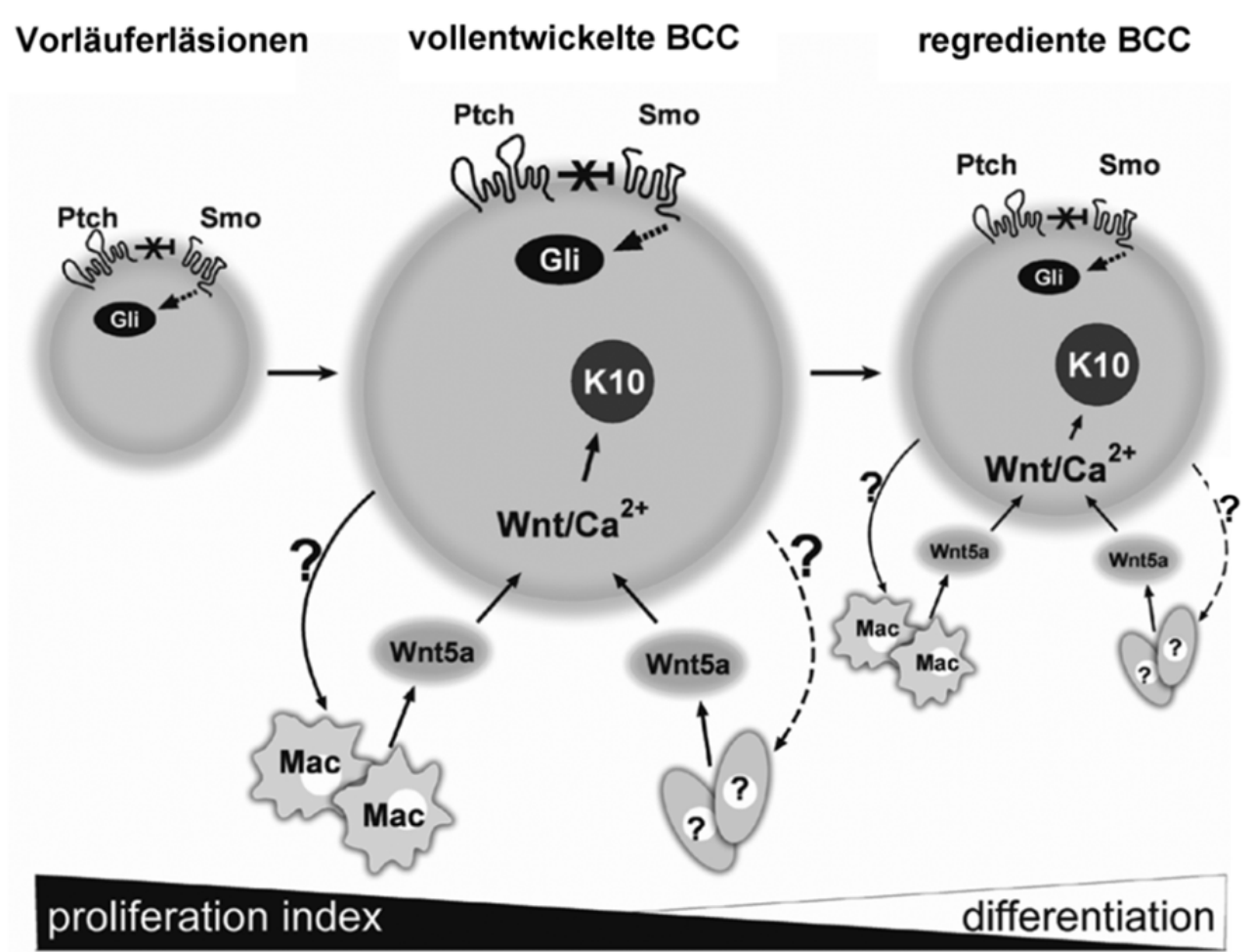

Abbildung 45: Modell der Funktion von Wnt5a in der BCC-Entstehung und /-Regression. Zur Erklärung siehe Text.

An dieser Stelle sollen noch kurz weitere, im Rahmen dieser Arbeit generierte Daten diskutiert werden. 
So wurde auch in humanen BCC versucht, die Wnt5a Expression mit dem Proliferationsstatus der Tumoren in Verbindung zu bringen. Wie schon in der Einleitung beschrieben, kommt es auch beim Menschen in ca. 20\% der Fälle zur Spontanregression von BCC (Curson, C und Weedon, D 1979). Zudem ist Wnt5a anscheinend in vielen humanen BCC überexprimiert (Bonifas, JM et al. 2001; Saldanha, G et al. 2004; Yang, SH et al. 2008). Für die Analysen wurden 28 humane BCC, die von der Abteilung Dermatologie (Universitätsmedizin Göttingen) bezogen worden sind, zunächst hinsichtlich ihrer Wnt5a Expression untersucht. Leider stand kein Frischgewebe zur Verfügung, so dass die Wnt5a Expression nicht quantifiziert werden konnte. Die Wnt5a Expression musste daher anhand von in situ-Hybridisierung gemessen werden, was sich jedoch aufgrund von Hintergrundfärbung als extrem schwierig gestaltete. Da die Proben nicht explizit für den Nachweis von RNA konserviert worden waren, könnte dies daher mit der RNA Qualität zusammenhängen. In 6 der Wnt5a positiven und 4 der Wnt5a negativen Proben wurde dann mittels immunhistologischer Färbung für Ki67 versucht, den Anteil proliferierender Tumorzellen prozentual zu quantifizieren. Es konnte jedoch keine Korrelation zwischen Wnt5a Expression und dem Proliferationsstatus hergestellt werden. Da jedoch a) keine Information zu den BCC hinsichtlich ihres Regressionsstatus vorlag, b) die RNA in den Proben möglicherweise degradiert war und c) daher auch keine klare Aussage zur stromalen Expression von Wnt5a gemacht werden konnte, ließ sich somit auch kein eindeutiger Rückschluss auf eine Korrelation von Wnt5a Expression, Proliferationsstatus oder Regression der Tumoren ziehen.

\subsection{Effekt von $\mathrm{Ca}^{2+}$ auf $\mathrm{BCC}$ im Mausmodell}

Aus den im ersten Abschnitt der Diskussion beschriebenen Zellkulturexperimenten geht hervor, dass die Wnt5a-vermittelte $K 10$ Induktion in ASZ001 höchstwahrscheinlich über den $\mathrm{Ca}^{2+}$-abhängigen Wnt Signalweg erfolgt. Da diese Erkenntnisse nur auf in vitro Analysen basierten, wurde der Einfluss von $\mathrm{Ca}^{2+}$ auf Differenzierung und BCC-Regression nun in vivo untersucht.

Um die $\mathrm{Ca}^{2+}$ Konzentration in der BCC-tragenden Haut anzuheben, wurden $\mathrm{Ptch}^{\text {floxfllox}} \mathrm{ERT2}^{+/-}$Mäuse über 90, 75 oder 45 Tage mit lonomycin behandelt. Dass Mäuse eine derartige Applikation des lonophors tolerieren, wurde bereits in der Studie von Perchellet et al. gezeigt (Perchellet, EM et al. 1990). In der hier vorgestellten Studie wurde die Behandlung in unterschiedlichen BCC-Stadien, d.h. direkt, 15 oder 45 Tage nach Tumorinduktion begonnen. Alle Mäuse wurden am Tag 90 nach der Tumorinduktion abgetötet.

Nun ist aus der Literatur bekannt, dass $\mathrm{Ca}^{2+}$ einen antiproliferativen und differenzierungsfördernden Effekt auf Keratinozyten hat (Perchellet, EM et al. 1990). 
Zusammen mit der Hypothese, dass der Wnt/ $\mathrm{Ca}^{2+}$ Signalweg eine Differenzierung der BCC aktivieren kann, wurde erwartet, dass die Applikation von lonomycin daher auf BCC a) antiproliferativ und b) differenzierungsfördernd wirkt. Obwohl die Applikation von Ionomycin in keiner der drei Kohorten einen Einfluss auf die histologisch-vermessbare Tumorgröße hatte, konnte die Expression von $\mathrm{K} 10$ und von weiteren epidermalen Differenzierungsmarkern nach einer 90tägigen Behandlung signifikant induziert werden. Dies lässt den Schluss zu, dass das Level der $\mathrm{Ca}^{2+}$ Konzentration in der Haut durch lonomycin tatsächlich ansteigt. Dieser Anstieg reicht anscheinend auch aus, um eine Verringerung proliferierender BCC-Zellen nach einer 90tägigen oder 45tägigen Applikation hervorzurufen. Warum sich allerdings der Proliferationsindex der Kohorte 2, welche von Tag 15 bis Tag 90 nach Tumorinduktion, also über 75 Tage mit Ionomycin behandelt wurde, gar nicht veränderte, ist etwas verwunderlich. Möglich ist, dass nicht die Dauer der IonomycinApplikation Einfluss auf die BCC-Proliferation nimmt, sondern dass der Zeitpunkt der Applikation viel entscheidender für eine Verminderung proliferierender Zellen ist. Sehr viel wahrscheinlicher ist jedoch, dass die Variabilität der Messdaten der einzelnen Tumoren zu groß und die Anzahl der vermessenen Tumoren zu gering war, um signifikante Ergebnisse zu erzielen.

Weiterhin ist schwer zu erklären, warum die Abnahme der Proliferationsrate nach lonomycinApplikation in den Kohorten 1 und 3 nicht mit einer Abnahme der histologisch messbaren Tumorgröße korrelierte. Da letztere aber eine eher ungenaue Methode war und in einem völlig zufällig getroffenen Tumorareal vermessen wurde, war die Auszählung von Ki67 positiven Zellen sicherlich die objektivere Methode.

Die Tatsache, dass eine 90-tägige Applikation von lonomycin zur signifikanten Expression von Differenzierungsmarkern in der Haut führt und zudem die Proliferationsrate der Tumoren senkt, ist sicherlich interessant. Es ist nämlich möglich, dass eine längere lonomycinBehandlung der Ptch floxflox ERT2 ${ }^{+/}$Mäuse (sprich länger als 90 Tage) die Differenzierung der Tumoren dann derart beeinflusst, dass die Behandlung schließlich sogar in einer histologisch-vermessbaren Tumorabnahme resultiert.

Zusammengefasst kann man festhalten, dass die lonomycin-Applikation zur Expression von Differenzierungsmarkern in BCC geführt hat. Zudem beweist dieses Experiment, dass $\mathrm{Ca}^{2+}$ auch in vivo eine bedeutende Rolle bei der Differenzierung und auch bei antiproliferativen Vorgängen von BCC spielt. 


\subsection{Einfluss der Wnt5a Überexpression und der verminderten Wnt5a Expression auf BCC im Mausmodell}

Im Rahmen dieser Dissertation sollte außerdem geprüft werden, ob Wnt5a auch in vivo in die Differenzierung von BCC und/oder Tumorregression involviert ist. Hierzu wurde die Wnt5a Expression in der Haut von BCC-tragenden Ptch $^{\text {floxflox }}$ ERT2 $^{+-}$Mäusen zum einen erhöht, und zum anderen vermindert. Sollte Wnt5a tatsächlich in Differenzierung und BCC-Regression involviert sein, sollte eine Wnt5a Überexpression zu vermindertem Tumorwachstum führen. Falls es sich im BCC bei Wnt5a jedoch wider Erwarten um ein Onkogen handeln sollte (wie dies für viele andere Tumorentitäten gezeigt worden war (lozzo, RV et al. 1995; Bittner, M et al. 2000)), dann sollte die Überexpression von Wnt5a in aggressiverem Tumorwachstum und schließlich in der Vergrößerung der BCC resultieren.

\subsubsection{Einfluss der Wnt5a Überexpression im BCC in vivo}

Um den Einfluss von Wnt5a auf das Wachstum und die Differenzierung von BCC im Mausmodell zu untersuchen, sollte Wnt5a in der Haut zunächst überexprimiert werden.

Am einfachsten wäre die topische Applikation von rWnt5a auf BCC-tragende Haut gewesen. Dieser Ansatz wurde jedoch aus Kostengründen schnell verworfen, da kommerziell erwerbliche rekombinante Proteine sehr teuer sind. Zudem unterscheiden sich die einzelnen Chargen rekombinanter Proteine häufig in ihrer Wirksamkeit. Eine andere alternative Möglichkeit zur Überexpression von Wnt5a in vivo wäre die Generierung transgener Mäuse gewesen, die Wnt5a in stromalen Makrophagen exprimieren. Dieser Ansatz wurde verworfen, weil bislang kein geeigneter Promotor bekannt ist, der zu einer Makrophagenspezifischen Expression von Genen genutzt werden kann. Voruntersuchungen zur Identifikation eines adäquaten Promotors hätten den Rahmen dieser Arbeit gesprengt. Auch wurde überlegt, Wnt5a-exprimierende Zelllinien wie beispielsweise die NIH3T3-Wnt5a Zelllinie, in BCC-tragende Mäuse zu transplantieren. Da es sich bei den $\mathrm{Ptch}^{\text {floxflox }} E R T 2^{+/-}$ Mäusen jedoch um immunkompetente Mäuse handelt, wurde auch diese Idee verworfen.

Im Rahmen dieser Arbeit sollte deshalb die Wnt5a Expression in der BCC-tragenden Haut durch Spritzen einer nackten Wnt5a-exprimierenden Plasmid-DNA erhöht werden. Dass die Überexpression von nackter Plasmid-DNA in vivo möglich ist, konnte bereits vor über einem Jahrzehnt gezeigt werden (Hengge, UR et al. 1996). Auch Collinet et al. zeigten in ihren Untersuchungen, dass die Applikation nackter DNA neben der herkömmlichen Behandlung von Ovarialkarzinomen ein unterstützendes therapeutisches Potential aufwies (Collinet, $\mathrm{P}$ et al. 2006). Auch bei primären bzw. metastasierenden Tumoren konnte eine intramuskuläre Injektion nackter Plasmid-DNA, die für IFN- $\alpha$ kodierte, einen antitumoralen Effekt erzielen (Horton, HM et al. 1999). 
Um diese Methode im Labor zu etablieren, wurde zunächst ein ßGalaktosidase-kodierendes Plasmid in der murinen Haut exprimiert. Die Abbildung 20 zeigt, dass diese Methode in der Maushaut funktionierte. Zudem konnte gezeigt werden, dass die ßGalaktosidase Aktivität 24h nach der letzten Injektion höher war als 7 Tage nach der letzten Injektion. Daher sollte die BCC-tragende Maushaut nach Spritzen des Wnt5a-exprimierenden Plasmids zukünftig bereits $24 \mathrm{~h}$ nach der letzten Injektion isoliert werden, um kontinuierlich ein hohes Wnt5aLevel in der Haut zu gewährleisten.

Leider konnte das Experiment aus Zeitgründen im Rahmen dieser Arbeit nicht abgeschlossen werden, da das zunächst verwendete Wnt5a-Expressionsplasmid für die Analysen nicht geeignet war und ein neues Wnt5a-exprimierendes Plasmid kloniert werden musste. Dabei war die Einführung einer Kozak-Konsensussequenz in das Plasmid für die bessere Wnt5a Expression notwendig. Das klonierte Plasmid steht nun für die Analysen bereit.

Es wurde außerdem überlegt, ob man die Wnt5a Expression in vivo durch eine Verpackung des Expressionsplasmids in Polyethylenimin(PEI)-Komplexe steigern kann. PEI ist das Polymerisationsprodukt des Monomers Ethylenimin. PEI-Komplexe werden in der Molekularbiologie bei der Transfektion von Nukleinsäuren, wie beispielsweise Plasmiden oder häufig auch siRNAs in humane oder murine Zellen, sowohl für in vitro als auch in vivo Transfektionen eingesetzt (Malek, A et al. 2009). In dem Review von Lemkine und Demeneix wurde beschrieben, dass PEls insbesondere zur Gentherapie in vivo eingesetzt werden können (Lemkine, GF und Demeneix, BA 2001). In einer aktuellen Studie konnte weiterhin gezeigt werden, dass DNA/PEI-Komplexe den Haarwuchs nach Transfektion von Haarfollikel-Stammzellen stimulieren konnten (Jan, HM et al.). Aufgrund dieser Daten ist anzunehmen, dass die PEI-Komplexierung des Wnt5a-Expressionsplasmids wahrscheinlich zu einer höheren Expression von Wnt5a in der Haut führen könnte. Bei dieser Applikationsform sollte jedoch die Gefahr berücksichtig werden, dass DNA/PEI-Komplexe bei systemischer Applikation nicht-spezifische Interaktionen mit Komponenten des Blutes und anderen Zellen eingehen können, was dann natürlich zu Nebenwirkungen der Applikation führt (siehe Review (Kichler, A 2004)).

Weiterhin wurde überlegt, ob die Überexpression von Wnt5a in vivo durch Elektroporation gesteigert werden kann. Dies ist schon für andere Expressionsplasmide gezeigt worden (Titomirov, AV et al. 1991; Heller, R et al. 2001). 


\subsubsection{Untersuchung der Effekte einer verminderten Wnt5a Expression auf BCC im Mausmodell}

Falls unsere Hypothese zutreffen sollte und Wnt5a im BCC tatsächlich als Tumorsuppressor agiert, d.h. dass Wnt5a sowohl in BCC-Differenzierung als auch in BCC-Regression involviert ist, müssten BCC der Maus nach Verminderung der Wnt5a Expression ein verstärktes Wachstum zeigen.

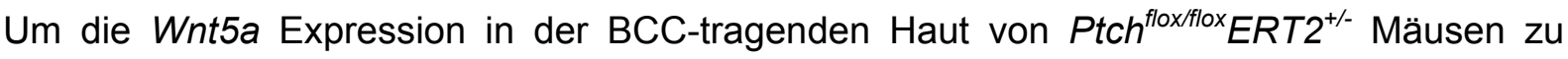
vermindern, wurden drei verschiedene experimentelle Ansätze verfolgt. Hierbei handelte es sich um das Einkreuzen von Wnt5a Knockout-Mäusen in das Ptch flox/flox ERT2 ${ }^{+/-}$Mausmodell als genetischer Ansatz, das Ersetzen von Wnt5a-exprimierenden Makrophagen durch Wnt5a-/- Makropagen und die Depletion der Wnt5a-exprimierenden Makrophagen durch eine systemische Gabe von Clodrolip.

\subsubsection{Einfluss der Deletion eines Wnt5a Allels auf das BCC-Wachstum}

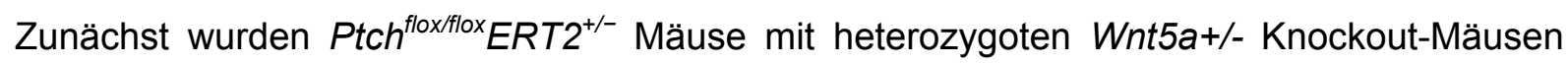
verpaart. Da Wnt5a-/- Knockout-Mäuse perinatal sterben (Yamaguchi, TP et al. 1999), konnten nur $\mathrm{Ptch}^{\text {floxfllox}} E R T 2^{+/-} W n t 5 a^{+/-}$generiert werden. In diesen Mäusen wurden dann mittels Tamoxifeninjektion BCC induziert. Als Kontrollen wurden BCC in Ptch ${ }^{\text {floxflox }} \mathrm{ERT2}^{+/-}$ Mäusen, d.h. in Mäusen ohne Wnt5a Knockout, induziert. Die BCC wurden dann 45 Tage (Vorläuferläsionen; Kohorte 1), 90 Tage (vollentwickelte BCC; Kohorte 2) und 250 Tage (regrediente BCC; Kohorte 3) nach Tumorinduktion analysiert.

In keiner der drei analysierten Kohorten (Vorläuferläsionen, vollentwickelte BCC und regrediente Tumoren) konnte eine signifikante Herunterregulierung der Wnt5a Expression gemessen werden. Diese Daten zeigen, dass die Deletion eines Wnt5a Allels nicht ausreicht, um eine signifikante Verminderung der Wnt5a Expression in der BCC-tragenden Haut zu erzielen. Deshalb war es nicht verwunderlich, dass bei diesem genetischen Versuchsansatz

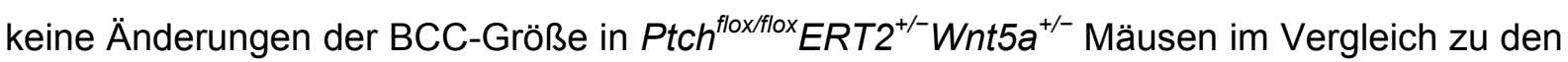
Kontrolltieren festgestellt werden konnten. Zudem zeigten alle $\operatorname{Ptch}^{\text {floxflox }} E R T 2^{+/-} W n t 5 a^{+/-}$

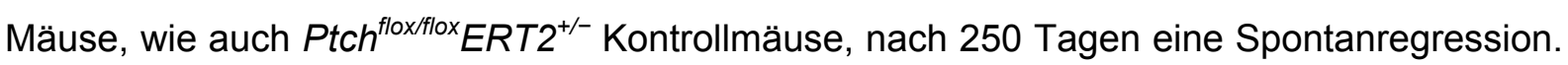
Hierzu ist jedoch zu sagen, dass manchmal schon geringe "dosage-Unterschiede“ zu einer Änderung des Phänotyps führen können. So ist bekannt, dass hemizygote Wnt5a KnockoutMäuse im Alter von etwa 24 Monaten in ca. 25\% der Fälle B-Zell Lymphome und chronisch myeloische Leukämien (CML) entwickeln (Liang, $\mathrm{H}$ et al. 2003).

Auffällig war in dem Versuchsansatz jedoch, dass eine der Ptch $^{\text {floxflox }} E R T 2^{+-} W n t 5 a^{+-}$Mäuse der Kohorte 3 (regrediente BCC) einen unerwarteten Phänotyp aufwies. So zeigte der Nackenbereich eine enorme Hyperplasie der Epidermis, was sofort mit der Verminderung 
der Wnt5a Expression in Verbindung gebracht wurde. Dieser Phänotyp könnte für eine tumorsuppressorische Funktion von Wnt5a sprechen, zudem nach dem Rasieren der Haut von $\mathrm{Ptch}^{\text {floxfllox }} E R T 2^{+/-} \mathrm{Wnt} \mathrm{a}^{+/-}$Mäusen weitere, kleinere hyperplastische Veränderungen in 3 von 11 Mäusen makroskopisch sichtbar wurden. Da jedoch ein solcher kleiner

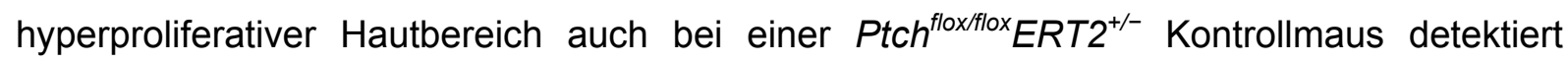
wurde, ist es möglich, dass diese Veränderungen häufiger im konditionellen Ptch $^{\text {floxfllox }} E R T 2^{+/-}$ BCC-Mausmodell auftreten und bisher nicht detektiert wurden. Um dies zu bestätigen, müsste man eine größere Zahl an BCC-tragenden $\mathrm{Ptch}^{\text {floxflox }} E R T 2^{+/-}$Mäuse untersuchen. Sollte man dann tatsächlich in mehreren dieser Mäuse nach der Rasur diese Hautveränderungen finden, könnten sie eventuell durch eine deregulierte Hh/Ptch Signalkaskade bedingt sein und hätten somit nichts mit Wnt5a Heterozygotie zu tun.

Da die Wnt5a Heterozygotie per se nicht zur verminderten Wnt5a Expression in der Haut führte, waren weitere Ansätze zur Verminderung der Wnt5a Expression, insbesondere in Makrophagen, notwendig.

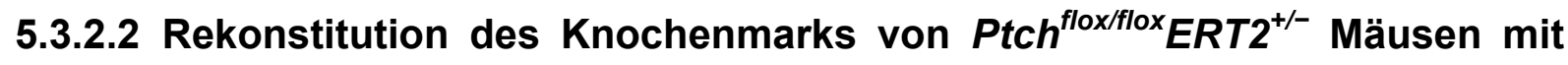 Wnt5a-defizienten Zellen}

In einem weiteren experimentellen Ansatz wurde daher versucht, Wnt5a-exprimierende Makrophagen durch Wnt5a-defiziente zu ersetzen.

Dazu wurden Ptch $^{\text {floxfllox}} E R T 2^{+/-}$Mäuse mit einer letalen Dosis von 10Gy bestrahlt. Am nächsten Tag wurden sie mit Leberzellen aus Wnt5a-defizienten Wnt5a-/- Embryonen transplantiert. Kontrollen erhielten Leberzellen aus wildtypischen Wnt5a+/+ Embryonen. Das genaue Vorgehen ist in Kapitel 3.4.6 beschrieben.

Dieses Experiment bereitete zunächst große Probleme, da die Methode inklusive der i.v. Injektion zunächst etabliert werden musste. Dass bestrahlte Mäuse mittels Transplantation fötaler Leberzellen jedoch generell repopulierbar sein müssen, stand außer Frage (siehe z.B. (Aziz, A et al. 2006)). Nach dem ersten missglückten Transplantationsexperiment sind alle Mäuse im Zeitraum von 8 und 11 Tagen nach Transplantation gestorben. Man hätte spekulieren können, dass die letale Strahlendosis möglicherweise zu hoch gewählt worden war. Da Mäuse in den Studien von Wüst et al. sogar eine Bestrahlung mit 11,5Gy überlebten (Wust, S et al. 2008), wurde diese Idee wieder verworfen. Weiterhin wurde spekuliert, dass Mäuse mit Wnt5a-defizientem Knochenmark nicht lebensfähig sind. Dagegen sprach jedoch,

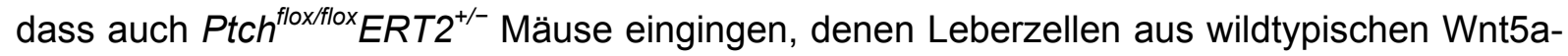
Embryonen injiziert wurden. Außerdem wurde schon im Jahr 2003 gezeigt, dass sich Leberzellen aus 16 Tage alten Wnt5a-/- Embryonen transplantieren lassen und ein funktionelles Knochenmark bilden (Liang, $\mathrm{H}$ et al. 2003). Außerdem konnte das Absterben der Tiere nicht durch eine "Graft versus Host Disease“ erklärt werden. Da die Wnt5a 
Knockout-Mäuse zudem auch in IVC-Haltung in einem sterilen Umfeld lebten, konnte auch die Übertragung von Infektionen der transplantierten fötalen Leberzellen ausgeschlossen werden. Letztendlich stellte sich dann heraus, dass die Ursache für die fehlgeschlagenen Transplantationsexperimente eine Paravasation der Zellen war. Tatsächlich konnten alle Mäuse erfolgreich transplantiert werden, als die i.v. Injektion von einer erfahrenen Wissenschaftlerin eines Nachbarlabors anstelle des Tierstall-Personals durchgeführt wurde.

Wie die FACS-Analysen des Blutes zeigten, hatten alle bestrahlten bzw. transplantierten Mäuse innerhalb von sechs Wochen wieder ein intaktes Immunsystem mit normaler Lymphozytenanzahl aufgebaut. Die Genotypisierungen des Blutes (siehe Abbildung 26)

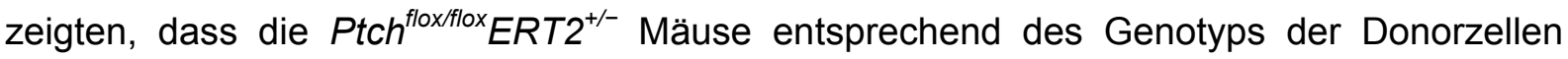
erfolgreich repopuliert waren. Allerdings sollte erwähnt werden, dass in 5 von 14 Mäusen im Blut weiterhin die Bande der ERT2 (Cre-Rekombinase) auftrat und somit durch die Bestrahlung nicht alle Knochenmarkszellen der bestrahlten Ptch $^{\text {floxflox }} E_{R T 2^{+-}}$Mäuse abgetötet wurden.

In allen transplantierten Tieren sind dann BCC induziert worden. Die Analysen sind jedoch noch nicht abgeschlossen und können erst nach Abgabe dieser Arbeit durchgeführt werden.

Bei den kommenden Analysen ist nun zu beachten, dass manche der Tiere ein chimäres Knochenmark haben dessen Zellen sowohl aus den ursprünglichen Wnt5a+/+ Knochenmarkszellen als auch aus den transplantierten Wnt5a-/- Leberzellen hervorgeht. Da es denkbar ist, dass wildtypische Wnt5a-Zellen möglicherweise einen Proliferationsvorteil gegenüber den Wnt5a-/- Zellen haben, könnte es sein, dass die Wnt5a-/- Zellen bei bestehendem Chimärismus von wildtypischen Zellen verdrängt werden. In der Literatur gibt es zwar keine konkreten Hinweise zur Bestätigung einer solchen Annahme, allerdings muss beim Abtöten der Mäuse erneut das Knochenmark analysiert werden.

Das Vorhandensein eines Chimärismus muss auch bei der Analyse der BCC-Größe beachtet werden. Falls nicht alle hämatopoetischen Wnt5a+/+ Zellen durch Wnt5a-defiziente ersetzt wurden, wird es sehr schwer sein, den Einfluss eines reinen Wnt5a-defizienten Stromas auf das BCC-Wachstum zu bestimmen. Außerdem muss beachtet werden, dass natürlich auch andere hämatopoetische Zellen wie beispielsweise B-/ und T-Zellen nach der Repopulation Wnt5a-defizient sind. Da auch diese Zellen in die Haut einwandern, können sie möglicherweise ebenfalls in das potentiell veränderte BCC-Wachstumsverhalten involviert sein.

Bezogen auf die Strahlung sollte noch erwähnt werden, dass die repopulierten $\mathrm{Ptch}^{\text {flox/flox }} \mathrm{ERT2}^{+/-}$Mäuse einer letalen Dosis ausgesetzt waren. Es ist daher nicht auszuschließen, dass strahlenbedingte Effekte den Organismus und auch die Haut 
geschädigt haben. Falls solche Effekte auftreten sollten, sind sie wahrscheinlich nicht gravierend, da sie in keiner der bisher beschriebenen Studien diskutiert wurden.

Die transplantierten Ptch $^{\text {floxfllox}} E R T 2^{+/-}$Mäuse werden momentan regelmäßig observiert und gewogen. Bisher sind die Tiere wohlauf. Das bedeutet, dass das Wnt5a-defiziente Knochenmark wahrscheinlich zu einem funktionstüchtigen Immun-/Blutsystem führt und nicht in Immun-/ oder Gerinnungsstörungen resultiert.

\subsubsection{Effektive Depletion Wnt5a-exprimierender Makrophagen durch Clodrolip}

Wie bereits mehrfach erwähnt, wurde die Spontanregression der BCC in Ptch $^{\text {floxflox }}{ }^{\text {ERT2 }}{ }^{+/}$ Mäusen mit der Wnt5a Expression in Makrophagen in Verbindung gebracht. In einem weiteren experimentellen Ansatz wurde daher versucht, diese Wnt5a-exprimierenden Makrophagen im BCC-Stroma zu depletieren. Die Depletion erfolgte durch Applikation von Clodrolip.

Bei Clodrolip handelt es sich um in Liposomen-verpacktes Clodronat, ein Bisphosphonat. Bisphosphonate sind Medikamente, die für diagnostische und therapeutische Zwecke bei Knochen-/ sowie Calciumstoffwechselkrankheiten eingesetzt werden. Sie haben eine hohe Affinität zu anorganischen Calciumverbindungen, binden also an Knochensubstanz. Bisphosphonate, wie Clodronat, werden in der Klinik gegen Knochenmetastasen und wegen der hohen Endocytosekapazität von Osteoklasten gegen Knochenresorption eingesetzt (Rogers, MJ et al. 2000). Die therapeutischen Effekte von Clodronat werden hierbei durch Depletion von Makrophagen, zu deren Familie auch Osteoklasten gehören, hervorgerufen. Die Depletion von Makrophagen durch Clodronat erfolgt durch eine Störung der ATPSynthese in diesen Zellen. Clodronat, also das Bisphosphonat, wird anstelle von Pyrophosphat in die ATP-Moleküle eingebaut. Dadurch wird Clodronat zum toxischen ATPAnalogon AppCCl $2 \mathrm{p}$ (Adenosin 5'-[ß,Y-Dichlormethyl] Triphosphat) metabolisiert, das die mitochondriale ATP-Synthese hemmt. Die neu entstehende Verbindung kann nicht mehr hydrolytisch gespalten werden, führt zum Verlust des Membranpotentials und schließlich zur Induktion von Apoptosevorgängen.

Auch Clodrolip (d.h. in Liposomen-verpacktes Clodronat) führt zur Apoptose von Makrophagen. Dies konnte bislang nicht nur in vitro gezeigt werden (Hiraoka, K et al. 2008), sondern auch durch in vivo Experimente. So führt die Applikation von Clodrolip zur signifikanten Reduzierung der Anzahl infiltrierender mononukleärer Makrophagen in Tumoren (Zeisberger, SM et al. 2006; Gazzaniga, S et al. 2007). Weiterhin belegen mehrere Studien, dass Applikation von Clodrolip die Anzahl F4/80-positiver Zellen in der Peritonealhöhle sowie Mac1/Gr1-positiver Zellen im peripheren Blut und andere 
mononukleäre Zellen vermindert (Priceman, SJ et al. ; Nakao, S et al. 2005; Torroella-Kouri, $\mathrm{M}$ et al. 2009).

Makrophagen sind wichtige Zellen des Immunsystems. Daher wurde in einem Vorversuch zunächst die Toleranz der Mäuse gegenüber der Substanz ausgetestet. In Anlehnung an die Empfehlungen von R. Schwendener erfolgte die Clodrolipapplikation jeden vierten Tag (erste Dosis $2 \mathrm{mg} / 20 \mathrm{~g}$; folgende Dosen $1 \mathrm{mg} / 20 \mathrm{~g}$ ). Die Mäuse vertrugen diese Dosis sogar über 75 Tage hinweg, ohne dass Gewichtsverlust oder weitere Anzeichen einer eingeschränkten Vitalität auftraten.

Die vorliegenden Daten zeigen eindeutig, dass die Applikation von Clodrolip in $\mathrm{Ptch}^{\text {flox/flox }} \mathrm{ERT2}^{+/-}$Mäusen zur signifikanten Depletion von Makrophagen in Milz und Haut führte. So wiesen immunhistologische Antikörperfärbungen an Milzen von Clodrolipbehandelten Mäusen deutlich weniger F4/80-positive Zellen im Vergleich zu denen von Leerliposomen-behandelten Mäusen auf. Außerdem konnte über quantitative RT-PCR gezeigt werden, dass sowohl die F4/80 als auch die Mac1 Expression in der Milz und Haut nach Applikation von Clodrolip signifikant vermindert wurde. Diese Ergebnisse stimmen mit den Studien von Zeisberger et al., Zumsteg et al. und Kataru et al. überein (Zeisberger, SM et al. 2006; Kataru, RP et al. 2009; Zumsteg, A et al. 2009). In der Studie von Zeisberger et al. führte die Applikation von Clodrolip zur Depletion F4/80 und MOMA-I positiver Zellen in der Milz. Zusätzlich zu diesen genannten Markern konnte eine Depletion CD11b positiver Zellen in Tumoren beobachtet werden, welche mit einer Inhibierung des Tumorwachstums und mit gleichzeitiger Verminderung der Angiogenese korreliert (Zeisberger, SM et al. 2006). In der Studie von Kataru et al. konnte gezeigt werden, dass die Clodrolipapplikation zur Depletion CD11b/Gr1 positiver Zellen der Haut führte (Kataru, RP et al. 2009). Auch in den $\mathrm{Ptch}^{\text {floxfllox}} \mathrm{ERT2}^{+/-}$Mäusen war nach Applikation von Clodrolip nahezu keine F4/80 Expression in der Haut mehr nachzuweisen. Der noch geringe Anteil an vorhandener Mac1 Expression lässt sich durch ständige Rekrutierung von Makrophagen in das Tumorgewebe erklären, da die Mäuse die Tumoren teilweise aufkratzen und es so zur verstärkten Inflammation der Haut kommen kann.

\subsubsection{Effekt der Makrophagendepletion auf das BCC-Wachstum}

Wie soeben erläutert, führte die Clodrolipbehandlung zur effizienten Makrophagendepletion in der Haut der BCC-tragenden Ptch ${ }^{\text {floxflox }} E R T 2^{+/-}$Mäuse. Die Daten zeigten weiterhin, dass dies gleichzeitig mit einer signifikant verminderten Wnt5a Expression in der BCC-tragenden Haut einherging. Letzteres lässt nun den Schluss zu, dass die stromale Wnt5a Expression im $\mathrm{BCC}$ der $\mathrm{Ptch}^{\text {floxfllox}} \mathrm{ERT2}^{+/-}$Mäuse tatsächlich von Makrophagen ausgeht. 
Allerdings konnte nicht ausgeschlossen werden, dass möglicherweise neben Makrophagen auch noch andere stromale Zellen Wnt5a exprimieren. Die qRT-PCR Analyse der Haut belegte zwar, dass die Wnt5a Expression nach Clodrolipapplikation signifikant vermindert, allerdings nicht vollständig eliminiert war. Die Tatsache, dass sich jedoch auch die Makrophagenmarker F4/80 bzw. Mac1 in der Haut mittels PCR nach 75tägiger Applikation von Clodrolip nachweisen ließen, könnte die residuale Wnt5a Expression erklären. Auf der anderen Seite ist es möglich, dass Makrophagen nicht die alleinige Quelle für die stromale Wnt5a Expression im BCC sind. Aufgrund dieser Tatsachen ist es schwer zu beurteilen, ob Wnt5a ausschließlich von Makrophagen oder noch von anderen stromalen Zellen exprimiert wird.

Laut unserer Hypothese und den in vitro Daten stand das Wnt5a Level auch im direkten Zusammenhang mit der Induktion des Differenzierungsmarkers K10. Aufgrund dieser Annahme hätte daher eine verminderte Wnt5a Expression in vivo auch die Expression von K10 in der BCC-tragenden Haut senken müssen. Die verminderte Expression dieses Differenzierungsmarkers konnte jedoch nicht eindeutig gezeigt werden. Dies kann möglicherweise mit der Behandlungsdauer (75 Tage) der BCC-tragenden Mäuse zusammenhängen. Dies widerspricht jedoch den erhobenen Daten hinsichtlich Proliferation und Größe der BCC, da beide Parameter nach Clodrolipapplikation zunahmen. Diese Daten lassen daher stark vermuten, dass Wnt5a Expression und K10 Induktion nicht direkt miteinander verknüpft sind.

Die Beobachtung, dass die Clodrolip-Gabe tatsächlich mit einer Zunahme des BCCWachstums assoziiert ist, ist hochinteressant. So nahmen sowohl die Größe der BCC als auch die Anzahl Ki67 positiver Zellen nach Clodrolipapplikation - im Gegensatz zur Leerliposomenbehandlung - zu. Da dies a) mit einer verminderten Anzahl an Makrophagen und b) mit einer verminderten Expression von Wnt5a einherging, ist es möglich, dass Makrophagen, oder Wnt5a oder beide Faktoren in den $\mathrm{Ptch}^{\text {flox/flox }} E R T 2^{+/-}$Mäusen eine tumorsuppressorische Funktion im BCC haben.

Welcher Faktor bei der Hemmung des BCC-Wachstums wichtiger ist, ist schwer zu sagen.

Es gibt Studien die belegen, dass tumorassoziierte Makrophagen (TAM) tatsächlich einen hemmenden Einfluss auf das Tumorwachstum haben können (Hallam, S et al. 2009). Auf der anderen Seite ist bekannt, dass TAM durch Interaktion mit den Tumorzellen zur Produktion von angiogenen Faktoren, entzündlichen Cytokinen, Wachstumsfaktoren und Proteasen angeregt werden. Dies kann dann einen fördernden Einfluss auf Angiogenese, Invasion und Metastasierung des Tumors haben (Polverini, PJ et al. 1977; Mantovani, A et al. 2003) und 
mit einer schlechten Prognose bei Patienten mit verschiedenen Tumoren assoziiert sein (Sunderkotter, C et al. 1994; Leek, RD et al. 1996).

Im Ptch ${ }^{\text {floxfllox}} \mathrm{ERT2}^{+/-}$Mausmodell für BCC scheinen TAM möglicherweise einen solchen tumorhemmenden Einfluss zu haben (siehe auch Diskussion im Kapitel 5.3.4). Dies steht im Gegensatz zu einer Studie von Tjiu et al., in der postuliert wird, dass TAM einen tumorfördernden Einfluss auf BCC haben könnten, indem sie COX2 in den Tumorzellen induzieren (Tjiu, JW et al. 2009). Dieser Rückschluss resultiert aus der Tatsache, dass aggressivere BCC vermehrt mit TAM infiltriert sind und dass die mit PMA-stimulierten THP-1 Zelllinie nach Kokultur mit einer BCC-Zelllinie von ATCC zur vermehrten COX2 Expression führt. Da jedoch bekannt ist, dass alle käuflichen BCC-Zelllinien zumindest bzgl. der Aktivität der Hh Signalkaskade keinerlei Ähnlichkeit mit nativen BCC haben und da THP-1 eine Leukämiezellline ist und zudem noch mit PMA stimuliert wurde, ist davon auszugehen, dass das Ptch $^{\text {floxflox }} \mathrm{ERT2}^{+/-}$Mausmodell für BCC sehr viel näher an der realen Situation ist.

\subsection{Zusammenfassung der Effekte von $\mathrm{Ca}^{2+}$ sowie einer Wnt5a- Manipulation auf BCC im Mausmodell}

Zusammenfassend für die in den Abschnitten 5.2 und 5.3 diskutierten Daten kann man sagen, dass Wnt5a tatsächlich in Makrophagen exprimiert wird. Dies resultiert aus der Tatsache, dass eine Depletion von Makrophagen mit einer signifikanten Verminderung der Wnt5a Expression in der Haut korreliert. Da jedoch die Abnahme von Wnt5a nicht mit einer Abnahme von $\mathrm{K} 10$ korreliert, impliziert diese Tatsache, dass Wnt5a nicht in die Regulation dieses Differenzierungsmarkers involviert ist. Vielmehr scheint $\mathrm{K} 10$ durch $\mathrm{Ca}^{2+}$-abhängige Prozesse reguliert zu werden, die jedoch nicht Wnt5a-abhängig sind. Dies wird auch durch die Ionomycin-Applikation deutlich. Weiterhin zeigen die Ergebnisse, dass die K10 Expression in keinem direkten Zusammenhang mit der BCC-Regression steht.

Am interessantesten ist jedoch die Beobachtung, dass eine Verminderung des Wnt5a Expressionslevels mit einem stärkeren BCC-Wachstum korreliert. Daher kann man annehmen, dass Wnt5a im BCC tatsächlich die Rolle eines Tumorsuppressors spielt

\subsection{Einfluss von Liposomen auf das Wachstum von BCC in Ptch $^{\text {flox/flox }}$ ERT2 $^{+/-}$Mäusen und auf BMDM in Zellkultur}

Die oben diskutierten Daten zur Makrophagendepletion und dem Einfluss auf das BCCWachstum basierten auf einem Vergleich einer Clodrolip-/ mit einer Leerliposomenbehandlung. Obwohl dieser direkte Vergleich eindeutig zeigte, dass Clodrolip 
(d.h. in Liposomen-verpacktes Clodronat) im Gegensatz zu Leerliposomen zu einer Abnahme von TAM, einer Abnahme von Wnt5a und zu einem vermehrten Tumorwachstum führte, schien jedoch das BCC-Wachstum durch beide Medikamente generell blockiert zu sein.

So zeigen unsere Daten, dass die Tumoren sowohl nach Clodrolip-/ als auch Liposomenapplikation extrem viel kleiner waren als sonst gesehene BCC in unserer Arbeitsgruppe. Dies bedeutet, dass Liposomen, die ja auch für die Verpackung von Clodronat eingesetzt worden waren, per se eine tumorsuppressorische Wirkung haben könnten.

Die Beobachtung, dass möglicherweise schon die alleinige Applikation von Leerliposomen im Ptch flox/flox ERT2 ${ }^{+/-}$BCC-Mausmodell einen tumorsuppressorischen Effekt hat, war sehr erstaunlich. Studien anderer Arbeitsgruppen haben einen derartigen Einfluss bisher nicht beschrieben. In der Studie von Jeon et al. wird sogar explizit darauf hingewiesen, dass sich bei Analysen zur Lymphbahn-Angiogenese im Ovarialkarzinom die mit Kontrollliposomenbehandelten nicht von denen mit PBS-behandelten Mäuse unterschieden (Jeon, BH et al. 2008). Eine Studie zeigt jedoch, dass Leerliposomen die Metastasierung von Pankreaskarzinomzellen in Nacktmäusen hemmen können. Die Autoren erklären diesen Effekt durch die Erhöhung des Phospholipid-Gehalts im Plasma, der zur systemischen Beeinflussung des Fettsäurestoffwechsels führen kann (Graeser, R et al. 2009). Aber auch in dieser Studie hatten die Liposomen keinen Einfluss auf das Wachstum des Primärtumors.

Um den tumorsuppressorischen Effekt von Liposomen im Ptch $^{\text {floxflox }} E_{R T 2^{+/}}$BCCMausmodell zu bestätigen, wurde das Experiment nochmals wiederholt. Hierzu wurden BCC-tragende Ptch $^{\text {floxflox }}$ ERT2 ${ }^{+/-}$Mäuse mit Leerliposomen, dem Lösungsmittel PBS oder mit BLP $\left(\mathrm{Pam}_{3} \mathrm{CSK}_{4}\right)$ behandelt. Bei BLP handelt es sich um ein bakterielles Lipoprotein. Die Wirkung dieses Lipoproteins beruht auf dem acetylierten Aminoterminus, welcher die TollLike-Rezeptoren TLR1/2 aktivieren kann. BLP ist somit ein TLR1/2-Agonist. Die Aktivierung von TLR1/2 resultiert in Aktivierung einer Signalkaskade, welche zur Induktion des Transkriptionsfaktors NF-kB führt. Weiterhin konnte gezeigt werden, dass BLP auch die Apoptose monozytärer Zellen sowie humaner epithelialer Zellen induzieren kann (Aliprantis, AO et al. 1999).

Von BLP ist weiterhin bekannt, dass es dosisabhängig zur Verkleinerung von Melanomen in vivo führt (Zhang, $Y$ et al. 2011). Zudem konnte gezeigt werden, dass BLP auch eine antitumorale Wirkung auf Lungenkarzinomzellen hat. Wir sind daher davon ausgegangen, dass eine systemische Gabe von BLP auch in den $\mathrm{Ptch}^{\text {floxflox }} E R T 2^{+/-}$Mäusen zur Hemmung des BCC-Wachstums führen könnte. 
Dies ist tatsächlich der Fall und BLP führt im Vergleich zu PBS-behandelten Kontrollen zu einer signifikanten Hemmung des BCC-Wachstums. Im gleichen Maße wie durch BLP wurde das Tumorwachstum auch durch die Applikation von Liposomen gehemmt.

Das zeigt zunächst, dass eine Applikation von Liposomen tatsächlich das BCC-Wachstum hemmen kann. Die wachstumshemmende Wirkung von BLP und Liposomen ging dabei mit einer signifikanten Induktion des Differenzierungsmarkers $K 10$ einher. Dass diese Differenzierung direkt mit der Hemmung des Tumorwachstums in Zusammenhang steht, ist durch die im Abschnitt 4.2 gezeigten Daten jedoch eher unwahrscheinlich.

Die Hemmung des BCC-Wachstums durch BLP oder Liposomen kann jedoch mit der beobachteten Modulation des Immunsystems erklärt werden. So zeigen unsere Daten, dass sowohl die Applikation von Liposomen als auch von BLP in vivo im Vergleich zu PBSKontrollen zur Verringerung des Makrophagenanteils in der Milz (Mac1_F4/80 positive Zellen; signifikanter Effekt) und der Haut (Mac1_F4/80 positive Zellen; Mac1_Gr1 positive Zellen; nicht signifikanter Effekt) führt. Auch wird durch Liposomenapplikation der Anteil von Mac1_F4/80 positiven Peritonealzellen vermindert. Dagegen führt die Applikation von BLP zu einem drastischen Anstieg der F4/80 positiven Zellen in der Peritonealhöhle. Dieser enorme Anstieg von F4/80 positiven Peritonealzellen nach BLP-Applikation könnte darin begründet sein, dass die BLP-Applikation einen inflammatorischen Stimulus darstellt, der zur verstärkten Rekrutierung von Makrophagen geführt haben kann. So gehört das verabreichte BLP $\left(\mathrm{Pam}_{3} \mathrm{CSK}_{4}\right)$ genau wie LPS zu den bakteriellen Lipoproteinen. Von BLP als auch von LPS ist bekannt, dass sie bei systemischer Applikation zur verstärkten Rekrutierung von Immunzellen führen können (Cabanski, M et al. 2009; Doi, $\mathrm{K}$ et al. 2009).

Liposomen dagegen führen zu einer signifikanten Abnahme der Makrophagen in der Peritonealhöhle. Dies zeigt, dass sich die Effekte von Liposomen und BLP auf Makrophagen unterscheiden. Das wird auch in den Zellkulturexperimenten deutlich, in denen BLP, nicht aber Liposomen, eine Freisetzung der Cytokine IL-6, MIP-1 $\alpha / C C L 3$, Rantes/CCL5, TNF- $\alpha$, $\mathrm{KC} / \mathrm{CXCL} 1$, und MCP-1/CCL2 induziert.

Nichtsdestotrotz führen beide Medikamente zu einer Abnahme von Makrophagen in Milz und Haut. Gerade die Abnahme der Makrophagen in der Haut könnte das Tumorwachstum in diesem Experiment gehemmt haben, da die mit PBS-behandelten Tiere im Gegensatz zu Liposomen-/ bzw. BLP-behandelten Tiere a) eine höhere Zahl von Hautmakrophagen und b) größere BCC aufwiesen.

Die Abnahme der Makrophagen in Haut und Milz könnte wiederum durch die durchgeführten in vitro Experimente erklärt werden. So werden BMDM durch sowohl BLP als auch Liposomen in ihrer Proliferation gehemmt und zudem vermehrt in die Apoptose getrieben 
(ein toxischer Effekt der Substanzen konnte in den Zellkulturexperimenten ausgeschlossen werden). Auf der anderen Seite werden die BMDM durch beide Substanzen aktiviert, da sie in Zellkultur eine größere migratorische Kapazität zeigen.

Für die Situation in den BLP-behandelten Tieren müsste dies dann zusammengefasst bedeuten, dass a) nach i.p. Injektion eine lokale inflammatorische Reaktion ausgelöst wird, die zur beobachteten lokalen Infiltration mit Makrophagen geführt hat (dies könnte möglicherweise durch eine BLP-bedingte Induktion von spezifischen Makrophagenanlockenden Faktoren ausgelöst worden sein) und b) Makrophagen in ihrer Proliferation gestoppt und in die Apotose getrieben werden (z.B. durch Stimulation von TLR2 (Aliprantis, AO et al. 1999)), was dann in Milz und Haut zu einer messbaren Abnahme der Makrophagen geführt hat.

Für die Liposomen-behandelten Tiere würden die Ergebnisse bedeuten, dass sich der Liposomen-induzierte antiproliferative und proapoptotische Effekt auf Makrophagen schon bei lokaler Injektion, sprich nach i.p. Injektion, bemerkbar macht und sich dann auch in der Peripherie, also in Milz und Haut, widerspiegelt. Diese Unterschiede der BLP-/ und Liposomenbehandlung könnten wiederum durch die oben beschriebenen Unterschiede in der Induktion von Cytokinen erklärt werden.

Nun wird sowohl durch eine Liposomen-/ als auch durch eine BLP-Behandlung die Tumorprogression gestoppt. In beiden Versuchsanordnungen korreliert dies mit einer Abnahme von TAM. Diese Tatsache bedeutet, dass TAM beim BCC tatsächlich auch einen tumorfördernden Effekt haben könnten. Dies steht auf den ersten Blick im Gegensatz zu den Ergebnissen aus den Experimenten mit Clodrolip. Unter der Clodrolipbehandlung kommt es zu einer ausgeprägteren Makrophagendepletion als mit Liposomen, allerdings scheint eine Makrophagendepletion im Gegensatz zur Liposomenbehandlung das Tumorwachstum jedoch nicht so stark zu beeinflussen.

Wie schon im Abschnitt 5.3.4 diskutiert wurde, gibt es sowohl tumorfördernde als auch tumorhemmende TAM. Hierbei handelt es sich um den M1 und M2 Subtyp (Hallam, S et al. 2009). Grundsätzlich hängt die Induktion des Makrophagen-Phänotyps von der Mikroumgebung ab und kann durch T-Lymphozyten und natürliche Killerzellen reguliert werden. M1 Makrophagen werden zumeist durch IFN-Y und durch LPS (TLR4-Agonist) aktiviert. Dann produzieren sie große Mengen an proinflammatorischen Cytokinen wie TNF und IL-12 (Mantovani, A et al. 2002), exprimieren hohe Level an MHC-Molekülen und können Tumorzellen abtöten. Dagegen wird der M2 Phänotyp durch IL-4, IL-13, IL-10, Immunkomplexe, Glucocorticoidhormone, Agonisten von TLR oder IL-1R induziert (Hallam, 
$S$ et al. 2009). Im Gegensatz zu M1 Makrophagen hemmen M2 Makrophagen eine inflammatorische Immunantwort und fördern die Angiogenese in Tumoren, d.h. sie haben eine tumorfördernde Funktion. Der M2 Phänotyp ist u.a. durch eine niedrige Expression von IL-12 und durch hohe Expression von IL-10 und IL1Ra charakterisiert (Mantovani, A et al. 2002).

Es ist möglich, dass sowohl BLP als auch Liposomen die Makrophagen in solch einer Art und Weise stimulieren, dass sie einen tumorhemmenden (M1) Phänotyp annehmen. Möglicherweise führen beide Substanzen zur Sekretion von bestimmten Cytokinen, die durch unsere Auswahl analysierter Cytokine nicht abgedeckt wurde. Es könnte auch sein, dass beide Substanzen die Sekretion bestimmter Cytokine hemmen, die normalerweise einen tumorfördernden Effekt haben. Hierbei könnte es sich beispielsweise um IL-10 handeln, welches weder durch BLP noch durch Liposomen in BMDM induziert wird. Dies könnte dann die Hemmung des BCC-Wachstums erklären. Clodronat könnte in nicht-depletierten Makrophagen hingegen eher einen M2 Phänotyp induzieren, so dass es gegenüber einer Liposomenbehandlung zu einem etwas verstärkten Tumorwachstum kommt. Dies könnte über bestimmte Cytokine laufen, die speziell durch Clodronat induziert werden und darüber hinaus für die Induktion eines M2 Phänotyps spezifisch sind. Sollte Clodronat tatsächlich den M2 Phänotyp induzieren können, würde entsprechend auch die Abnahme von Wnt5a typisch für einen M2 Subtyp sein. 


\section{Zusammenfassung}

Das Basalzellkarzinom (BCC) ist der häufigste Tumor des Menschen. Interessanterweise zeigen etwa 20\% der BCC eine Spontanregression. Eine Spontanregression der BCC tritt auch im Ptch $^{\text {floxflox }}$ ERT2 $^{+/}$Mausmodell auf und geht mit einer Differenzierung der Tumoren sowie einer stromalen Wnt5a Expression einher. In Zellkulturexperimenten wird gezeigt, dass Wnt5a in tumorassoziierten Makrophagen durch unbekannte Faktoren induziert wird. Wnt5a wiederum induziert in den Tumorzellen die Expression des Differenzierungsmarkers K10, was über den $\mathrm{Wnt} / \mathrm{Ca}^{2+}$ Signalweg in Abhängigkeit der CaMKII vermittelt wird (veröffentlicht als Zweitautor in (Nitzki, F et al. 2010)). Aufgrund dieser Daten wurde die Hypothese aufgestellt, dass Wnt5a direkt in die Regression von BCC involviert ist, wobei es Differenzierungsvorgänge im BCC anregt.

Um zu überprüfen, ob diese Hypothese zutrifft, wurden mehrere Experimente an BCC-

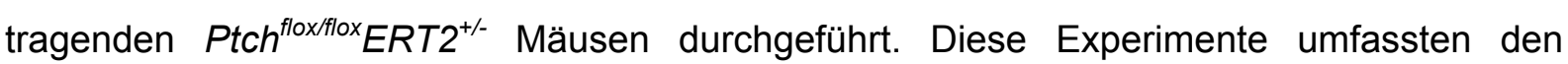
Einsatz des Calcium-lonophors lonomycin, die Generierung einer $\mathrm{Ptch}^{\text {floxflox }} E R T 2^{+/-} W n t 5 a^{+/-}$ Mauslinie, sowie die Applikation von Clodrolip (in Liposomen-verpacktes Clodronat). Zusammengefasst zeigen diese Experimente, dass der Differenzierungsmarker $K 10$ in der tumortragenden Haut nicht durch Wnt5a, sondern lediglich $\mathrm{Ca}^{2+}$-abhängig reguliert wird. Auch wird gezeigt, dass Differenzierungsvorgänge eine untergeordnete Rolle beim BCCWachstum spielen. Sehr interessant ist die Beobachtung, dass eine Clodronat-vermittelte Makrophagendepletion in der Haut neben einer Reduzierung des Wnt5a Expressionslevels mit einem stärkeren BCC-Wachstum korreliert. Daher kann man davon ausgehen, dass Wnt5a im BCC tatsächlich die Rolle eines Tumorsuppressors spielt. Den eindeutigen Beweis hierfür wird ein noch nicht abgeschlossenes Experiment liefern, in dem in BCC-tragenden $\mathrm{Ptch}^{\text {flox/flox}} \mathrm{ERT2}^{+/-}$Mäusen Wnt5a-positive Makrophagen durch Wnt5a-defiziente ersetzt wurden.

Weiterhin wurde im Verlauf der Arbeit deutlich, dass auch Leerliposomen zur Makrophagendepletion und zur BCC-Wachstumshemmung führen können. Diese Effekte werden möglicherweise durch Liposomen-induzierte Proliferationshemmung, Apoptose und Migrationsstörung von Makrophagen ausgelöst, was eine Abnahme von tumorassoziierten Makrophagen in der BCC-tragenden Haut zur Folge hat.

Die Daten der vorliegenden Arbeit tragen somit zum besseren Verständnis der Spontanregression von BCC bei und können dadurch möglicherweise zu neuen Therapieansätzen gegen diesen sehr häufig auftretenden Tumor führen. 


\section{Abkürzungsverzeichnis}

\begin{tabular}{|c|c|}
\hline $154 \mathrm{CF}$ & Medium 154 (calcium-free) \\
\hline AP & alkalische Phosphatase \\
\hline $\mathrm{AppCCl}_{2} \mathrm{p}$ & Adenosin $5^{\prime}-[ß, \gamma$-Dichlormethyl] Triphosphat \\
\hline ATCC & American Type Culture Collection \\
\hline ATP & Adenosintriphosphat \\
\hline B6 & C57BL/6N \\
\hline $\mathrm{BCC}$ & Basal cell carcinoma - Basalzellkarzinom \\
\hline BIM & BisindolyImaleimid I; spezifischer PKC-Inhibitor \\
\hline BLP & bacterial lipoprotein \\
\hline BMDM & bone marrow-derived macrophages \\
\hline $\mathrm{bp}$ & basepairs; Basenpaare \\
\hline BrdU & 5-Bromo-2-Deoxyuridin \\
\hline BSA & bovine serum albumine - Rinderserumalbumin \\
\hline bspw & beispielsweise \\
\hline$c$ & Konzentration von Nukleinsäuren \\
\hline CaMKII & Calcium/Calmodulin-Dependent Protein Kinase Type II \\
\hline $\mathrm{CCL}$ & chemokine ( $\mathrm{C}-\mathrm{C}$ motif) ligand \\
\hline cDNA & copyDNA \\
\hline $\mathrm{Ci}$ & Cubitus interuptus (D. Melanogaster Gli-Homolog) \\
\hline $\mathrm{CM}$ & conditioned medium; konditioniertes Medium \\
\hline CML & chronisch myeloische Leukämien \\
\hline CMV & Cytomegalie Virus \\
\hline $\operatorname{cox}$ & Cyclooxygenase \\
\hline Cre-ERT2 & Tamoxifen-induzierbare Cre-Rekombinase \\
\hline $\mathrm{CXCL}$ & chemokine (C-X-C motif) ligand \\
\hline Cy & Indodikarbocyanin-Derivate \\
\hline$d$ & days - Tage \\
\hline DAB & Diamino-Benzidin \\
\hline DB & Dot blot \\
\hline $\mathrm{dd}_{2} \mathrm{O}$ & doppelt-destilliertes Wasser \\
\hline DEPC & Diethylpyrocarbonat \\
\hline Dhh & Desert Hedgehog \\
\hline Dkk-1 & Dickkopf-1 \\
\hline DMEM & Dulbecco's Modified Eagle Medium \\
\hline DMSO & N.N.-Dimethylsulfoxid \\
\hline DNA & Desoxyribonukleinsäure \\
\hline dNTPs & Desoxyribonukleotidtriphosphate \\
\hline$d p c$ & days post coitum (Tage nach der Kopulation) \\
\hline DTT & Dithiothreitol \\
\hline$D v l$ & Dishevelled \\
\hline EDTA & Ethylen-diamin-tetraacetat \\
\hline ERT2 & Mauslinie ROSA26CreERT2 \\
\hline Fab & antigenbindendes Fragment \\
\hline
\end{tabular}




\begin{tabular}{|c|c|}
\hline FACS & fluorescent-activated cell sorting (durchflusszytometrische Analyse) \\
\hline FCS & fetal calf serum (fötales Kälberserum) \\
\hline FITC & Fluoresceinisothiocyanat \\
\hline FOP & SuperFOPFlash-Expressionsplasmids \\
\hline$F u$ & Fused \\
\hline Fzd & Frizzled \\
\hline G0-Phase & Ruhephase \\
\hline G1-Phase & postmitotische Phase bzw. Präsynthesephase \\
\hline G2-Phase & prämitotische Phase bzw. Postsynthesephase \\
\hline G418 & Geneticinsulfat \\
\hline Gapdh & Glycerinaldehyd-3-phosphatase-dehydrogenase \\
\hline gDNA & genomische DNA \\
\hline Gy & Gray \\
\hline $\mathrm{h}$ & Stunde \\
\hline HE & Hämatoxylin/Eosin \\
\hline$H h$ & Hedgehog \\
\hline HRP & horseradish peroxidase (Meerrettich Peroxidase) \\
\hline HSC70 & Heat Shock Cognate 70-Proteins \\
\hline i.m. & intramuskulär \\
\hline i.p. & intraperitoneal \\
\hline i.v. & intravenös \\
\hline IFN & Interferon \\
\hline $\lg$ & Immunglobulin \\
\hline $\mathrm{IHC}$ & Immunhistochemie \\
\hline Ihh & Indian Hedgehog \\
\hline IL & Interleukin \\
\hline ISH & in situ-Hybridisierung \\
\hline IVC & individuell ventilierbarer Käfig \\
\hline$|v|$ & Involucrin \\
\hline JNK & c-Jun-N-terminale Kinase \\
\hline K1 & Keratin 1 \\
\hline K10 & Keratin 10 \\
\hline KC & keratinocyte-derived chemokine \\
\hline $\mathrm{kDa}$ & Kilodalton \\
\hline Kif7 & Kinesin family member 7 \\
\hline $\mathrm{KN}-93$ & spezifischer Inhibitor der CaMKII \\
\hline LacZ & ß-Galaktosidase \\
\hline LB-Medium & lysogeny broth-Medium \\
\hline loxP & IoxP Sequenz (DNA-Konsensussequenz zur Bindung der Cre-Rekombinase) \\
\hline LPS & Lipopolysaccharid \\
\hline LRP & Low-density lipoprotein receptor-related protein \\
\hline MBSTL & Maleinsäure/Natriumchlorid/Levamisol/Tween-20-haltiger Puffer \\
\hline MCP-1 & monocyte chemoattractant protein-1 \\
\hline $\min$ & Minute \\
\hline MIP-1a & macrophage inflammatory protein- 1 alpha \\
\hline MMTV & Mouse Mammary Tumorvirus \\
\hline
\end{tabular}




\begin{tabular}{|c|c|}
\hline MOMA I & Monocyte/Macrophage I \\
\hline M-Phase & Mitose-Phase \\
\hline mRNA & messenger RNA \\
\hline $\mathrm{n}$ & Anzahl \\
\hline NT & Natriumchlorid/Tris-haltiger Puffer \\
\hline ntc & no template control \\
\hline NTMLT & Natriumchlorid/Tris/Magnesiumchlorid/Levamisol/Tween-20-haltiger Puffer \\
\hline $\mathrm{P} / \mathrm{S}$ & Penicillin/Streptomycin \\
\hline $\mathrm{Pam}_{3} \mathrm{CSK}_{4}$ & Pam3CysSerLys4 \\
\hline PBS & Phosphate buffered saline (Phoshat-gepufferte Natriumchlorid Lösung) \\
\hline PCP & planar cell polarity \\
\hline PCR & Polymerase chain reaction - Polymerasekettenreaktion \\
\hline PE & Phycoerythrin \\
\hline PEI & Polyethylenimin \\
\hline PFA & Paraformaldehyd \\
\hline $\mathrm{PI}$ & Propidiumiodid \\
\hline PKC & Protein Kinase C \\
\hline Ptch & Patched \\
\hline$P_{t c h}^{d e l}$ & Ptch Allel mit Cre-vermittelter Deletion der Exone 8 und 9 \\
\hline Ptch $^{f l o x}$ & Ptch Allel zur Cre-vermittelten Deletion der Exone 8 und 9 \\
\hline $\operatorname{Ptch}^{\text {wt }}$ & Wildtyp Ptch Allel \\
\hline qRT-PCR & quantitative real time PCR \\
\hline Rantes & CCL5; chemokine (C-C) motif ligand 5 \\
\hline RLU & relative light units \\
\hline RNA & Ribonukleinsäure \\
\hline ROX & 6-Carboxy-X-rhodamin \\
\hline rpm & rotations per minute \\
\hline RT & Raumtemperatur \\
\hline S33Y & $\mathrm{pCl}-$ neo-b-catS33Y \\
\hline SCC & squamous cell carcinoma - Plattenepithelkarzinom \\
\hline SDS & Natriumdodecylsulfat \\
\hline Shh & Sonic Hedgehog \\
\hline Smo & Smoothened \\
\hline SNP & single nucleotide polymorphism - Einzelpunktmutation \\
\hline SP600125 & Inhibitor der JNK \\
\hline S-Phase & Synthesephase \\
\hline SSC & standard saline citrate (Standard Natriumcitrat Lösung) \\
\hline STE & SDS/Tris/EDTA-haltiger Puffer \\
\hline Sufu & Suppressor of fused \\
\hline TAM & tumor-associated macrophages \\
\hline Taq & Thermus aquaticus \\
\hline TBE & Tris-Borsäure-EDTA Lösung \\
\hline TBS & tris-buffered saline (Tris-gepufferte Natriumchlorid Lösung) \\
\hline TCF/LEF & T-cell factor/lymphoid enhancer factor \\
\hline Tgm & Transglutaminase \\
\hline TLR & toll-like receptor \\
\hline
\end{tabular}




\section{Abkürzungsverzeichnis}

$\begin{array}{ll}\text { TNF- } \alpha & \text { Tumor-Nekrosefaktor alpha } \\ \text { TOP } & \text { SuperTOPFlash-Expressionsplasmids } \\ \mathrm{U} & \text { unit (Enzymaktivitätseinheit) } \\ \text { UV-Licht } & \text { Ultraviolettes Licht } \\ \text { v/v } & \text { volume/volume (Volumen/Volumen) } \\ \text { Vol } & \text { Volumen } \\ \text { w/v } & \text { weight/volume (Gewicht/Volumen) } \\ \text { WB } & \text { Western Blot } \\ \text { Wif1 } & \text { Wnt inhibitory factor 1 } \\ \text { Wnt/WNT } & \text { Wingless } \\ \text { WST } & \text { water soluble tetrazolium } \\ \text { wt } & \text { Wildtyp } \\ \text { xg } & \text {-fache Erdbeschleunigung } \\ \text { X-Gal } & 5-\text {-Bromo-4-chloro-3-indolyl-ß-Galaktosid }\end{array}$




\section{Literaturverzeichnis}

Abdulla, FR, et al. (2005). "Tanning and skin cancer." Pediatr Dermatol 22(6): 501-512.

Aliprantis, AO, et al. (1999). "Cell activation and apoptosis by bacterial lipoproteins through toll-like receptor-2." Science 285(5428): 736-739.

Asplund, A, et al. (2008). "Expression profiling of microdissected cell populations selected from basal cells in normal epidermis and basal cell carcinoma." Br J Dermatol 158(3): 527-538.

Aszterbaum, M, et al. (1999). "Ultraviolet and ionizing radiation enhance the growth of BCCs and trichoblastomas in patched heterozygous knockout mice [In Process Citation]." Nat Med 5(11): $1285-1291$

Athar, M, et al. (2006). "Hedgehog signalling in skin development and cancer." Exp Dermatol 15(9): 667-677.

Aziz, A, et al. (2006). "Development of macrophages with altered actin organization in the absence of MafB." Mol Cell Biol 26(18): 6808-6818.

Berman, DM, et al. (2003). "Widespread requirement for Hedgehog ligand stimulation in growth of digestive tract tumours." Nature 425(6960): 846-851.

Bittner, M, et al. (2000). "Molecular classification of cutaneous malignant melanoma by gene expression profiling." Nature 406(6795): 536-540.

Blumenthal, A, et al. (2006). "The Wingless homolog WNT5A and its receptor Frizzled-5 regulate inflammatory responses of human mononuclear cells induced by microbial stimulation." Blood 108(3): 965-973.

Bonifas, JM, et al. (2001). "Activation of expression of hedgehog target genes in basal cell carcinomas." J Invest Dermatol 116(5): 739-742.

Boutros, M, et al. (1998). "Dishevelled activates JNK and discriminates between JNK pathways in planar polarity and wingless signaling." Cell 94(1): 109-118.

Bridge, JA, et al. (2000). "Novel genomic imbalances in embryonal rhabdomyosarcoma revealed by comparative genomic hybridization and fluorescence in situ hybridization: an intergroup rhabdomyosarcoma study." Genes Chromosomes Cancer 27(4): 337-344.

Cabanski, M, et al. (2009). "Genome-wide transcriptional profiling of mononuclear phagocytes recruited to mouse lungs in response to alveolar challenge with the TLR2 agonist Pam3CSK4." Am J Physiol Lung Cell Mol Physiol 297(4): L608-618.

Cabrera, CV, et al. (1987). "Phenocopies induced with antisense RNA identify the wingless gene." Cell 50(4): 659-663.

Cebrat, M, et al. (2004). "Wnt inhibitory factor-1: a candidate for a new player in tumorigenesis of intestinal epithelial cells." Cancer Lett 206(1): 107-113.

Chen, X, et al. (2007). "Hedgehog signal pathway is activated in ovarian carcinomas, correlating with cell proliferation: it's inhibition leads to growth suppression and apoptosis." Cancer Sci 98(1): 68-76.

Church, VL und Francis-West, P (2002). "Wnt signalling during limb development." Int J Dev Biol 46(7): 927-936.

Clevers, $\mathrm{H}$ (2006). "Wnt/beta-catenin signaling in development and disease." Cell 127(3): 469-480.

Cohen, MM, Jr. (2010). "Hedgehog signaling update." Am J Med Genet A 152A(8): 1875-1914.

Collinet, $\mathrm{P}$, et al. (2006). "In vivo expression and antitumor activity of p53 gene transfer with naked plasmid DNA in an ovarian cancer xenograft model in nude mice." J Obstet Gynaecol Res 32(5): 449-453.

Crowson, AN (2006). "Basal cell carcinoma: biology, morphology and clinical implications." Mod Pathol 19 Suppl 2: S127-147.

Curson, C und Weedon, D (1979). "Spontaneous regression in basal cell carcinomas." J Cutan Pathol 6(5): 432-437.

Doglioni, C, et al. (2003). "Alterations of beta-catenin pathway in non-melanoma skin tumors: loss of alpha- $A B C$ nuclear reactivity correlates with the presence of beta-catenin gene mutation." Am J Pathol 163(6): 2277-2287.

Doi, K, et al. (2009). "Animal models of sepsis and sepsis-induced kidney injury." J Clin Invest 119(10): 2868-2878.

El-Bahrawy, M, et al. (2003). "Expression of beta-catenin in basal cell carcinoma." Br J Dermatol 148(5): 964-970.

Epstein, EH (2008). "Basal cell carcinomas: attack of the hedgehog." Nat Rev Cancer 8(10): 743-754.

Evangelista, M, et al. (2006). "The hedgehog signaling pathway in cancer." Clin Cancer Res 12(20 Pt 1): $5924-5928$. 
Fan, H und Khavari, PA (1999). "Sonic hedgehog opposes epithelial cell cycle arrest." J Cell Biol 147(1): 71-76.

Fanto, M, et al. (2000). "Nuclear signaling by Rac and Rho GTPases is required in the establishment of epithelial planar polarity in the Drosophila eye." Curr Biol 10(16): 979-988.

Gailani, MR, et al. (1992). "Developmental defects in Gorlin syndrome related to a putative tumor suppressor gene on chromosome 9." Cell 69(1): 111-117.

Gailani, MR, et al. (1996). "Relationship between sunlight exposure and a key genetic alteration in basal cell carcinoma [see comments]." J Natl Cancer Inst 88(6): 349-354.

Gazzaniga, S, et al. (2007). "Targeting tumor-associated macrophages and inhibition of MCP-1 reduce angiogenesis and tumor growth in a human melanoma xenograft." J Invest Dermatol 127(8): 2031-2041.

Giles, RH, et al. (2003). "Caught up in a Wnt storm: Wnt signaling in cancer." Biochim Biophys Acta 1653(1): 1-24.

Goppner, D und Leverkus, M (2011). "Basal cell carcinoma: from the molecular understanding of the pathogenesis to targeted therapy of progressive disease." J Skin Cancer 2011: 650258.

Gordon, MD und Nusse, R (2006). "Wnt signaling: multiple pathways, multiple receptors, and multiple transcription factors." J Biol Chem 281(32): 22429-22433.

Gorlin, RJ (1987). "Nevoid basal-cell carcinoma syndrome." Medicine (Baltimore) 66(2): 98-113.

Graeser, R, et al. (2009). "Antimetastatic effects of liposomal gemcitabine and empty liposomes in an orthotopic mouse model of pancreatic cancer." Pancreas 38(3): 330-337.

Habas, R, et al. (2003). "Coactivation of Rac and Rho by Wnt/Frizzled signaling is required for vertebrate gastrulation." Genes Dev 17(2): 295-309.

Hahn, $\mathrm{H}$, et al. (1996). "Mutations of the human homolog of Drosophila patched in the nevoid basal cell carcinoma syndrome." Cell 85(6): 841-851.

Hallam, S, et al. (2009). "Activated macrophages in the tumour microenvironment-dancing to the tune of TLR and NF-kappaB." J Pathol 219(2): 143-152.

Hamed, S, et al. (2004). "Accelerated induction of bladder cancer in patched heterozygous mutant mice." Cancer Res 64(6): 1938-1942.

Hameyer, D, et al. (2007). "Toxicity of ligand-dependent Cre recombinases and generation of a conditional Cre deleter mouse allowing mosaic recombination in peripheral tissues." Physiol Genomics 31(1): 32-41.

Hammerschmidt, M, et al. (1996). "Protein kinase $A$ is a common negative regulator of Hedgehog signaling in the vertebrate embryo." Genes Dev 10(6): 647-658.

Han, YG, et al. (2009). "Dual and opposing roles of primary cilia in medulloblastoma development." Nat Med 15(9): 1062-1065.

Hatsell, S, et al. (2003). "Beta-catenin and Tcfs in mammary development and cancer." J Mammary Gland Biol Neoplasia 8(2): 145-158.

$\mathrm{He}, \mathrm{X}$, et al. (1997). "A member of the Frizzled protein family mediating axis induction by Wnt-5A." Science 275(5306): 1652-1654.

$\mathrm{He}, \mathrm{X}$, et al. (2004). "LDL receptor-related proteins 5 and 6 in Wnt/beta-catenin signaling: arrows point the way." Development 131(8): 1663-1677.

Heller, R, et al. (2001). "Intradermal delivery of interleukin-12 plasmid DNA by in vivo electroporation." DNA Cell Biol 20(1): 21-26.

Hengge, UR, et al. (1996). "Expression of naked DNA in human, pig, and mouse skin." J Clin Invest 97(12): 2911-2916.

Henneman, ZJ, et al. (2008). "Bisphosphonate binding affinity as assessed by inhibition of carbonated apatite dissolution in vitro." J Biomed Mater Res A 85(4): 993-1000.

Hennings, $\mathrm{H}$, et al. (1980). "Calcium regulation of growth and differentiation of mouse epidermal cells in culture." Cell 19(1): 245-254.

Hikasa, H, et al. (2002). "The Xenopus receptor tyrosine kinase Xror2 modulates morphogenetic movements of the axial mesoderm and neuroectoderm via Wht signaling." Development 129(22): 5227-5239.

Hiraoka, K, et al. (2008). "Inhibition of bone and muscle metastases of lung cancer cells by a decrease in the number of monocytes/macrophages." Cancer Sci 99(8): 1595-1602.

Holmberg, E, et al. (1996). "Differential allele loss on chromosome 9q22.3 in human non-melanoma skin cancer." Br J Cancer 74(2): 246-250.

Hooper, JE und Scott, MP (2005). "Communicating with Hedgehogs." Nat Rev Mol Cell Biol 6(4): 306317.

Horton, HM, et al. (1999). "A gene therapy for cancer using intramuscular injection of plasmid DNA encoding interferon alpha." Proc Natl Acad Sci U S A 96(4): 1553-1558. 
Hsieh, JC, et al. (1999). "A new secreted protein that binds to Wnt proteins and inhibits their activities." Nature 398(6726): 431-436.

Hunt, MJ, et al. (1994). "Regression in basal cell carcinoma: an immunohistochemical analysis." $\mathrm{Br} \mathrm{J}$ Dermatol 130(1): 1-8.

lozzo, RV, et al. (1995). "Aberrant expression of the growth factor Wnt-5A in human malignancy." Cancer Res 55(16): 3495-3499.

Itoh, K, et al. (1998). "A role for Xenopus Frizzled 8 in dorsal development." Mech Dev 74(1-2): 145157.

Jan, HM, et al. "The use of polyethylenimine-DNA to topically deliver hTERT to promote hair growth." Gene Ther 19(1): 86-93.

Jeon, $\mathrm{BH}$, et al. (2008). "Profound but dysfunctional lymphangiogenesis via vascular endothelial growth factor ligands from CD11b+ macrophages in advanced ovarian cancer." Cancer Res 68(4): 1100-1109.

Johnson, RL, et al. (1996). "Human homolog of patched, a candidate gene for the basal cell nevus syndrome." Science 272(5268): 1668-1671.

Jonsson, M, et al. (2002). "Loss of Wnt-5a protein is associated with early relapse in invasive ductal breast carcinomas." Cancer Res 62(2): 409-416.

Kataru, RP, et al. (2009). "Critical role of CD11b+ macrophages and VEGF in inflammatory lymphangiogenesis, antigen clearance, and inflammation resolution." Blood 113(22): 56505659 .

Kichler, A (2004). "Gene transfer with modified polyethylenimines." J Gene Med 6 Suppl 1: S3-10.

Kohn, AD und Moon, RT (2005). "Wnt and calcium signaling: beta-catenin-independent pathways." Cell Calcium 38(3-4): 439-446.

Korinek, V, et al. (1997). "Constitutive transcriptional activation by a beta-catenin-Tcf complex in APC/- colon carcinoma." Science 275(5307): 1784-1787.

Kremenevskaja, N, et al. (2005). "Wnt-5a has tumor suppressor activity in thyroid carcinoma." Oncogene 24(13): 2144-2154.

Kuhl, M, et al. (2000). "Ca(2+)/calmodulin-dependent protein kinase II is stimulated by Wnt and Frizzled homologs and promotes ventral cell fates in Xenopus." J Biol Chem 275(17): 1270112711.

Lacarrubba, F, et al. (2011). "Successful treatment and management of large superficial basal cell carcinomas with topical imiquimod 5\% cream: a case series and review." J Dermatolog Treat 22(6): 353-358.

Lam, CW, et al. (1999). "A frequent activated smoothened mutation in sporadic basal cell carcinomas." Oncogene 18(3): 833-836.

Lambiv, WL, et al. "The Wnt inhibitory factor 1 (WIF1) is targeted in glioblastoma and has a tumor suppressing function potentially by induction of senescence." Neuro Oncol 13(7): 736-747.

Leek, RD, et al. (1996). "Association of macrophage infiltration with angiogenesis and prognosis in invasive breast carcinoma." Cancer Res 56(20): 4625-4629.

Lemkine, GF und Demeneix, BA (2001). "Polyethylenimines for in vivo gene delivery." Curr Opin Mol Ther 3(2): 178-182.

Leris, AC, et al. (2005). "WNT5A expression in human breast cancer." Anticancer Res 25(2A): 731734.

$\mathrm{Li}, \mathrm{L}$, et al. (2009). "Wnt5a induces simultaneous cortical axon outgrowth and repulsive axon guidance through distinct signaling mechanisms." J Neurosci 29(18): 5873-5883.

Liang, $\mathrm{H}$, et al. (2003). "Wnt5a inhibits $B$ cell proliferation and functions as a tumor suppressor in hematopoietic tissue." Cancer Cell 4(5): 349-360.

Lien, MH und Sondak, VK (2011). "Nonsurgical treatment options for Basal cell carcinoma." J Skin Cancer 2011: 571734.

Lin, YC, et al. (2007). "Wnt inhibitory factor-1 gene transfer inhibits melanoma cell growth." Hum Gene Ther 18(4): 379-386.

Lindstrom, E, et al. (2006). "PTCH mutations: distribution and analyses." Hum Mutat 27(3): 215-219.

Logan, CY und Nusse, R (2004). "The Wnt signaling pathway in development and disease." Annu Rev Cell Dev Biol 20: 781-810.

Malek, A, et al. (2009). "In vivo pharmacokinetics, tissue distribution and underlying mechanisms of various PEI(-PEG)/siRNA complexes." Toxicol Appl Pharmacol 236(1): 97-108.

Mancuso, M, et al. (2004). "Basal cell carcinoma and its development: insights from radiation-induced tumors in Ptch1-deficient mice." Cancer Res 64(3): 934-941.

Mantovani, A, et al. (2003). "Tumor-associated macrophages and dendritic cells as prototypic type II polarized myeloid populations." Tumori 89(5): 459-468. 
Mantovani, A, et al. (2002). "Macrophage polarization: tumor-associated macrophages as a paradigm for polarized M2 mononuclear phagocytes." Trends Immunol 23(11): 549-555.

Mikels, AJ und Nusse, R (2006). "Purified Wnt5a protein activates or inhibits beta-catenin-TCF signaling depending on receptor context." PLoS Biol 4(4): e115.

Morin, PJ, et al. (1997). "Activation of beta-catenin-Tcf signaling in colon cancer by mutations in betacatenin or APC." Science 275(5307): 1787-1790.

Mullor, JL, et al. (2001). "Wnt signals are targets and mediators of Gli function." Curr Biol 11(10): 769773.

Murphy, LL und Hughes, CC (2002). "Endothelial cells stimulate T cell NFAT nuclear translocation in the presence of cyclosporin $A$ : involvement of the wnt/glycogen synthase kinase-3 beta pathway." J Immunol 169(7): 3717-3725.

Nakao, S, et al. (2005). "Infiltration of COX-2-expressing macrophages is a prerequisite for IL-1 betainduced neovascularization and tumor growth." J Clin Invest 115(11): 2979-2991.

Nitzki, F, et al. (2010). "Tumor stroma-derived Wnt5a induces differentiation of basal cell carcinoma of Ptch-mutant mice via CaMKII." Cancer Res 70(7): 2739-2748.

Nusse, R und Varmus, HE (1992). "Wnt genes." Cell 69(7): 1073-1087.

Nusslein-Volhard, C und Wieschaus, E (1980). "Mutations affecting segment number and polarity in Drosophila." Nature 287(5785): 795-801.

Palmer, HG, et al. (2008). "The vitamin D receptor is a Wht effector that controls hair follicle differentiation and specifies tumor type in adult epidermis." PLoS ONE 3(1): e1483.

Pandur, P, et al. (2002). "Wnt-11 activation of a non-canonical Wnt signalling pathway is required for cardiogenesis." Nature 418(6898): 636-641.

Pazzaglia, S, et al. (2004). "Modulation of patched-associated susceptibility to radiation induced tumorigenesis by genetic background." Cancer Res 64(11): 3798-3806.

Perchellet, EM, et al. (1990). "Ability of the Ca2+ ionophores A23187 and ionomycin to mimic some of the effects of the tumor promoter 12-O-tetradecanoylphorbol-13-acetate on hydroperoxide production, ornithine decarboxylase activity, and DNA synthesis in mouse epidermis in vivo." Cancer Res 50(18): 5806-5812.

Polverini, PJ, et al. (1977). "Activated macrophages induce vascular proliferation." Nature 269(5631): 804-806.

Pongracz, JE und Stockley, RA (2006). "Wnt signalling in lung development and diseases." Respir Res 7: 15.

Priceman, SJ, et al. "Targeting distinct tumor-infiltrating myeloid cells by inhibiting CSF-1 receptor: combating tumor evasion of antiangiogenic therapy." Blood 115(7): 1461-1471.

Pukrop, T, et al. (2006). "Wnt 5a signaling is critical for macrophage-induced invasion of breast cancer cell lines." Proc Natl Acad Sci U S A 103(14): 5454-5459.

Raffel, C, et al. (1997). "Sporadic medulloblastomas contain PTCH mutations." Cancer Res 57(5): 842-845.

Reddy, S, et al. (2001). "Characterization of Wnt gene expression in developing and postnatal hair follicles and identification of Wnt5a as a target of Sonic hedgehog in hair follicle morphogenesis." Mech Dev 107(1-2): 69-82.

Reddy, ST, et al. (2004). "Expression of Frizzled genes in developing and postnatal hair follicles." J Invest Dermatol 123(2): 275-282.

Reifenberger, J, et al. (2005). "Somatic mutations in the PTCH, SMOH, SUFUH and TP53 genes in sporadic basal cell carcinomas." Br J Dermatol 152(1): 43-51.

Reifenberger, J, et al. (1998). "Missense mutations in SMOH in sporadic basal cell carcinomas of the skin and primitive neuroectodermal tumors of the central nervous system." Cancer Res 58(9): 1798-1803.

Reya, T und Clevers, H (2005). "Wnt signalling in stem cells and cancer." Nature 434(7035): 843-850.

Rijsewijk, F, et al. (1987). "The Drosophila homolog of the mouse mammary oncogene int-1 is identical to the segment polarity gene wingless." Cell 50(4): 649-657.

Robinson, JK und Dahiya, M (2003). "Basal cell carcinoma with pulmonary and lymph node metastasis causing death." Arch Dermatol 139(5): 643-648.

Roewert-Huber, J, et al. (2007). "Epidemiology and aetiology of basal cell carcinoma." Br J Dermatol 157 Suppl 2: 47-51.

Rogers, MJ, et al. (2000). "Cellular and molecular mechanisms of action of bisphosphonates." Cancer 88(12 Suppl): 2961-2978.

Rubin, Al, et al. (2005). "Basal-cell carcinoma." N Engl J Med 353(21): 2262-2269.

Saldanha, G, et al. (2004). "Nuclear beta-catenin in basal cell carcinoma correlates with increased proliferation." Br J Dermatol 151(1): 157-164. 
Saneyoshi, T, et al. (2002). "The Wnt/calcium pathway activates NF-AT and promotes ventral cell fate in Xenopus embryos." Nature 417(6886): 295-299.

Scales, SJ und de Sauvage, FJ (2009). "Mechanisms of Hedgehog pathway activation in cancer and implications for therapy." Trends Pharmacol Sci.

Sharma, RP und Chopra, VL (1976). "Effect of the Wingless (wg1) mutation on wing and haltere development in Drosophila melanogaster." Dev Biol 48(2): 461-465.

Sheldahl, LC, et al. (1999). "Protein kinase C is differentially stimulated by Wnt and Frizzled homologs in a G-protein-dependent manner." Curr Biol 9(13): 695-698.

Sheldahl, LC, et al. (2003). "Dishevelled activates Ca2+ flux, PKC, and CamKII in vertebrate embryos." J Cell Biol 161(4): 769-777.

Stark, K, et al. (1994). "Epithelial transformation of metanephric mesenchyme in the developing kidney regulated by Wnt-4." Nature 372(6507): 679-683.

Sunderkotter, C, et al. (1994). "Macrophages and angiogenesis." J Leukoc Biol 55(3): 410-422.

Thayer, SP, et al. (2003). "Hedgehog is an early and late mediator of pancreatic cancer tumorigenesis." Nature 425(6960): 851-856.

Titomirov, AV, et al. (1991). "In vivo electroporation and stable transformation of skin cells of newborn mice by plasmid DNA." Biochim Biophys Acta 1088(1): 131-134.

Tjiu, JW, et al. (2009). "Tumor-associated macrophage-induced invasion and angiogenesis of human basal cell carcinoma cells by cyclooxygenase-2 induction." J Invest Dermatol 129(4): 10161025.

Torroella-Kouri, M, et al. (2009). "Identification of a subpopulation of macrophages in mammary tumorbearing mice that are neither M1 nor M2 and are less differentiated." Cancer Res 69(11): 4800-4809.

Tostar, U, et al. (2006). "Deregulation of the hedgehog signalling pathway: a possible role for the PTCH and SUFU genes in human rhabdomyoma and rhabdomyosarcoma development." J Pathol 208(1): 17-25.

Uhmann, A, et al. (2007). "The Hedgehog receptor Patched controls lymphoid lineage commitment." Blood 110(6): 1814-1823.

Uhmann, A, et al. (2005). "A model for PTCH1/Ptch1-associated tumors comprising mutational inactivation and gene silencing." Int J Oncol 27(6): 1567-1575.

Umbhauer, M, et al. (2000). "The C-terminal cytoplasmic Lys-thr-X-X-X-Trp motif in frizzled receptors mediates Wnt/beta-catenin signalling." Embo J 19(18): 4944-4954.

Vorechovsky, I, et al. (1997). "Somatic mutations in the human homologue of Drosophila patched in primitive neuroectodermal tumours." Oncogene 15(3): 361-366.

Walling, HW, et al. (2004). "Aggressive basal cell carcinoma: presentation, pathogenesis, and management." Cancer Metastasis Rev 23(3-4): 389-402.

Watkins, DN, et al. (2003). "Hedgehog signalling within airway epithelial progenitors and in small-cell lung cancer." Nature 422(6929): 313-317.

Weeraratna, AT, et al. (2002). "Wnt5a signaling directly affects cell motility and invasion of metastatic melanoma." Cancer Cell 1(3): 279-288.

Wetmore, C (2003). "Sonic hedgehog in normal and neoplastic proliferation: insight gained from human tumors and animal models." Curr Opin Genet Dev 13(1): 34-42.

Wissmann, C, et al. (2003). "WIF1, a component of the Wnt pathway, is down-regulated in prostate, breast, lung, and bladder cancer." J Pathol 201(2): 204-212.

Wong, DA, et al. (2000). "Cytokine profiles in spontaneously regressing basal cell carcinomas." $\mathrm{Br} \mathrm{J}$ Dermatol 143(1): 91-98.

Wong, SY, et al. (2009). "Primary cilia can both mediate and suppress Hedgehog pathway-dependent tumorigenesis." Nat Med 15(9): 1055-1061.

Wust, S, et al. (2008). "Peripheral T cells are the therapeutic targets of glucocorticoids in experimental autoimmune encephalomyelitis." J Immunol 180(12): 8434-8443.

Xie, J, et al. (1998). "Activating Smoothened mutations in sporadic basal-cell carcinoma." Nature 391(6662): 90-92.

Yamaguchi, TP, et al. (1999). "A Wnt5a pathway underlies outgrowth of multiple structures in the vertebrate embryo." Development 126(6): 1211-1223.

Yang, SH, et al. (2008). "Pathological responses to oncogenic Hedgehog signaling in skin are dependent on canonical Wnt/beta3-catenin signaling." Nat Genet 40(9): 1130-1135.

Zeisberger, SM, et al. (2006). "Clodronate-liposome-mediated depletion of tumour-associated macrophages: a new and highly effective antiangiogenic therapy approach." $\mathrm{Br} \mathrm{J}$ Cancer 95(3): 272-281. 
Zeng, $\mathrm{X}$, et al. (2008). "Initiation of Wnt signaling: control of Wnt coreceptor Lrp6 phosphorylation/activation via frizzled, dishevelled and axin functions." Development 135(2): 367-375.

Zhai, L, et al. (2004). "Drosophila wnt-1 undergoes a hydrophobic modification and is targeted to lipid rafts, a process that requires porcupine." J Biol Chem 279(32): 33220-33227.

Zhang, Y, et al. (2011). "TLR1/TLR2 agonist induces tumor regression by reciprocal modulation of effector and regulatory $T$ cells." J Immunol 186(4): 1963-1969.

Zibat, A, et al. (2010). "Activation of the hedgehog pathway confers a poor prognosis in embryonal and fusion gene-negative alveolar rhabdomyosarcoma." Oncogene: Sep 6. [Epub ahead of print].

Zibat, A, et al. (2009). "Time-point and dosage of gene inactivation determine the tumor spectrum in conditional Ptch knockouts." Carcinogenesis 30(6): 918-926.

Zumsteg, A, et al. (2009). "Myeloid cells contribute to tumor lymphangiogenesis." PLoS One 4(9): e7067. 


\section{Danksagung}

Die vorliegende Arbeit wurde am Institut für Humangenetik (Universität Göttingen) in der Abteilung Molekulare Entwicklungsgenetik unter der Leitung von Frau Prof. Dr. Heidi Hahn angefertigt.

Mein Dank gilt daher in erster Linie Dir, Heidi! Nicht nur für die Bereitstellung des überaus spannenden Themas und die intensive wissenschaftliche Betreuung, sondern auch dafür, dass Du wirklich jederzeit bei notwendigem Diskussionsbedarf hinsichtlich des Projektes für Deine Mitarbeiter ansprechbar bist.

Außerdem möchte ich mich bei Herrn Prof. Dr. Felix Brembeck sowie Herrn Prof. Dr. Matthias Dobbelstein für die wissenschaftliche Unterstützung bzw. wertvollen Anregungen während der Thesis Committee Meetings bedanken. Weiterhin bedanke ich mich bei Herrn Prof. Dobbelstein für die Übernahme des Korreferats dieser Arbeit.

Darüber hinaus möchte ich an dieser Stelle Dr. Tobias Pukrop für die interessanten Anregungen sowie PD Dr. Walter Schulz-Schaeffer für die Interpretation histologischer Färbungen danken.

Ein großes Dankeschön geht an Dr. Kai Dittmann und Dr. Michael Engelke (Institut für Zelluläre und Molekulare Immunologie, Universität Göttingen) für die Ermöglichung der FACS-Analysen.

Weiterhin gilt ein großer Dank unserer gesamten Arbeitsgruppe für die entspannte Arbeitsatmosphäre und die unterhaltsamen Mittagspausen. Ach, es ist schön mit euch!

Insbesondere danke ich Dr. Frauke Nitzki und Dr. Arne Zibat, weiterhin Dr. Anja Uhmann, Diana Marklein und Penelope Pelczar für den wissenschaftlichen und auch nicht-wissenschaftlichen Austausch. Außerdem möchte ich mich bei Ina Heß \& Anke Frommhold für ihre technische Unterstützung sowie allen für ihre Menschlichkeit im „ganz normalen Laboralltag“ danken.

Mein herzlicher Dank gilt jedoch meiner Mutter für ihr immerwährendes Verständnis und ihre Unterstützung egal in welcher Hinsicht - eine Verbindung, die keiner Worte bedarf.

Schön, dass ich Dich habe \& danke für alles, Mama! 


\section{Curriculum vitae}

Persönliche Angaben

geboren am 26. Januar 1982 in Stade

Staatsangehörigkeit: deutsch

\section{Ausbildung}

SS 2012

$08 / 2008$ bis $01 / 2012$

$02 / 2008$

Disputation und Abschluss der Dissertation (Dr. rer. nat)

2007-2008

Promotion am Institut für Humangenetik (Abteilung Molekulare Entwicklungsgenetik), Arbeitsgruppe Prof. Dr. Heidi Hahn, Georg-AugustUniversität Göttingen

„Die Rolle von Wnt5a im Basalzellkarzinom“

Diplom in Biologie (Note: sehr gut)

Diplomarbeit am Johann-Friedrich-Blumenbach-Institut für Zoologie \& Anthropologie, Georg-August-Universität Göttingen

$10 / 2003$

2001-2007

Vordiplom in Biologie

$05 / 2001$

Studium der Biologie, Georg-August-Universität Göttingen

Abitur, Vincent-Lübeck-Gymnasium Stade

\section{Berufserfahrung und Praktika}

$04 / 2006$ bis $05 / 2008$

$07 / 2005$
Studentische bzw. wissenschaftliche Hilfskraft am Johann-FriedrichBlumenbach-Institut für Zoologie \& Anthropologie, Georg-AugustUniversität Göttingen

Praktikum in der Rechtsmedizin, Abteilung Forensische Entomologie, an der Johann Wolfgang Goethe-Universität Frankfurt/Main

\section{Publikationen}

Nitzki, F, et al. (2010). "Tumor stroma-derived Wnt5a induces differentiation of basal cell carcinoma of Ptch-mutant mice via CaMKII." Cancer Res 70(7): 2739-2748. 
